\author{
MASSACHUSETTS INSTITUTE OF TECHNOLOGY \\ DEPARTMENT OF NUCLEAR ENGINEERING \\ Cambridge, Massachusetts
}

\title{
THE EFFECT OF REACTOR SIZE. \\ ON THE BREEDING ECONOMICS \\ OF LMFBR BLANKETS
}

by

A. Tagishi and M.J. Driscoll

February, 1975

\author{
COO-2250-13 \\ MITNE-168 \\ ERDA Research and Development Report \\ UC-79d LMFBR - Physics \\ Contract $\operatorname{AT}(11-1)-2250$
}

U.S. Energy Research and Development Administration 


\section{DISCLAIMER}

This report was prepared as an account of work sponsored by an agency of the United States Government. Neither the United States Government nor any agency Thereof, nor any of their employees, makes any warranty, express or implied, or assumes any legal liability or responsibility for the accuracy, completeness, or usefulness of any information, apparatus, product, or process disclosed, or represents that its use would not infringe privately owned rights. Reference herein to any specific commercial product, process, or service by trade name, trademark, manufacturer, or otherwise does not necessarily constitute or imply its endorsement, recommendation, or favoring by the United States Government or any agency thereof. The views and opinions of authors expressed herein do not necessarily state or reflect those of the United States Government or any agency thereof. 


\section{DISCLAIMER}

Portions of this document may be illegible in electronic image products. Images are produced from the best available original document. 


\section{DISTRIBUTION}

COO-2250-13 MITNE-168

ERDA Research and Development Contract

$$
\begin{gathered}
\text { AT }(11-1)-2250 \\
\text { UC-79a LMFBR - Physics }
\end{gathered}
$$

13 U.S. Energy Research and Development Administration Division of Reactor Development and Technology. Reactor Physics Branch

Wastington, D.C. 20545

4-10. U.S. Energy Research and Development Administration Chicago Operations office 9800 South Cass Avenue

Argonne, Illinois 60439 , for distribution in accordance with Category UC-79d 


\begin{abstract}
The effect of reactor size on the neutronic and economic performance of LMFBR blankets driven by radially-power-flattened cores has been investigated using both simple models and state-of-the-art computer methods. Reactor power ratings in the range 250 to 3000 $\mathrm{MW}$ e were considered. Correlations for economic breakeven and optimum irradiation times and blanket thicknesses have been developed for batch-irradiated blankets.

It is shown that at a given distance from the core-blanket interface the fissile buildup rate per unit volume remains very nearly constant in the radial blanket as (radially-power-flattened, constant-height) core size increases. As a consequence, annual revenue per blanket assembly, and breakeven and optimum irradiation times and optimum blanket dimensions, are the same for all reactor sizes.

It is also shown that the peripheral core fissile enrichment, hence . neutron leakage spectra, of the (radially-power-flattened, constant-height) cores remains essentially constant as core size increases. Coupled with the preceding observations, this insures that radial blanket breeding performance in demonstration-size LMFBR units will be a good measure of that in much larger commercial LMFBR's.
\end{abstract}




\section{ACKNOWLEDGMENTS}

The work described in this report has been performed primarily by the principal author, A. Tagishi; who has submitted substantially the same report in partial fulfillment of the requirements for the Sc.D. degree at.M.I.T.

Financial support from the U.S. Atomic Energy Commission under Contract AT (11-1)-2250 is gratefully acknowledged.

The advice and suggestions of $\mathrm{V}$. A. Miethe on computational problems are gratefully acknowledged.

Computer calculations were carried out at the M.I:T. Information Processing Center, and the Laboratory for Nuclear Science. Typing of this manuscript has been very ably handled by Mrs. Mary Bosco and Miss Cindi Mitaras.

Finally, the principal author wishes to thank his wife, Akiko Tagishi, whose patience and good humor have made life bearable during the most trying times prior to completion of this work. 


\section{TABLE OF CONTENTS}

Page

Abstract

A cknowledgments

Table of Contents

List of Figures

List of Tables

Chapter 1. Introduction

1. 1 Foreword

1. 2 Size Projections for LMFBR Units

1.3 Outline of Present Work

Chapter 2. Analytic and Computer Models

2.1 Introduction

2. 2 Predictions Using a One-Group Reactor Physics Model

2.2.1 The Effect of Changing Core Radius at Constant Core Height on the Beginningof-Life Breeding Performance

2.2.1.1 Neutronics of Radially-PowerFlattened Core

2.2.1.2 Fissile Buildup Rate in the Radial Blanket

2.2.1.3 Fissile Buildup Rate in the Axial Blanket

2.2.2 The Effect of Changing Core Radius at Constant Core Height on DepletionEconomics Performance

2.2.2.1 Fuel Cycle Cost Contribution from the Radial Blanket 
Page

2.2.2.2. Fuel Cycle Cost Contribution from the Axial Blanket

2.2.2.3 Local Breakeven and Optimum Irradiation Time

2.2.2.4 Optimum Irradiation Time for a Blanket Row

2.2.2.5 Fuel Cycle Cost - Blanket Thickness Relation

2. 2.2.6 Optimum Irradiation Time for an Entire Blanket

2.2.2.7 Global Optimum Thickness and Irradiation Time

2.2.3 The Effect of Changing Core Height at Constant Core Radius on the Beginningof-Life Breeding Performance

2.2.3.1 Radial Blanket

2.2.3.2. Axial Blanket

2.3. Computer Methods

2.3.1 Reference Reactor Configurations

2.3.2. Variations in Reactor Size

2.3.3 Method for Depletion-Economics Analysis

2. 3. 3. 1. Cross-Section Preparation

2.3.3.2 Burnup Zones

2.3.3.3 Equilibrium Core

2.3.3.4 Material Included in the Burnup 
$\underline{\text { Page }}$

Chapter 3. Beginning-of-Life Breeding Analysis

3. 1 Introduction

3.2 Evaluation of One-Group Model Using Uniformly Loaded Cores

3. 3 Radially-Power-Flattened Core

3.3.1 BOL Core Characteristics

3.3.2 Effect of Changing Core Radius at Constant Core Height on Radial Blanket Breeding Performance

3.3.3 Effect of Changing Core Radius at Constant Core Height on Axial Blanket Breeding Performance

3.3.4 Effect of Changing Core Height at Constant Core Radius on Blanket Breeding Performance

3. 3.4.1 Radial Blanket

4.1 Introduction 126

4.2 Depletion Analysis $\quad 126$

4.2.1 Design of Equilibrium Core 126

4.2.2 Model of Fissile Material Buildup in the Blanket

4. 3 Economic Analysis

4.3.1 Local Breakeven and Optimum Irradiation Times 
Page

4.3.3 Breakeven and Optimum Irradiation Times of an Entire Blanket

4.3.4 Minimum Fuel Cycle Cost Contribution of an Entire Blanket

4.3.5 Global Optimum Thickness and Irradiation Time and Global Minimum Cost

4. 4 Conclusions

Chapter 5. Summary; Conclusions and Recommendations

5.1 Introduction

5.2 Computer and Analytic Models

5.2.1 Method of Burnup

5.2.2 Depletion-Economics Model

5.2.3 One-Group Model

5.2.4 Simplified Economic Analysis

5. 3. Beginning-of-Life Breeding Physics Results

5.3.1 Physics-Related Parameters

5.3.2 Effect of Changing Core Radius at Constant Core Height on Blanket Performance

5.3.2.1 Radial Blanket

5.3.2.2 Axial Blanket

5. 3:2.3 Combined System Breeding Performance

5.3.3 Effect of Changing Core Height at Constant Core Radius on Blanket Performance

5.4 Depletion-Economics Results 
5.5 Conclusions $\quad 234$

5.6 Recommendations . 236

Appendix A. Nomenclature : $\quad 240$

Appendix B. Neutronics of Uniformly Loaded Cores . 249

B. 1 Critical Core Enrichment … 249

B. 2. Critical Core Mass. . 253

B. 3 Breeding Ratio 254

Appendix C. Neutronics of Radially-Power-Flattened Cores 258

C. 1 Derivation of Equations : 258

C. 2 Comparison with Uniformly Loaded Core. . 263

C. 3 Critical Mass Ratio . . 265

C. 4 Central and Peripheral Enrichment . 266

C. 5 Zone-Averaged Enrichment 269

A ppendix D. Blanket Neutronics . 274

D. 1 Flux Distribution in the Blanket 274

D. 2 Fissile Material Buildup Rate $\quad 276$

D. 3. Row-by-Row Fissile Màterial Buildup Rate 276

Appendix E. Depletion Economics Analysis $\quad 279$

E. 1 Optimum Irradiation Time 279

E.2 Breakeven Irradiation Time ' $\quad 286$

E. 3 Relation of Optimum Irradiation Time and
Distance into Blanket

E:4 Fuel. Cycle Cost of the Radial Blanket 295

E. 5 Relation of Optimum Irradiation Time and
Blanket Thickness

E. 6 Global Optima 306

Appendix F. Tabulation of Data Plotted in Figures . 311

Appendix G. References 344 


\section{LIST OF FIGURES}

Fig. No.

$\underline{\text { Page }}$

1. 1 LMFBR Unit Size Projections 23

2.1 Typical Normalized Flux Profile of Radially-

Power-Flattened Core

2.2 Schematic Illustration of One-Group Results for the Effect of Core Radius on Fissile Buildup Rate in the Radial Blanket Driven by Radially-Power-Flattened Cores

2.3 Schematic Illustration of One-Group Results for the Effect of Core Radius on Fissile Buildup Rate in the Axial Blanket Driven by Either Radially-PowerFlattened or Uniformly Loaded Cores

2. 4 Schematic Illustration of the Effect of Core Radius on the Fuel Cycle Cost Contribution of the Radial Blanket Driven by Radially-Power-Flattened Cores

2.5 Typical Variation of Fuel Cycle Cost Contribution from a Fast Reactor Blanket

2.6 Schematic Illustration of the Effect of Core Radius on Breakeven Irradiation Time in the Radial and Axial Blankets

2. 7 Schematic. Illustration of the Effect of Core Radius and Economic Environment on Optimum Blanket Ir radiation Time

2.8 Schematic Illustration of the Relation Between Breakeven and Optimum Irradiation Time

2.9. Schematic Diagram of Local Breakeven and Local Optimum Positions as a Function of Irradiation Time

2.10 Relation of "Local Cost-Distance" Curve and "Total Cost-Thickness" Curve at a given Irradiation Time

2.11 Schematic Diagram of Breakeven and Optimum Batch-Irradiated Blanket Thickness as a Function of Irradiation Time

2.12 Schematic Diagram of Breakeven and Optimum Loci as a Function of Irradiation Time 
Fig. No.

2.13 Schematic Illustration of the Effect of Changing Core Height at Constant Core Radius on Breeding Ratio of the Radial Blanket

2.14 Schematic Illustration of the Effect of Changing Core Height at Constant Core Radius on the Breeding Performance of the Axial Blanket

2.15 Schematic Elevation View of the Upper Right Quadrant of the Standard 1000-MW $\mathrm{e}$ Reactor System

2.16 Schematic Elevation View of the Upper Right Quadrant of the Standard 1000-MW Reactor System with Burnup Zones Included

2.17 Unpoisoned Reactivity Swing

2.18 Poisoned Reactivity Swing

3.1 The Effect of Core Radius on the Linear Extrapolation Length

3.2 Core-Averaged Critical Enrichment as a Function of Buckling for One-Zone Cores

3. 3 The Effect of Core Radius on BOL Physics Parameters

3.4 The Effect of Zoning on the Radial Power Density Distribution

3.5 The Effect of Core Radius on Zone-Averaged Peripheral Enrichment

3.6 Comparison of Peripheral Neutron Energy Spectra

3. 7 Ratio of Critical Mass Between Radially-PowerFlattened Cores and Uniformly Loaded Cores as a Function of Core Radius

3.8 Core-Averaged Critical Enrichment as a Function of Core Radius

3.9 The Effect of Core Radius on BOL Fissile Specific Inventory Buildup Rate in the Radial Blanket 
Fig. No.

3.11 The Effect of Core Radius on Radial Blanket

Breeding Ratio

3.12 The Effect of Core Radius on Fissile Specific Inventory Buildup Rate in the Axial Blanket

3.13 Product of Axial External Breeding Ratio and Core-Averaged Critical Enrichment as a Function of Core Radius

3.14 The Effect of Changing Core Radius (Size) at Constant Core Height on the Breeding Ratio

3.15 The Effect of Changing Core Height at Constant Core Radius on the Radial Blanket Breeding Ratio

3.16 The Effect of Changing Core Height at Constant Core Radius on the Axial Blanket Breeding Ratio

3.17 The Effect of Changing Core Height at Constant Core Radius on the Breeding Ratio

4.1 Burnup Reactivity Swing for Various Power Ratings

128

$4.2^{*}$ The Effect of Boron Control Pois on on the Fissile Inventory in Row 1 of the Radial Blanket

4. 3 : Peak Power Flatness Changes Due to Irradiation for Various Power Ratings

4.4 The Effect of Core Conditions on Row-by-Row Fissile Inventory of the Radial Blanket

4.5 The Effect of Core Conditions on the Fuel Cycle Cost Contribution from the Radial Blanket

4.6 The Effect of Core Radius on the Row-by-Row Fissile Specific Inventory of the Radial Blanket

4.7 Burnup Dependence of the BOL-Normalized Fissile Buildup Rate Ratio for Various Power Ratings.

4. 8 Comparison of 2DB-BRECON and Linear Models of Fissile Inventory and Fuel Cycle Cost of Row 1 of the Radial Blanket ( $1000 \mathrm{MW}_{\mathrm{e}}$ ) 
Fig. No.

$\underline{\text { Page }}$

4.9 Burnup Dependence of the Ratio of $\mathrm{Pu}-241$

Inventory to $\mathrm{Pu}-239$ Inventory

4.10 The Effect of Blanket Row Position on Local

Fuel Cycle Cost Contribution

4. 11 The Effect of Core Radius on the Optimum Irradiation Time for Row 1, and the Breakeven Irradiation Time for Rows 1 and 2 of the Radial Blanket

4.12 Comparison of Optimum and Breakeven Irradiation Times for Radial Blanket-Row 1 Predicted by Correlations and 2DB-BRECON

4.13 Comparison of Optimum and Breakeven Irradiation Times for Radial Blanket-Row 2 Predicted by Correlations and 2DB-BRECON

4.14 The Effect of Core Radius on the Minimum Fuel Cycle Cost Contribution from the Radial Blanket

4.15 The Effect of Core Radius on Revenue (Profit) Per Assembly in the Radial Blanket

4. 16 Fuel Cycle Cost Contribution Per Row as a Function of Blanket Thickness.

4.17 Local Breakeven and Local Optimum Positions as a Function of Irradiation Time

4.18 Minimum Loca1 Fuel Cycle. Cost Contribution as a Function of Blanket Thickness

4. 19. Row-by-Row Fissile Specific Inventory and Minimum Profitable Fissile Specific Buildup Rate

4.20 The Effect of Blanket Thickness on the Total Fuel Cycle Cost Contribution (Reference case of Table 2.14)

4. 21 Comparis on of Optimum and Breakeven Irradiation - Times for 2-Row Radial Blankets Predicted by Correlation and 2DB-BRECON

4.22 Comparison of Optimum and Breakeven Irradiation Times for 3-Row Radial Blankets Predicted by Correlation and 2DB-BRECON 
Fig. No.

4.23 Breakeven and Optimum Thicknesses as a Function of Irradiation Time for Entire Batch-Irradiated Radial Blankets

4.24 Fuel Cycle Cost Contribution from Entire BatchIrradiated Radial Blankets as a Function of Blanket Thickness

4.25 Revenue per Assembly and Fuel Cycle Cost Contribution per Row or per Entire BatchIrradiated Radial Blanket as a Function of Blanket Thickness (for a Given Irradiation Time)

4.26 The Effect of Core Radius on the Minimum Fuel Cycle Cost Contribution of the Entire BatchIrradiated Radial Blanket

4.27 Minimum Fuel Cycle Cost Contribution as a Function of Blanket Thickness

4.28 Comparison of Four Key Loci on the Blanket Economic Performance Curves

4. 29 Comparison of Global Optima Predicted by Correlation and 2DB-BRECON

4.30 Comparison of Global Minimum Cost Predicted by Correlation and 2DB-BRECON

5. 1 Schematic Elevation View of the Upper Right Quadrant of the Reference 1000- $\mathrm{MW}_{\mathrm{e}}$ Reactor System

5.2 Timing of Cash Flows for Fuel Cycle Cost Calculations

5.3 Typical Variation of Fuel Cycle Cost Contribution from a Fast Reactor Blanket

5.4 Schematic Diagram of Breakeven and Optimum Loci as a Function of Irradiation Time

5. 5 Core-Averaged Critical Enrichment as a Function of Core Size 
Fig. No.

$\underline{\text { Page }}$

5.6 The Effect of Core Radius on Central and Peripheral or Central-Zone and Outermost-Zone Enrichment

208

5.7 Comparison of Peripheral Neutron Energy Spectra

209

5.8 The Effect of Core Radius on BOL Fissile Specific Inventory Buildup Rate in the Radial Blanket

210

5.9 The Effect of Core Radius on Radial Blanket

Breeding Ratio

212

5.10 The Effect of Core Radius on the BOL Specific Inventory Buildup Rate in the Axial Blanket

213

5.11 The Product of the Core-Averaged Critical Enrichment and the Axial Blanket Breeding Ratio as a Function of Core Radius

5.12 The Effect of Core Size (Radius) on Breeding Ratio at Constant Core Height

5.13 The Effect of Changing Core Height at Constant Core Radius on the Radial Blanket Breeding Ratio

5.14 The Effect of Changing Core Height at Constant Core Radius on the Axial Blanket Breeding Performance

5.15 The Effect of Changing Core Height at Constant Core Radius on the Breeding Ratio

5.16 The Effect of Core Radius on the Optimum Irradiation Time for Row 1, and the Breakeven Irradiation Times for Rows 1 and 2, of the Radial Blanket

5.17 Revenue per Blanket Assembly and Fuel Cycle Cost Contribution per Row or per Entire Batch-Irradiated Radial Blanket as a Function of Blanket Thickness

5.18 The Effect of Core Radius on the Minimum Local Fuel Cycle Cost Contribution from the Radial Blanket

5.19 Typical Comparis on of the Optimum and Breakeven Irradiation Times in the Radial Blanket-Row 1 Predicted by Correlation and the 2DB-BRECON

5.20 Burnup Economic Correlation Lines Showing Key Loci 
Fig. No.

$\underline{\text { Page }}$

5.21 Comparison of the Global Optima Predicted by Correlation and 2DB-BRECON

5. 22 Comparison of the Global Minimum Costs. Predicted by Correlation and 2DB-BRECON

B. 1 Comparison of the Breeding Ratio Predicted by the One-Group Model and $2 \mathrm{DB}$ as a Function of Core Radius (One-Zone Cores)

C. 1 Fissile Atom Density Distribution for the Radially-Power-Flattened Cores

C. 2 The Effect of Core Radius on Central and Peripheral or Central-Zone and Outermost-Zone Enrichment

E. 1 Timing of Cash Flows for Fuel Cycle Cost Calculations

E. 2 Typical Variation of Fuel Cycle Cost Contribution from a Fast Reactor Blanket

E. 3 Schematic Illustration of Local Cost-TimeThickness Relations

E. 4 Relation of "Local Cost-Distance" Curve and

"Total Cost-Thickness" Curve at a Given Irradiation Time

E. 5 Schematic Illustration of Total Cost-TimeThickness Relations

E.6 Relations Between Three Coordinates: Total CostTime-Thickness

E. 7 Relations Between Three Coordinates: Local CostTime-Distance

E. 8 Breakeven and Optimum Thickness and Positions as a Function of Irradiation Time 


\section{LIST OF TABLES}

Table No.

Page

2.1 One-Group Physics Parameters of 1000-MW e Core

2.2 Summary of the Effect of Changing Core Radius at Constant Core Height on the Neutronic and Economic Performance of the Radial Blanket (Predictions of Simple One-Group Model)

2.3 Summary of the Effect of Changing Core Radius at Constant Core Height on the Neutronic and Economic Performance of the Axial Blanket (Predictions of Simple One-Group Model)

2. 4 Summary of the Coefficients Predicted by the Simplified Economic Model for the Correlation of the Breakeven and Optimum Irradiation Times of the Radial Blanket

2. 5 Summary of Relations Between Local Blanket

Region Positions or Total Blanket Thickness and Irradiation Time

2. 6 Summary of the Six Key Intercepts Predicted by Simplified CFM Analysis

2.7 Summary of the Effect of Changing Core Height at Constant Core Radius on the Breeding Performance of the Radial and Axial Blankets (Predictions of Simple One-Group Model)

2.8 Characteristics of the Standard 1000-MW $\mathrm{e}$ Reactor

2.9 Standard 1000-MW e Reactor Parameters

2.10(a) Key Characteristics of Reactor Sizes Examined (Constant Core Height)

2.10(b) Key Characteristics of Reactor Sizes Examined (Constant Core Radius)

2.11 Comparison of Collapsed Group Structures 80

2.12 Summary of Burnup Region Types

2.13 Region-Collapsed Cross Sections Used in the Burnup Analysis

2.14 Reference Economic Environment 
Table No.

Page

3. 1 One-Group Cross Sections for the Core Used in Present Work

3. 2 Zone-Averaged Enrichment for Radially-PowerFlattened Cores of Various Ratings

3. 3 One-Group Cross-Section Set for the Blanket

4. 1 Comparis on of the Optima for Row 1 in the Radial Blanket for Various Frozen-Composition Cores

4.2 Range of Variation of Economic Parameters

4. 3 Discount Rate, Wood's Economic Parameter and Modified Economic Parameter

4.4 Comparison of the Correlations: $T=a_{j} W^{b}{ }^{b}{ }^{c}$ Predicted by the Simplified Model and $\mathrm{j}$ 2DB-BRECON

4.5 Comparison of the Correlations: $T_{B}=p_{j}\left(T_{o}\right)^{q_{j}} X^{r_{j}}$ and 2DB-BRECON

4. 6 Comparis on of Correlations for the Global Optima Predicted by the Simplified Model and 2DB-BRECON

5.1 Characteristics of the Standard 1000-MW Reactor $\quad 185$

5.2 Standard 1000-MW e Reactor Parameters

5.3 Key Characteristics of Reactor Sizes Examined (Constant Core Height)

5.4 Key Characteristics of Reactor Sizes Examined (Constant Core Radius)

5. 5 Reference Economic Environment

5. 6 Summary of the Effect of Changing Core Radius at Constant Core Height on the Neutronic and Economic Performance of the Radial Blanket

5. 7 Summary of the Effect of Changing Core Radius at Constant Core Height on the Neutronic and Economic Performance of the Axial Blanket 
Table No.

$\underline{\text { Page }}$

5.8 Summary of the Effect of Changing Core Height at Constant Core Radius on the Breeding Performance of the Radial and the Axial Blankets

5.9 Summary of Relations Between Local Blanket Region Positions or Total Blanket Thickness and Irradiation Time

5.10. Summary of the Six Key Intercepts Predicted by Simplified CFM Analysis

5.11 Zone-Averaged Enrichments for Critical BOL Cores of Various Ratings

5.12 Comparison of Correlation Coefficients Predicted by the Simplified Model to Those Obtained by CurveFitting 2DB-BRECON Results

5.13 Range of Variation of Economic Parameters

5.14 Comparison of the Correlation Coefficients for the Global Optimum: Simplified Model vs. 2DB-BRECON

B. 1 Neutron Balance for 1000-MW $\mathrm{M}_{\mathrm{e}}$ 1-Zone, BOL Reactor 252

C. 1 Comparis on of Zone-Averaged Enrichment for 250$\mathrm{MW}_{\mathrm{e}}, 6-\mathrm{Z}$ one Core Predicted by One-Group Model and GA Formula

D. 1 Comparis on of 2DB and One-Group Model for Rowby-Row Fissile Buildup Rate

E. 1 Summary of Relations Between Local Blanket Region Position or Total Blanket Thickness and Irradiation Time

E. 2 Summary of the Six Key Intercepts Predicted by Simplified CFM Analysis

F.1 The Effect of Core Radius (Power Rating) on BOL Physics Parameters

F. 2 Core-Averaged Critical Enrichment as a Function of Buckling for One-Zone Cores 
Table No.

$\underline{\text { Page }}$

F. 3 Central and Peripheral Zone-Averaged Enrichment of the Radially-Power-Flattened Cores

F.4 Comparison of Peripheral Neutron Energy.Spectra.

316

F. 5 Ratio of Critical Mass of Radially-Power-Flattened Cores to Uniformly Loaded.Cores as a Function of Core Radius

F.6. The Effect of Core Radius on BOL Fissile Specific Inventory Buildup Rate in the Radial Blanket

F. 7 Relative Breeding Contribution of Radial Blanket Rows

F. 8 The Effect of Changing Core Radius at Constant Core Height on the Breeding Performance of the Blanket

F.9. The Effect of Changing Core Radius at Constant Core Height on the Fissile Specific Inventory Buildup Rate in the. Axial Blanket (2DB Results)

F. 10 The Effect of Changing Core Radius at Constant Core Height on the Breeding Performance in the Axial Blanket

F.11 The Effect of Changing Core Height at Constant Core Radius on the Breeding Ratio

F.12 The Effect of Changing Core Height at Constant Core Radius on the Breeding Performance of the Axial Blanket

F.13a Fissile and Poison Concentrations of $250-\mathrm{MW}_{\mathrm{e}}$, 2-Zone "Equilibrium" System

F. 13b Fissile and Poison Concentrations of $1000-\mathrm{MW}$, 2-Zone "Equilibrium" System

F.13c Fissile and Poison Concentrations of $3000-\mathrm{MW}$ e, 2-Zone "Equilibrium" System

F. 14 Non-Fuel Material Number Densities Used in the Present Work

F.15 The Effect of Core Radius (Power Rating) on Peak Power Density Changes and Peak Power Flatness. Changes Due to Irradiation

F.16 The Effect of Core Radius on Fissile Specific Inventory 330 
Table No.

F.17 Burnup Dependence of the BOL-Normalized Fissile Buildup Rate Ratio for Various Power Ratings

F.18 Burnup Dependence of the Ratio of Pu-241 Inventory to $\mathrm{Pu}-239$ Inventory

F.19 The Effect of Changing Core Radius at Constant Core Height on Breakeven, Optimum and Physical Lifetime Points of the Radial Blanket

F. 20 Comparison of Optimum and Breakeven Irradiation Times for the Radial Blanket-Row 1 (One-Row Radial Blanket) Predicted by Correlation and 2DB-BRECON

F.21 Comparison of Optimum and Breakeven Irradiation Times for the Radial Blanket-Row 2 Predicted by Correlations and 2DB-BRECON

F. 22 2DB Results for Four Key Loci (Irradiation TimeBlanket Row Position or Entire-Blanket Thicknesses Loci) and Two Key Curves (Cost-Blanket Row. Position or Entire-Blanket Thickness Curves)

F.23 Comparison of Optimum and Breakeven Irradiation Times for the Two-Row Radial Blanket Predicted by Correlations and 2DB-BRECON

F.24 Comparison of Optimum and Breakeven Irradiation Times for the Three-Row Radial Blanket Predicted by Correlations and 2DB-BRECON

F.25 The Effect of Changing Core Radius at Constant Core Height on Breakeven, Optimum and Physical Lifetime Points of an Entire Batch-Irradiated Radial Blanket

F. 26 Comparison of Global Optimum Irradiation Time and Thickness for the Radial Blanket Predicted by Correlations and 2DB-BRECON

F.27 Comparison of Global Minimum Fuel Cycle Cost Contribution of the Radial Blanket Predicted by Correlations and 2DB-BRECON

F.28 Comparison of the Breeding Ratio Predicted by the One-Group Model and 2DB as a Function of Core Radius (One-Zone Cores)

F. 29 The Effect of Core Radius on Central and Peripheral or Central-Zone and Outermost-Zone Enrichment 


\author{
Chapter 1 \\ INTRODUCTION
}

\title{
1.1 FOREWORD
}

The necessity of generating increasing amounts of electric power economically and without unduly affecting the environment is one of the major technological challenges of our times. The Liquid-MetalCooled Fast Breeder Reactor (LMFBR) offers a promising solution, in large part due to its ability to breed excess nuclear fuel and its amenability to exploitation of the economy of scale. The former ability is due, to large extent, to the inclusion of a breeding blanket of fertile material around the fissile-fueled core; the latter attribute is favored by the high power density and low design pressure achieved by use of sodium coolant.

Past experience suggests that the economically optimum unit size for future central station power plants will increase to keep pace with the growth in total electrical demand: over the last fifty years or so, both electric power demand and new unit size have doubled every decade. Thus, a demand for very large LMFBR's, in unit sizes well over 1,000 $\mathrm{MW}_{\mathrm{e}}$, has been projected.

The purpose of the work presented in this report is to quantitatively characterize the neutronic and economic interaction of these two key characteristics of the LMFBR: unit rating (core size) and. breeding (blanket) performance. In this introductory chapter, a discussion will be presented motivating consideration of the subject. 
This will be followed by a brief outline of the detailed evaluation presented in the remainder of the report.

\subsection{SIZE PROJECTIONS FOR LMFBR UNITS}

Very large LMFBR's are expected to be in operation within several decades of the demonstration of commercial practicability. Figure 1.1 shows unit size trends as a function of time as projected by EEI (E1), ORNL (B2) and the U.S. AEC (D2, S1), together with the rating of LMFBR plants now in operation, under construction or planned. Three demonstration-size LMFBR's are now in operation: the $250-\mathrm{MW}$ e Phenix in France, the $250-\mathrm{MW}_{\mathrm{e}} \mathrm{PFR}$ in England, and the $15.0-\mathrm{MW}_{\mathrm{e}}$ dual-purpose BN-350 in the U.S.S.R. Commercial scale LMFBR:'s are planned by the same three countries: the $1200-\mathrm{MW}_{\mathrm{e}}$ Super Phenix, the $1000-\mathrm{MW}$ e $\mathrm{CFR}$, and the $600-\mathrm{MW}_{\mathrm{e}} \mathrm{BN}-600$, respectively (A1, B1). In this country, work has begun on the $380-\mathrm{MW}_{\mathrm{e}}$ Clinch River Demonstration Plant, to be followed by a $1000-\mathrm{MW}_{\mathrm{e}}$ commercial LMFBR (M1). Based upon these realities and projections, we are led to consider LMFBR performance in the $250-3000 \mathrm{MW}$ range of unit ratings.

It is well known that as fast reactor size increases, the internal (core) breeding ratio increases and the external (blanket) breeding ratio decreases. Consequently, net blanket revenue (i.e., plutonium credit less fabrication and reprocessing costs) earned per unit of total system energy delivered, decreases. Since the relative economic importance of the blanket tends to decrease with reactor size, it is sometimes argued that for very large reactors it might be preferable to use thinner blankets or even to substitute a. nonbreeding reflector for the breeding 


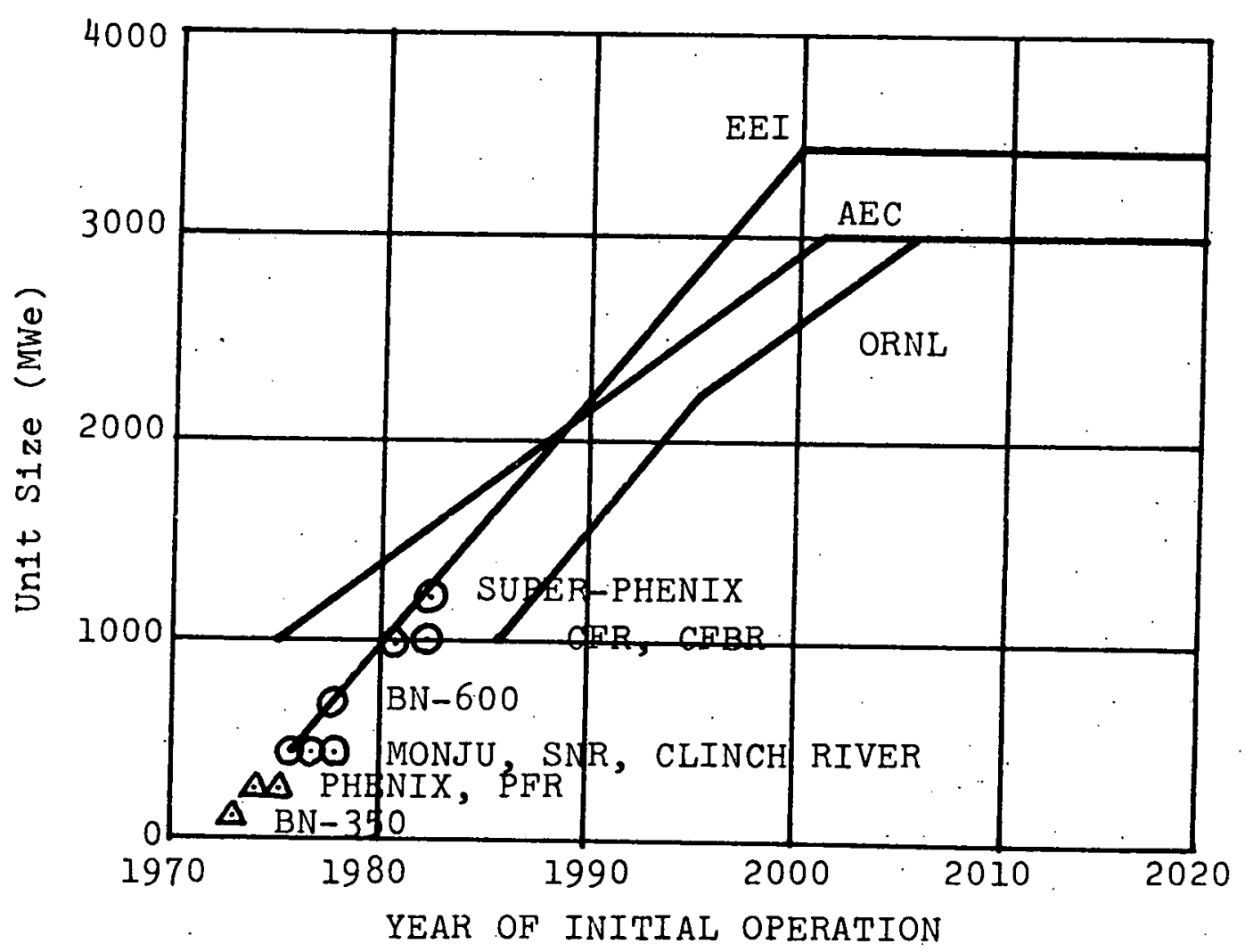

KEY $\odot$ Under Construction or Planned

$\Delta$ In Operation

F1g. 1.1. LMFBR Unit Size Projections 
blanket (B3). However, no sufficiently realistic and systematic analysis of this postulate has yet been reported. Brewer (B3) has presented a preliminary analysis based on a uniformly enriched spherical core which tends to confirm the conclusion that an ultralarge LMFBR need · not have a radial blanket. If this is indeed the case, it is questionable whether the extensive work now under way to develop thick radial blankets for demonstration plants is justified, since commercial units would not. need them. At the very least, if the optimum radial blanket thickness were to decrease significantly as core size increases, then each reactor would present a new design and fuel management optimization problem, again mitigating against overdoing the attention paid

to blankets on early noncommercial LMFBR plants. This consideration was a major factor leading to initiation of the present study. On a more immediate level, the work was also motivated by the need for such information in support of program planning for experimental investigations of blanket performance carried out within the MIT Blanket Research Project.

\section{3 OUTLINE OF PRESENT WORK}

Throughout this report the work will proceed along two parallel paths: development and application of simple analytic models to facilitate interpretation and correlation of the results; and use of state-ofthe-art computer calculations, involving appropriate cross-section sets and multigroup programs coupled to a detailed fuel cycle economics code, to provide realistic sample data. 
In Chapter 2, the predictions made by simple one-group analytical models will be presented together with a brief discussion of the methods, programs and input data which will be used in the more accurate computer analyses. Comparisons between the predictions of the simple models and the results of the computer calculations for beginning-of-life (BOL) blanket performance as a function of reactor core size will be presented in Chapter 3 . In Chapter 4 , an investigation will be made of the effect of reactor size on the depletioneconomics performance of the blanket. Finally, a summary, conclusions and recommendations for future work will be presented in Chapter 5. 


\section{Chapter 2 \\ ANALYTIC AND COMPUTER MODELS}

\subsection{INTRODUCTION}

This chapter contains a description of the two levels of attack employed to determine the relation between reactor size and blanket breeding performance : simple analytic modelling and the more sophisticated state-of-the-art computer modelling. A one-group model will be developed to display the effect of reactor size on the neutronic and economic performance of LMFBR blankets. A number of interesting results for radially power-flattened cores will be presented and contrasted with similarly derived results for uniformly loaded cores.

In order to quantify the qualitative predictions of the one-group mode1, more accurate methods using computer codes applied to realistic cases will be employed. In this chapter, the input data and general methodology will be reviewed; detailed results will be presented in later chapters. 


\subsection{PREDICTIONS USING A ONE-GROUP REACTOR PHYSICS MODEL}

2.2.1 The Effect of Changing Core Radius at Constant Core Height . on the Beginning-of-Life Breeding Performance

2.2.1.1 Neutronics of Radially Power-Flattened Cores

In order to study the effect of radial power-flattening on LMFBR core neutronics; a simple one-group model in cylindrical geometry will be examined, in which fissile concentration is varied to achieve uniform power density. The governing equation in diffusion theory is

$$
D \cdot \nabla^{2} \phi(\mathrm{r})+\left[\nu \Sigma_{\mathrm{f}}(\mathrm{r})-\Sigma_{\mathrm{a}}(\mathrm{r})\right] \phi(\mathrm{r})=0 .
$$

Let $\quad \Sigma_{\mathrm{f}}(\mathrm{r}) \phi(\mathrm{r})=\left(1+\delta_{28}\right) \Sigma_{\mathrm{f}}^{49}(\mathrm{r}) \phi(\mathrm{r})=$ constant $=\mathrm{p}$

and neglect the small variation of $D$ and the fertile-to-fissile fission ratio, $\delta_{28}$, with enrichment (approximations which are substantiated by multigroup calculations). Rearranging and solving Eq. 2.1. in several steps, described in Appendices B and.C, one finally obtains the neutron flux, $\phi(r)$ :

$$
\phi(r)=\frac{F}{\kappa^{2}}\left[1-\beta(\kappa a) I_{o}(\kappa r)\right]
$$

where $\quad \beta(\kappa a)=\left[I_{0}(k a)+\kappa \delta_{R_{1}}(k a)\right]^{-1}$,

a is the core radius,

${ }^{\delta_{R}}$ is the linear extrapolation distance,

$\kappa$ is a "pseudo" reciprocal-diffusion-length,

F. is a power density factor. 
Typical values of these parameters are $\delta_{R}=20 \mathrm{~cm}, \kappa=0.04 \mathrm{~cm}$, and $F=1.9 \times 10^{16}$ fissions $/ \mathrm{cm}^{3}-\mathrm{sec}$, all of which are assumed to be constants independent of core radius, assumptions which will be confirmed later.

Figure 2. 1 shows a typical normalized flux distribution for a radially power-flattened core, which is obtained by dividing Eq. 2.3 by the constant value of $F / \kappa^{2}$, based on the data of Table 2.1 . It is interesting to note that both the central flux and the peripheral flux have essentially constant values: around 1.0 and 0.5 (normalized), respectively, regardless of core radius; the flux shape in the interval $0<r<a$ differs, however (see Appendix C for analytical confirmation). Since the product of the enrichment and the neutron flux is constant (by our definition, Eq. 2.2, of a radially power-flattened core), constant peripheral flux implies constant peripheral enrichment. This suggests that the radial blanket for the radially power-flattened core will be driven by the same energy spectrum of leakage neutrons, regardless of core radius. This is important because the regionwise-collapsed, onegroup cross sections for the blanket will then remain the same as the core radius is varied.

The ratio of critical mass for radially power-flattened cores to uniformly loaded cores having the same core volume is approximately (see Appendix C):

$$
\frac{\mathrm{M}_{\mathrm{RPF}}}{\mathrm{M}_{\mathrm{UL}}} \simeq 1.09
$$




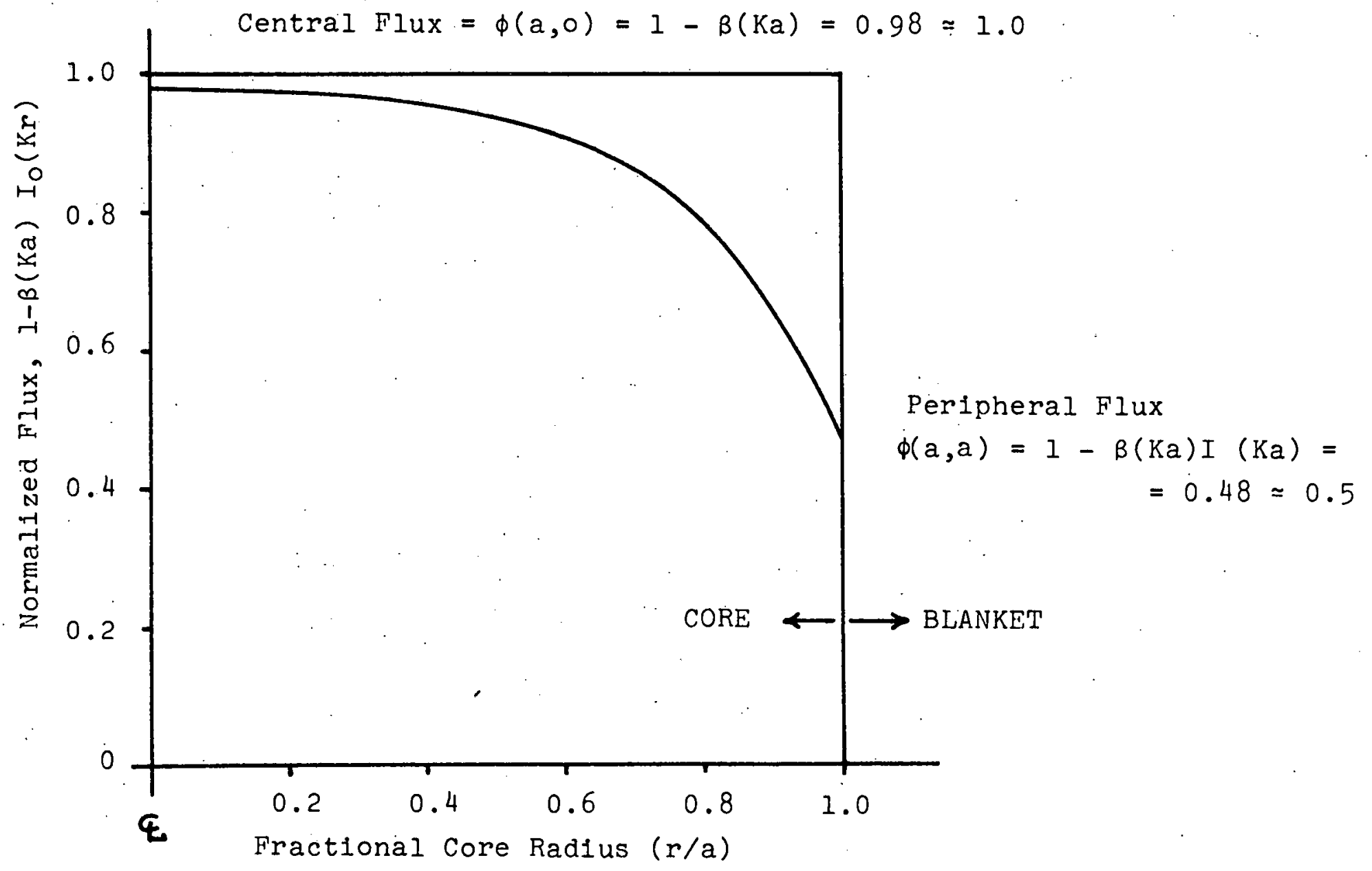

Fig. 2.1. Typical. Normalized Flux Profile of Radially-Power-Flattened Core 


$\begin{array}{lc}\text { Core Radius : a } & 12.5 \mathrm{~cm} \\ \begin{array}{l}\text { Inverse Diffusion } \\ \text { Length : }\end{array} & 0.04 \mathrm{~cm}^{-1} \\ B(k a)=\left[I_{0}(k a)+k \delta_{r} I_{I}(k a)\right]^{-1} & 0.0172 \\ \text { Linear Extrapolation } \\ \text { Distance, } \delta_{r}\end{array}$

Table 2.1 One-Group Physics Parameters of $1000 \mathrm{MH}$ e Core 
Since the critical mass of both cores is approximately equal (i. e., the core-averaged critical enrichment is also equal), the physics parameters such as the diffusion coefficient, the fertile-to-fissile fission ratio and the linear extrapolation length are also equal: Thus: the core-averaged physics parameters for uniformly loaded cores, which can be predicted using simple models, are in many instances nearly the same as those for radially power-flattened cores, which are hard to calculate exactly using simple models.

\subsubsection{Fissile Buildup Rate in the Radial Blanket}

The radial neutron leakage rate, $L_{r}$, per unit height, for a core slice having radius, $a$, is

$$
\mathrm{L}_{r}=2 \pi \mathrm{aJ}(\mathrm{a})
$$

where $J(a)$ is the net current, calculated from Eq. 2.3

$$
J(a)=\frac{D F}{\kappa} \beta(\kappa a) I_{1}(\kappa a) .
$$

Since the Bessel function term can be approximated to be constant (i.e., 0.5) regardless of core radius (proven in Appendix B), the radial neutron leakage rate, $L_{r}$, is

$$
\mathrm{L}_{\mathrm{r}}=\frac{\pi \mathrm{DF}}{\kappa} \mathrm{a}
$$

$$
\text { or } \mathrm{L}_{\mathrm{r}} \propto \mathrm{a}
$$

Since the total fissile buildup rate in a given row of assemblies or the entire blanket, $R_{\text {or }}(\mathrm{gPu} / \mathrm{yr})$, is proportional to the radial neutron leakage rate, one has 


$$
\mathrm{R}_{\text {or }} \propto \mathrm{L}_{\mathrm{r}} \propto \mathrm{a},
$$

which indicates that both the local and total fissile buildup rates are proportional to core radius. The volume of a row or rows, $\mathrm{V}_{\mathrm{B}}$, is approximated by

$$
\mathrm{V}_{\mathrm{B}}=2 \pi \tau \mathrm{a},
$$

where $\tau$ is the thickness of the row(s). Dividing Eq. 2.8 by Eq. 2.9, one has

$$
\mathrm{U}_{\mathrm{o}} \equiv \frac{\mathrm{R} \text { or }}{\mathrm{V}_{\mathrm{B}}} \propto \frac{\mathrm{a}}{2 \pi \tau \mathrm{a}} \propto \text { constant }
$$

which indicates that the fissile buildup rate per unit volume (or per blanket assembly), $U_{0}(\mathrm{gPu} /$ liter-yr), is constant regardless of core radius. Since the mass of heavy metal present, $M_{H M}$, is proportional to the volume, one has the similar equation,

$$
\mathrm{S}_{\text {or }} \equiv \frac{\mathrm{R}_{\text {or }}}{\mathrm{M}_{\mathrm{HM}}} \propto \text { constant }
$$

which indicates that the fissile material specific inventory buildup rate, $\mathrm{S}_{\text {or }}(\mathrm{gPu} / \mathrm{kgHM}-\mathrm{yr})$, or equivalently the enrichment buildup rate, $\dot{\varepsilon}_{\mathrm{o}}$ $(\% / y r)$, is also independent of core radius. These results lead to several interesting consequences, which will be discussed in later sections. Figure 2.2 illustrates the above findings in a schematic manner.

It should be noted that these results a re true only for the (constantcore-height) radially power-flattened core and are not applicable to the uniformly loaded core, in which the fissile buildup rate, $R_{\text {or }}$, is 

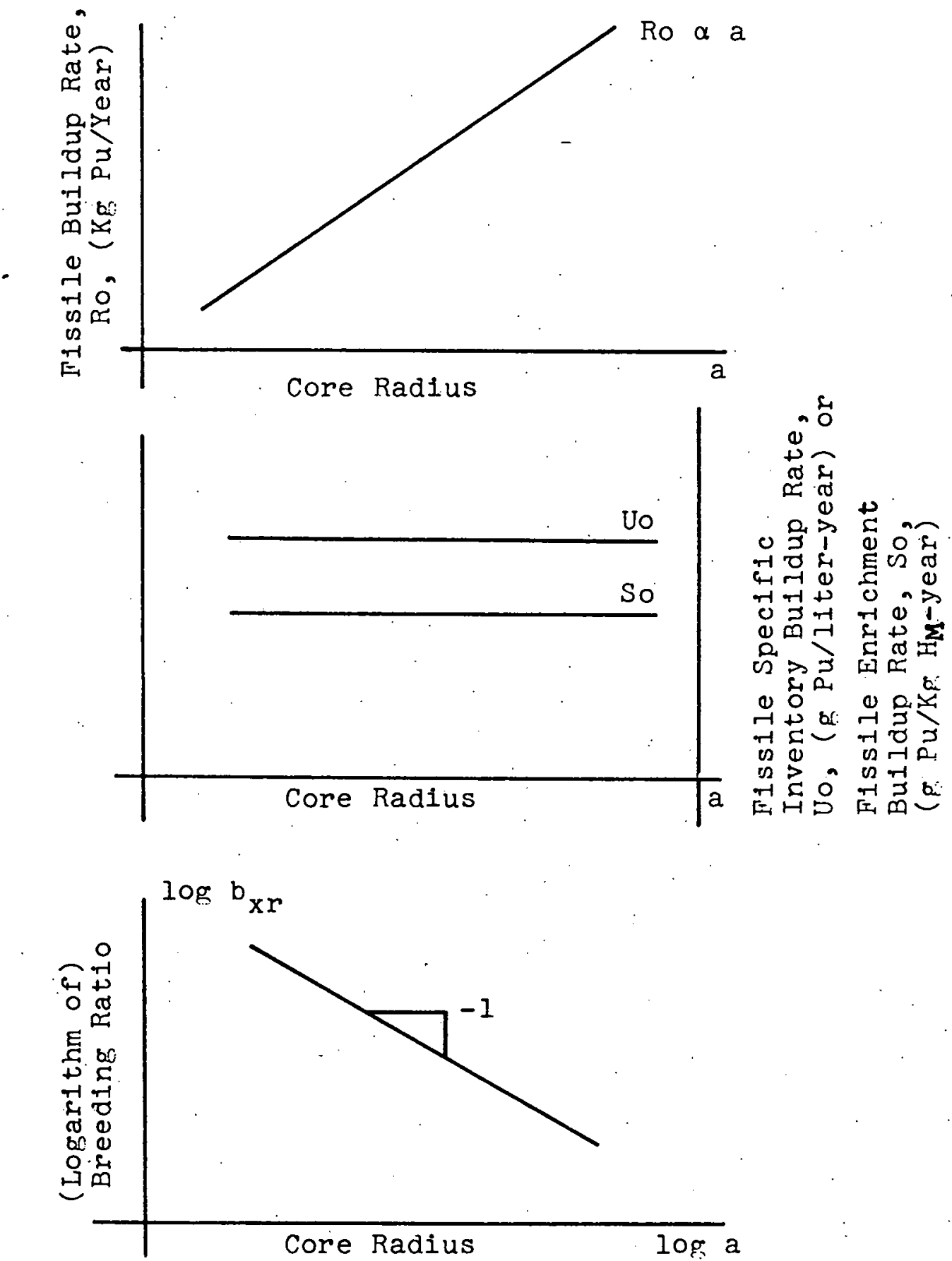

F1g. 2.2. Schematic Illustration of One-Group Results for the Effect of Core-Radius on Fissile Buildup Rate in the Radial Blanket Driven By Radially-Power-Flattened Cores 
constant and the specific inventory buildup rate, $\mathrm{S}_{\text {or }}$, is proportional to $\mathrm{a}^{-1}$ (see Appendix $\mathrm{C}$ ).

The radial blanket breeding ratio, $\mathrm{b}_{\mathrm{xr}}$, can be expressed in the approximate form (see Appendix B):

$$
\mathrm{b}_{\mathrm{xr}} \propto \frac{\text { fissile buildup rate per unit height in the radial blanket }\left(\mathrm{R}_{\mathrm{or}}\right)}{\text { thermal power per unit height in the core }\left(\mathrm{p} \pi \mathrm{a}^{2}\right)} \text {. }
$$

Since the buildup rate, $R_{\text {or }}$, is proportional to a, one can obtain:

$$
\mathrm{b}_{\mathrm{xr}} \propto \frac{1}{\mathrm{a}}
$$

which indicates that the radial blanket breeding ratio is proportional to $\mathrm{a}^{-1}$ for radially power-flattened cores. On the other hand, the radial blanket breeding ratio is proportional to $\left(a+\delta_{R}\right)^{-2}$ for uniformly loaded cores (see Appendices B and C).

\subsubsection{Fissile Buildup Rate in the Axial Blanket}

While the radial blanket is driven by the peripheral core neutron flux, which was predicted to be constant regardless of core size, the axial blanket is driven by the core-averaged neutron flux, which is related to the core-average critical enrichment. Since the coreaveraged critical enrichment decreases as the core radius increases, any analysis of breeding in the axial blanket must take into account the effect of core critical enrichment. One approximate definition of the breeding ratio, which takes into account this effect of core critical enrichment is (see Appendix B): 
$\mathrm{b}_{\mathrm{xa}} \propto \frac{\text { the axial neutron leakage cross section }}{\text { the fissile absorption cross section of the core }}$.

Since the fissile absorption cross section of the critical core is proportional to the core critical enrichment, one can obtain:

$$
b_{x a} \propto \frac{D B_{z}^{2}}{\varepsilon_{c}},
$$

where $\quad \mathrm{B}_{\mathrm{z}}^{2}=\left(\pi / \mathrm{H}+2 \delta_{\mathrm{a}}\right)^{2}$ is the axial geometrical buckling,

$\delta_{a}$ is the axial extrapolation distance.

For constant height cores, $\mathrm{DB}_{z}^{2}$ is constant. Thus the axial blanket breeding ratio is:

$$
\begin{gathered}
b_{\mathrm{xa}} \propto \varepsilon_{\mathrm{c}}^{-1} \\
\text { or } b_{\mathrm{xa}} \cdot \varepsilon_{\mathrm{c}} \propto \text { constant. }
\end{gathered}
$$

Since Eq. 2.13 is also valid for the fissile buildup rate per unit volume of the axial blanket, the fissile specific inventory buildup rate in the axial blanket is:

$$
\begin{gathered}
S_{\mathrm{oa}} \propto \varepsilon_{\mathrm{c}}^{-1} \\
\text { or } \mathrm{S}_{\mathrm{oa}} \cdot \varepsilon_{\mathrm{c}} \propto \text { constant. }
\end{gathered}
$$

By multiplying $\mathrm{S}_{\mathrm{Oa}}$ by the volume per unit height of the axial blanket, the fissile buildup rate for the entire axial blanket is obtained:

$$
\mathrm{R}_{\mathrm{oa}} \propto \frac{\mathrm{a}^{2}}{\varepsilon_{\mathrm{c}}} .
$$


These results are summarized as follows:

1) The product of the fissile specific inventory buildup rate, $S_{0}$ (gPu/kgHM-yr), (or the enrichment buildup rate, $\dot{\varepsilon}_{\mathrm{O}}(\% / \mathrm{yr})$ and the core critical enrichment is constant regardless of core radius.

2) The product of the axial blanket breeding ratio and the core critical enrichment is also constant for all core radii (sizes):

These conclusions hold true for axial blankets driven by either uniformly loaded or radially power-flattened cores: the results are shown in schematic fashion in Fig. 2.3. It should be noted that since the core critical enrichment approaches asymptotic values for larger cores (over $1000 \mathrm{MW}_{\mathrm{e}}$ ), the above observations can be modified as follows:

1) For the larger cores, the fissile specific inventory buildup rate is the same for all core radii.

2) For the larger cores, the axial blanket breeding ratio is also the same for all core radii.

\subsubsection{The Effect of Changing Core Radius at Constant Core Height on Depletion-Economics Performance}

\subsubsection{Fuel Cycle Cost Contribution from the Radial Blanket}

The fuel cycle cost contribution, e (mills/kwhr), attributable to each zone or to the entire blanket can be described by the following simplified expression ([B3]; also see section 2.3.3.5, this report): 

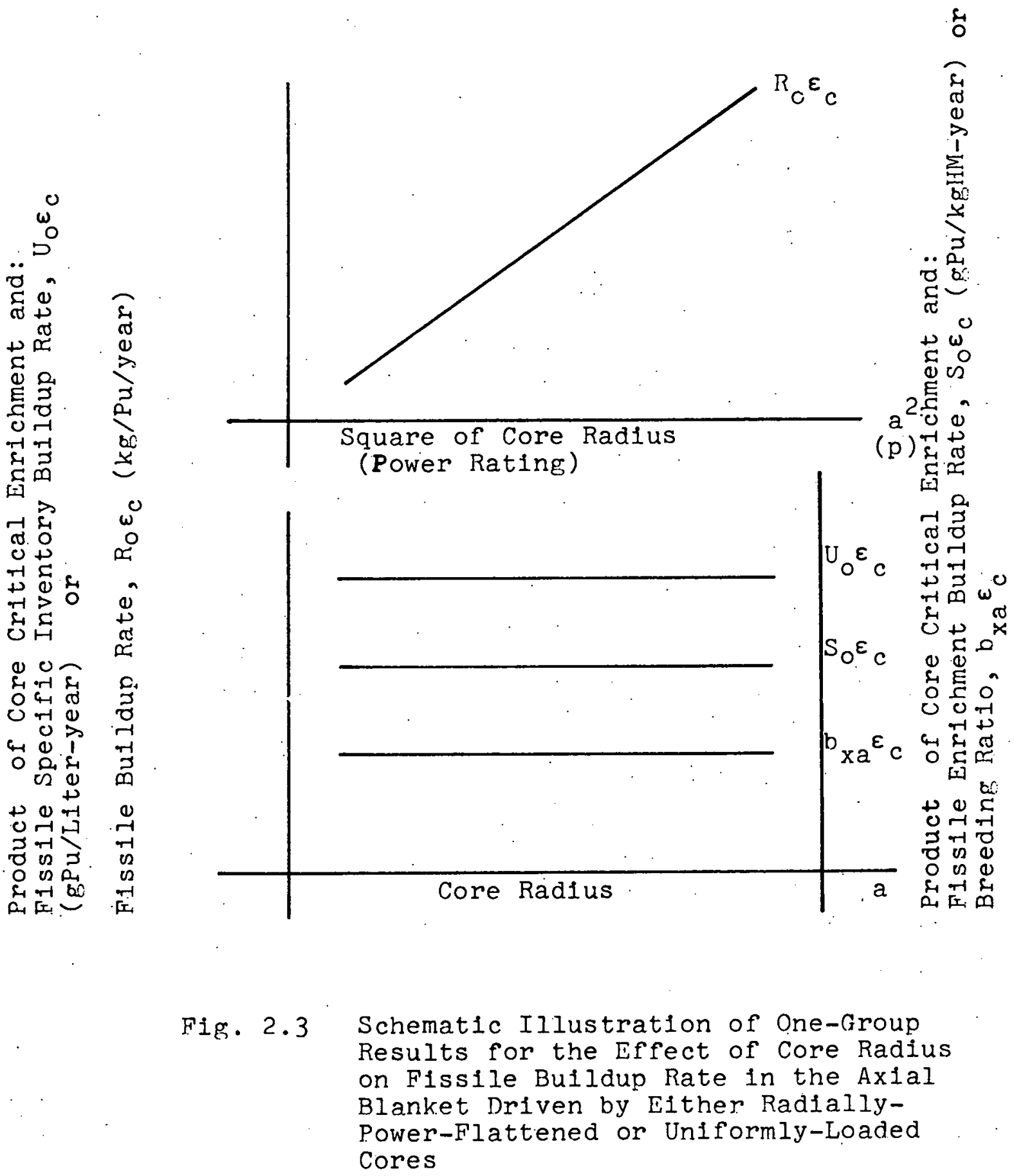


$$
\mathrm{e}=\frac{\mathrm{M}_{\mathrm{HM}}}{\mathrm{E}}[\mathrm{FOB}]
$$

where $\quad \mathrm{M}_{\mathrm{HM}}$ is the initial total mass of heavy metal loaded in the region in question ( $\mathrm{kgHM)}$,

$E$ is the total electricity generated from the entire reactor $(\mathrm{kwhr})$, and

- $[\mathrm{FOB}]$ is an "economic figure-of-merit" function; which accounts for fuel cycle cost per unit mass of heavy metal and is a function of enrichment, $\varepsilon(T)$, at irradiation time, $\mathrm{T}(\mathrm{yr})$.

The only term related to core radius in the FOB function is the enrichment, $\varepsilon(T)$. Applying the approximation that the fissile enrichment. builds up linearly with time, which has been shown to be a good approximation (see [W2, B3] and subsequent chapters of this report):

$$
\varepsilon(T)=\dot{\varepsilon}_{0} T \propto S_{o} T,
$$

where $\quad \dot{\varepsilon}_{0}$ is the fissile enrichment buildup rate (\%/yr),

$\mathrm{S}_{\mathrm{O}}$ is the fissile specific inventory buildup rate ( $g P u / k g H M-y r)$.

Recalling the results obtained in the previous section, namely that. $\dot{\varepsilon}_{0}$ and $S_{O}$ are constant for all core radii, the conclusion follows that the economic performance history $(\mathrm{FOB})$ of each row or of the entire radial blanket, driven by radially power-flattened cores, remains the same as the core radius (power rating) changes. 
On the other hand, the total mass of heavy metal loaded into each row or into the entire blanket, $\mathrm{M}_{\mathrm{HM}}$, is approximately proportional to core radius, again described in the previous section. The total electricity generated from the entire reactor, $\mathrm{E}$, is proportional to the core volume (i.e., the square of the core radius for constant-height cores). Thus, one has:

$$
\begin{aligned}
\mathrm{e} & =\frac{\mathrm{M}_{\mathrm{HM}}}{\mathrm{E}}[\mathrm{FOB}] \propto \frac{\mathrm{R} \text { or }}{\pi \mathrm{a}^{2}} \propto \frac{\mathrm{a}}{\mathrm{a}^{2}}, \\
\text { or } \mathrm{e} & \propto \frac{1}{\mathrm{a}},
\end{aligned}
$$

which indicates that the fuel cycle cost contribution from each row or from the entire radial blanket, driven by radially power-flattened cores, is inversely proportional to the core radius.

It must be noted that the preceding discussion applies to entire blanket rows. If one examines a single radial blanket assembly, one will find that the total dollar revenue per assembly remains constant as the core radius is increased. Only because the volume of blanket fuel relative to the volume of fuel in the core decreases as core. radius increases, do we see the decreasing effect on total fuel cycle costs predicted by Eq. 2.19. This is an important distinction which must be kept in mind throughout the discussions in the remainder of this report. In summary (see Fig. 2.4): Dollar revenue per assembly remains the same, total blanket dollar revenue increases, and the blanket contribution to the overall fuel cycle cost (i.e., mills/kwhr) decreases, as the core radius is increased. 

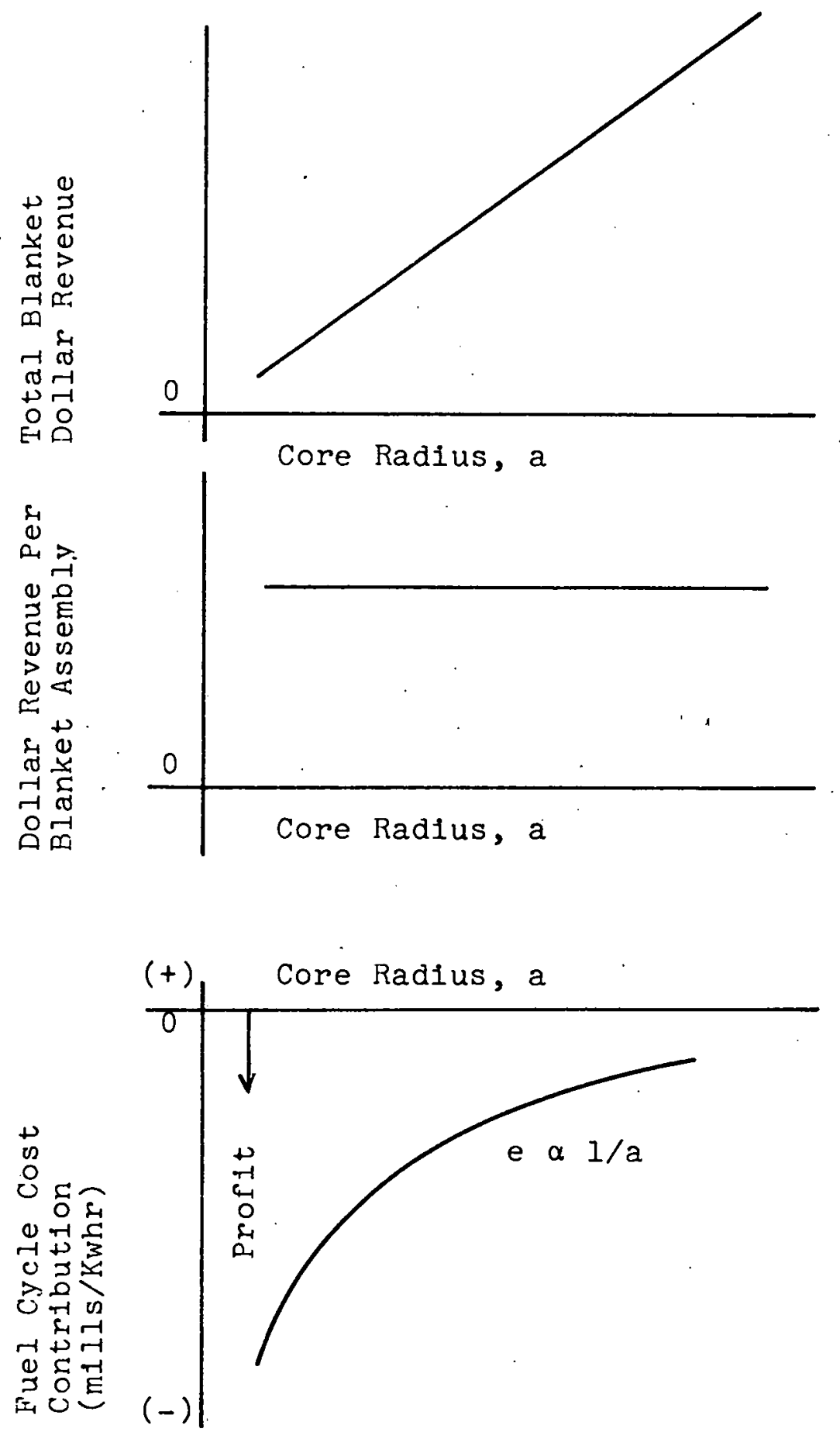

Fig. 2.4. Schematic Illustration of the Effect of Core-Radius on the Economic Performance of the Radial Blanket Driven by Radially Power-Flattened Cores 
However, the fuel cycle cost contribution is proportional to $\left(a+\delta_{R}\right)^{-2}$ for uniformly loaded cores because the fissile buildup rate from each row or from the entire blanket is constant. In a similar manner, one is led to the conclusions that dollar revenue per assembly decreases, total blanket dollar revenue is constant, and the blanket contribution to the fuel cycle cost decreases, as the core radius is increased. Table 2.2 summarizes the neutronic and economic performance of the radial blanket driven by either radially power-flattened or uniformly loaded cores as a function of core radius (size). Note that the revenue per assembly decreases for the uniformly loaded core, which would lead to a decrease in optimum blanket thickness as core size increases--in support of the intuitive notion sometimes expressed on blanket designs for large cores. We have shown here that the more realistic radially power-flattened cores instead lead to uniform-thickness radial blankets.

\subsubsection{Fuel Cycle Cost Contribution from the Axial Blanket}

Since the fissile specific inventory buildup rate in the axial blanket is also constant for all large core radii (sizes), the same conclusions as were found for the radial blanket follow; namely, that the economic performance history (FOB) of each axial zone or of the entire axial blanket, driven by either radially power-flattened or uniformly loaded cores, remains the same as the core radius (power rating) changes. 


\begin{tabular}{|c|c|c|}
\hline Items & $\begin{array}{l}\text { Radially Power } \\
\text { Flattened Core }\end{array}$ & $\begin{array}{l}\text { Uniformly } \\
\text { Loaded Core }\end{array}$ \\
\hline $\begin{array}{l}\text { Whole Blanket } \\
\text { (or Row) Fissile } \\
\text { Buildup Rate } \\
\mathrm{R}_{\mathrm{o}}(\mathrm{KgPu} / \mathrm{yr}) \\
\text { Specific Inventory } \\
\text { Buildup Rate } \\
\text { So (gPu/Kg HM yr) } \\
\text { Breeding Ratio } \\
\mathrm{b}_{\mathrm{xa}}\end{array}$ & $\begin{array}{c}\dot{a} \\
\text { Constant } \\
\propto a^{-1}\end{array}$ & $\begin{array}{l}\text { Constant } \cdot\left(1+\frac{\delta R}{a}\right)^{-2} \\
a^{-1}\left(1+\frac{\delta R}{a}\right)^{-2} \\
a^{-2}\left(1+\frac{\delta R}{a}\right)^{-2}\end{array}$ \\
\hline $\begin{array}{l}\text { Revenue per } \\
\text { Blanket Row (\$) } \\
\text { Pevenue per } \\
\text { Blanket Assembly } \\
\text { Contribution to } \\
\text { Fuel Cycle Cost } \\
\text { (mills/Kw Hr) } \\
\text { Optimum Irradiation } \\
\text { Time (full power } \\
\text { Days) } \\
\text { Ootimum Thickness } \\
\text { (CM) }\end{array}$ & $\begin{array}{c}\propto a \\
\text { Constant } \\
\propto a^{-1}\end{array}$ & $\begin{array}{l}\text { Constant } \cdot\left(1+\frac{\delta R}{a}\right)^{-2} \\
a^{-1}\left(1+\frac{\delta R}{a}\right)^{-2} \\
a^{-2}\left(1+\frac{\delta R}{a}\right)^{-2} \\
\text { Increases } \\
\text { Decreases }\end{array}$ \\
\hline
\end{tabular}

$$
\begin{aligned}
a & =\text { Core Radius } \\
\delta_{R} & =\text { Extrapolation Distance }
\end{aligned}
$$

Table 2.2. Summary of the effect of Changing Core Radius at Constant Core Height on the Neutronic and Economic Performance of the Radial Blanket (Predictions of simple one-groun model) 
Since the total mass of heavy metal loaded into each axial zone or into the entire axial blanket, $\mathrm{M}_{\mathrm{HM}}$, is proportional to $\pi \mathrm{a}^{2}$, as described in the previous section, one has for the fuel cycle cost contribution:

$$
\begin{aligned}
e & =\frac{M_{H M}}{E}[F O B] \propto \frac{R_{\text {oa }}}{\pi a^{2}} \propto \frac{\mathrm{a}^{2}}{\mathrm{a}^{2}}, \\
\text { or } \mathrm{e} & \propto \text { constant }
\end{aligned}
$$

which indicates that the fuel cycle cost contribution from each axial zone or from the entire axial blanket, driven by either radially powerflattened or uniformly loaded cores, is constant for all large core radii (sizes).

By applying the same logic as in the case of the radial blanket to axial blanket fuel contained in a single assembly, one can conclude that the total revenue per assembly remains constant as the core radius is increased. Since the ratio of the axial blanket volume to the volume of the core remains the same as the core radius is increased, the fuel cycle cost contribution behaves in the same manner. The total revenue from the entire axial blanket is proportional to $a^{2}$. These results are summarized in Table 2.3.

\subsubsection{Local Breakeven and Optimum Irradiation Time}

Figure 2.5 shows a typical variation of the fuel cycle cost contribution from a given region of blanket. Three interesting irradiation times are noted in Fig. 2.5: $\mathrm{T}_{\mathrm{BE}-1}, \mathrm{~T}_{\text {opt }}$ and $\mathrm{T}_{\mathrm{BE}-2}$. Below some irradiation time, $\mathrm{T}_{\mathrm{BE}-1}$, the bred fissile inventory in the subject 


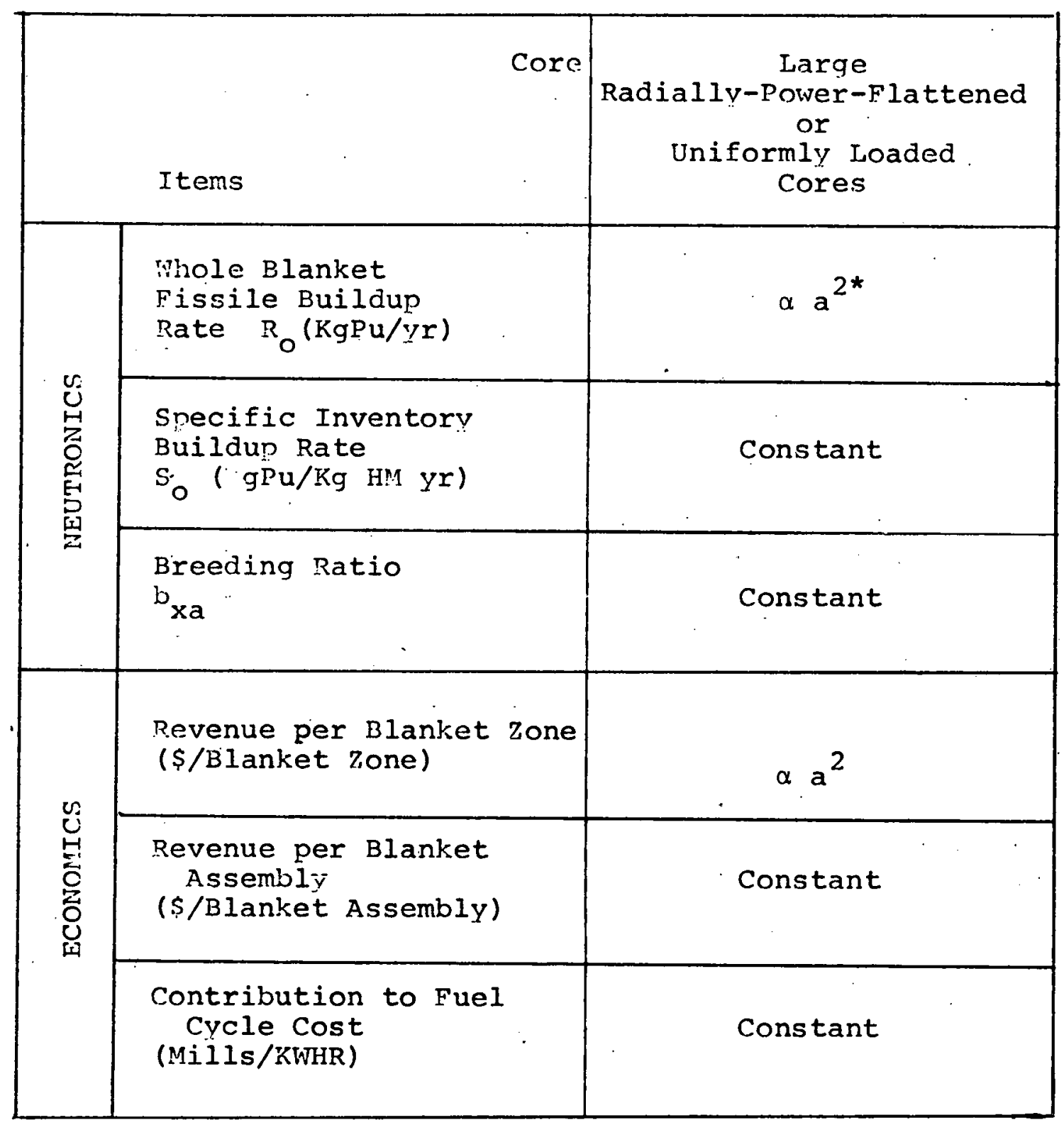

* See Appendix B and Section 2.2.1.3

$a=$ core radius

Table 2.3 Summary of the Effect of Changing Core Radius at Constant Core Height on the Neutronic and Economic Performance of the Axial Blanket (Predictions of Simple nne-Group Model) 


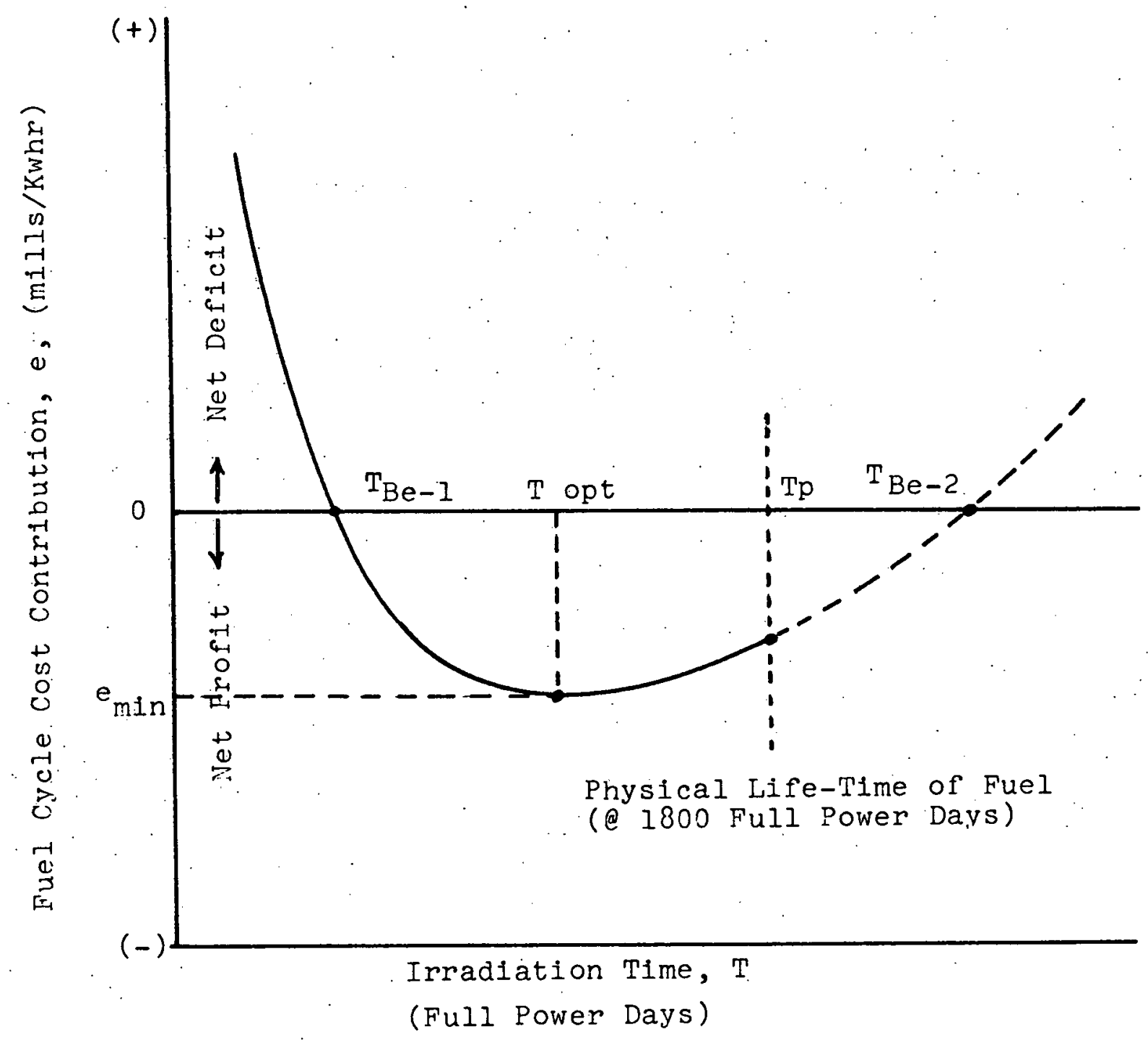

Fig. 2.5. Typical Varlation of Fuel Cycle Cost Contribution From A rast Reactor Blanket 
region of the blanket is not sufficient to offset the blanket fabrication, reprocessing and carrying charges for that region. At $\mathrm{T}_{\mathrm{BE}-1}$, the breakeven point, the revenue from bred fissile material credit is just equal to the costs incurred.

Beyond $\mathrm{T}_{\mathrm{BE}-1}$, the region produces a net profit. As irradiation time is further increased, carrying charges increase and fissile production increases. These opposing effects result in an optimum irradiation time for the region, $T_{\text {opt; }}$, at which time the maximum net revenue from the region can be obtained. Beyond $\mathrm{T}_{\text {opt }}$, the carrying charges increase more rapidly than revenue from fissile production, and gradually the net profit from the region decreases, once again becoming negative, after passing through the second breakeven point, $T_{B E-2}$ (assuming the physical lifetime of the fuel, $\mathrm{T}_{\mathrm{p}}$, permits).

Both the breakeven and the optimum irradiation time depend on the economic environment. In other words, higher fabrication and reprocessing costs or lower fissile credit lead to longer breakeven and optimum irradiation times. Since both irradiation times are key parameters affecting blanket design and fuel management, it is desirable to correlate them against a parameter or parameters which characterize the economic environment. As derived in Appendix E and shown in Fig. 2.6, the breakeven irradiation time, $\mathrm{T}_{\mathrm{BE}-1}$, can be shown to be proportional to the economic parameter, $W$, originally derived in a slightly different form by Wood (W2, H2) and modified by this study. We have: 

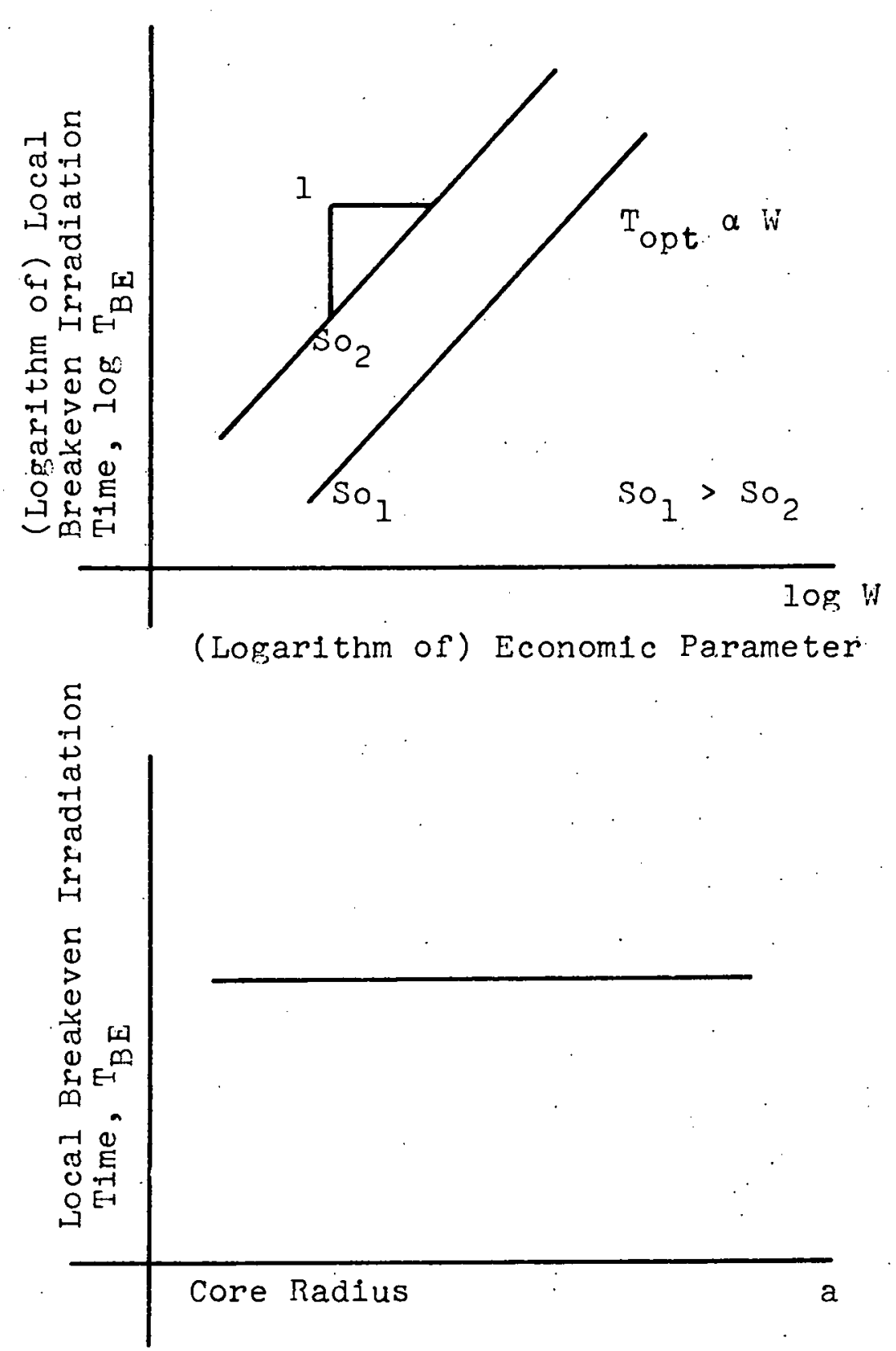

Fig. 2.6. Schematic Illustration of the Effect of Core-Radius on Breakeven Irradiation Time in the Axial or Radial Blanket 


$$
\mathrm{T}_{\mathrm{BE}-1}=\frac{\text { cost }}{\text { revenue buildup rate }}=\frac{\mathrm{W}}{\mathrm{S}_{\mathrm{o}}} \text {, }
$$

where

$$
\mathrm{W} \equiv\left[\frac{\mathrm{C}_{1} \mathrm{~F}_{1}\left(-\Delta \mathrm{T}_{1}\right)+\mathrm{C}_{2} \mathrm{~F}_{2}\left(\Delta \mathrm{T}_{2}\right)}{\mathrm{C}_{3} \mathrm{~F}_{3}\left(-\Delta \mathrm{T}_{3}\right)}\right]
$$

in which

$\mathrm{C}_{1}$ is the fabrication cost $(\$ / \mathrm{kgHM})$

$\mathrm{C}_{2}$ is the reprocessing cost $(\$ / \mathrm{kgHM})$

$\mathrm{C}_{3}$ is the fissile credit $(\$ / \mathrm{kgPu})$

and the carrying charge factors are:

$$
\begin{array}{ll}
\mathrm{F}_{1}\left(-\Delta \mathrm{T}_{1}\right)=\frac{1}{1-\tau}\left[(1+\mathrm{X})^{\left.\Delta \mathrm{T}_{1}-\tau\right]}\right. & \text { (for fabrication), } \\
\mathrm{F}_{2}\left(\Delta \mathrm{T}_{2}\right)=(1+\mathrm{X})^{-\Delta \mathrm{T}_{2}} & \text { (for reprocessing), } \\
\mathrm{F}_{3}\left(\Delta \mathrm{T}_{3}\right)=(1+\mathrm{X})^{-\Delta \mathrm{T}_{3}} & \text { (for credit), }
\end{array}
$$

where

$\Delta \mathrm{T}_{1}$ is the length of time from fabrication cash flow to the beginning of the irradiation,

$\Delta \mathrm{T}_{2}$ is the length of time from the end of the irradiation to the reprocessing cash flow,

$\Delta \mathrm{T}_{3}$ is the length of time from the end of the irradiation to the material credit cash flow,

$\tau$. is the income tax rate,

and

$\mathrm{S}_{\mathrm{O}}$ is the fissile specific inventory buildup rate ( $\mathrm{gPu} / \mathrm{kgHM}-\mathrm{yr}$ ).

Since the fissile specific inventory buildup rate in a given region is the same for all core radii, as derived in the previous section, it follows that: 
1) The breakeven irradiation time for a given row or rows of radial blankets driven by radially power-flattened cores is the same for all core radii (i.e., all core power ratings).

2) The breakeven irradiation time for a given axial zone or for the entire axial blanket, driven either by radially power-flattened or uniformly loaded cores; is the same.

The optimum irradiation time for a given region in the blanket, as derived by Wood (W2) (see also Appendix E) is:

$$
T_{\text {opt }}=\sqrt{\frac{2 W}{S_{o}} \frac{X}{X}}
$$

Thus, one can also conclude that the optimum irradiation time for a given row of (or the entire) radial blanket driven by radially powerflattened cores and for a given zone of (or the entire) axial blanket driven by either radially power-flattened or uniformly loaded cores, is the same for all core radii, as shown in Fig. 2..7.

In order to compare Eqs. 2.21 and 2.26 with the correlations which will be discussed in later chapters, it is convenient to rearrange these equations in the form:

$$
\mathrm{T}=\mathrm{a} \mathrm{W}^{\mathrm{b}} \mathrm{X}^{\mathrm{c}}
$$

where $a, b$ and $c$ are the coefficients appropriate to Eqs. 2.21 and 2.26. Table 2.4 summarizes the coefficients for various individual rows or combinations of rows. By combining Eq. 2.21 and Eq. 2.26, one can relate the breakeven irradiation time and the optimum irradiation time:

$$
\mathrm{T}_{\mathrm{BE}}=\frac{\mathrm{X}}{2}\left(\mathrm{~T}_{\mathrm{opt}}\right)^{2} .
$$

Figure 2.8 illustrates this relationship. 

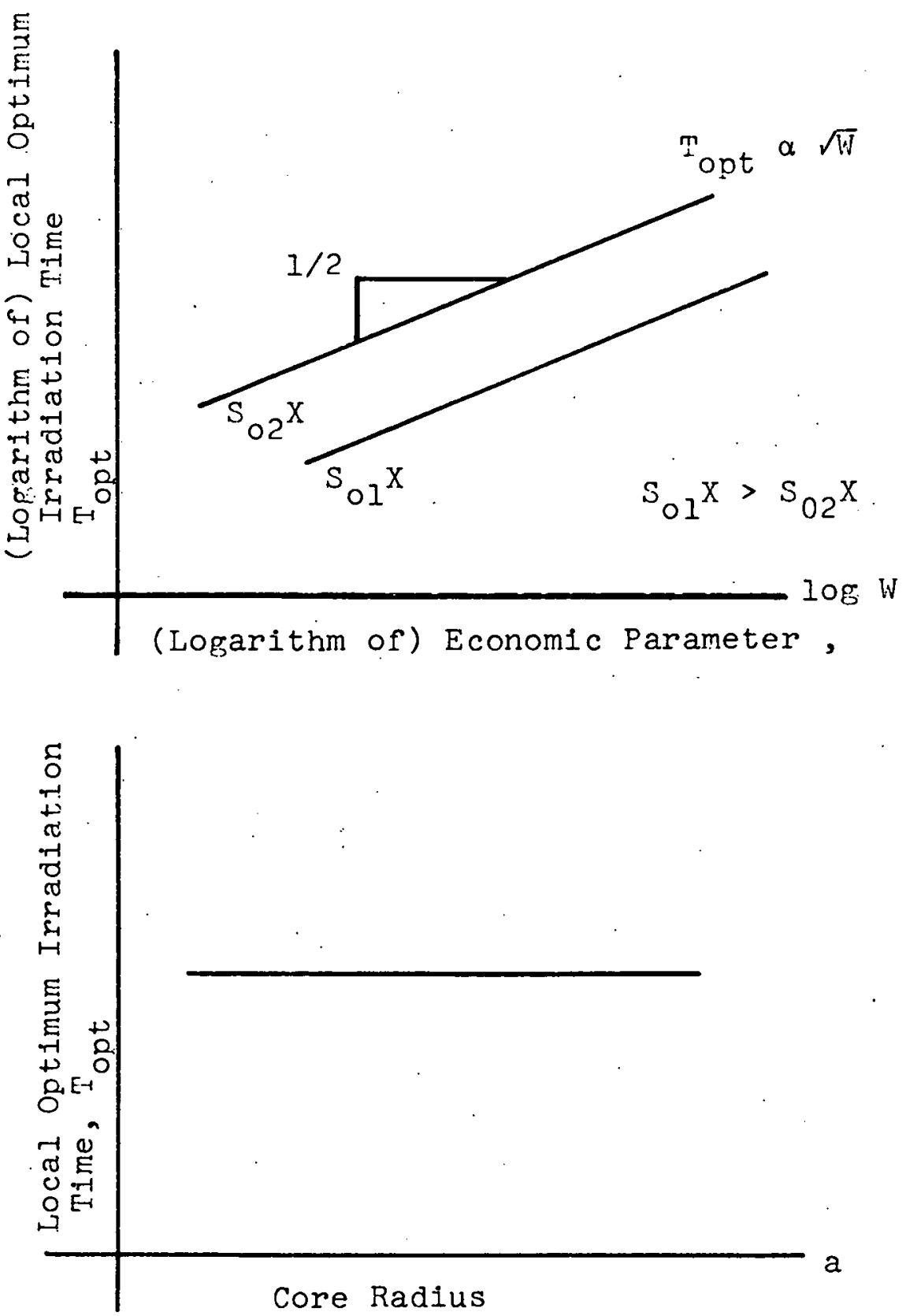

Fig. 2.7. Schematic Illustration of the Effect of Core-Radius and Economic Environment on Optimum Blanket Irradiation Time 


\begin{tabular}{|c|c|c|c|c|c|}
\hline & & & $a_{j}$ & $b_{j}$ & $c_{j}$ \\
\hline \multirow{2}{*}{ 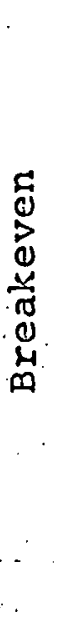 } & 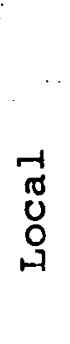 & $\begin{array}{l}\text { Row } 1 \\
\text { Row } 2 \\
\text { Row } 3\end{array}$ & \multirow{2}{*}{$\begin{array}{l}\times 10^{4} \\
2.64 \\
6.38 \\
10.8 \\
2.64 \\
38.2 \\
53.4\end{array}$} & \multirow[t]{2}{*}{1.0} & \multirow[b]{2}{*}{0.0} \\
\hline & $\begin{array}{l}-1 \\
0 \\
0 \\
0 \\
E\end{array}$ & $\begin{array}{l}1 \text { Row Blanket } \\
2 \text { Row Blanket } \\
3 \text { Row Blanket }\end{array}$ & & & \\
\hline \multirow{2}{*}{ 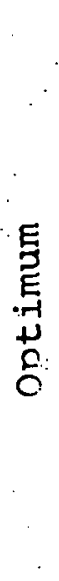 } & 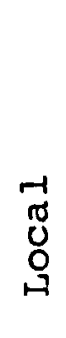 & $\begin{array}{l}\text { Row } 1 \\
\text { Row } 2 \\
\text { Row } 3\end{array}$ & \multirow{2}{*}{$\begin{array}{l}\times 10^{3} \\
3.98 \\
6.19 \\
10.0 \\
3.98 \\
4.79 \\
5.66\end{array}$} & \multirow{2}{*}{0.5} & \multirow{2}{*}{-0.5} \\
\hline & 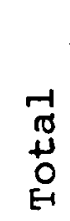 & $\begin{array}{l}1 \text { Row Blanket } \\
2 \text { Row Blanket } \\
3 \text { Row Blanket }\end{array}$ & & & \\
\hline
\end{tabular}

Table 2.4 Summary of the Coefficients Predicted by the Simplified Economic Model for the Correlation of the Breakeven and the notimum Irradiation Times of the Radial Blanket. 


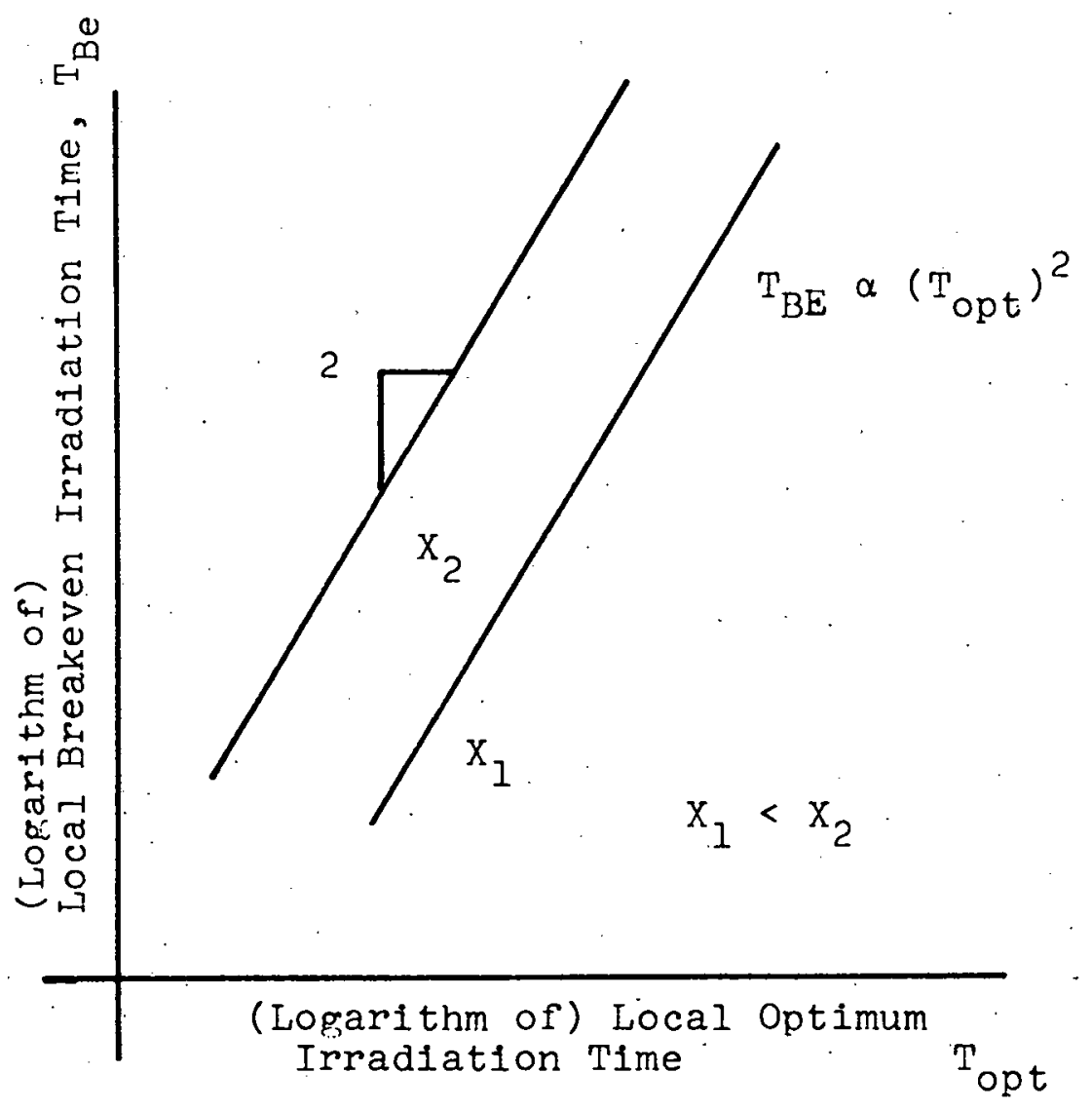

Fig. 2.8. Schematic Illustration of the Relation Between Breakeven and Optimum Irradiation Time 


\subsubsection{Optimum Irradiation Time for a Blanket Row}

Based upon both multigroup calculations and experimental measurements, and as developed in Appendix. E, it is a good approximation to assume that the fissile material buildup rate per unit volume in the blanket, $\mathrm{S}_{0, \ell}$, decreases exponentially as the distance from the core/blanket interface increases:

$$
S_{o, \ell}=S_{o}(0) e^{-\gamma \tau}
$$

where

$S_{0}(0)$ is the fissile buildup rate per unit volume at the interface between the core and the blanket constant for all core radii in the present instance,

$\gamma$ is the inverse diffusion length,

$\tau \quad$ is the distance from the core/blanket interface.

Combining Eq. 2.21 with Eq. 2.29 and eliminating the fissile buildup rate per unit volume; one obtains the relation between the local breakeven.irradiation time and the distance from the core/ blanket interface:

$$
\mathrm{T}_{\mathrm{BE}}=\left[\frac{\mathrm{W}}{\mathrm{S}_{\mathrm{o}}(0)}\right] \mathrm{e}^{\gamma \tau},
$$

or

$$
\tau=\frac{1}{\gamma}\left[\ln \mathrm{T}_{\mathrm{BE}}-\ln \left\{\frac{\mathrm{W}}{\mathrm{S}_{\mathrm{O}}(0)}\right\}\right] .
$$

This relation is expected to be linear when plotted on semi-log paper as shown in Fig. 2.9. The intercept of the. "local breakeven" curve and the zero distance line (i.e., the core/blanket interface) is: 


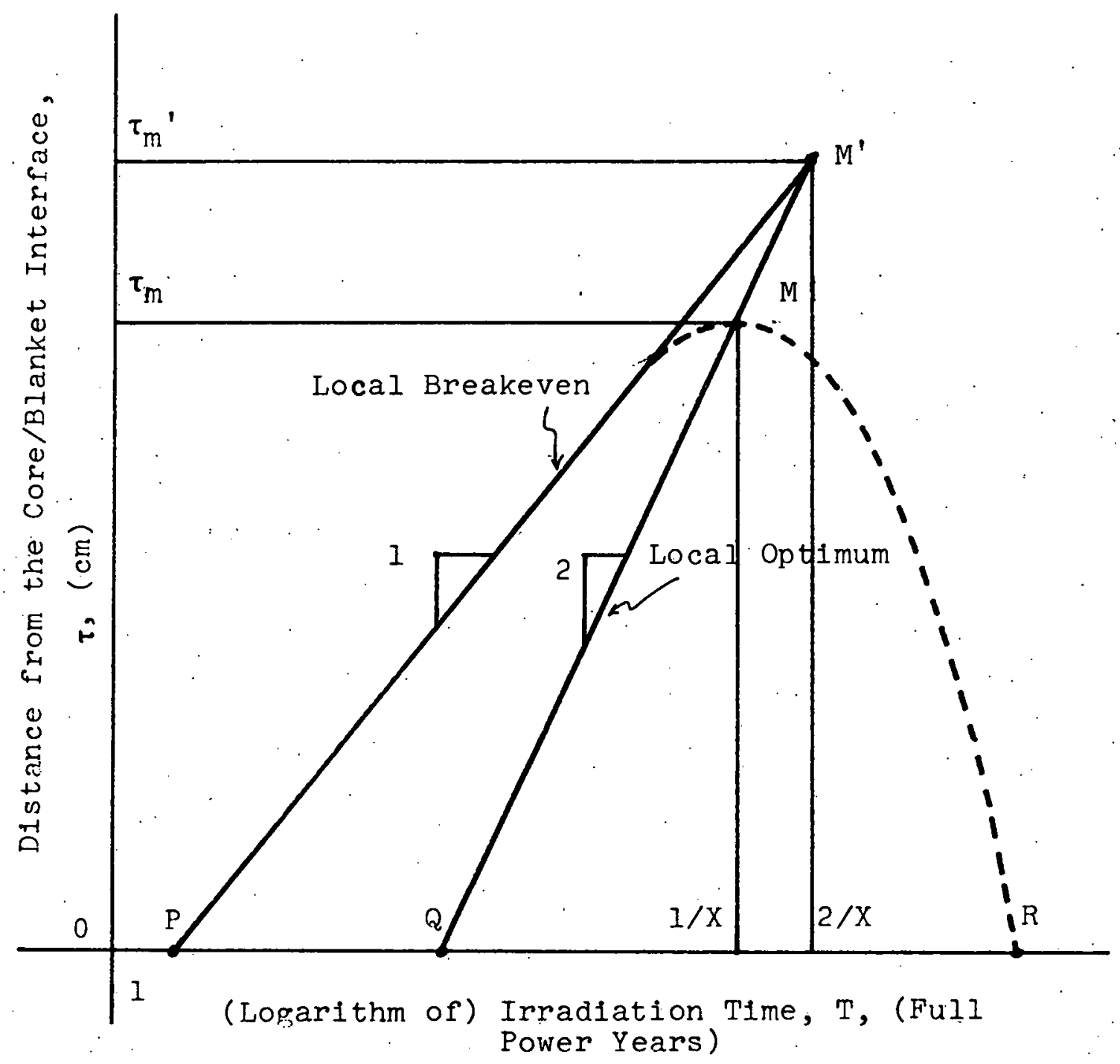

Fig. 2.9. Schematic Diagram of Local Breakeven and Local Optimum Positions as a Function of Irradiation Time 


$$
\mathrm{T}_{\mathrm{BE}-\mathrm{P}}=\frac{\mathrm{W}}{\mathrm{S}_{\mathrm{O}}(0)}
$$

which we have designated as point $P$.

In a similar manner, the local optimum irradiation time can be. expressed in the form:

$$
\mathrm{T}_{\text {opt }}=\sqrt{\frac{2 \mathrm{~W}}{\mathrm{~S}_{\mathrm{O}}(0) \mathrm{X}}} \mathrm{e}^{\frac{1}{2} \gamma \tau}
$$

or

$$
\tau=\frac{2}{\gamma}\left[\ln \mathrm{T}_{\mathrm{opt}}-\frac{1}{2} \ln \left(\frac{2 \mathrm{~W}}{\mathrm{~S}_{\mathrm{o}}(0) \mathrm{X}}\right)\right]
$$

The intercept of the "local optimum" curve and the zero blanket thickness line is:

$$
\mathrm{T}_{\text {opt }-\mathrm{Q}}=\sqrt{\frac{2 \mathrm{~W}}{\mathrm{~S}_{\mathrm{o}}(0) \mathrm{X}}}
$$

which we have designated as point $Q$. This is also sketched in Fig. 2.9. Note the $\mathrm{T}_{\mathrm{BE}}{ }^{-\mathrm{T}}$ opt intercept at $\mathrm{T}=2 / \mathrm{X}$ years, which defines, in a grossly overconservative manner, the thickest possible no-loss blanket. To obtain a better estimate, it is preferable to use the form:

$$
\mathrm{T}_{\mathrm{BE}}=\frac{1}{\mathrm{X}}\left(1 \pm \sqrt{1-\frac{2 \mathrm{WX}}{\mathrm{S}_{\mathrm{O}, \ell}}}\right)
$$

which can be obtained by solving the cost equation (2.17) (i.e., e $=0$ ). At the point where the two roots degenerate (designated point $M$ ), one obtains:

$$
\mathrm{T}_{\mathrm{M}}=\frac{1}{\mathrm{X}}
$$

where the zero discriminant also tells us that

$$
\mathrm{s}_{\mathrm{O}, \ell}=2 \mathrm{WX} \text {. }
$$


The point $M$ defines a time at which the thickest economically viable blanket has its maximum profit, provided that the whole blanket is. discharged at the same time, i.e., in batch fuel management. As discussed in later chapters, this intersection point will not occur during the practical lifetime of radial blanket fuel assemblies (here assumed to be about 6 years) under usual economic conditions (Fabrication cost $\cong$ $69 \$ / \mathrm{kgHM}$, Reprocessing cost $\cong 50 \$ / \mathrm{kgHM}, \mathrm{Pu}$ price $\cong 10 \$ / \mathrm{gPu}$ and Discount rate $\cong 0.08 \mathrm{yr}^{-1}$ ).

Since a non-negative discriminant in Eq. 2.34 corresponds to real roots, Equation 2.36 defines the minimum profitable fissile buildup rate which produces a zero net profit. The two roots of Eq. 2. 34 can be approximated as:

$$
\begin{aligned}
& \mathrm{T}_{\mathrm{BE}-1} \cong \frac{1}{\mathrm{X}} \\
& \mathrm{T}_{\mathrm{BE}-2} \cong \frac{2}{\mathrm{X}}-\frac{\mathrm{W}}{\mathrm{S}_{\mathrm{O}, \ell}} .
\end{aligned}
$$

The smaller root (Eq. 2.34a) is, of course, the first breakeven irradiation time, and the larger root $(\mathrm{Eq} .2 .34 \mathrm{~b})$ is the second breakeven irradiation time discussed in the previous section (see Fig. 2.5). Thus the "local breakeven" curve increases semi-log-linearly as the distance into the blanket increases, then curves down after passing point $M$ and finally intercepts the zero-distance-into-the-blanket line (i.e., the core/ blanket interface), designated point $R$ in the present work, which corresponds to the point in time where:

$$
\mathrm{T}_{\mathrm{BE}-\mathrm{R}} \cong \frac{2}{\mathrm{X}}-\frac{\mathrm{W}}{\mathrm{S}_{\mathrm{O}}(0)},
$$

where $S_{0}(0)$ is again the interfacial fissile specific inventory buildup rate. 
It should be noted that these results hold true for all core radii because the interfacial fissile buildup rate per unit volume, $S_{0}(0)$, is constant regardless of core radius, as demonstrated in the previous section.

At a given time, fuel deeper in the blanket than that which has reached breakeven gives a positive fuel cycle cost contribution (negative net profit). The total fuel cost contribution summed over all inner regions of the blanket which have reached or exceeded breakeven yields the maximum net profit. Thus, the relation between the local breakeven irradiation time and the distance into the blanket also defines the optimum thickness of the blanket at a given time. This "breakeven irradiation time-distance into the blanket" ( $\mathrm{T}_{\mathrm{BE}}$ vs. $\tau$ ) curve determines the optimum thickness of the axial blanket, whose irradiation. time is fixed by core fuel management considerations: On the other hand, the "optimum irradiation time-distance" ( $\mathrm{T}_{\text {opt }} \mathrm{vs} . \tau$ ) curve . determines the most profitable discharge schedule for assemblies in a given radial blanket row.

\subsubsection{Fuel Cycle Cost-Blanket Thickness Relation}

The fuel cycle cost contribution distribution, $e_{L}(\tau, T)$ (mills/. kwhr-cm), which is proportional to the revenue per. unit mass, $\mathrm{K}_{\mathrm{L}}(\tau, \mathrm{T})(\$ / \mathrm{kgHM})$, can be expressed in the form (see Appendix $\left.\mathrm{E} .4\right)$ :

$$
\mathrm{e}_{\mathrm{L}}(\tau, \mathrm{T}) \propto \mathrm{K}_{\mathrm{L}}(\tau, \mathrm{T}) \equiv \mathrm{G}_{1}(\mathrm{~T})-\mathrm{G}_{2}(\mathrm{~T}) \mathrm{S}_{\mathrm{o}}(0) \mathrm{e}^{-\gamma \tau}
$$

where

$$
\begin{array}{ll}
\mathrm{G}_{1}(\mathrm{~T}) \equiv \frac{\mathrm{C}_{1} \mathrm{~F}_{1}\left(-\mathrm{T}_{1}\right)+\mathrm{C}_{2} \mathrm{~F}_{2}\left(\mathrm{~T}_{2}\right)}{\mathrm{T}} & \begin{array}{l}
\text { Fabrication and } \\
\text { reprocessing cost }
\end{array} \\
\mathrm{G}_{2}(\mathrm{~T}) \equiv \mathrm{C}_{3} \mathrm{~F}_{3}\left(\mathrm{~T}_{3}\right) & \text { Plutonium credit }
\end{array}
$$


$\tau$. is the distance into the blanket or the blanket thickness,

$\mathrm{T}$ is the irradiation time.

Equation 2.37 indicates that the cost distribution increases exponentially (hence the revenue per unit mass decreases exponentially as the distance into the blanket increases for any irradiation time).

The zero cost distribution occurs at:

$$
G_{1}\left(T_{B}\right)=G_{2}\left(T_{B}\right) S_{0}(0) e^{-\gamma \tau} \text {, }
$$

where the irradiation time is equal to the breakeven irradiation time for a given distance into the blanket.

The total cost of the entire blanket having thickness, $\tau, \mathrm{e}_{\mathrm{T}}(\tau, \mathrm{T})$ (mills/kwhr), can be obtained by integrating Eq. 2.37 over the blanket thickness:

$$
e_{T}(\tau, T)=G_{1}(T) \tau-\frac{G_{2}(T) S_{o}(0)}{\gamma}\left(1-e^{-\gamma \tau}\right)
$$

which indicates that the total cost first decreases and then increases after passing through a minimum value as shown in Fig. 2.10. The minimum cost (maximum profit) occurs at the point where the derivative of Eq. 2.40, i.e., Eq. 2.37, is zero:

$$
\frac{\partial e_{T}}{\partial \tau}=e_{L}=0
$$

which gives Eq. 2.39. Thus it is again shown that the local-breakevenirradiation-time curve gives the total optimum blanket thickness. It should be noted that these results hold true for all size (radius) cores because of the constant specific inventory buildup rate, $S_{0}(0)$. 

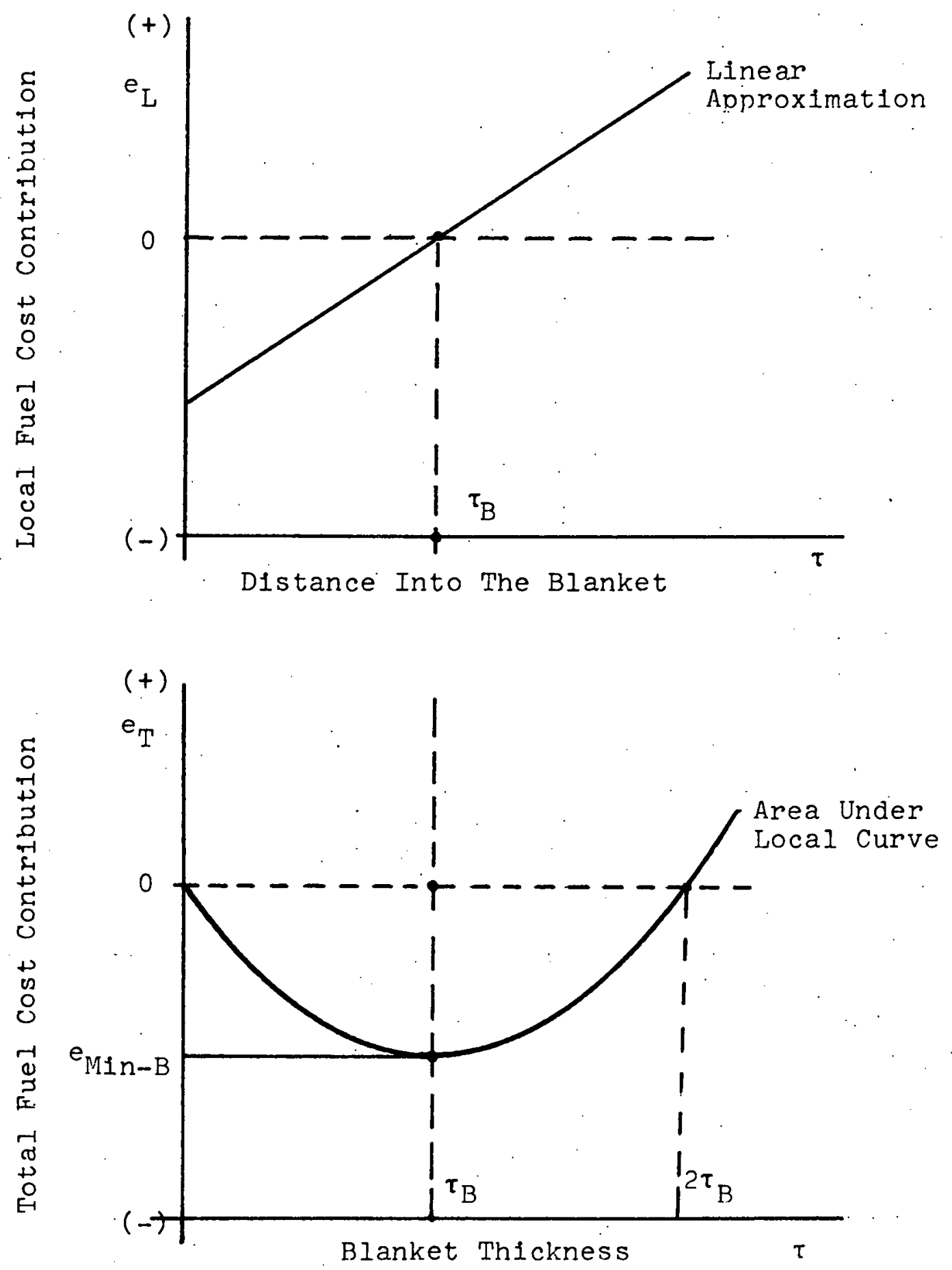

Fig. 2.10. Relation of "Local Cost-Distance" Curve and "Total Cost-Thickness" Curve at a Given Irradiation Time 


\subsubsection{Optimum Irradiation Time for an Entire Blanket}

In a similar manner as in the local optimum thickness case and as developed in Appendix $E$, it is assumed that the entire-blanketfissile buildup rate, $\bar{S}_{o, t}$, decreases exponentially as the thickness of the blanket increases:

$$
\bar{S}_{o, t} \cong S_{o}(0) \cdot e^{-\gamma \tau / 2}
$$

Since the total blanket breakeven and optimum irradiation times are related to the entire-blanket fissile buildup rate by Eqs. 2.21 and 2.26,

$$
\begin{aligned}
& T_{B E}=\frac{W}{\bar{S}_{o, t}} \\
& T_{o p t}=\sqrt{\frac{2 W}{\bar{S}_{o, t} X}},
\end{aligned}
$$

substituting Eq. 2.42 into Eq. 2.21 and Eq. 2.26; respectively, relates the total blanket breakeven and optimum irradiation times to the thickness of the blanket:

$$
\begin{array}{ll}
\text { Breakeven } & \tau=\frac{2}{\gamma}\left[\ln \mathrm{T}_{\mathrm{BE}}-\ln \left\{\frac{\mathrm{W}}{\mathrm{S}_{\mathrm{o}}(0)}\right\}\right] \\
\text { Optimum } & \tau=\frac{4}{\gamma}\left[\ln \mathrm{T}_{\mathrm{opt}}-\frac{1}{2} \ln \left\{\frac{2 \mathrm{~W}}{\mathrm{~S}_{\mathrm{o}}(0) \mathrm{X}}\right\}\right] .
\end{array}
$$

These relations have the same form as those for the local (row-average) cases, except that the coefficients weighting the logarithm of the time for the entire-blanket cases are double those for the row-average cases. Figure 2.11 shows the "total breakeven time-blanket thickness" and "total optimum time-blanket thickness" curves, which indicate that the entire blanket having thickness, $\tau$, has zero total cost at the intercept 


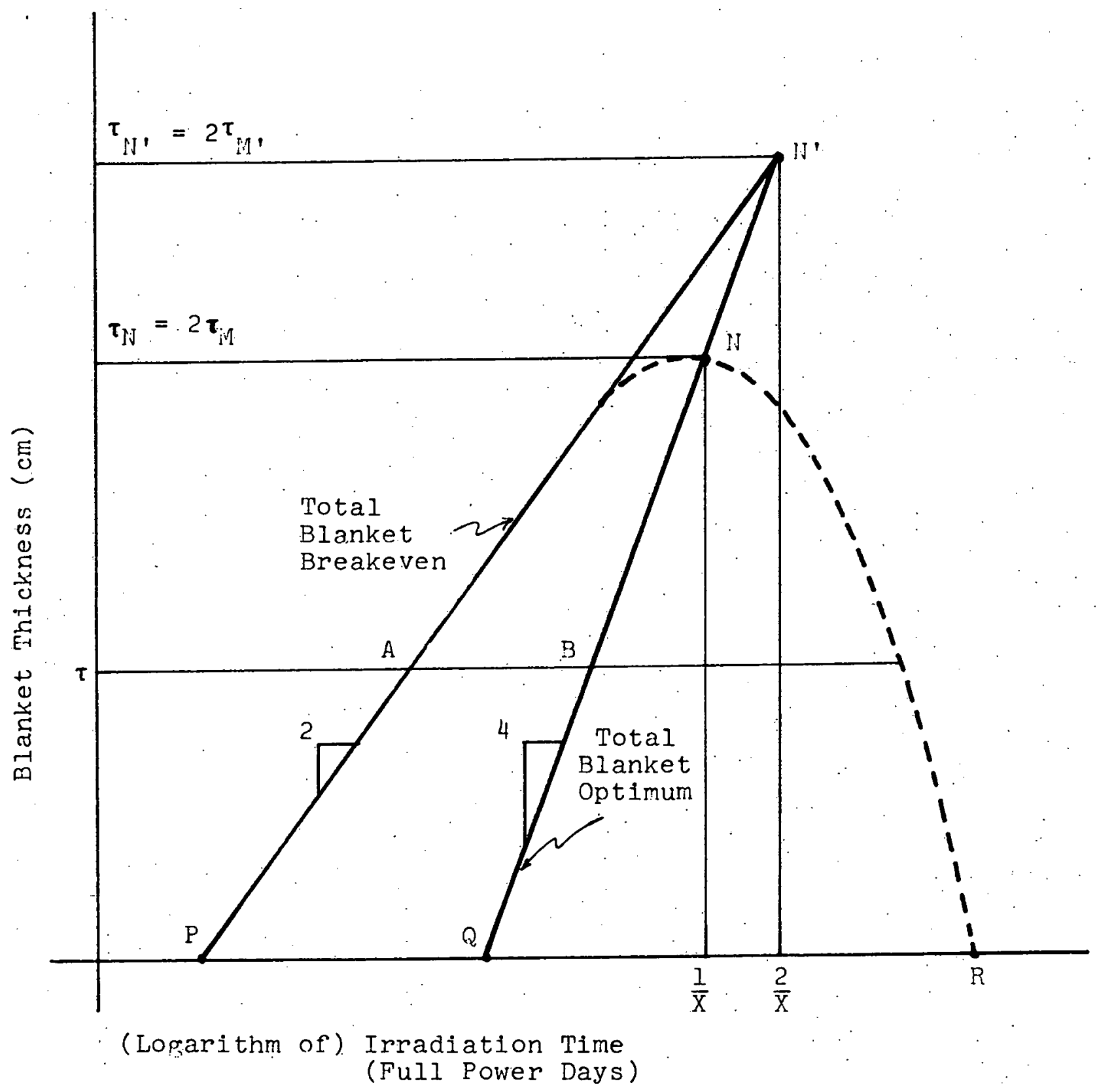

Fig. 2.11 Schematic Diapram of Breakeven and Optimum Batch-Irradiated Blanket Thickness as a

Function of Irradiation Time 
of the "total breakeven"curve (point A in Fig. 2.11) and the minimum total cost (the maximum total profit) at the intercept of the "total optimum" curve (point B in Fig. 2.11). The intercept of the "total breakeven" curve and "total optimum" curve (points $\mathrm{N}$ or $\mathrm{N}^{\prime}$ in Fig. 2.11) does not appear under reference economic conditions, but for higher discount rates and lower plutonium prices it appears at the less conservative estimate, point $N^{\prime}$, in Fig. 2.11 following the same reasoning as before (see Appendix E).

As discussed in the previous section, the "total breakeven" curve behaves in a similar manner to the "local breakeven" curve. In other words, the "total breakeven" curve increases semi-log-linearly as the blanket thickness increases, curves downward after passing point $\mathrm{N}$, and then intercepts the zero thickness line at point $R$, which is the same point as the intercept of the "local breakeven" curve and the zero "distance-into-the-blanket" line.

\subsubsection{Global Optimum Thickness and Irradiation Time}

By superimposing Fig. 2.9 and Fig. 2.11, one can obtain the four key curves: "local breakeven," "local optimum," "total breakeven," and "total optimum," as shown in Fig. 2.12 and Table 2.5. The intercept of the "local breakeven (i.e., optimum thickness for a given time)" and "total optimum (i.e., optimum time for a given thickness)" curves, designated as point $S$, gives the global optimum thickness and irradiation time. At this time the total fuel cycle cost contribution is a minimum (the profit is a maximum). By solving Eqs. 2.31 and 2.44, one can obtain simple expressions for the global optimum thickness, ${ }^{\tau}$, and 


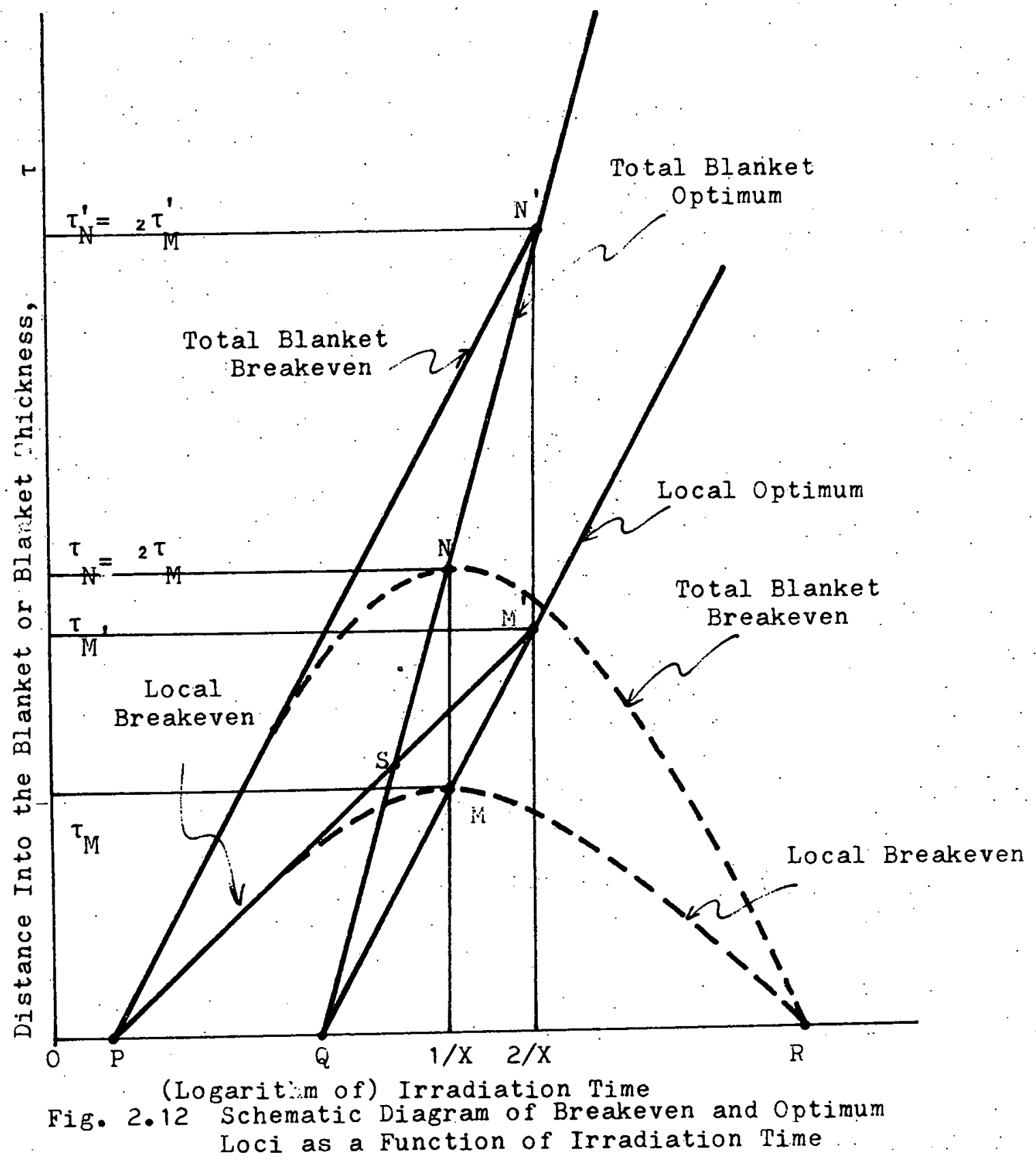




\begin{tabular}{|c|c|c|}
\hline & Local & Total \\
\hline Brcalieven & $\tau=\frac{1}{\gamma}\left(\ln \mathrm{T}-\ln \mathrm{T}_{\mathrm{B}}\right)$ & $\tau=\frac{2}{\gamma}\left(\operatorname{liT}-\ln \mathrm{T}_{\mathrm{B}}\right)$ \\
\hline Optimum & $\tau=\frac{2}{\gamma}\left(\ln \mathrm{T}-\ln \mathrm{T}_{\mathrm{O}}\right)$ & $\tau=\frac{4}{\gamma}\left(\ln \mathrm{T}-\ln \mathrm{T}_{\mathrm{O}}\right)$ \\
\hline
\end{tabular}

$T_{B}=$ The Interfacial Break Even Time, $\mathrm{Eq} \cdot 2.31(\mathrm{a})$

$T_{0}=$ The Interfacial optimum Time, Eq. 2..33(a)

$\gamma=$ Reciprocal Diffusion Iength of the Blanket

Table 2.5 Summary of Relations between Local

Blanket Region Position or Total

Blanket Thickness and Irradiation

Time 
the global optimum time, $\mathrm{T}_{\mathrm{S}}$, in the form:

$$
\begin{aligned}
& \tau_{S}=\frac{2}{3 \gamma} \ln \left\{\frac{2 S_{o}(0)}{W X}\right\} \\
& T_{S}=\left\{\frac{4}{S_{o}(0)}\right\}^{1 / 3} \mathrm{w}^{1 / 3} \mathrm{x}^{-2 / 3},
\end{aligned}
$$

which indicates that the global optimum thickness and time can be completely characterized by the economic parameter, $W$, and the discount rate, $X$, provided that the interfacial specific buildup rate, $S_{0}(0)$, and the reciprocal diffusion length of the blanket; $\gamma$; are given.

Table 2.6 summarizes the governing equations and typical values for the six key intercepts: $P, Q, R, M, N$ and $S$ under the reference economic environments defined later in this chapter.

\subsubsection{The Effect of Changing Core Height at Constant Core Radius} on the Beginning-of-Life Breeding Performance

\subsubsection{Radial Blanket}

In a similar manner as discussed in section 2.2.1, the breeding ratio in the radial blanket driven by radially power-flattened cores is:

$$
\mathrm{b}_{\mathrm{xr}} \propto \frac{1}{\mathrm{a}}
$$

Since Eq. 2.12 does not depend on core height, one can conclude that for changing core height at constant core radius, the radial blanket breeding ratio driven by radially power-flattened cores is constant regardless of core height. 
Table 2.6 Summary of the Six Key Intercepts Predicted by Simplified CFM Analysis

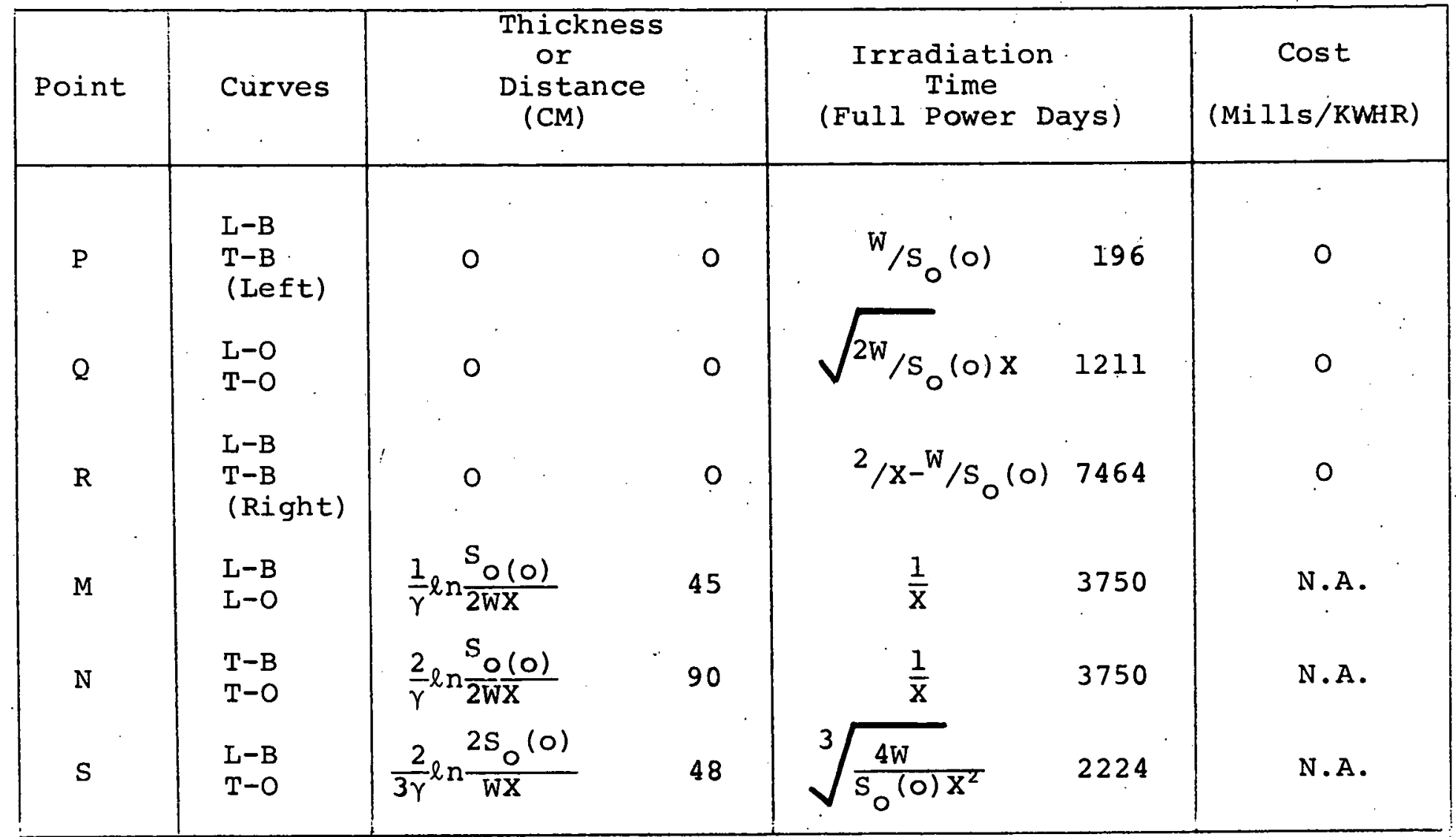


Again, in a similar manner as discussed in section $2.2: 1$, the breeding ratio in the radial blanket driven by uniformly loaded cores, is:

$$
\mathrm{b}_{\mathrm{xr}} \propto \mathrm{DB}_{\mathrm{r}}^{2}
$$

where it has been assumed that the effect of core critical enrichment is negligible by the same reasoning as before. Since the radial geo-. metrical buckling is constant because of constant core radius, one can obtain:

$$
\mathrm{b}_{\mathrm{xr}} \propto \text { constant }
$$

which indicates that the radial blanket breeding ratio is constant for all core heights (sizes) for uniformly loaded cores, as shown in Fig. 2. 13.

\subsubsection{Axial Blanket}

Again as discussed in section 2.2.1, the breeding ratio in the axial blanket driven by either radially power-flattened or uniformly loaded cores, is:

$$
\mathrm{b}_{\mathrm{xa}} \propto \frac{\mathrm{DB}_{\mathrm{z}}^{2}}{\varepsilon_{\mathrm{c}}} .
$$

Since the axial geometrical buckling is proportional to $\left(\mathrm{H}+2 \delta_{\mathrm{a}}\right)^{-2}$, the axial blanket breeding ratio is:

$$
b_{x a} \propto \frac{1}{\left(H+2 \delta_{a}\right)^{2} \varepsilon_{c}} \text {, }
$$

which indicates that the axial blanket breeding ratio decreases as the core height increases. Again it should be noted that since the core 
6.;

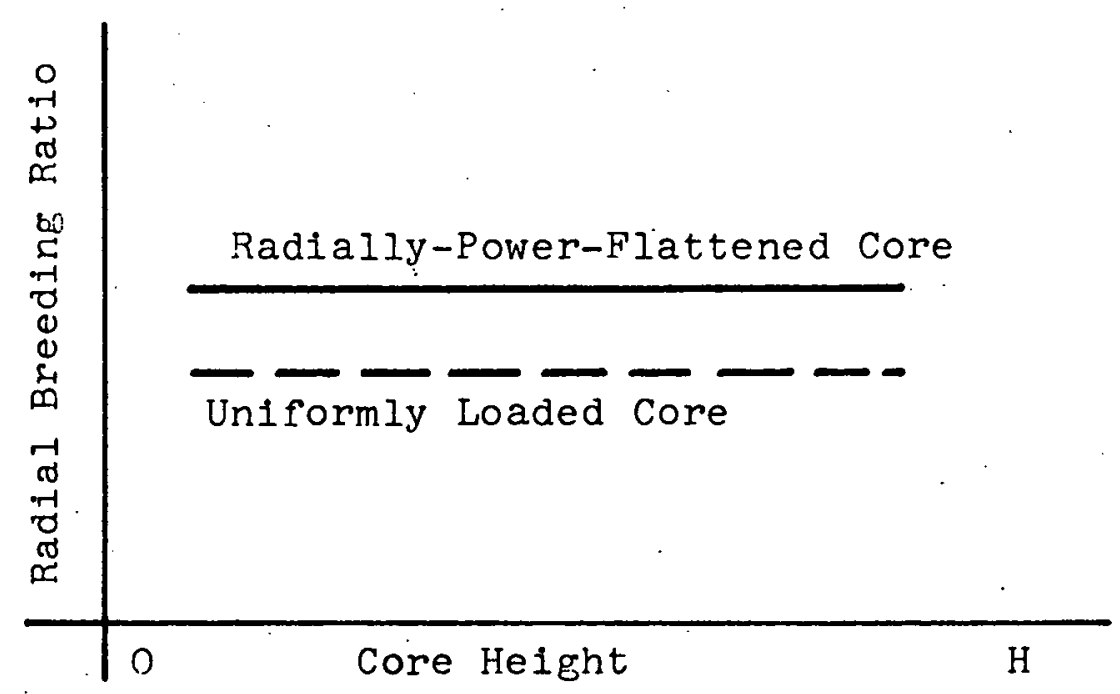

Fig. 2.13. Schematic Illustration of the Effect of Changing Core Helght at Constant Core Radius on Breeding Ratio of the Radlal Blanket 
critical enrichment decreases and appröaches an asymptotic value more gradually than the buckling as the core height increases, the effect of the core critical enrichment is overridden by the buckling effect as the core height increases, as shown in Fig. 2.14. The relation of $\varepsilon_{C}$ to core height is given by the linear function of buckling displayed in Eq. B. 12 in Appendix B; the same relation can be used for both radially power-flattened and uniformly loaded cores since their critical masses (for equal-volume cores) are very nearly equal, as discussed in section 2.2.1.1.

Table 2.7 summarizes the effect of changing core height at constant core radius on blanket breeding performance.

\section{3 COMPUTER METHODS}

In the previous sections, the predictions of a simple one-group model have been presented. While the one-group model can provide useful insight, state-of-the-art computation methods are needed to : confirm the results. Suitable computer programs for this purpose, 2DB and BRECON, have been made ope rational and applied at M.I.T. by Brewer (B3), Brown (B4), Ducat (D2) and Wood (W2).

\subsubsection{Reference Reactor Configuration}

In order to analyze the effect of reactor size on the physics performance of LMFBR blankets, the 1000-MW LMFBR configuration shown in Fig. 2.15 and variations on it were employed. The dimensions and compositions closely resemble other $1000-\mathrm{MW}_{\mathrm{e}}$ LMFBR studies (B4, W2). The main features of this system are the 


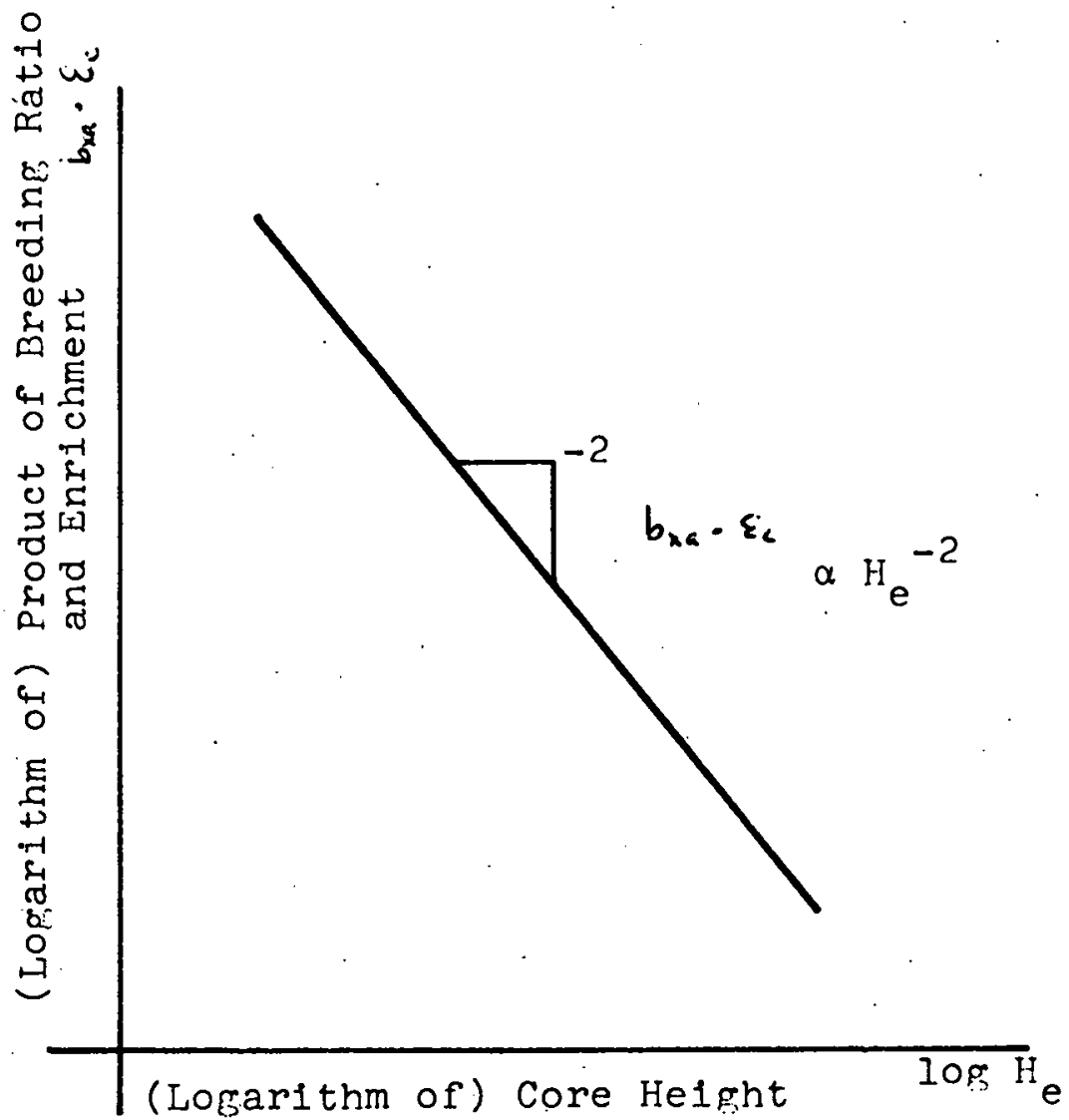

Fig. 2.14 Schematic Illustration of the Effect of Changing Core Height at Constant. Core Radius on the Breeding Performance of the Axial Blanket 


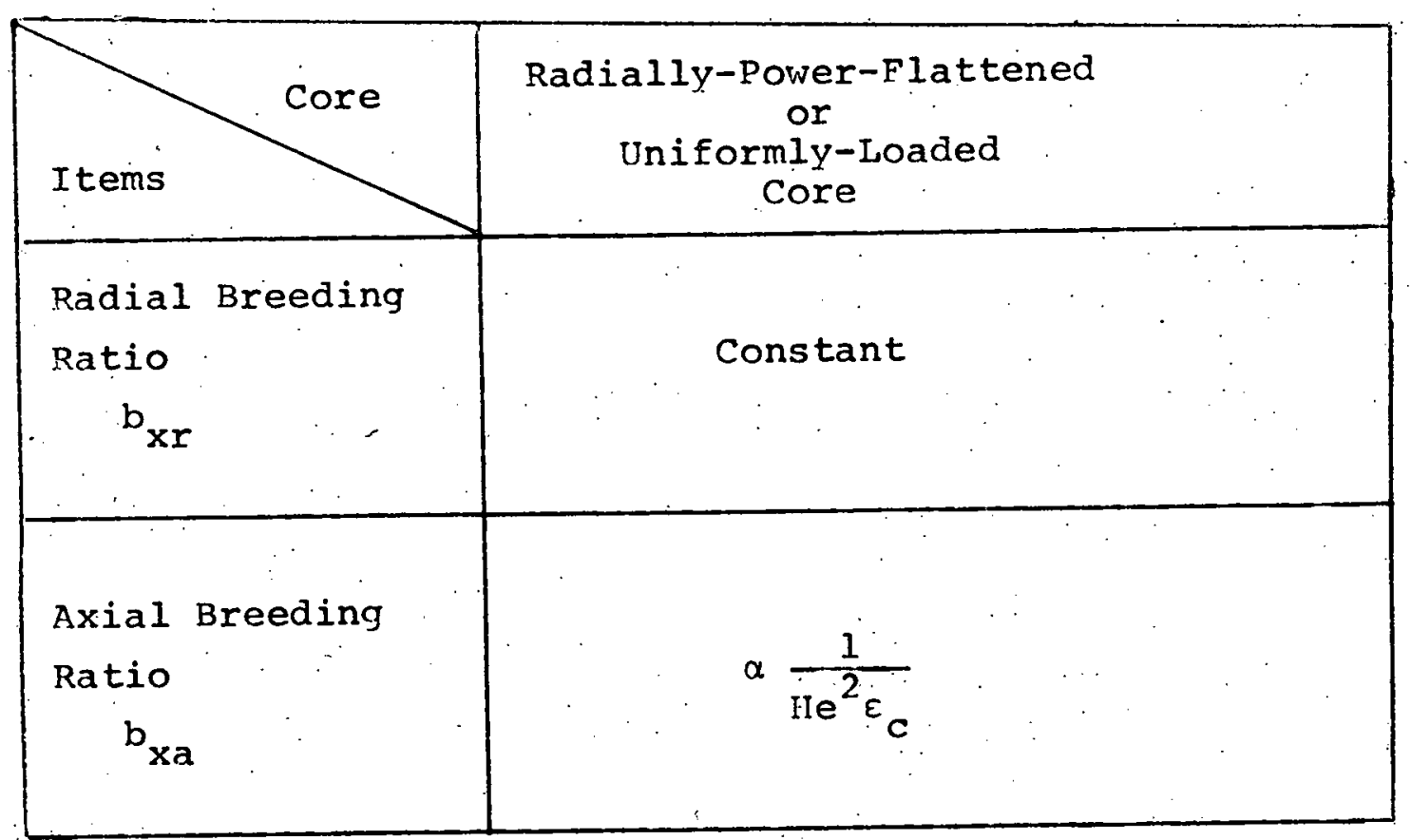

$$
\begin{aligned}
H e & =\mathrm{H}+2 \delta_{\mathrm{a}} \\
\mathrm{H} & =\text { Core Hejght } \\
\delta_{\mathrm{a}} & =\text { Linear Extrapolation Distance }
\end{aligned}
$$

Table 2.7 sumary of the effect of Changing core Heights at Constant Core Radius on the Breeding Performance of the Radial and Axial Blankets (Predictions of simnle one-Group Model) 


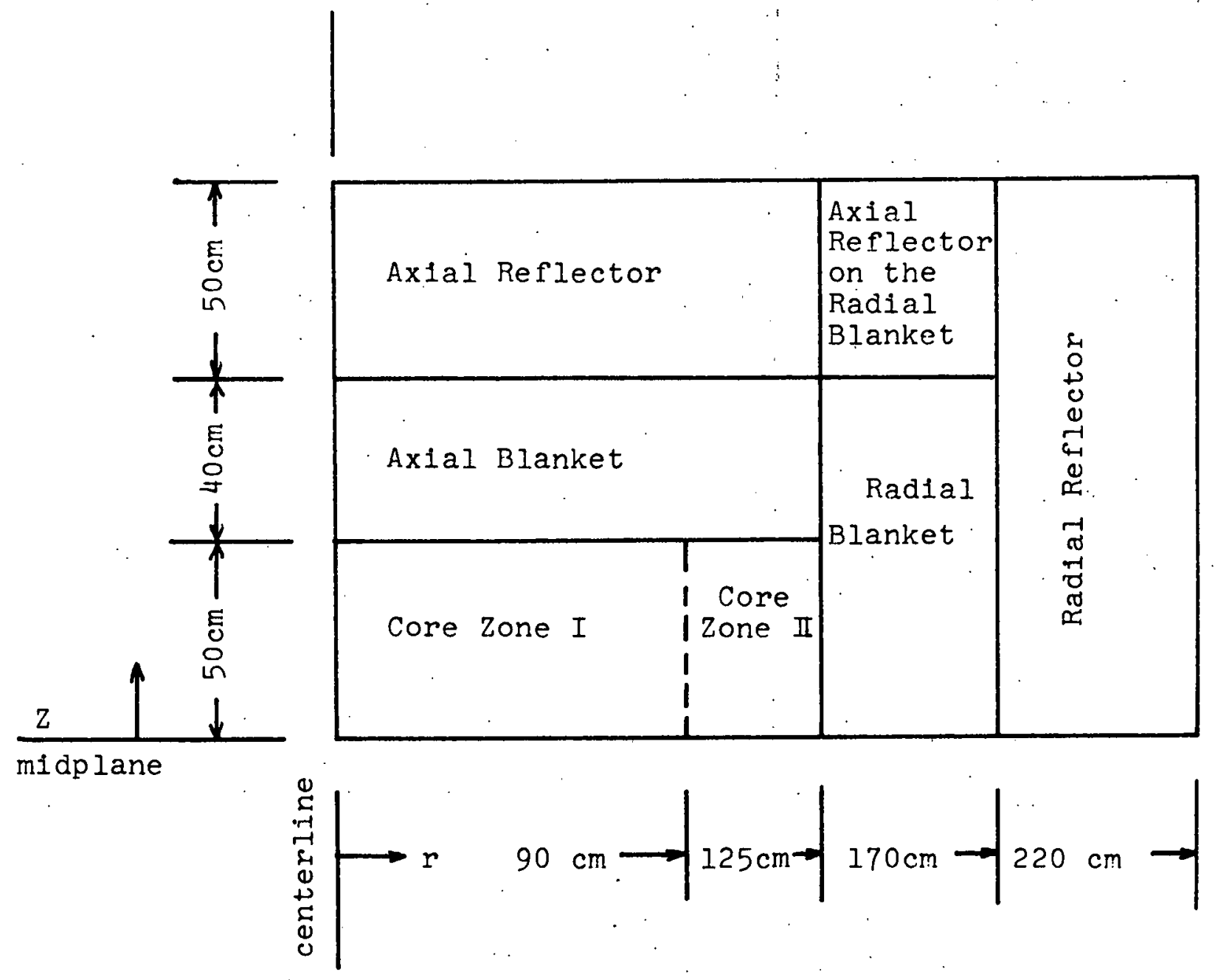

Fig. 2.15 Schematic Elevation View of the Upper Right Quadrant of the Standard 1000 MWe Reactor System 
two-zone, oxide-fueled core; a three-row, oxide-fueled radial blanket, with $50 \mathrm{~cm}$ of stainless steel serving as a radial reflector and shielding; and $40-\mathrm{cm}$-thick axial blankets, with $50 \mathrm{~cm}$ of axial steel reflectorshielding. Table 2.8 summarizes the physical characteristics and dimensions, and Table 2.9 summarizes the compositions of the various regions shown in Fig. 2. 15 .

\subsubsection{Variations in Reactor Size}

Most of the computer calculations in this study have been made for the constant-core-height reactor in recognition of the fact that there are a broad spectrum of engineering constraints and considerations which favor increasing core power by expansion of radial rather than axial dimensions. In support of this observation the following examples can be cited. The $250-M W$ Phenix design in France has been scaled up to Phenix-4 at $450 \mathrm{MW}$ e using the same core height of $85 \mathrm{~cm}$ (A1). In England, the 1000-MW $\mathrm{CFR}$ has the same core height, $100 \mathrm{~cm}$; as the 250-MW PFR (B1). Finally, the Clinch River Demonstration Plant of $380 \mathrm{MW}$ and the Westinghouse design for a $1000-\mathrm{MW}$ commercial LMFBR plant are based on the 250-MW $\mathrm{MWTF}_{\mathrm{t}}$ having core height of $91 \mathrm{~cm}(\mathrm{~W} 1)$. With constant core height, the power rating (unit size) is increased by increasing the core radius under the assumption of a constant àveraged-power density of about $500 \mathrm{kwth} /$ liter.

Although the major emphasis will be on increasing the radius at constant height, some cases in which height is increased at constant radius will also be examined in the interests of generality. 


\begin{tabular}{|c|c|c|}
\hline Parameter & nimension & Value \\
\hline Core: ileight & $\mathrm{cm}$ & 100 \\
\hline Diameter & $\mathrm{cm}$ & 250 \\
\hline Volume & liters & 4906 \\
\hline Axial Blanket Thickness & $\mathrm{CT}$ & 40 \\
\hline Radial Blanket Thickness & $\mathrm{cm}$ & 45 \\
\hline Core Averaged Power Density & $\mathrm{KWTH} / 1$ iter & $\sim 500$ \\
\hline Core Peak Power Density & $\mathrm{KWTH} /$ liter & 2730 \\
\hline Core ione I O.D. & $\mathrm{cm}$ & 90 \\
\hline Core Zone I Volume & liters & 2540 \\
\hline Core Zone II O.D. & $\mathrm{cm}$ & 125 \\
\hline Core Znne II Volume & liters & 2366 \\
\hline Rated Thermal Power* & $M W_{T}$ & 2500 \\
\hline Rated Electrical Power** & inve & 1000 \\
\hline
\end{tabular}

*Core plus blankets

* Assumed system efficiency $=40 \%$

Table 2.8 Characteristics of the standard $1000 \mathrm{NW}$ Reactor 
Table 2.9 Standard $1000 \mathrm{MWe}$ Reactor Parameters

\begin{tabular}{|c|c|c|c|c|c|}
\hline \multirow[t]{2}{*}{ r. } & \multirow[b]{2}{*}{$\begin{array}{l}\text { Ht. } \\
(\mathrm{cm})\end{array}$} & \multirow{2}{*}{$\begin{array}{l}\text { Rad. } \\
\text { Thick, } \\
\text { (cm) }\end{array}$} & \multicolumn{3}{|c|}{ Percent by Volume } \\
\hline & & & Fue ${ }^{C}$ & Coolant & Structure ${ }^{e}$ \\
\hline Core & & & & & \\
\hline $\begin{array}{l}\text { Zone } 1 \\
\text { Zone } 2\end{array}$ & $\begin{array}{l}100 \\
100\end{array}$ & $\begin{array}{l}90 \\
35\end{array}$ & $\begin{array}{l}30\left(85 \% t . d_{.}\right) \\
30\left(85 \% t . d_{.}\right)\end{array}$ & $\begin{array}{l}50 \\
50\end{array}$ & $\begin{array}{l}20 \\
20\end{array}$ \\
\hline $\begin{array}{l}\text { Axial } \\
\text { Blanket }\end{array}$ & 80 & 125 & $30(85 \%$ t.d.) & 50 & 20 \\
\hline $\begin{array}{l}\text { Radial b } \\
\text { Blanket }\end{array}$ & & & & & \\
\hline $\begin{array}{ll}\text { Row } & 1 \\
\text { Row } & 2 \\
\text { Row } & 3\end{array}$ & $\begin{array}{l}180 \\
180 \\
180\end{array}$ & $\begin{array}{l}15 \\
15 \\
15\end{array}$ & $\begin{array}{l}50\left(95 \% t . d_{.}\right) \\
50\left(95 \% t . d_{.}\right) \\
50(95 \% t . d .)\end{array}$ & $\begin{array}{l}30 \\
30 \\
30\end{array}$ & $\begin{array}{l}20 \\
20 \\
20\end{array}$ \\
\hline $\begin{array}{l}\text { Axial } \\
\text { Reflector }\end{array}$ & & & & & \\
\hline $\begin{array}{c}\text { For axial } \\
\text { blanket }\end{array}$ & 50. & 125 & -- & 50 & 50 \\
\hline $\begin{array}{c}\text { For radial } \\
\text { blanket }\end{array}$ & 50 & 45 & -- & 30 & 70 \\
\hline $\begin{array}{l}\text { Radial } \\
\text { Reflector }\end{array}$ & 1.40 & 50 & -- & 10 & 90 \\
\hline
\end{tabular}

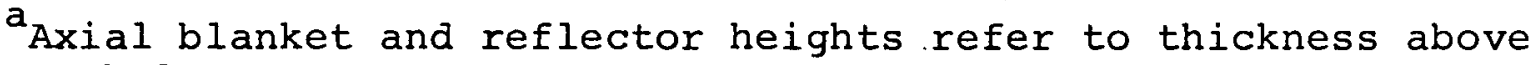
or below core.

${ }^{b}$ Assumes hexagonal assemblies $15 \mathrm{~cm}$ across the flats.

$C_{\text {Fuel }}$ consists of mixed uranium and plutonium dioxide in the core and uranium dioxide in the blanket. The $100 \mathrm{v} / \mathrm{o}$, $100 \%$ t.d. molecular density is taken as 0.02447 atoms/barn$\mathrm{cm}$. Plutonium is assumed to be typical light water reactor discharge $\mathrm{Pu}$ at $30,000 \mathrm{MWD} / \mathrm{T}: 63 \% \mathrm{Pu}-239 / 27.3 \% \mathrm{Pu}-240 / 5.9 \%$ $\mathrm{Pu}-241 / 3.8 \% \mathrm{Pu}-242$ (D4) .

$\mathrm{d}_{\text {Coolant is sodium at }} \sim 900^{\circ} \mathrm{F}$ having a $\left(100^{\circ} / 0\right)$ density $=$ 0.0220 atoms/barn-cm.

estructure is stainless steel with $17.7 \%$ chromium/8.3\% nic$\mathrm{kel} / 74.0 \%$ iron having a $(100 \mathrm{~V} / \mathrm{o})$ density $=0.0850$ atoms $/$ barn-cm. 
As previously noted, radial power-flattening is employed in essentially all commercial power reactor designs because of the resulting large improvement in overall fuel cycle economics. The ideal power-flattened core is approximated by dividing the core into zones of approximately equal volume, each having different enrichment. Thus, in the present study the core power rating will be increased by adding zones with progressively higher enrichment around the outside of the original core. In the ideal case, the augmented core radius would satisfy the relation:

$$
r_{i}=\sqrt{i} r_{1} \text {, }
$$

where

$i$ is the number of enrichment zones in the core,

$\mathrm{r}_{1}$ is the radius of the innermost core zone ( $\equiv$ one-zone core radius),

$r_{i}$ is the outer radius of the $i-z o n e$ core.

Actual zone radii differ from the ideal values because of the need to employ an integer number of assemblies in a zone.

Table 2.10a shows the power ratings, corresponding core radii and zone numbers used in this study. The power rating ranges from $250 \mathrm{MW}_{\mathrm{e}}$ to $3000 \mathrm{MW}_{\mathrm{e}}$, with corresponding core radii of $65 \mathrm{~cm}$ and $215 \mathrm{~cm}$, respectively. It is interesting to note that the core-height-todiameter ratio, $H / D$, decreases from 0.77 for the $250-M W_{e}$ unit to $0: 23$ for the $3000-\mathrm{MW}_{\mathrm{e}}$ unit. Decreasing this ratio is favorable from a safety point of view, since it enhances the negative leakage component of the sodium yoid coefficient. Table $2.10 \mathrm{~b}$ shows the key characteristics of reactor sizes examined in the case of constant core radius and 


\begin{tabular}{|c|c|c|c|c|c|c|}
\hline $\begin{array}{l}\text { Poryer } \\
\text { Pating } \\
\text { (ine) }\end{array}$ & $i$ & $\begin{array}{l}\text { Core } \\
\text { Radius } \\
(\mathrm{cm})\end{array}$ & $\begin{array}{l}\text { Core } \\
\text { Volume } \\
\text { (Liters) }\end{array}$ & $\begin{array}{l}\text { Incremental } \\
\text { Core Volume } \\
\text { (Liters) }\end{array}$ & $\mathrm{H} / \mathrm{D}_{\mathrm{O}}{ }^{\star 1}$ & $\begin{array}{l}\text { Number of Radial } \\
\text { Enrichment Zones }\end{array}$ \\
\hline 250 & & 65 & 1328 & 1212 & 0.77 & $1,2,6$ \\
\hline 500 & & 90 & 2540 & 1260 & 0.56 & 1,2 \\
\hline 750 & & $\begin{array}{r}110 \\
0 i, 3\end{array}$ & 3800 & 1100 & 0.45 & 1,2 \\
\hline 1000 & & 125 & 4900 & 2440 & 0.40 & $1,2,6$. \\
\hline 1500 & & 155 & 7340 & 2640 & 0.32 & 1,3 \\
\hline 2000 & & 180 & 9980 & 2380 & 0.28 & 1,4 \\
\hline 2500 & & 200 & $12360^{\circ}$ & 1956. & 0.25 & 1,5 \\
\hline 3000 & & 215 & 14316 & & 0.23 & $1,2,6$ \\
\hline
\end{tabular}

* 1 Core Height $=100 \mathrm{~cm}$

Table 2.10(a) Key Characteristics of Reactor Sizes Examined

(constant Core Height) 


\begin{tabular}{|c|c|c|c|c|c|}
\hline $\begin{array}{l}\text { Core } \\
\text { lyeight } \\
(\mathrm{cm})\end{array}$ & $\begin{array}{l}\text { Core } \\
\text { Volume } \\
\text { (Liters) }\end{array}$ & $\begin{array}{l}\text { Core }^{\star 1} \\
\text { Averaqe } \\
\text { Poiver } \\
\text { Density } \\
\text { (KWTH/LITER) }\end{array}$ & $\begin{array}{l}\text { Peak *2 } \\
\text { Power } \\
\text { Density } \\
\text { (KWTH/LITER) }\end{array}$ & $\mathrm{H} / \mathrm{D}_{\mathrm{O}}{ }^{* 3}$ & $\begin{array}{l}\text { Number of Radial } \\
\text { Enrichment zones }\end{array}$ \\
\hline 100 & 4900 & 510.2 & 1118.0 & 0.40 & 1,2 \\
\hline 150 & 7363 & 327.7 & 791.0 & 0.60 & 1,2 \\
\hline 200 & 9817 & 254.7 & 615.1 & 0.80 & 1,2 \\
\hline
\end{tabular}

* I Total Reactor Thermal Power $=2500 \mathrm{MWTH}$

Power Rating. $=1000$ MNe

Assumed Thermal Efficiency $=40$ ?

*2 One Zone core

*3 Constant Core Diameter $=250 \mathrm{~cm}$

Table 2.10(b)Key Characteristics of Reactor Sizes Examined

(Constant Core Radius) 
constant core power ratings: In this study, however, there is no attempt made to optimize the core shape or the core-height-todiameter ratio with respect to any criteria such as void coefficient or breeding ratio, or from an overall design/economics point of view.

Power-flattening (at beginning-of-life) was achieved in all designs examined by trial and error adjustment of zone enrichment to obtain radially constant peak zone power within the limit:

$$
\left|\frac{p_{i}-p_{1}}{p_{1}}\right| \leqslant 5 \%
$$

where

$$
p_{i} \text { is the peak power density in the } i-\text { th zone of the core, }
$$

and

$$
p_{1} \text { is the peak power density in the central zone of the core. }
$$

\subsubsection{Method for Depletion-Economics Analysis}

\subsubsection{Cross-Section Preparation}

In the interests of consistency, all studies were performed using the two-dimensional diffusion theory code, 2DB, (L1) with 4-group cross sections prepared by region-collapsing the modified ABBN Type FTR-200, 26-group cross-section set (A 3, N1). : The energy group structure of the collapsed cross sections is specified in Table 2.11, together with values used by other investigators. The energy group structure is similar to the others, except that the last two groups of the set used by Hoover and Menley ( $\mathrm{H} 1)$ have been combined into one. 
TABLE 2.11 Comparison of Collansed Group Structures

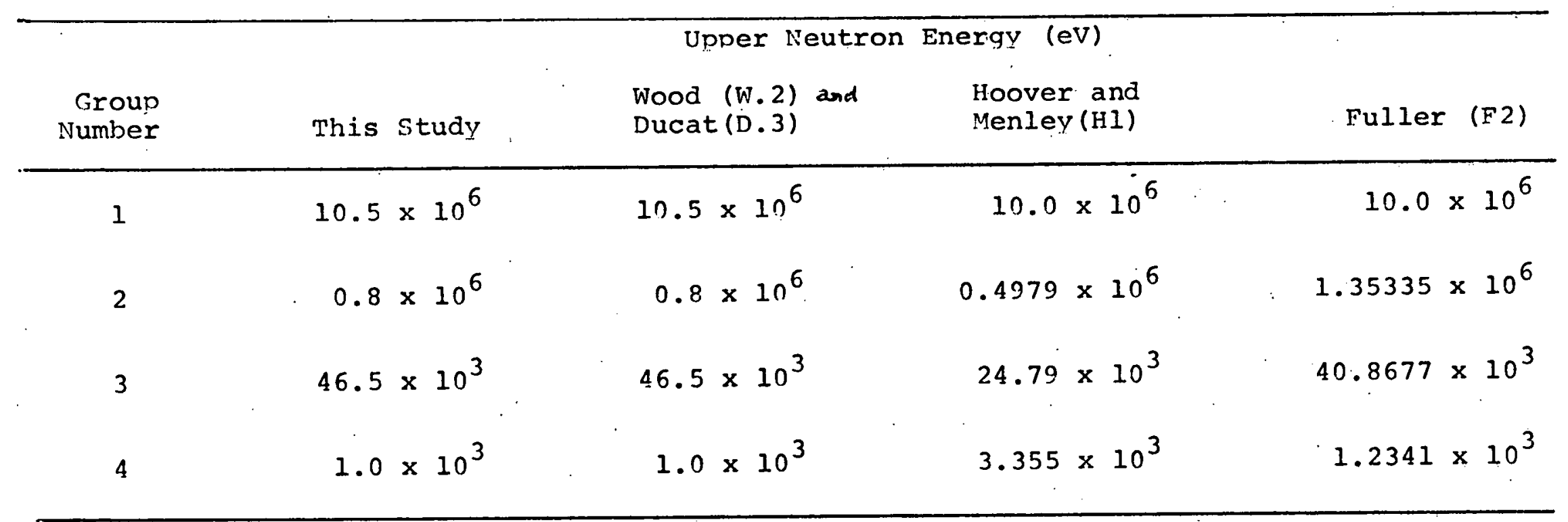


Since diffusion theory calculations. will be performed, it is desirable to compare diffusion theory to the more accurate transport calculations. This has been done by Wood (W2) and by others (R1), who showed that use of 4-group sets of region-collapsed cross sections is adequate to describe blanket burnup and breeding performance, and also that the errors introduced by the use of diffusion theory rather than transport theory in analyzing the radial and axial blankets are small.

\section{3.3.2 Burnup Zones}

The 2DB code places a limit of 99 on the sum of the number of burnup zones and cross-section sets. It also treats each burnup zone as a homogeneous mixture during irradiation. Thus, after irradiation each burnup zone has uniform material concentrations, which makes it desirable to have many separate burnup zones in regions of the reactor where the spatial distribution of bred isotopes is important. Figure 2.16 shows the typical arrangement of burnup zones for $2 \mathrm{DB}$ analysis. Table 2.12 shows the correspondence between burnup zones and regions in the reactor as shown in Fig. 2.15.

Fourteen different elements and isotopes appear in the various reactor regions. Table 2.13 contains a summary of the crosssection sets that were individually collapsed for each reactor region. 


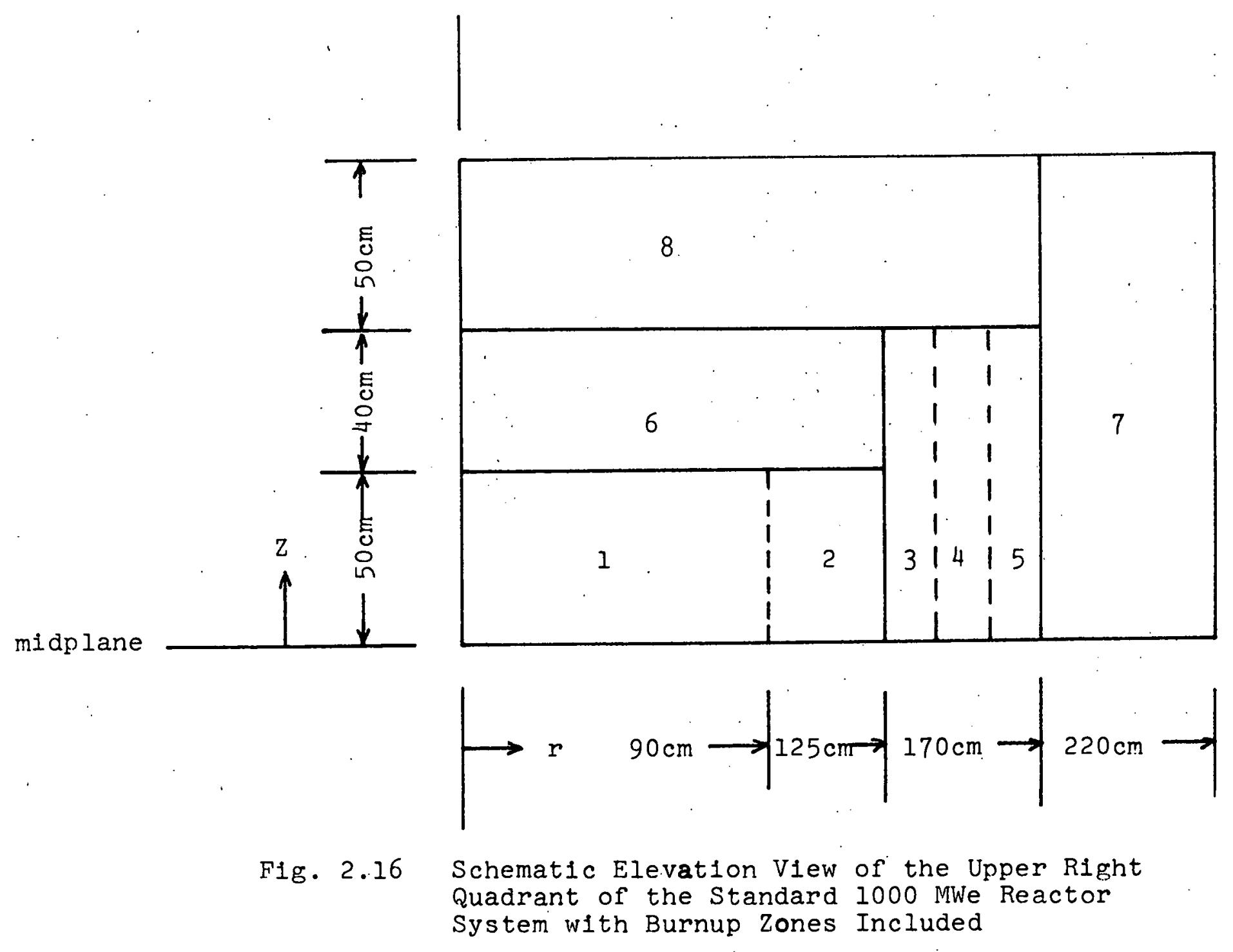


Table 2.12

Summary of Burnup Region Types

(See Figure 2.15 and Tables 2.8 and 2.9 for further details)

\begin{tabular}{|c|c|}
\hline Burnup Zones & \multicolumn{1}{|c|}{ Region } \\
\hline 1 & Core Zone I \\
2 & Core Zone II $\quad$ \\
3 & Radial Blanket Row 1 \\
4 & Radial Blanket Row 2 \\
5 & Radial Blanket Rov 3 \\
6 & Axial Blanket \\
7 & Radial Reflector \\
8 & Axial Reflector \\
\hline
\end{tabular}


TABLE 2.13 Region-Collapsed Cross Sections Used in the Burnup Analysis ( $x$ indicates that region-collansed cross sections were used.)

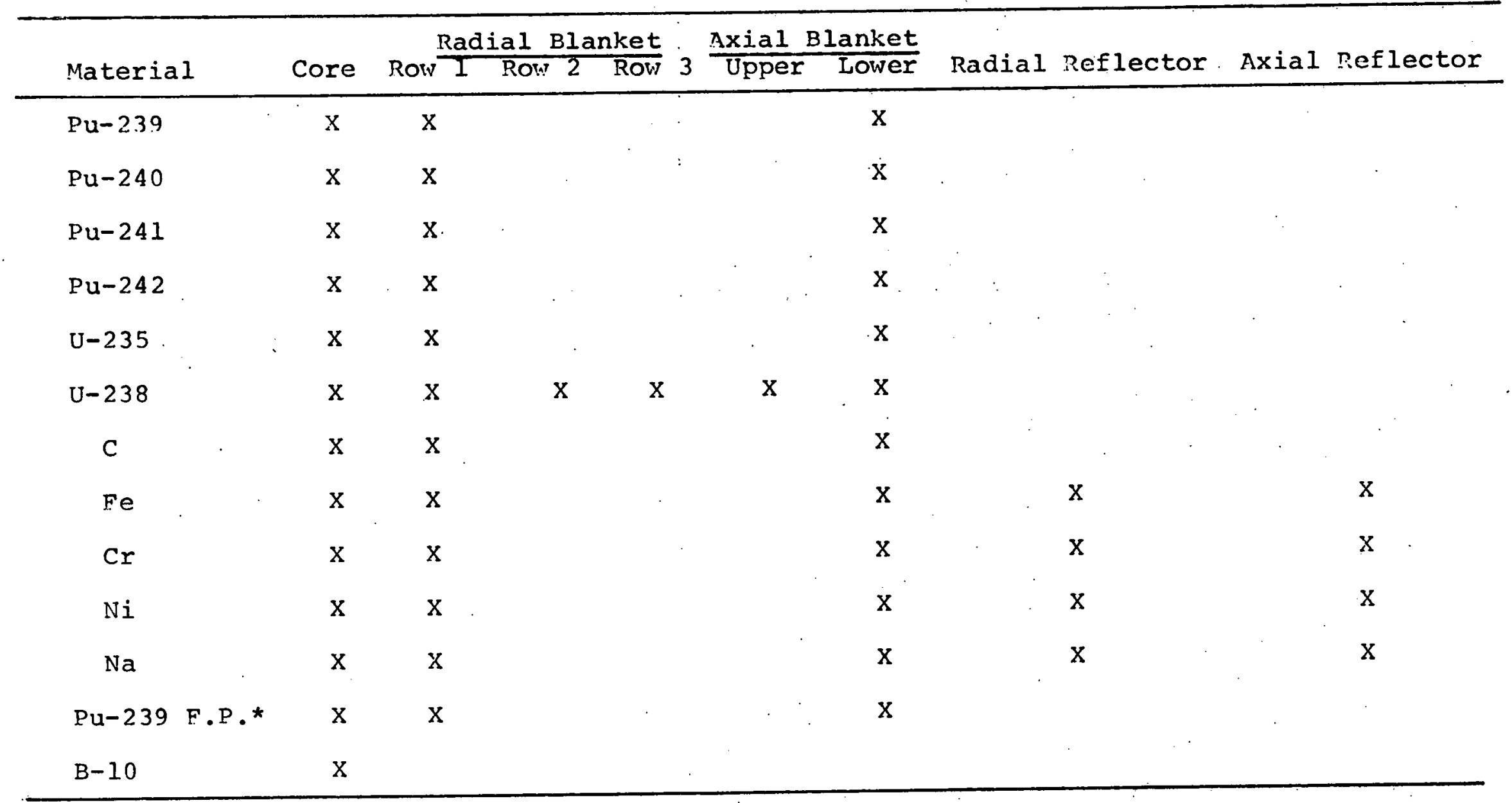

*F.P. indicates fission products from fission of named isotope. 


\subsubsection{Equilibrium Core}

The purpose of this section is to discuss the formation of an "equilibrium" core and axial blanket that will remain fixed in time as the irradiation of the radial blanket progresses. The motivation for adopting this procedure lies in the fact that typical radial blanket irradiations are long (on the order of six years) with respect to core refueling intervals (two years in this case). Thus the radial blanket surrounds a core and axial blanket that will have gone through quite a few refuelings and the subsequent control pois on variations required to keep the reactor just critical.

Figure 2.17 shows a schematic of the unpois oned reactivity swing of a batch-managed core with a two-year refueling interval. It should be noted that $k^{\prime}$, the initial, unpoisoned, effective multiplication factor $\left(\mathrm{k}_{\mathrm{eff}}\right)$, is chosen such that at each refueling $\mathrm{k}_{\text {eff }}$ is just equal to unity. In actual operation, it is necessary to maintain the system $k_{\text {eff }}$ at unity throughout the operating cycle. This is accomplished through the use of movable control rods which are. progressively withdrawn from the core.

For the purposes. of this study, it was necessary to simulate the actual operating sequence, since the $2 \mathrm{DB}$. code does not have the capability for handling movable control rods. This was done by adding boron-10 control poison in a concentration such that its reactivity worth was equal to the linearized time-averaged excess reactivity, $\left(\mathrm{k}_{\text {eff }}{ }^{-1}\right) / 2$, during the refueling interval. Figure 2.18.shows a schematic of the reactivity swing of a core poisoned in this manner. 

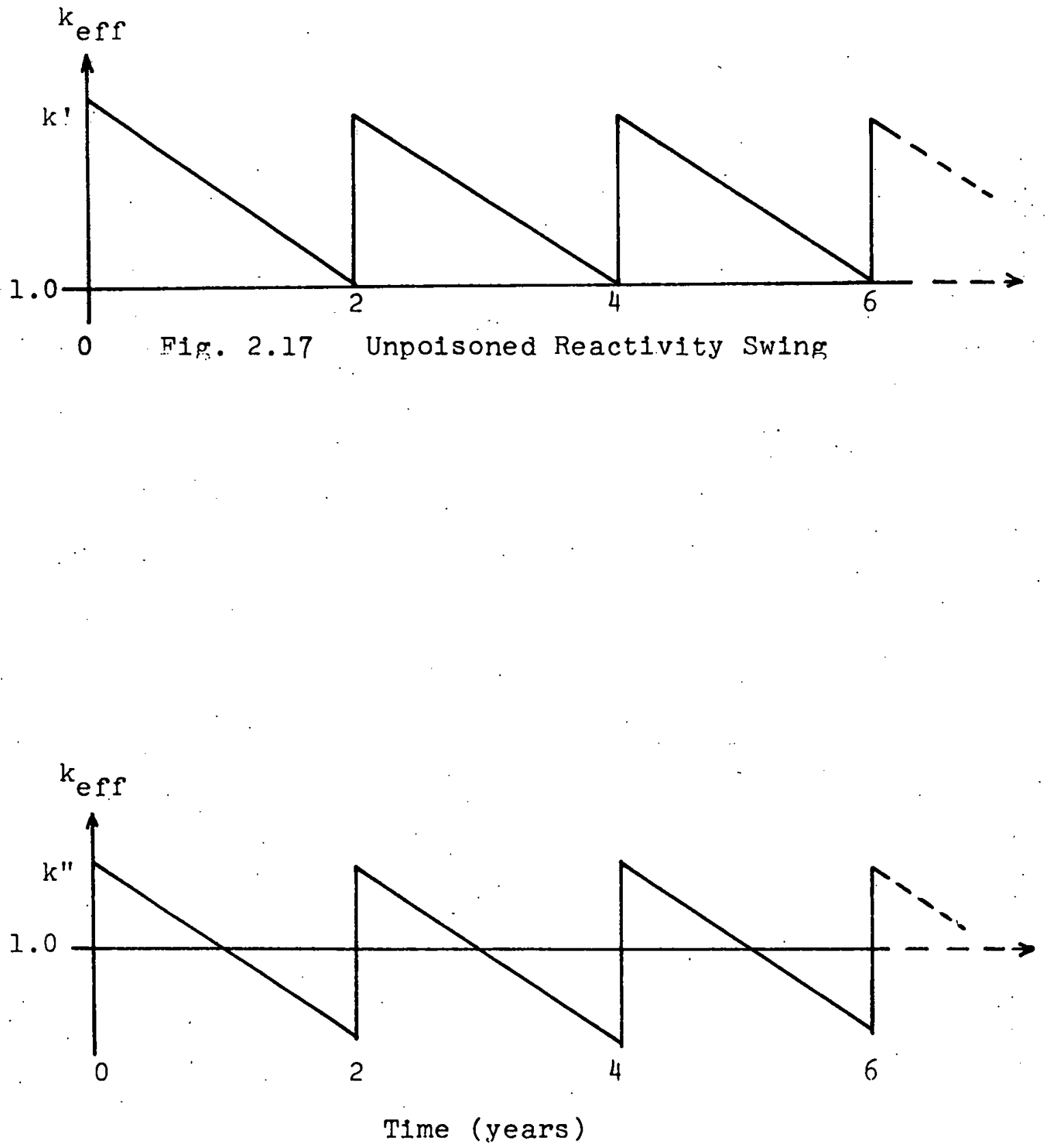

F1g. 2.18 Poisoned Reactivity Swing: 
The "equilibrium" core occurs at the point where the poisoned $k_{\text {eff }}$ is equal to unity. Since the axial blanket is an integral part of the core, an equilibrium axial blanket is also determined at the point where the poisoned $\mathrm{k}_{\mathrm{eff}}$ is equivalent to unity. It should also be noted that the poison concentration in the axial blanket will be greater than that in. the core (here about 2.3 times) because of the continuous presence of control and safety rods in that region. The factor of 2.3 was determined by applying the following observations and assumptions (W2).

1. The safety system is composed of rods which a re always in the ready position in the upper axial blanket with their lower ends at the interface between the axial blanket and the core.

2. The safety system has 50 percent more poison material than the control system.

3. : The reference reactor refueling cycle is one refueling every two years. During that year the control rods are uniformly withdrawn from the fully inserted position (at the lower core/blanket interface) to the fully withdrawn position (at the upper core/ blanket interface).

4. The control system has sufficient worth (on a time-average basis) to make the system $\mathrm{k}_{\text {eff }}$ equal to 1.0 after one year of operation.

5. For the reactor analyzed here (which was assumed symmetric about the center plane), it is assumed that the poison concentration in the combined (upper and lower) axial blankets is half the pois on concentration expected in the upper axial blanket. 
6. For the burnup analysis it is assumed that the poison is distributed uniformly throughout the core at the appropriate concentration, and uniformly throughout the axial blanket at the higher appropriate concentration.

7. For the burnup analysis, the poison concentration is held constant at the time-averaged value throughout the life of the system.

Although considerable care has been placed on definition of a realistic core composition, it should be noted that other investigators ( $\mathrm{B} 5, \mathrm{H} 3, \mathrm{~W} 2$ ) have looked into the effect of different core management methods on radial blanket economics, and have concluded that there is an insignificant effect.

\section{3. 3.4 Material Included in the Burnup}

In the burnup analysis performed by $2 \mathrm{DB}$, materials whose concentration changed as a function of irradiation time were specified; together with the precursor isotope and the reaction which produced the isotope of interest. The fissioning of the following heavy metals contributed to the creation of fission products: $\mathrm{Pu}-239, \mathrm{Pu}-240, \mathrm{Pu}-241$, $\mathrm{Pu}-242, \mathrm{U}-235, \mathrm{U}-238$. The buildup of heavy isotopes was assumed to occur by the following neutron capture reactions:

$$
\begin{aligned}
& P u-239(n, \gamma) P u-240 \\
& P u-240(n, \gamma) P u-241 \\
& P u-241(n, \gamma) P u-242 \\
& U-238(n, \gamma) P u-239
\end{aligned}
$$


As shown, neutron capture in $U-238$ is assumed to lead directly to the production of $\mathrm{Pu}-239$, neglecting the formation of intermediate decay products, which can be shown to lead to a very slight overprediction in the formation rate of $\mathrm{Pu}-239$ (B 5). Similarly, Pu-241:decay is neglected, again with justification (B4).

These burnup reactions will be limited to the radial and axial blanket region for the remainder of the report. In determining the equilibrium core and axial blanket, these burnup reactions were previously employed for the core and both blankets.. However, as discussed in section 2.3.3.3, the equilibrium core and axial blanket remain fixed in time as the irradiation of the radial blanket progresses.

\subsubsection{Burnup Economics}

In this work the burnup-economics analysis was performed utilizing the cash flow method contained in the computer code BRECON, developed by Brewer. (B3), and modified by Wood (W2) to permit direct use of $2 \mathrm{DB}$ burnup results. Levelized fuel cycle costs (in mills/kwhr) were calculated according to the following general expression:

$$
\begin{aligned}
& \mathrm{e}=\frac{1000}{\mathrm{E}} \mathrm{M}_{\mathrm{HM}}^{\mathrm{o}}\left[\frac{\mathrm{C}_{\text {fiss }} \varepsilon_{\mathrm{o}} \mathrm{F}^{\mathrm{mp}}(\mathrm{T})}{\mathrm{T}} \quad \begin{array}{l}
\text { material purchase } \\
\text { cost component }
\end{array}\right. \\
& +\frac{\mathrm{C}_{\mathrm{fab}} \mathrm{F}^{\mathrm{fab}}(\mathrm{T})}{\mathrm{T}} \cdot \quad \begin{array}{l}
\text { fabrication } \\
\text { cost component }
\end{array} \\
& +\frac{\mathrm{C}_{\text {repr }} \mathrm{F}^{\text {repr }}(\mathrm{T})}{\mathrm{T}} \quad \begin{array}{l}
\text { reprocessing } \\
\text { cost component }
\end{array} \\
& \left.+\frac{\mathrm{C}_{\text {fiss }} \varepsilon(\mathrm{T}) \mathrm{F}^{\mathrm{mc}}(\mathrm{T})}{\mathrm{T}}\right] \begin{array}{l}
\text { material credit } \\
\text { cost component }
\end{array}
\end{aligned}
$$


where

$\mathrm{e}$ is the local levelized fuel component of the energy cost (mills/kwhr),

$\mathrm{E}$ is the electrical energy produced by the reactor in one year (kwhr/yr),

$\mathrm{T}$ is the local irradiation time (yr),

$\mathrm{C}_{\text {fiss }}$ is the fissile price $(\$ / \mathrm{kgPu})$,

$\mathrm{C}_{\mathrm{fab}}, \mathrm{C}_{\mathrm{repr}}$ is the unit fabrication and reprocessing cost $(\$ / \mathrm{kgHM})$,

$\varepsilon_{0} \quad$ is the initial enrichment,

$\varepsilon(T)$ is the discharge en richment ( $\mathrm{kg}$ fissile discharged per $\mathrm{kg}$ of heavy metal loaded),

$F^{q}(T)$ is the carrying charge factor for cost component $q$, $\mathrm{M}_{\mathrm{HM}}^{\mathrm{O}}$ is the mass of heavy metal loaded.

The carrying charge factors, $F^{q}(T)$, are given by

$$
\begin{aligned}
& F^{\mathrm{q}}(\mathrm{T})=\frac{1}{1-\tau}\left[\frac{1}{(1+\mathrm{X}) \mathrm{T}_{\mathrm{q}}}-\tau\right] . \quad \begin{array}{l}
\text { for capitalized } \\
\text { costs or revernues }
\end{array} \\
& =\frac{1}{(1+X)^{\mathrm{T}} \mathrm{q}} \quad \begin{array}{l}
\text { for noncapitalized costs or revenues } \\
\text { (expensed cost or taxed revenue) }
\end{array}
\end{aligned}
$$

where

$X=(1-\tau) r_{b} f_{b}+r_{s} f_{s} \quad$ is the discount rate,

$\tau$ is the income tax rate,

$f_{b}$ is the debt fraction,

$f_{S}$ is the equity fraction,

$r_{b}$ is the debt rate of return,

$r_{S}$ is the equity rate of return,

$\mathrm{T}_{\mathrm{q}}$ is the time between the cash flow transaction $\mathrm{q}$ and the irradiation midpoint. 
All the results quoted here were computed using an accounting method, suggested by Brewer (B3), in which material purchases and fabrication charges were capitalized and consequently depreciated for tax purposes; whereas reprocessing charges and material credit were treated as an expensed cost and taxable revenue, respectively.

It should be noted that Eq. 2.53 can be applied to an entire region (e.g., radial blanket) or subregion (e.g., radial blanket row) under fixed element (batch) management. This feature of Eq. 2.53 facilitates the determination of the minimum fuel cycle cost contribution (i.e., the optimum irradiation time) for a blanket row or for the entire blanket.

Table 2.14 lists the reference economic parameters used in this study of blanket burnup economics. These conditions (except for discount rate calculations) are the same as those presented by Brewer (B3) and Wood (W2) and are within the range projected for the mature U.S. nuclear fuel cycle economy(D5). These parameters will also be varied over a considerable range to develop input for burnupeconomics correlations.

\section{$2 . \dot{4}$ CONCLUSIONS}

In this chapter some key blanket performance characteristics were examined using a one-group model. The fissile material buildup rate per unit volume for radial blankets driven by radially powerflattened cores (and for axial blankets with either radially powerflattened or uniformly loaded cores) was found to be independent of 
Unit Fuel Processing Costs, $\$ / \mathrm{kg} H M$

oneration

Fabrication

Reprocessing

Isotope

$\mathrm{U}-238$

Pu-239

$\mathrm{Pu}-240$

Pu-24l

Pu-242

Financial Parameter

Income tax rate, $\tau$

Capital structure Bond (debt) fraction, $f_{b}$ Stock (equitv) fraction, $f_{s}$

Rates of return

Bonds, $r_{b}$
stocks, ${ }_{s}$

Discount rate, $x^{*}$
Axial Blanket Radial Blanket.

80

69

50

50

Isotope Market Value, $\$ / \mathrm{kg} P$

0

10,000

0

10,000

0

Value of Parameter

Private Utility

0.5

0.5

0.5

0.07

0.125

0.8

$\star X=(I-\tau) r_{b} f_{b}+r_{s} f_{s}$ 
core radius (hence, reactor power rating). Because of this, the breakeven and optimum irradiation time and the optimum blanket thickness are also independent of core radius. The relations among the blanket optimum thickness, the optimum irradiation time and the minimum fuel cycle cost have been investigated. The peripheral enrichment (hence, neutron energy spectrum) was shown to be independent of core radius, which means that there is no need to regionwise collapse separate blanket cross-section sets for each core radius. Thus, in a given economic environment, the radial blankets of all radially power-flattened LMFBR's will perform identically on a per-assembly basis. Because there are fewer blanket assemblies per core assembly as core size is increased, the relative importance of the radial blanket decreases on a fuel-cycle-cost basis (mills/kwhr) as the core radius increases.

The second major section of the chapter dealt with the state-ofthe-art computer methods which will be used to develop more precise results than can be obtained from a one-group model. 


\author{
Chapter 3 \\ BEGINNING-OF-LIFE BREEDING ANALYSIS
}

\title{
3.1 INTRODUCTION
}

In this chapter beginning-of-life (BOL) blanket physics performance will be investigated using the methods described in Chapter 2. The first order of business will be to verify the applicability and accuracy of the simple one-group model by comparing it to state-of-the-art computer methods for simple one-zone cores. Then the one-group approach will be used to examine the more interesting case of the radially power-flattened core to develop an idealized model for radial and axial blanket performance as the core size is increased. These results will be.compared with those obtained using 2DB-BOL snapshot calculations to analyze more realistic multizone cores. Blanket physics performance characteristics investigated include $\mathrm{BOL}$ fissile material (enrichment) buildup rates, and the breeding ratio, row-byrow in the radial blanket and zone-by-zone in the axial blanket.

\subsection{EVALUATION OF ONE-GROUP MODEL USING UNIFORMLY LOADED CORES}

Since the one-group analytic model becomes excessively cumbers,ome (thereby losing its chief virtue) when applied to multizone cores, and the more sophisticated computer methods can only deal with uniform zones, the common ground of the uniformly loaded, single-zone core was employed to evaluate the simple model's performance. One-

group cross sections were developed by collapsing multigroup sets over

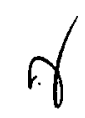


representative spectra: the 4-group standard set used in. 2DB and its parent 26-group set (used with the ANISN program) were employed. Table 3.1 lists the one-group cross sections. A further simplification was introduced by defining a composite fissile material " $\mathrm{Pu}^{239}$ " to represent all fissile isotopes present $\left(\mathrm{U}^{235}, \mathrm{Pu}^{239}, \mathrm{Pu}^{241}\right)$ and a composite fertile material "U $\mathrm{U}^{238 "}$ which combined $\mathrm{U}^{238}$ and $\mathrm{Pu}^{240}$.

The composite cross section, $\bar{\sigma}$, satisfied the relation:

$$
\bar{\sigma}=\frac{\sum \mathrm{N}^{\mathrm{j}} \sigma^{\mathrm{j}}}{\sum \mathrm{N}^{j}},
$$

where

$\mathrm{N}^{j}$ is the atom number density for the $j$-th nuclide

and

$\sigma^{j}$. is the microscopic cross section of the $j$-th nuclide.

For a one-zone core, the critical materials buckling, $\mathrm{B}_{\mathrm{C}}$, is

$$
\mathrm{B}_{\mathrm{c}}^{2}=\frac{\nu \Sigma_{\mathrm{f}, \mathrm{c}}-\Sigma_{\mathrm{a}, \mathrm{c}}}{\mathrm{D}_{\mathrm{c}}}
$$

where

$\mathrm{D}_{\mathrm{c}}$ is the diffusion coefficient $=\frac{1}{3 \Sigma \mathrm{tr}, \mathrm{c}}$

$\Sigma_{\text {tr, }}$ is the transport cross section,

$\nu \Sigma_{\mathrm{f}, \mathrm{c}}$ is the macroscopic neutron production cross section, and

$\Sigma_{a, c}$ is the macroscopic absorption cross section.

Equation 3.2 can be arranged to relate critical enrichment to buckling: 


$$
\varepsilon_{c}=A+C B_{c}^{2}
$$

where

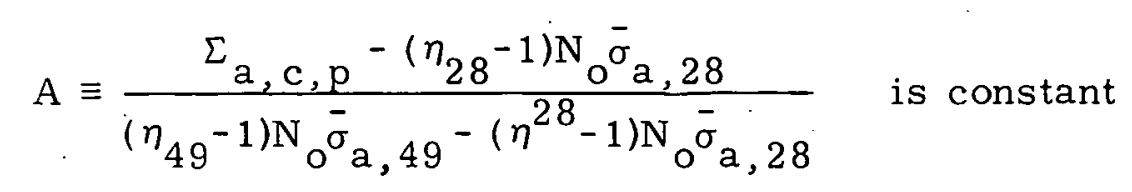

and

$$
\mathrm{C} \equiv \frac{\mathrm{D}_{\mathrm{c}}}{\left(\eta_{49}-1\right) \mathrm{N}_{0} \bar{\sigma}_{\mathrm{a}}^{-49}-\left(\eta^{28}-1\right) \mathrm{N}_{0} \bar{\sigma}_{\mathrm{a}}^{28}} \quad \text { is constant }
$$

in which

$$
\eta_{i}=\nu_{i} \frac{\sigma_{f, i}}{\sigma_{a, i}} \quad \text { (for } i-t h \text { nuclide) }
$$

$\mathrm{N}_{\mathrm{o}}$ is the atom number density of heavy metal

$\Sigma_{a, c, p}$ is the non-fuel absorption cross section.

On the other hand, the critical core geometric buckling is computed from:

$$
\mathrm{B}_{\mathrm{c}}^{2}=\left(\frac{\pi}{\mathrm{H}+2 \delta_{\mathrm{a}}}\right)^{2}+\left(\frac{\nu_{\mathrm{o}}}{\mathrm{a}+\delta_{\mathrm{R}}}\right)^{2}
$$

where

$\mathrm{H}$ is the actual core height

a is the actual core radius

$\nu_{\mathrm{O}}=2.4048$, fundamental eigenvalue of $\mathrm{J}_{\mathrm{O}}$

$\delta_{a}$ is the linear extrapolation distance into the axial blanket

$\delta_{R}$ is the linear extrapolation distance into the radial blanket.

The linear extrapolation distance was obtained from 2DB 4-group calculations. by linear extrapolation of the total flux near the core periphery:

$$
\begin{aligned}
& \delta_{\mathrm{R}}=20 \mathrm{~cm} \\
& \delta_{\mathrm{a}}=25 \mathrm{~cm}
\end{aligned}
$$




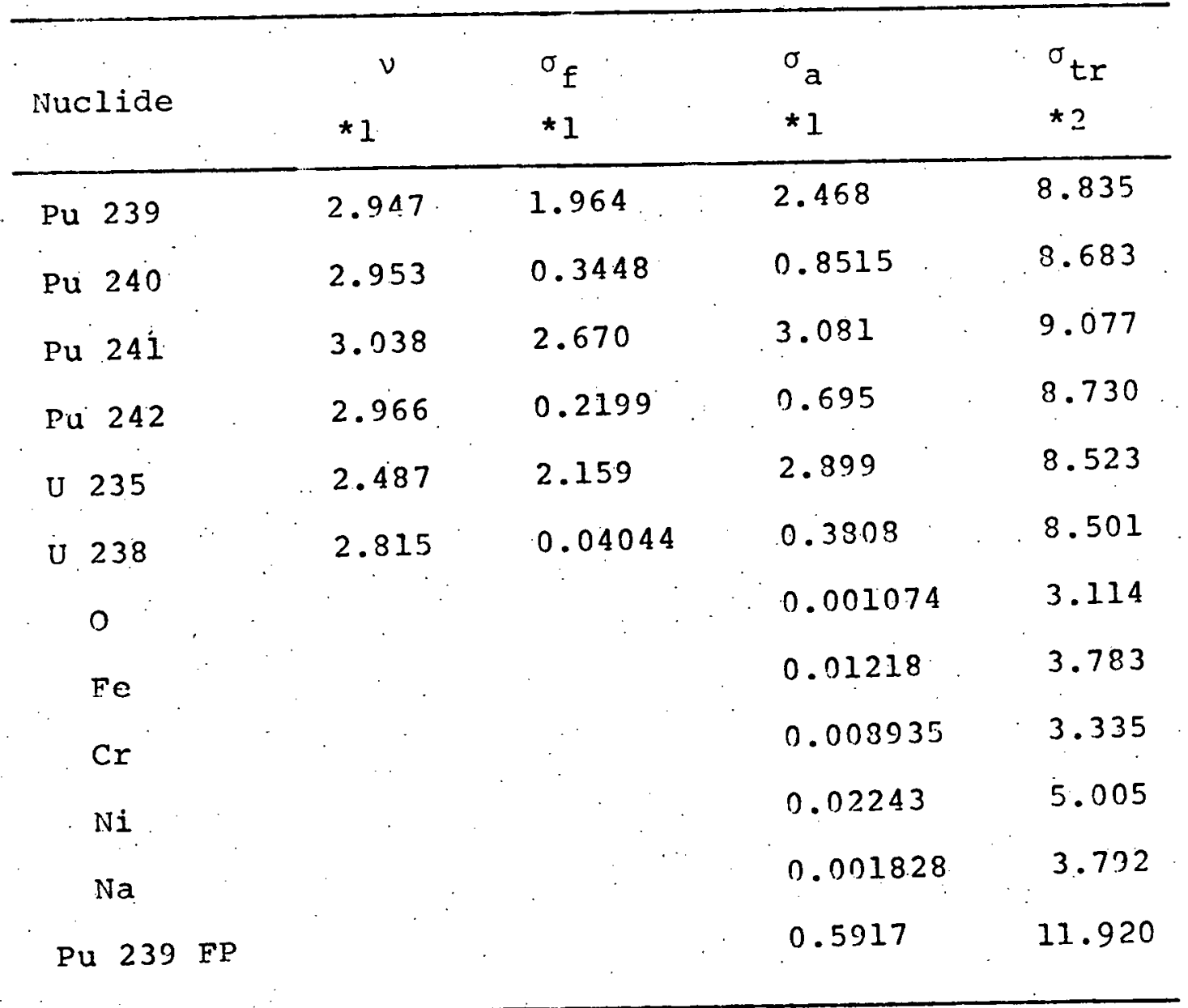

- All values of cross sectionsin barns

* 1 obtained from 4-Group 2DB results

*2 Obtained by collapsing over 26-rroun ANISN spectra using the prescrintion

$$
\bar{\sigma}_{t r}=\frac{\sum_{i=1}^{G} \phi_{i}}{\sum_{i=1}^{G} \phi_{i} / \sigma_{i}} \quad \text { where } i \text { is ith groun }
$$

Table 3.1 one Group cross sections for the Core used in Present Work 
Figure 3.1 shows that the effect of core radius (hence core size, enrichment, neutron spectrum) on the extrapolation distance is negligible. Using the one-group cross-section set of Table 3.1, one has:

$$
\varepsilon_{\mathrm{c}}=0.0829+76.8 \mathrm{~B}_{\mathrm{r}}^{2} \text {. }
$$

Figure 3.2 shows this relationship together with the enrichment obtained from the $2 \mathrm{DB}$ calculations. The agreement is satisfactory.

The simple one-group model also requires that several other parameters characterizing the core remain constant. Figure 3. 3 confirms that this is so within acceptable bounds for $D_{c}$, the core diffusion coefficient, $\delta_{28}$, the fertile-to-fissile fission ratio, and $k$, the reciprocal pseudo-diffusion length defined in Eq. C. 19 of Appendix C.

\section{3 RADIALLY POWER-FLATTENED CORES}

\subsubsection{BOL Core Characteristics}

In order to design a radially power-flattened core, an initial estimate of the $i$-th zone-averaged enrichment, $\bar{\varepsilon}_{i}$, may be calculated using the one-group prescription (see Appendix C),

$$
\bar{\varepsilon}_{i}=\frac{\int_{r_{i-1}}^{r_{i}} \varepsilon(r) 2 \pi r d r}{\int_{r_{i-1}}^{r_{i}} 2 \pi r d r},
$$

where

$$
\varepsilon(r)=\frac{\varepsilon_{\infty}(0)}{1-\beta(\kappa a) I_{o}(\kappa r)} \quad \begin{aligned}
& \text { is the enrichment } \\
& \text { at position } r
\end{aligned}
$$




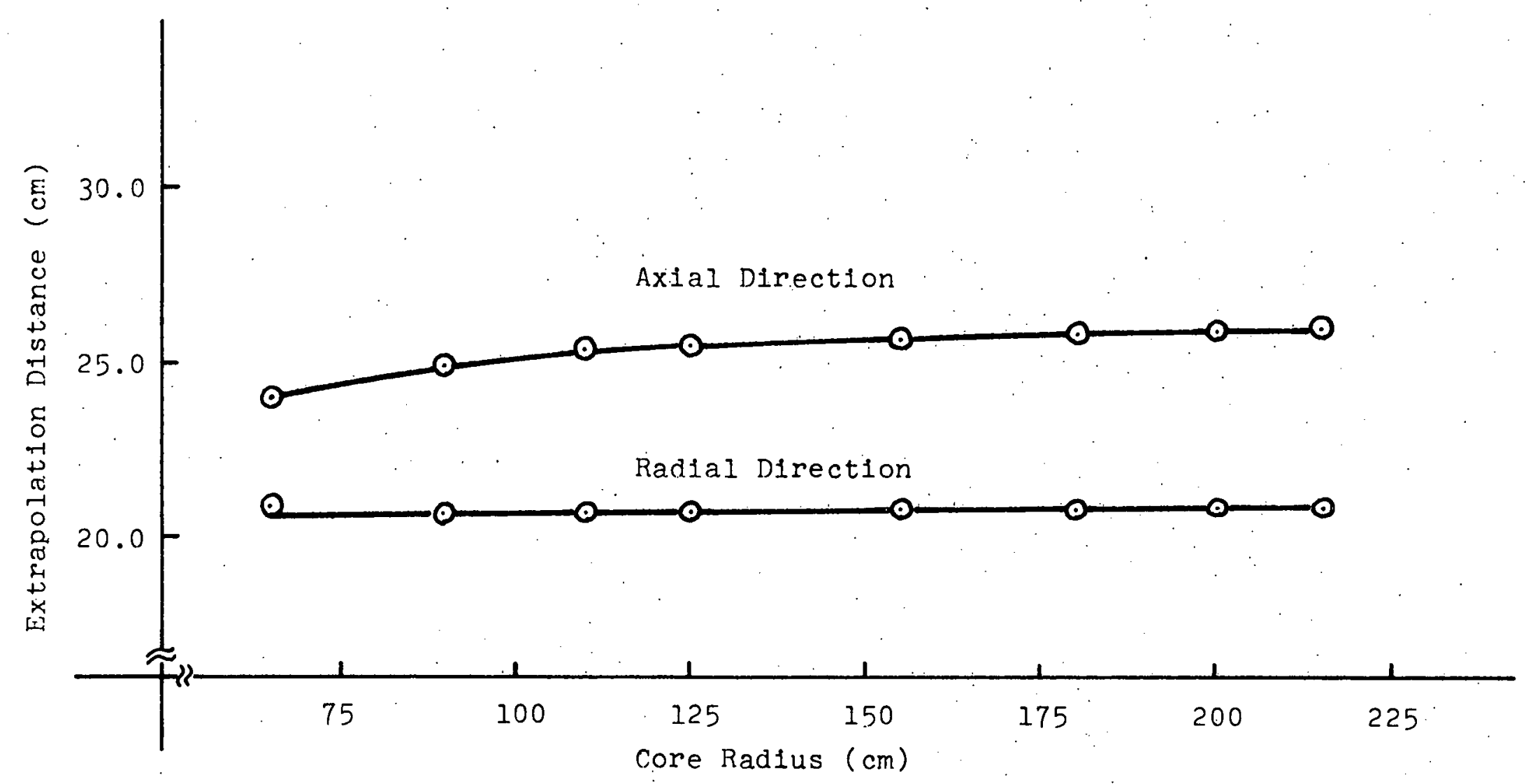

Fig. 3.1 The Effect of Core Radius on the Linear Extrapolation Distance 


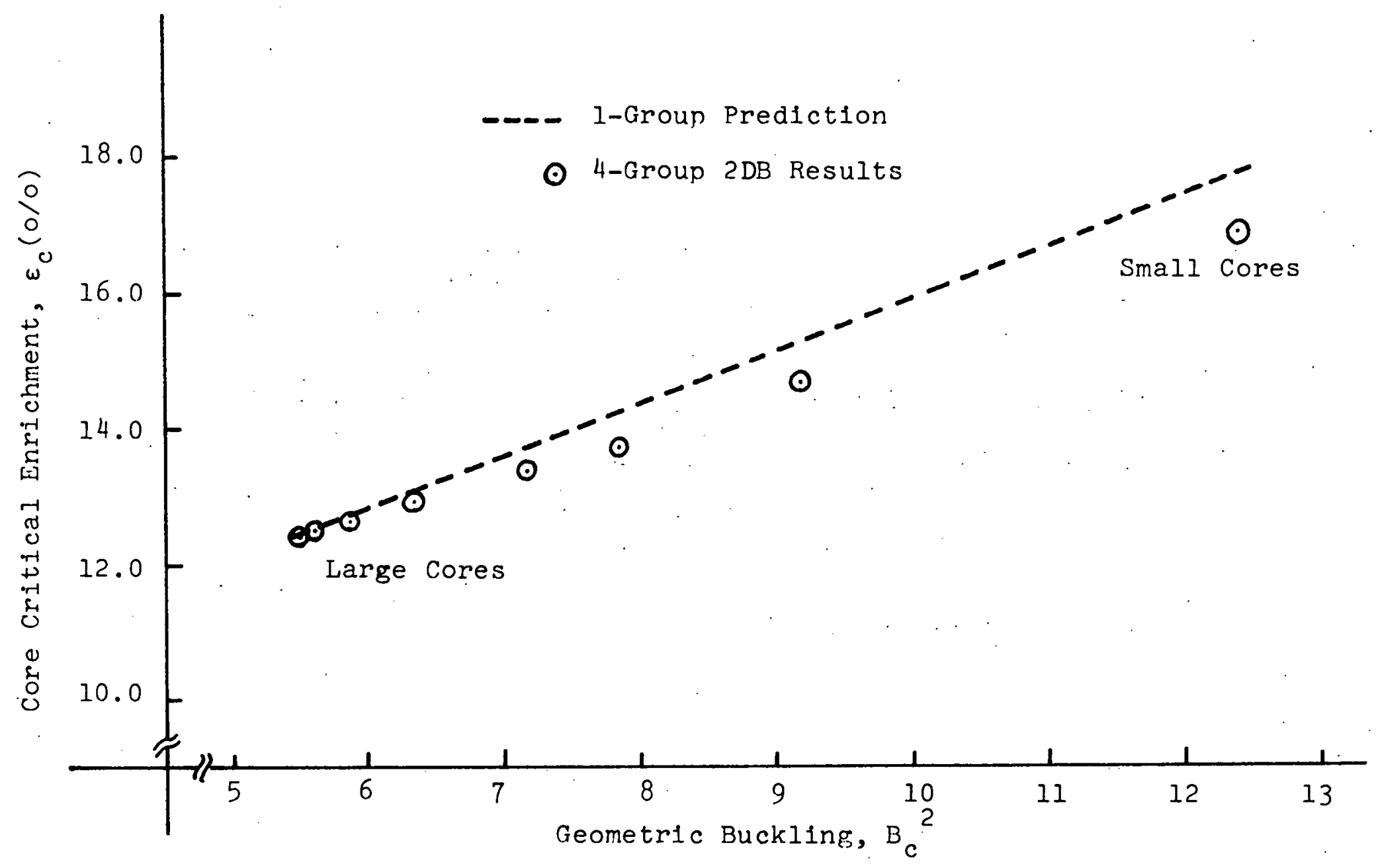

Fig. 3.2 Core-Averaged Critical Enrichment as a Function of Buckling For 


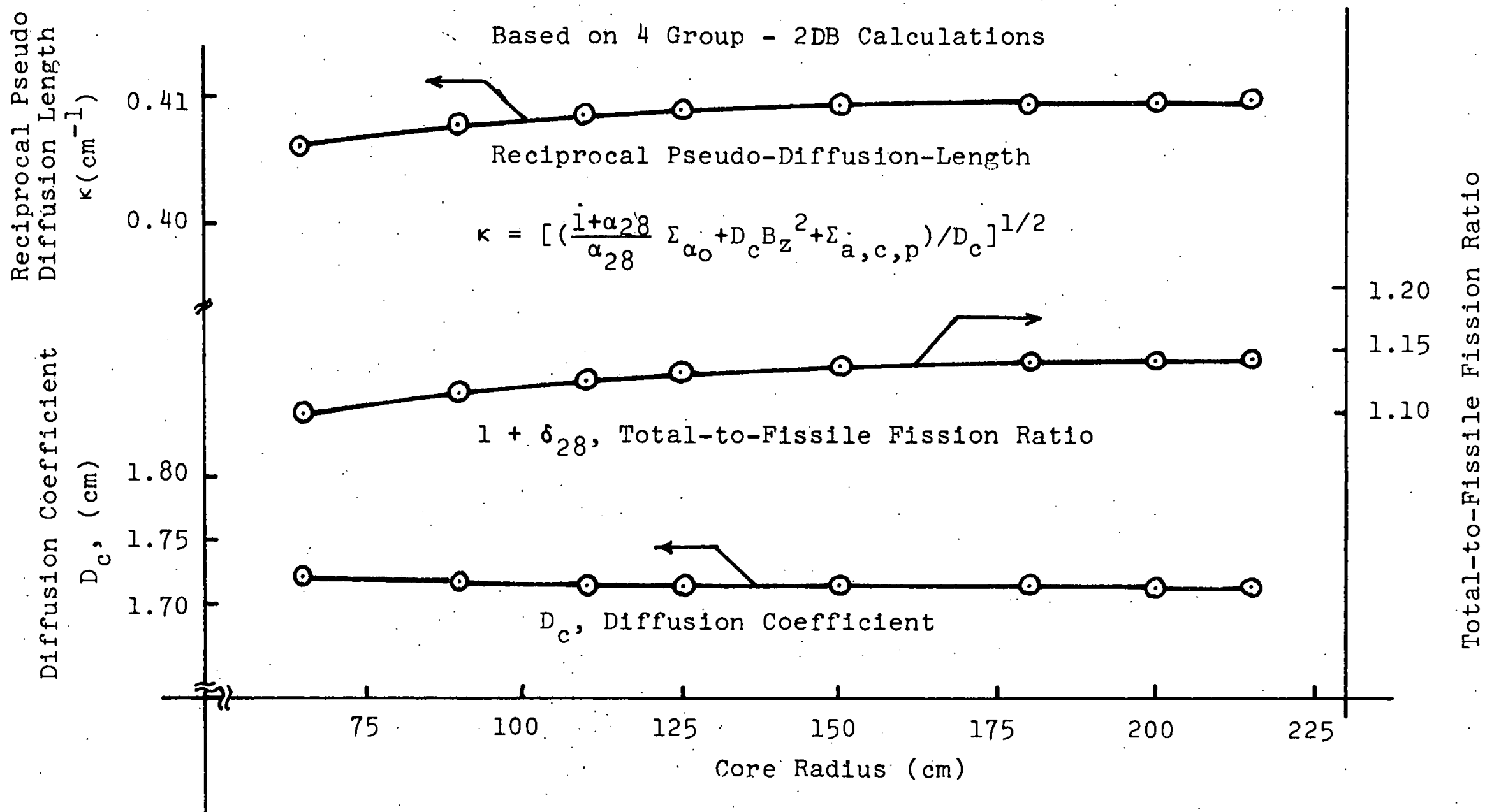

Fig. 3.3 The Effect of Core Radius on BOL Physics Parameters 
$\varepsilon_{\infty}(0)$ is the central enrichment for a core having an infinite radius,

$r_{i}$ and $r_{i-1}$ are the outer and the inner radii of the $i$-th annular zone.

Figure 3.4 shows the zone-averaged enrichments for a 2-zone, $1000-\mathrm{MW}_{\mathrm{e}}$, radially power-flattened core obtained using both the onegroup model and 2DB calculations. Table 3.2 shows the zone-averaged enrichments for various radially power-flattened cores obtained using $2 \mathrm{DB}$ calculations. The final values in the latter case were to satisfy both the criticality relationship and an arbitrary criterion on zone peak power flatness, as described in Chapter 2:

$$
\left|\frac{p_{i}-p_{1}}{p_{1}}\right| \leqslant 5 \%
$$

Table 3.2 shows the zone-averaged enrichment distributions satisfying the criticality and power flatness constraints for the multizone cores examined in this evaluation. As noted in Chapter 2, the zone radii (hence zone volumes and number of zones) were selected to give reasonable overall core power-flattening within practical constraints imposed by finite assembly size.

We are now in a position to test an important prediction of the onegroup model derived in Chapter 2 - namely, that the peripheral enrichment in a radially power-flattened core remains very nearly constant as core radius increases. Figure 3.5 confirms that the zone-averaged peripheral enrichment is essentially independent of core radius, provided that the number of zones employed increases as core radius increases, 


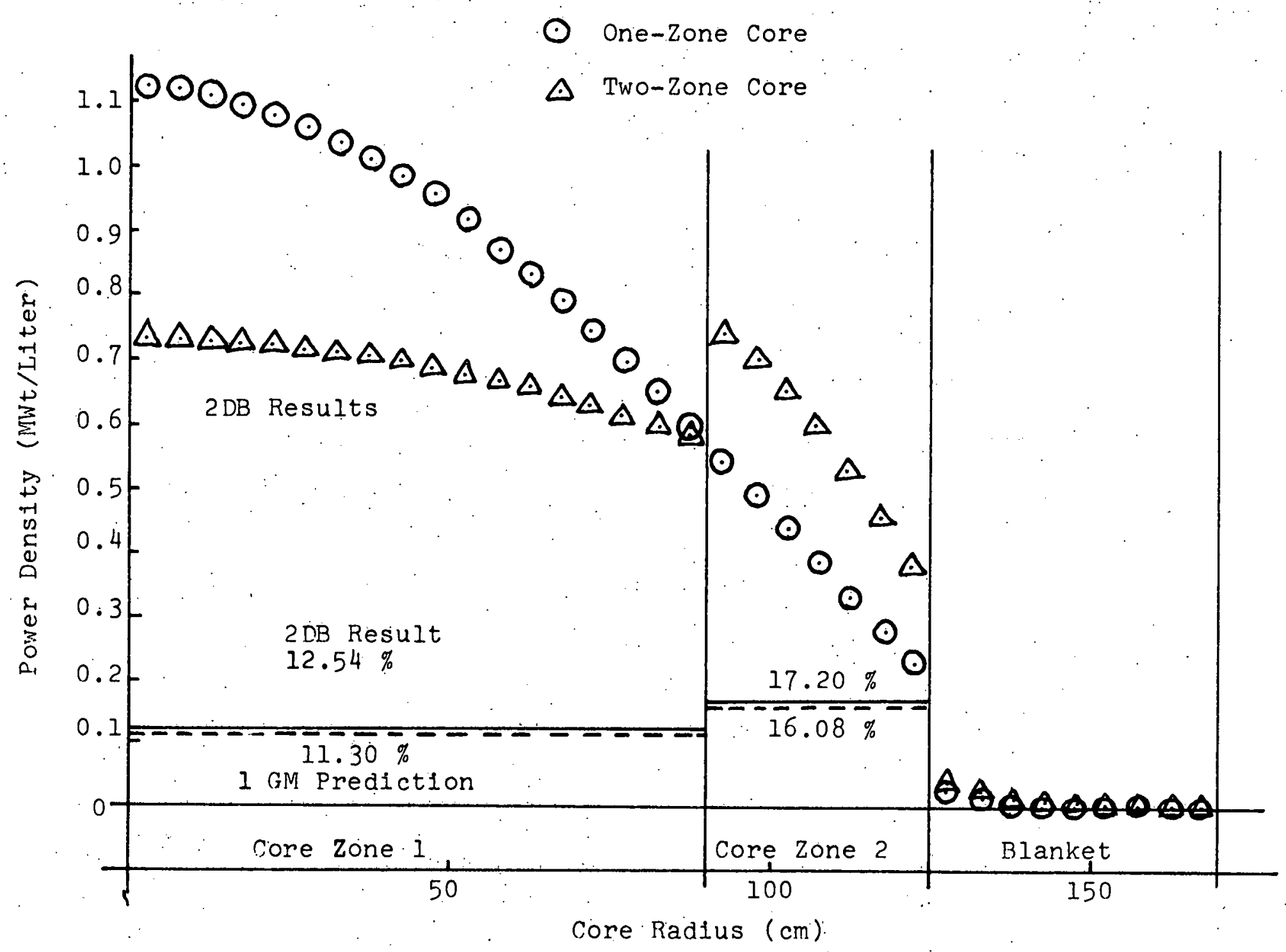

Fio. 3.4 The Effect of Zoning on the Radial Power Density Distribution 


\begin{tabular}{|c|c|c|c|c|c|c|c|c|c|}
\hline $\begin{array}{l}\text { Power } \\
\text { Rating } \\
\text { (nrive) }\end{array}$ & $\begin{array}{l}\text { Core* } \\
\text { Radius } \\
(\mathrm{cm})\end{array}$ & \multicolumn{2}{|c|}{$\begin{array}{l}2 \text { Zone Cores } \\
\text { Zone: } \\
11\end{array}$} & \multicolumn{6}{|c|}{ Multi-Zone-Cores } \\
\hline 250 & 65 & 15.2 & 23.0 & & & $N A$ & & & \\
\hline 500 & 90 & 13.3 & 19.1 & & $\therefore$ & NA & & & \\
\hline 750 & 110 & 12.7 & 17.7 & & & NA & & & \\
\hline 1000 & 125 & 12.5 & 17.2 & 11.5 & 12.1 & 13.0 & 14.1 & 16.8 & 20.0 \\
\hline 1500 & 155 & $\mathrm{~N}$ & & 11.8 & 13.0 & 16.4 & & & \\
\hline 2000 & 180 & $\mathrm{~N}$ & & 11.7 & 12.0 & 13.2 & 17.0 & & \\
\hline 2500 & 200 & $\mathrm{~N}$ & & 11.7 & 11.6 & 12.2 & 13.5 & 17.9 & \\
\hline 3000 & 215 & 12.0 & & $12 . n$ & 11.2 & 12.0 & 12.6 & 14.8 & 20.0 \\
\hline
\end{tabular}

${ }^{*}$ Constant core height $=100 \mathrm{~cm}$, all cases

Table 3.2 zone Averaged Enrichments for Radially-Power-Flattened-Critical BOL Cores of Various Ratings (2DB Calculations) 


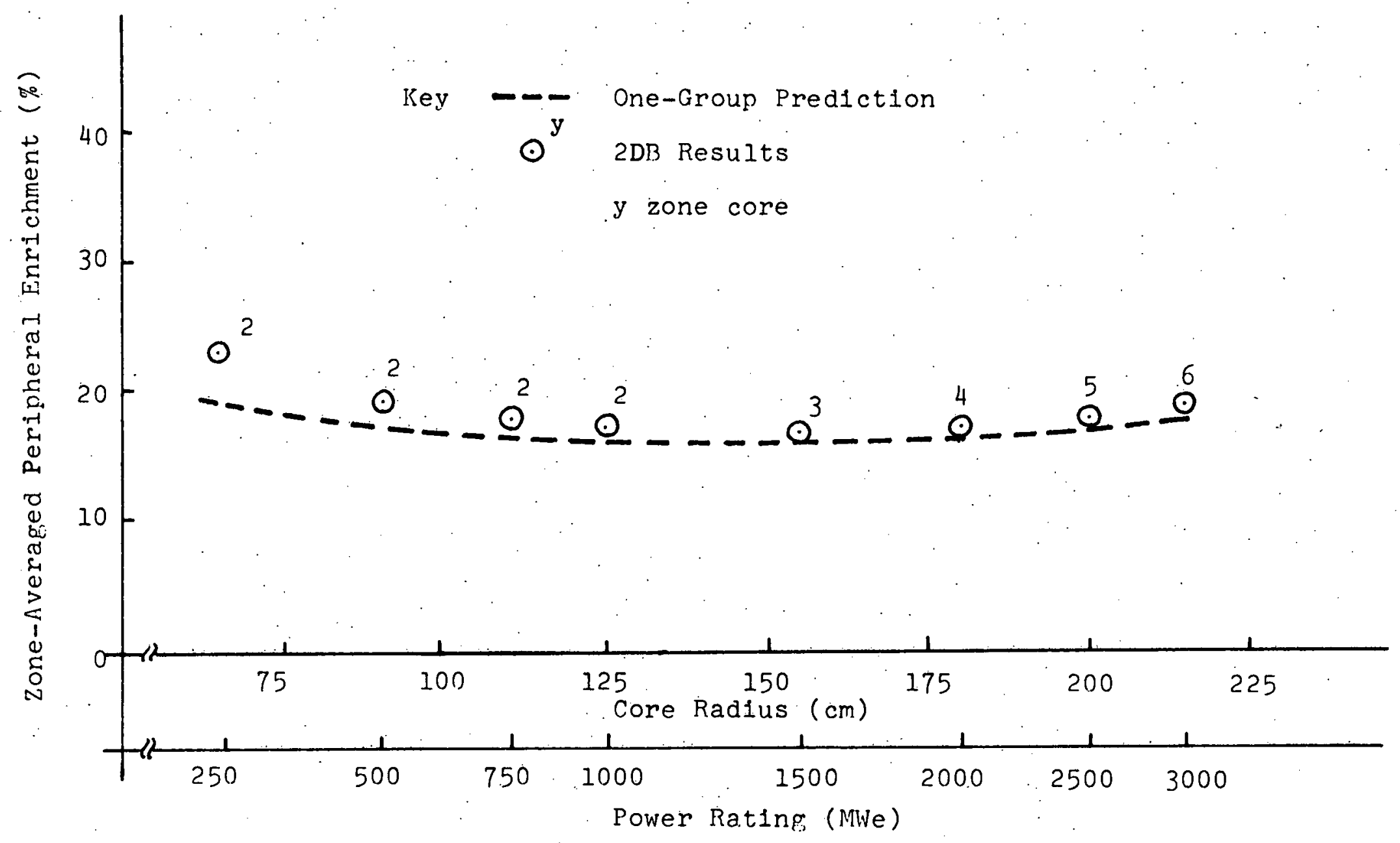

Fig. 3.5 The Effect of Core-Radius on Zone-Averaged Peripheral. Enrichment 
as discussed in Chapter 2. The one-group predictions a re in good agreement with the $2 \mathrm{DB}$ calculations. This result has important implications. Since local enrichment determines the local neutron spectrum, this observation indicates that the blanket is exposed to the same neutron spectrum regardless of core radius. Furthermore, given similar. driving spectra, geometrically and constituently similar blankets will have similar internal spectra, hence identical group-averaged cross sections and relative neutron balances. To confirm this important point, a test case using the full 26-group, parent cross-section set was carried out (ANISN one-dimensional $\mathrm{S}_{8}$ transport calculation [E2]). Figure 3.6 shows the energy spectrum of the neutron flux at the core/ blanket interface for the 250-MW, 2 -zone core and for the 3000-MW $e^{\text {, }}$ 6-zone core. The excellent agreement confirms the hypothesis.

In Chapter 2 the ratio of the critical mass of a radially powerflattened core to that of a uniformly loaded core was predicted to be approximately equal to unity, and the same regardless of core radius. Figure 3.7 shows the one-group prediction and the $2 \mathrm{DB}$ results. The qualitative agreement is good. The core-averaged critical enrichments also vary similarly with core radius (i.e., the enrichments decrease and approach asymptotic values) as shown in Fig. 3.8.

Thus, based on the above results for uniformly loaded cores, it is reasonable to assume that the one-group, collapsed cross-section set and the equations derived for the physics parameters of interest should be applicable to the cases involving radially power-flattened cores. 


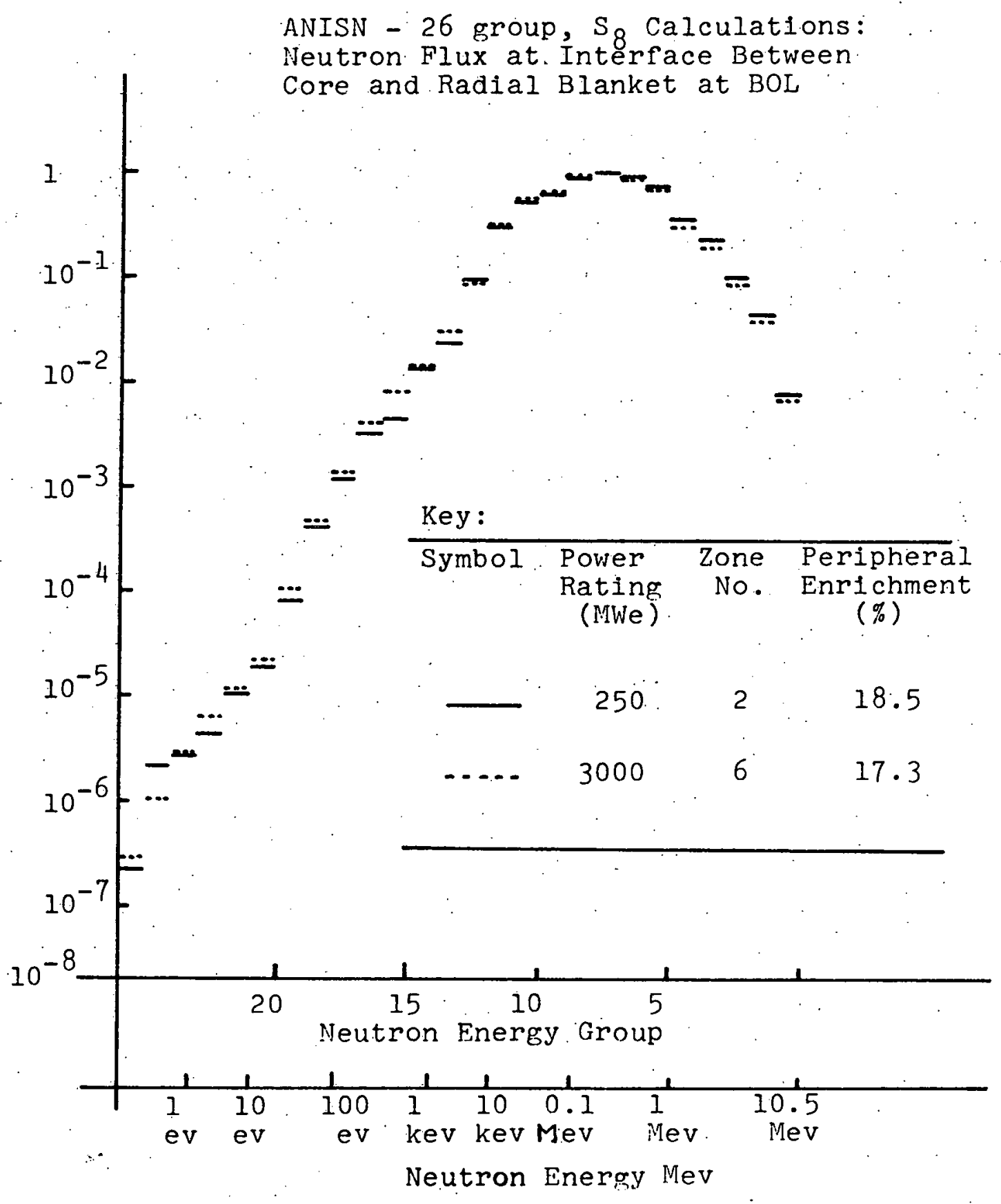

Fig. 3.6 Comparison of Peripheral Neutron Energy Spectra 


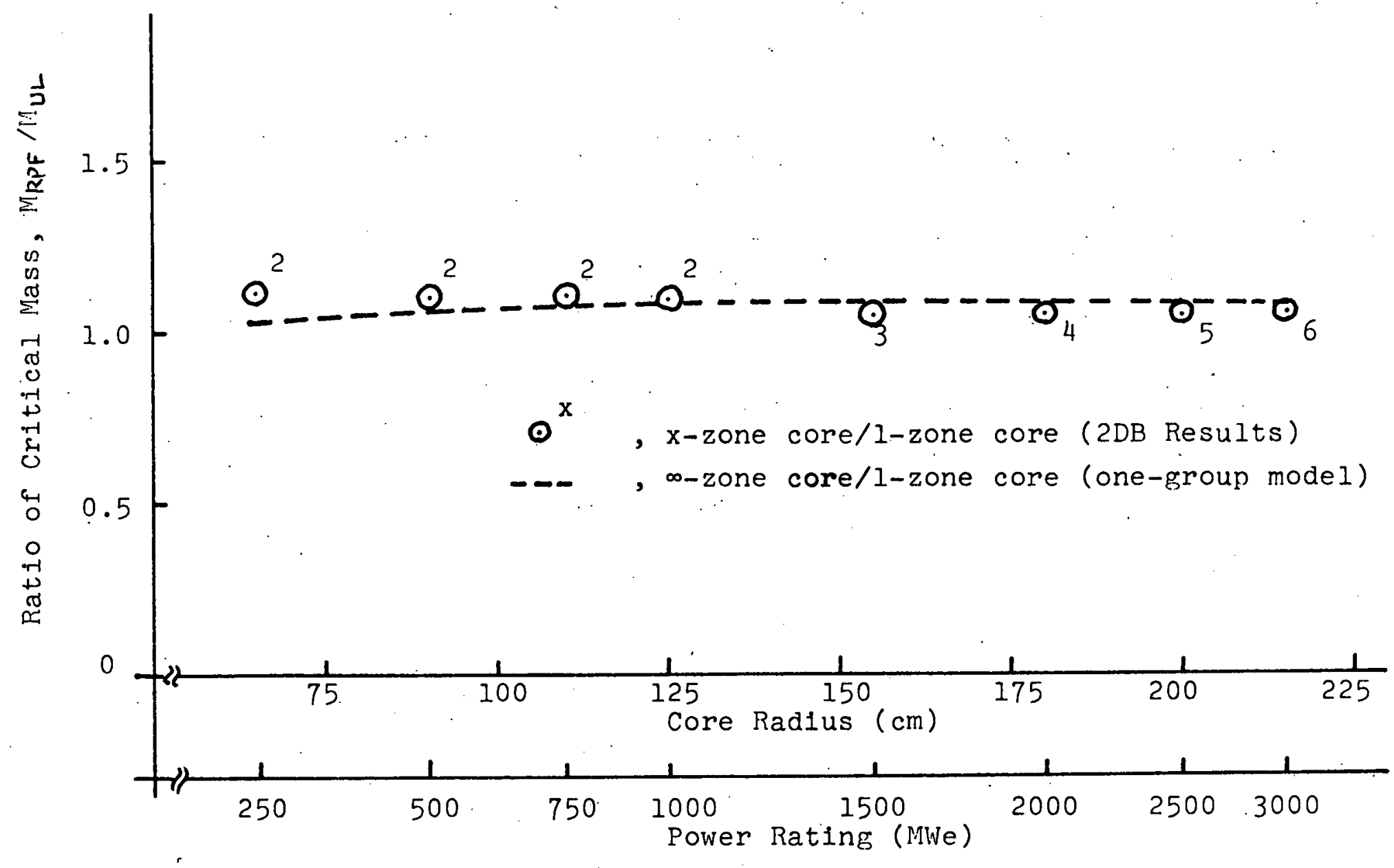

Fig. 3.7 Ratio of Critical Mass for Radially-Power-Flattened Cores to Uniformly-Loaded Cores as a Function of Core Radius (Power Rating) 


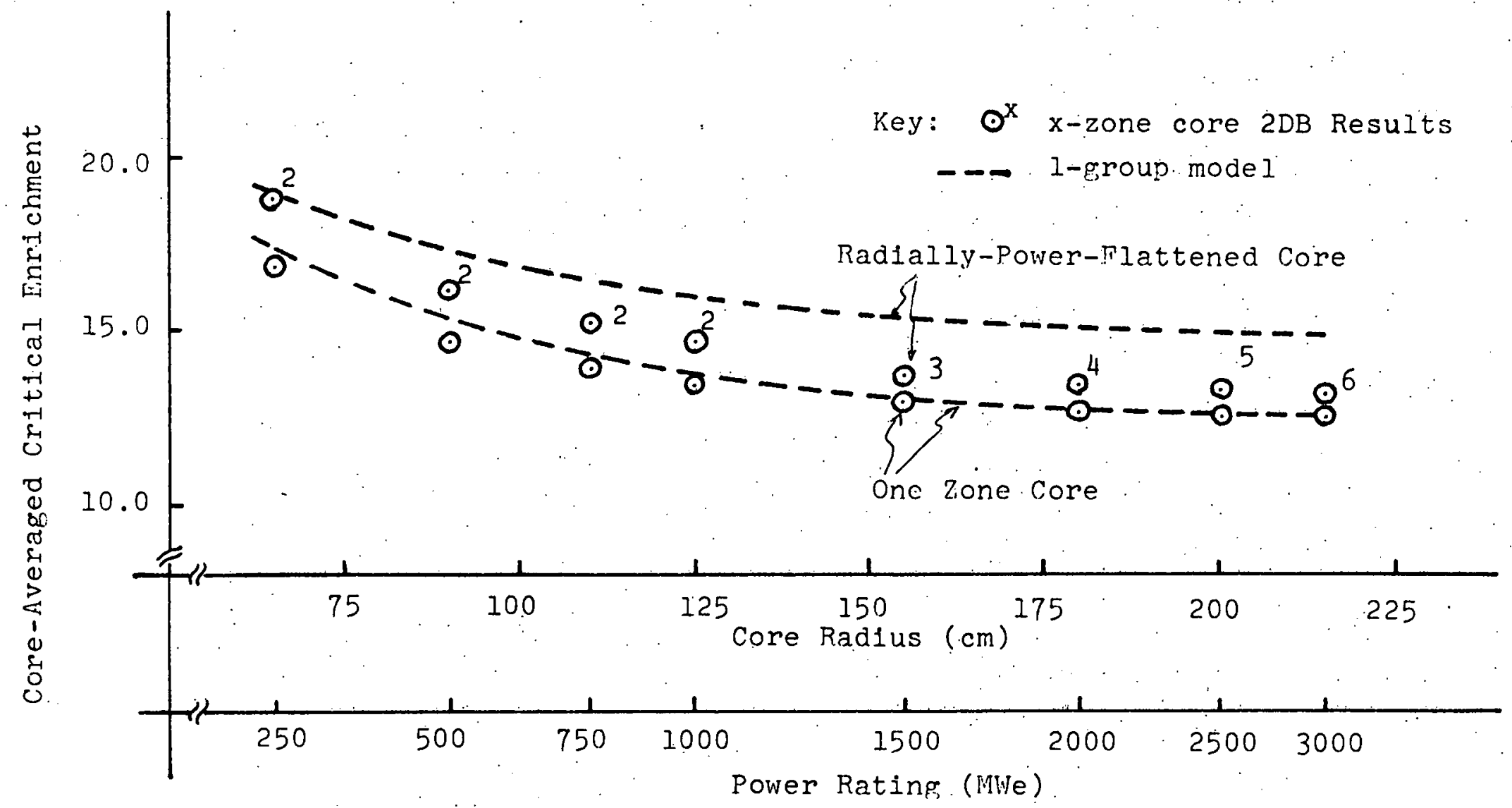

Fig. 3.8 Core-Averaged Critical Enrichment as a Function of Core Radius 
3. 3.2 Efferet of Changing Core Radius at Constant Core Height on Radial Blanket Breeding Performance

It was show: in Chapter 2 that the fissile specific inventory buildup rate, $S_{\text {or }}$ ( $(\mathrm{gPu} / \mathrm{kgHM}-\mathrm{yr})$ in a radial blanket driven by a radially power-flattened core is the same for all core radii.

Figure 3.9 shows that this prediction by the one-group model.is also observed in the $2 \mathrm{DB}$ results for the multizone cores. The fissile enrichment, $\varepsilon$, is directly proportional to the fissile inventory per unit volume, $M^{49} / V_{B}$, i. e. ,

$$
\varepsilon=\frac{\mathrm{M}^{49}}{\mathrm{M}_{\mathrm{HM}}}=\frac{.1}{\rho_{\mathrm{oB}}{ }_{\mathrm{oB}} \mathrm{oHM}_{\mathrm{HM}}}\left(\frac{\mathrm{M}^{49}}{\mathrm{~V}_{\mathrm{B}}}\right) \text {, }
$$

where

$M^{49}$ is the total fissile mass in the blanket, $\mathrm{kg}$

$\cdot \mathrm{M}_{\mathrm{HM}}$ is the total heavy metal mass in the blanket, $\mathrm{kg}$

$\rho_{\mathrm{OB}}$ is the density of the HM oxide fuel

$\rho_{\mathrm{OB}} \simeq 10$ (kgHM oxide/liter-HM oxide)

$\theta_{\circ B}$ is the fractional volume occupied by the fuel in the blanket $\simeq 0.5$

$\alpha_{\mathrm{HM}}$ is the fractional mass of heavy metal in the fuel $\simeq 0.95$

$\mathrm{V}_{\mathrm{B}}$ is the total volume occupied by the blanket, liters.

Thus the fissile material buildup per unit volume (or per assembly) is also the same for all core radii. This characteristic holds true not only at the BOL but also at any irradiation time, a point which will be confirmed in Chapter 4. Since neither the magnitude nor the energy distribution of the driving spectrum changes, at a given distance frorn 


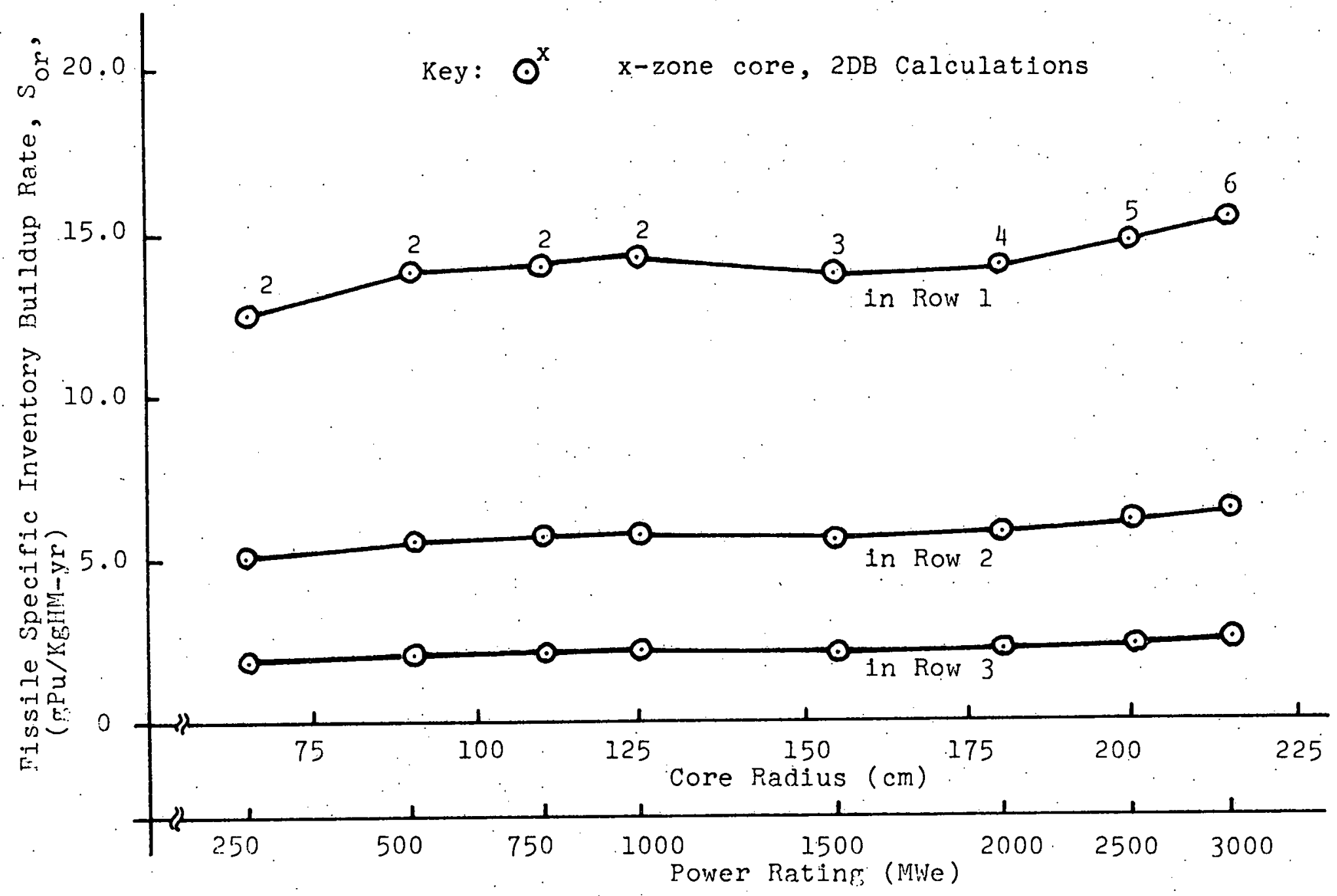

Pif. 3.9 The Effect of Core-Radius on the BOL Fissile Specific Inventory Buildup Rate in the Radial Blanket 
the core/blanket interface the relative row-by-row fissile inventory at any irradiation time should be independent of core radius (size).

Figure 3.10 shows confirmatory results from 2DB 100-day-times.tep-burnup calculations. The row-by-row fissile inventory given by a one-group model in which the flux is assumed to fall off exponentially in the radial blanket, is:

$$
\frac{M_{o i}}{M_{o}}=\frac{e^{-\gamma \tau} i-1-e^{-\gamma \tau} i}{1-e^{-\gamma \tau}}
$$

where

$M_{\text {oi }}$ is the fissile mass in the $i-$ th row

$M_{0}$. is the total fissile mass in the entire blanket

$\tau_{i-1}$ and $\tau_{i}$ are the inner and the outer radius of the $i-$ th row

$\tau: \quad$ is the total thickness of the blanket $=45 \mathrm{~cm}$

$\gamma \quad$ is the reciprocal of the effective blanket diffusion length, which is calculated using the formula:

$$
\gamma=\sqrt{\frac{\Sigma_{\mathrm{a}, \mathrm{B}}-\nu \Sigma_{\mathrm{f}, \mathrm{B}}}{\mathrm{D}_{\mathrm{B}}}}=0.05 \mathrm{~cm}^{-1}
$$

in which

$\Sigma_{a, B} \quad$ is the macroscopic absorption cross section of the blanket

$\nu \Sigma_{\mathrm{f}, \mathrm{B}}$ is the macroscopic neutron production cross section of the blanket

$D_{B}$ is the diffusion coefficient of the blanket.

The above parameters were calculated using the data of Table 3. 3, which were obtained from 2DB 4-group caiculations. 


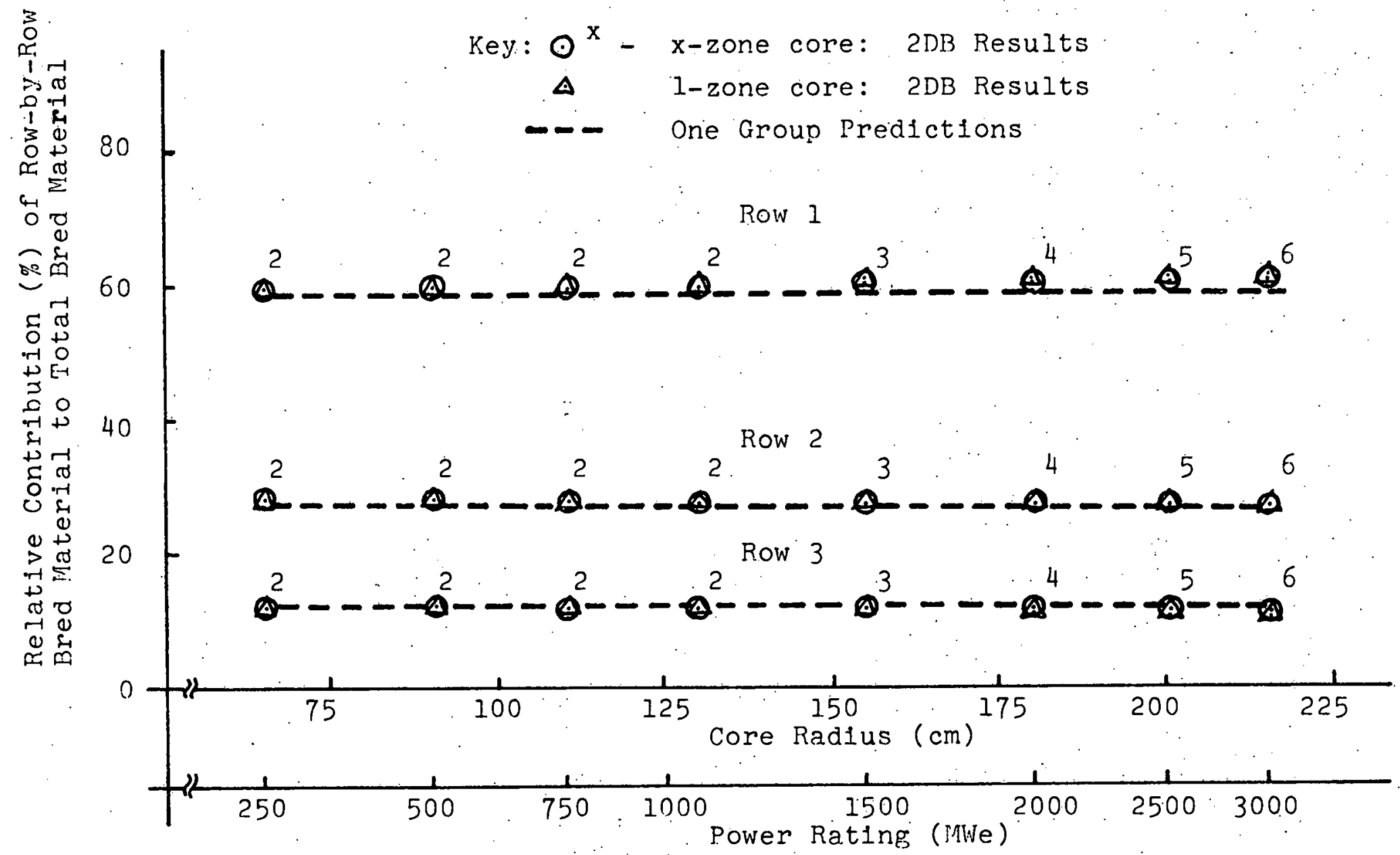

Pip. 3.10 Relative Breeding Contribution of Radial Blanket Rows 


\begin{tabular}{|c|c|c|c|c|}
\hline Nuclide & $\nu_{\star 1}$ & $\sigma_{f_{\star 2}}$ & $\sigma_{a_{\star 2}}$ & $\sigma_{t r_{\star 1}}$ \\
\hline $\mathrm{U} 235$ & 2.487 & 3.875 & 5.741 & 8.523 \\
$\mathrm{U} 238$ & 2.815 & 0.003 & 0.5257 & 8.501 \\
0 & & & 0.00008 & 3.114 \\
$\mathrm{Fe}$ & & & 0.0198 & 3.783 \\
$\mathrm{Cr}$ & & & 0.0155 & 2.335 \\
$\mathrm{Ni}$ & & & 0.0202 & 5.005 \\
$\mathrm{Na}$ & & & 0.0363 & 3.792 \\
\hline
\end{tabular}

All values of cross sections in barns

* 1 The same as used in the core (see Table 3.1)

*2 From 2DB results

Table 3.3 One Group cross Sections for the Blanket used in the Present Work 
Figure 3.11 confirms the predictions by the one-group model, as discussed in Chapter 2 , that the external breeding ratio in the radial blanket is proportional to $\mathrm{a}^{-1}$ when driven by a radially powerflattened core and to $\left(a+\delta_{R}\right)^{-2}$ when driven by a uniformly loaded core.

\section{3. 3 Effect of Changing Core Radius at Constant Core. Height on Axial Blanket Breeding Performance}

Figure 3: 12 shows the fissile specific inventory buildup rate in an axial blanket driven by either radially power-flattened or uniformly loaded cores, which confirms the predictions of the one-group model that the product of the specific rate and the core critical enrichment is essentially constant for all core radii.(sizes), and the specific rate itself is constant for the larger cores examined.

Figure 3.13 shows the product of the axial blanket breeding ratio and the core critical enrichment for both sets of results, which confirms the prediction of the one-group model that the product is constant for all core radii, as discussed in Chapter 2 and Appendices B and C. Figure 3.13 also shows the axial blanket breeding ratio, which again. confirms that the breeding ratio is constant for the larger cores examined.

The combined external (blanket) breeding ratio of the axial and radial blankets decreases as the core radius increases. Figure 3.14 shows this together with the internal (core) breeding ratio and the total (core + blanket) breeding ratio. It is interesting to note that the internal breeding ratio does not exceed unity even at $3000 \mathrm{MW}$. Radial power-flattening does not improve the total breeding performance very much because the gain in the radial blanket is cancelled out by the loss in the core due to the slightly higher critical mass. 


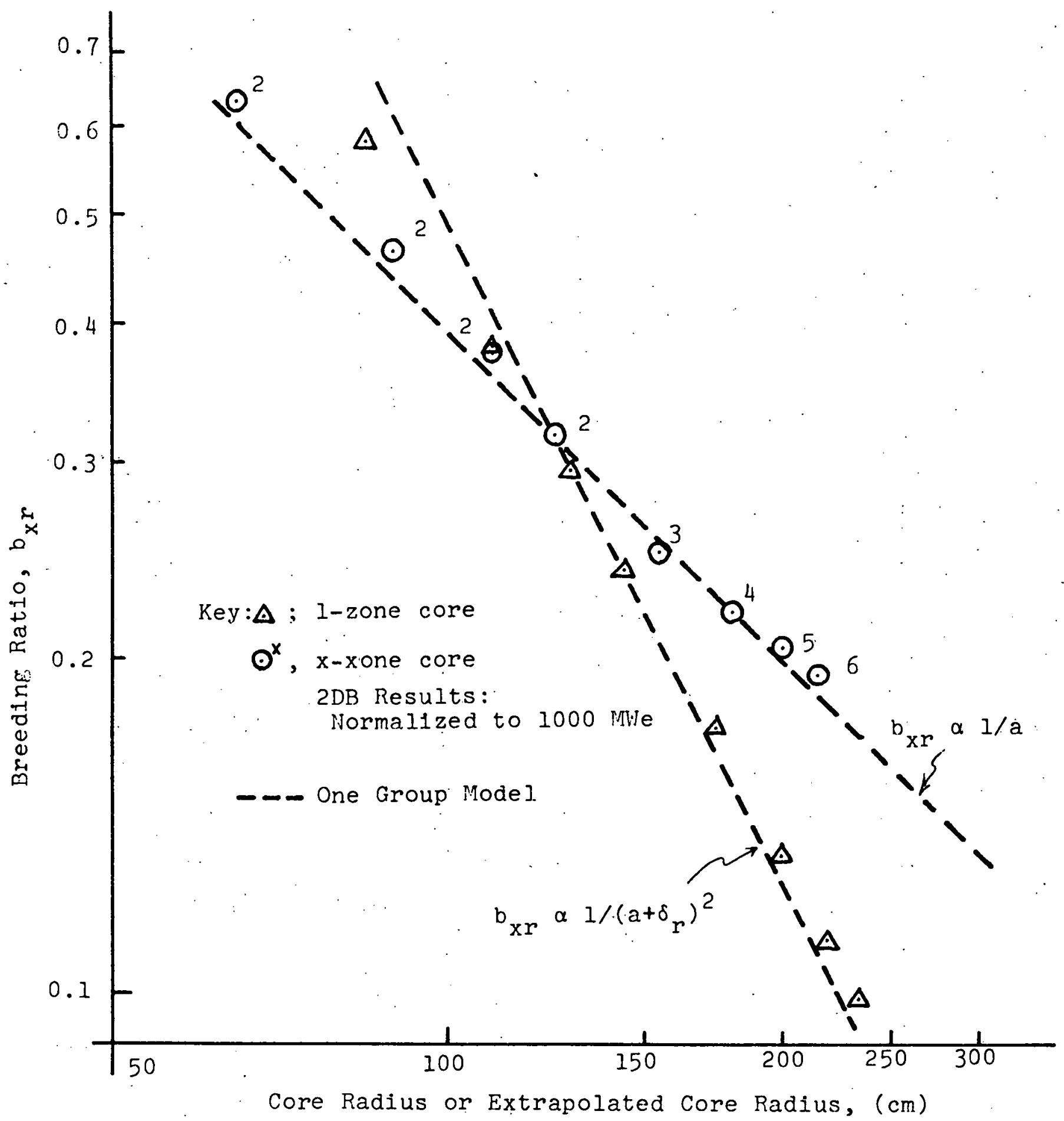

Fig. 3.11: The Effect of Core Radius on Radial Blanket Breeding Ratio 


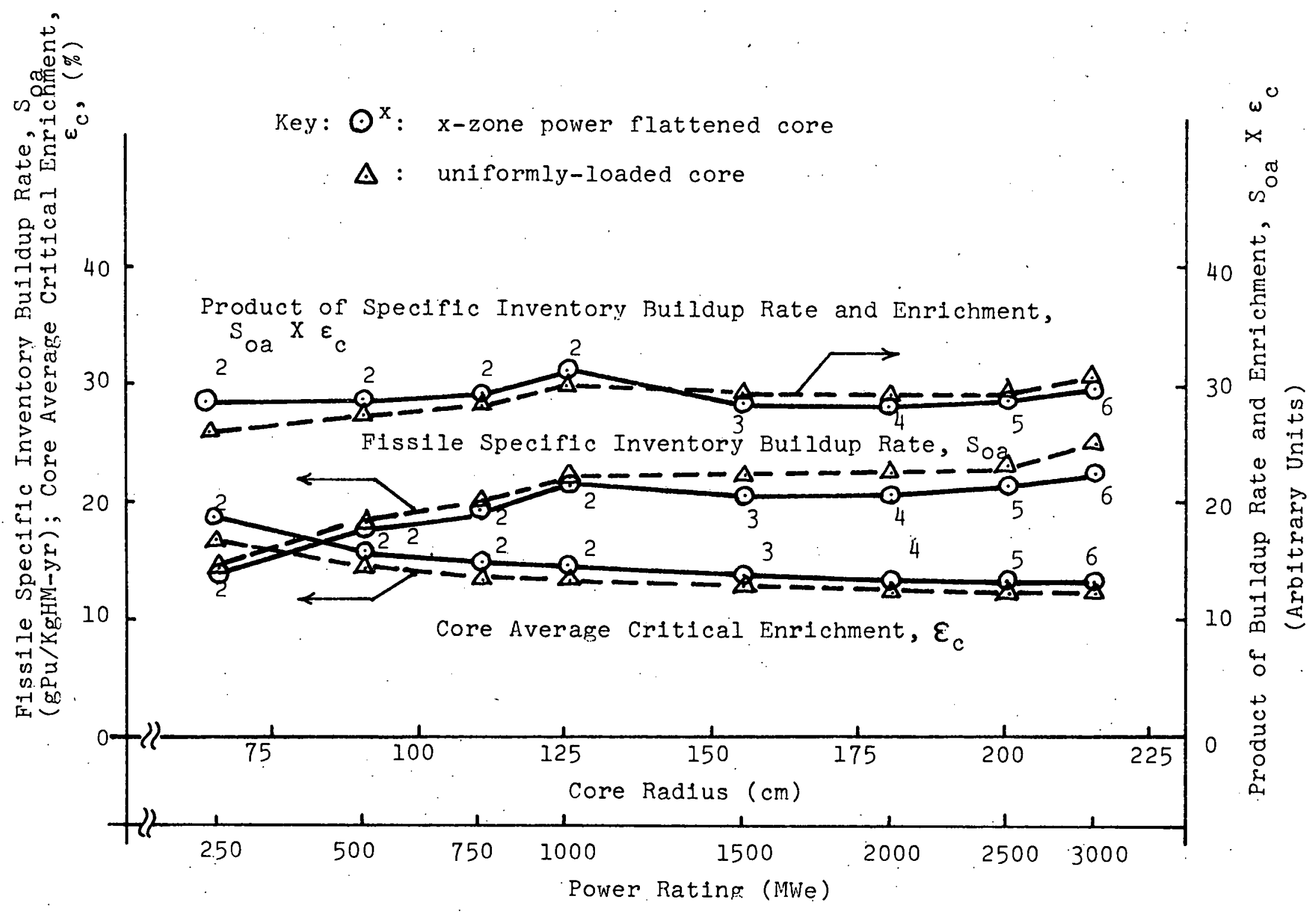

Fig. 3.12 The Effect of Core-Radius on the BOL Fissile specific Inventory Buildup Rate in the Axial Blanket 


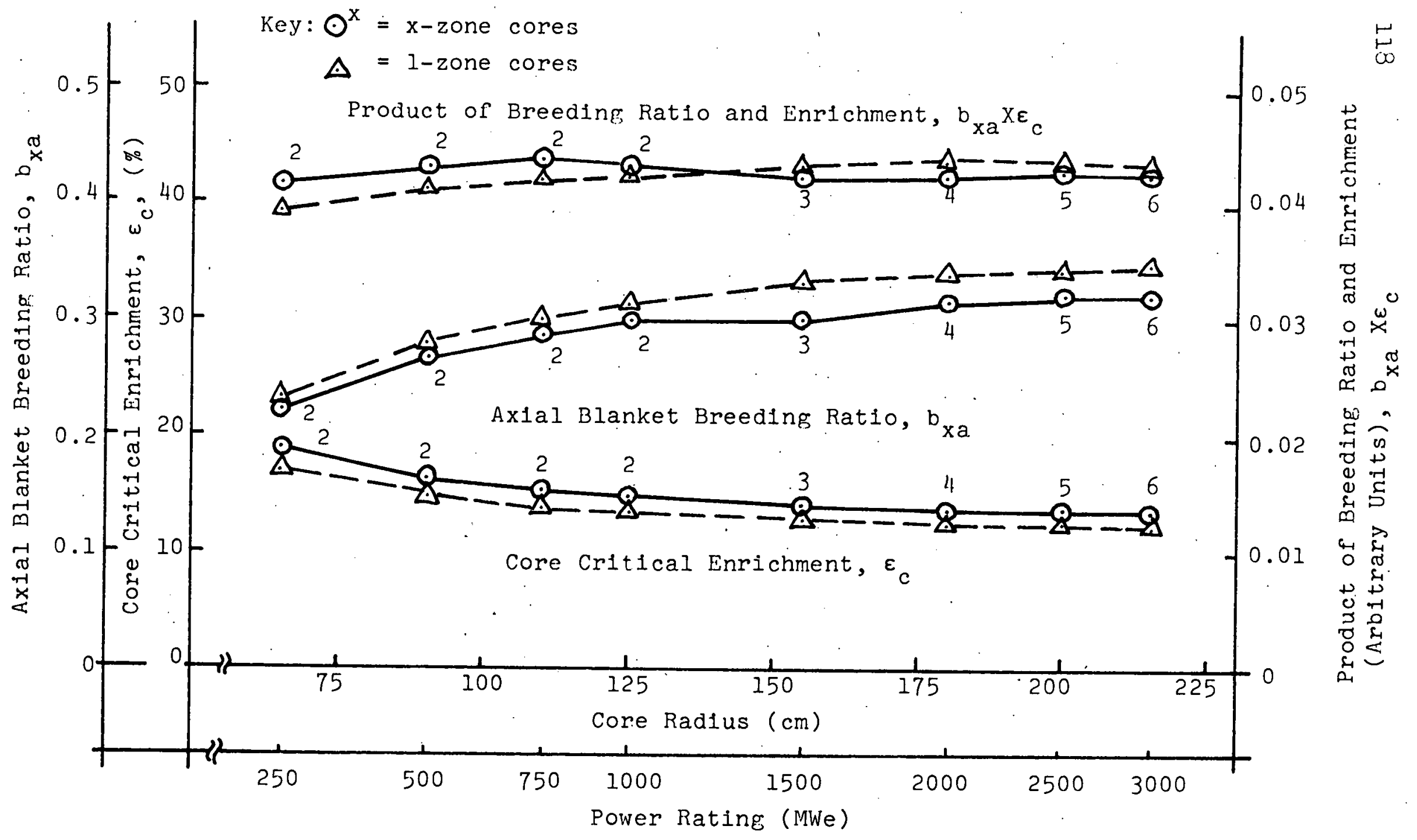

F1g. 3.13 Product of Axial Blanket Breeding Ratio and Core Averaged Critical Enrichment as a Function of Core Radius 


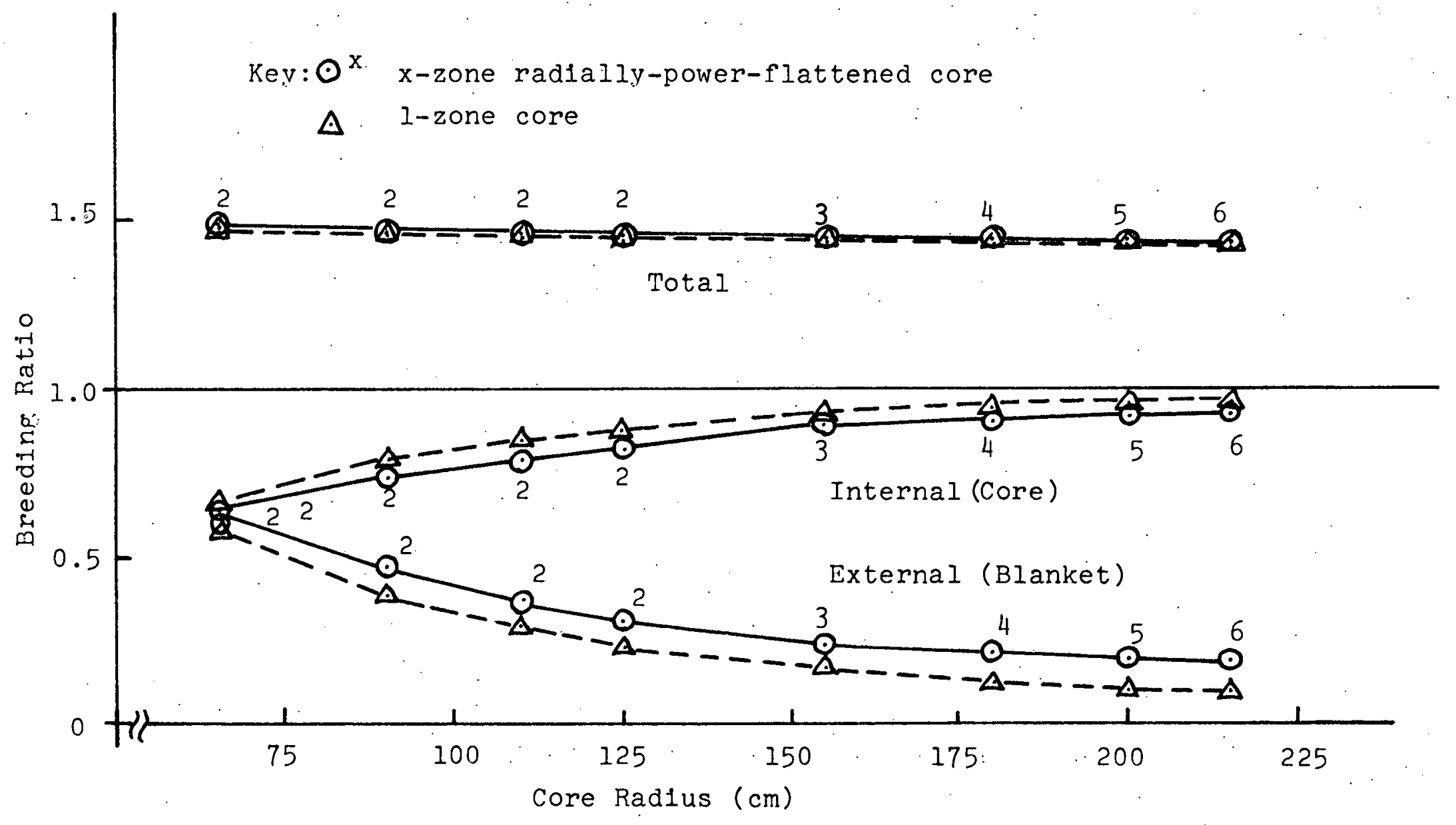

Fig. 3.14 The Effect of Changing Core Radius (Size) at Constant Core Height on the Breedinf Ratio 
3. 3.4 The Effect of Changing Core Height at Constant Core Radius on Blanket Breeding Performance

\section{3.4.1 Radial Blanket}

Figure 3.15 shows the radial blanket breeding ratio, which is demonstrated to remain essentially constant as core height increases. Multigroup and one-group trends are in good agreement.

\section{3.4.2 Axial Blanket}

Figure 3.16 shows the product of the axial blanket breeding ratio and the core critical enrichment for either two-zone, radially power-

flattened or uniformly loaded cores, which confirms the $\mathrm{H}_{\mathrm{e}}^{-2}$ variation predicted by the one-group model. The agreement is good. Figure 3.16 also shows the rapid decrease of the axial blanket breeding ratio and the slow decrease of the core critical enrichment as core height increases.

Figure 3.17 shows that the combined external (blanket) breeding ratio of the axial and radial blankets decreases as the core height increases. The internal breeding ratio exceeds unity when core height is greater than $200 \mathrm{~cm}$ for radially power-flattened cores or $150 \mathrm{~cm}$ for uniformly loaded cores, which will requirespecial consideration of the reactivity control problem. The total breeding ratio is again constant regardless of core height, which is a result similar to that found for core radius changes at constant core height. Thus it is concluded that the total breeding ratio cannot be improved significantly by changing the core radius or the core height using constant thickness blankets. It is also interesting that radial power-flattening cannot improve the total breeding 


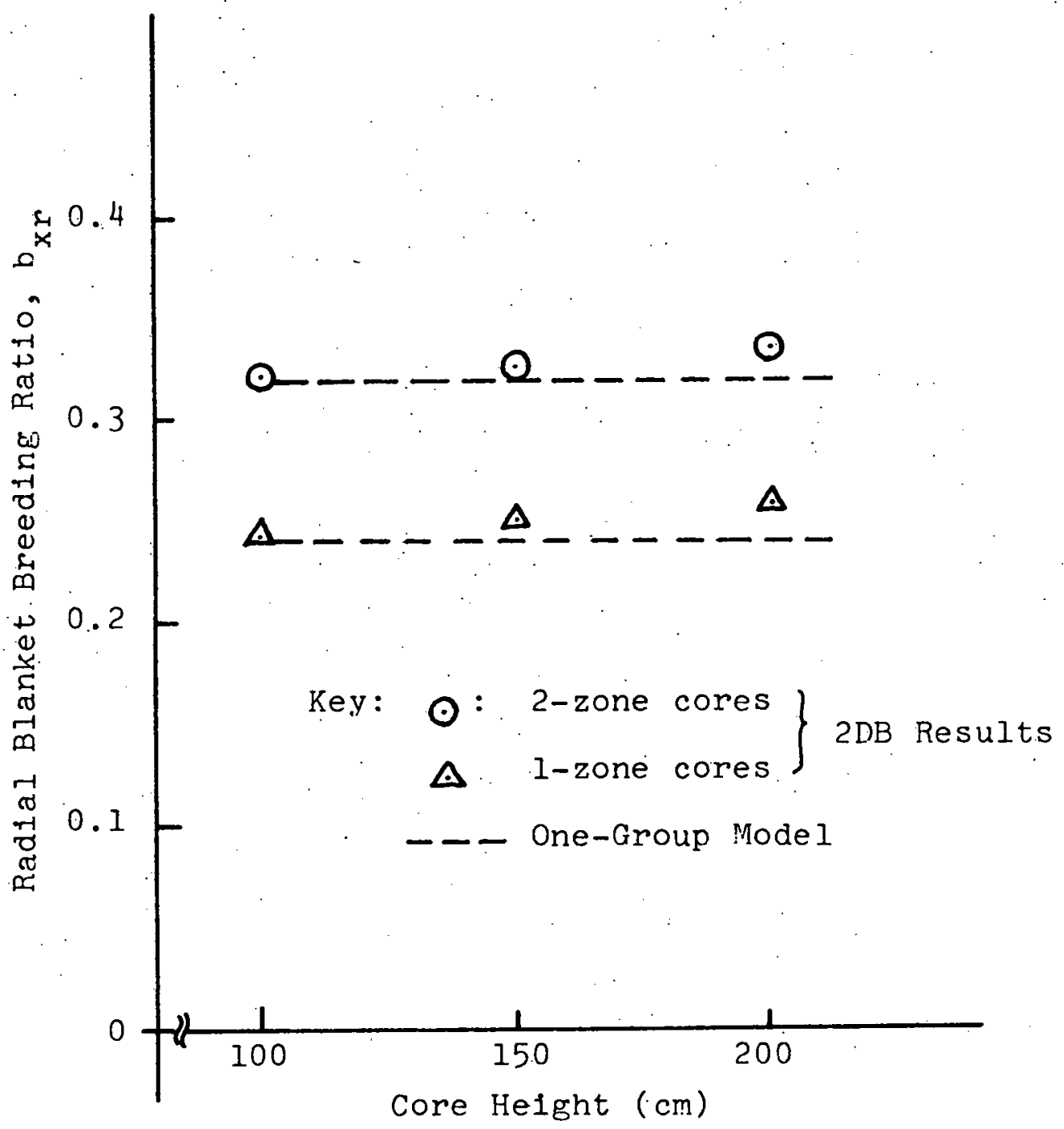

Fig. 3.15 The Effect of Changing Core Height at Constant Core Radius on the Radial

Blanket Breeding Ratio 


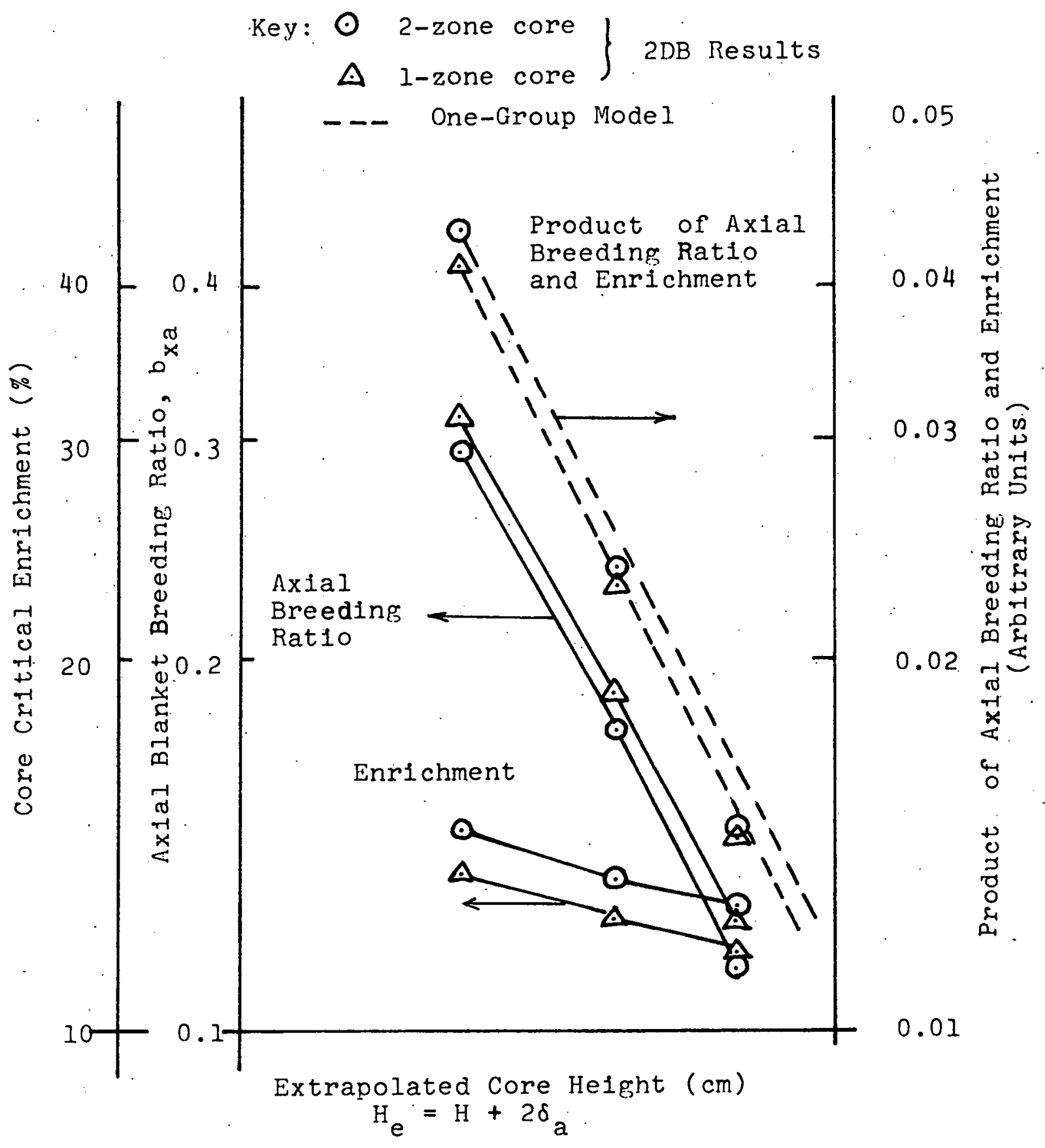

F1g. 3.16 The Effect of Changing Core Height at Constant Core Radius on Axial Blanket Breeding, Performance 


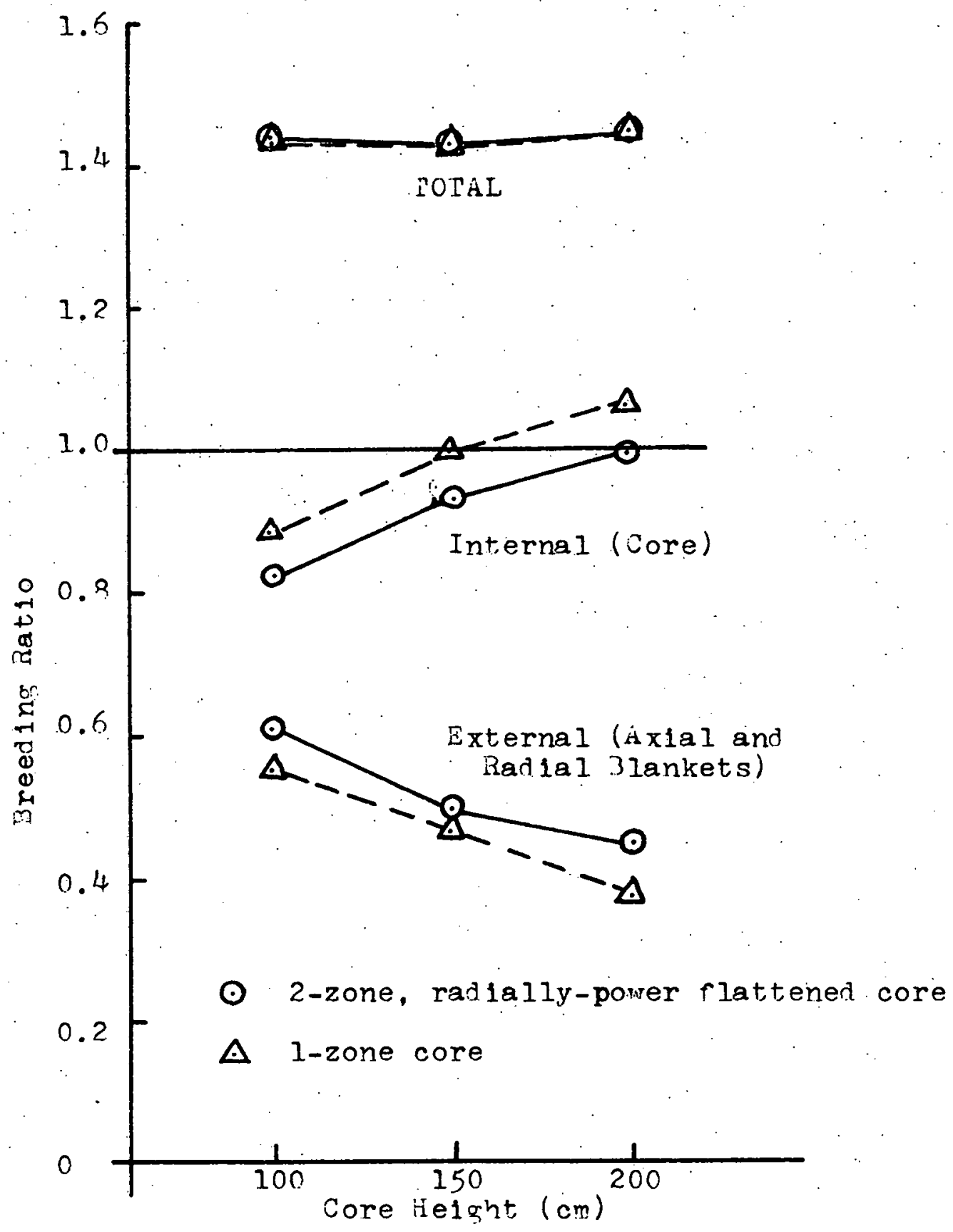

Fig. 3.17 The Effect of Changing Core Height at Constant Core Rarlius on the Breeding Ratio 
ratio. In this regard, we should note that while Tzanos ( $\mathrm{T} 1$ ) demonstrated that power-flattened cores have minimum critical mass and maximum breeding ratio, he applied the constraints of constant total power and peak power density, while the present comparisons are for constant volume cores.

We have dealt in this chapter with idealized BOL cases where cores do not contain control poison or over-enrichment to compensate for burnup. This is the reas on why rather high total breeding ratios $(\cong 1.5)$ have been computed. In the next chapter, we will discuss more realistic cores with boron control poison and the excess reactivity required to compensate for burnup.

\subsection{CONCLUSIONS}

In the initial sections of this chapter, the validity of using the one-group models for LMFBR scoping analyses was established by comparing one-group results to $2 \mathrm{DB} 4$-group calculations for one-zone cores. The core diffusion coefficient, $D_{C}$, the fertile-to-fission ratio, $\delta_{28}$, and the extrapolation distance, into both the radial and the axial blankets were confirmed to be essentially independent of core radius, as required by the one-group model. It was also shown in a later section that the effective diffusion length of the blanket is also constant for all core radii.

Based upon these verified assumptions and cross sections, characteristics of radially power-flattened cores were predicted using the one-group model. The results were shown to be in good agreement with $2 \mathrm{DB}$ calculations for multizone cores in the 250-3000 MW size 
range. The following important conclusions were developed:

1). The peripheral enrichment (i.e., neutron spectrum) of radially power-flattened cores is the same for all core radii.

2). The magnitude of the peripheral neutron flux is the same for all core radii.

3) Thus, the fissile inventory and enrichment buildup rates per unit volume in each row of the radial blanket driven by radially power-flattened cores are also the same for all core radii. Consequently, total dollar revenue per. blanket assembly is the same for all cores.

4) However, the fuel cycle cost contribution (mills/kwhr) of the entire blanket decreases as the core radius increases because. the number of blanket assemblies per core assembly decreases. Thus, the relative importance of the radial blanket decreases as the core radius increases.

5) The predictions by the one-group model of the effect of core height changes (at constant core radius) on breeding performance are-in good agreement with the $2 \mathrm{DB}-\mathrm{BRECON}$ results.

Now that BOL physics has been discussed, depletion and economics are of interest: the topics addressed in the next chapter. 
Chapter 4

DEPLETION-ECONOMICS ANALYSIS

\section{1 INTRODUCTION}

In this chapter, LMFBR blanket performance will be analyzed with respect to the optimum irradiation time, the optimum thickness and the minimum fuel cycle cost (the maximum profit), again comparing the predictions of simple models to more sophisticated (2DB-BRECON) calculations to extend the conclusions of the previous chapter regarding the effect of reactor size on BOL blanket characteristics.

First the general characteristics of the fissile buildup process in the LMFBR blanket will be discussed and a simple linear buildup approximation will be examined. Next an "equilibrium" core, which is fixed in composition during blanket burnup, will be devised. Then "equilibrium" core results from $2 \mathrm{DB}-\mathrm{BRECON}$ will be correlated against parameter groupings developed by analysis using the simple models. Correlations relating the optimum and breakeven irradiation times and the optimum thickness to parameters characterizing the economic environment a re displayed.

\subsection{DEPLETION ANALYSIS}

\subsubsection{Design of Equilibrium Core}

Based upon the approach described in Chapter 2, an equilibrium core and axial blanket were defined as a prelude to studies of radial blanket performance. The refueling interval for this equilibrium core and axial blanket system was assumed to be two years (actually 730 days 
at $82 \%$ load factor $=600$ full power days). This convention was adopted to insure that a more severe change in core characteristics could be accommodated than would generally be encountered in LMFBR's using the more likely yearly refueling. In this chapter, three reactor sizes (250 $\mathrm{MW}_{\mathrm{e}}, 1000 \mathrm{MW}_{\mathrm{e}}$, and $3000 \mathrm{MW}_{\mathrm{e}}$ ) each having two zone cores, will be examined. The calculation, using the $2 \mathrm{DB}$ burnup code (L1) with the 4-group cross sections previously described, proceeded as follows:

1. The initial fissile loading in the inner and outer core regions was approximated by extrapolation using the BOL critical loading and the reactivity loss after 100 full power days operation. The reactivity loss, $\Delta \mathrm{k} / \mathrm{k}$, was translated into changes in the fissile loading, $\Delta \mathrm{M} / \mathrm{M}$, , using the approximate relation (B4, W2):

$$
\frac{\Delta \mathrm{k}}{\mathrm{k}} \cong 0.5 \frac{\Delta \mathrm{M}}{\mathrm{M}}
$$

which was applied independently to each core zone.

2. By trial and error, the appropriate fissile loading, which gave $\mathrm{k}_{\mathrm{eff}} \cong 1.0$ at the end of the two-year period, was determined. The final loadings for three core sizes.are shown in Fig. 4.1 together with the variation of $k_{\text {eff }}$ with time; the linearity of $k_{\text {eff }}$ with time, as postulated in Chapter 2, is shown to be a rather good assumption.

3. The next step was to determine the time-averaged mean boron-10 pois on concentration, as indicated in Fig. 2.18. The effect of boron- 10 concentration changes on $\mathrm{k}_{\mathrm{eff}}$ was estimated using the following approximate formula (B4): 


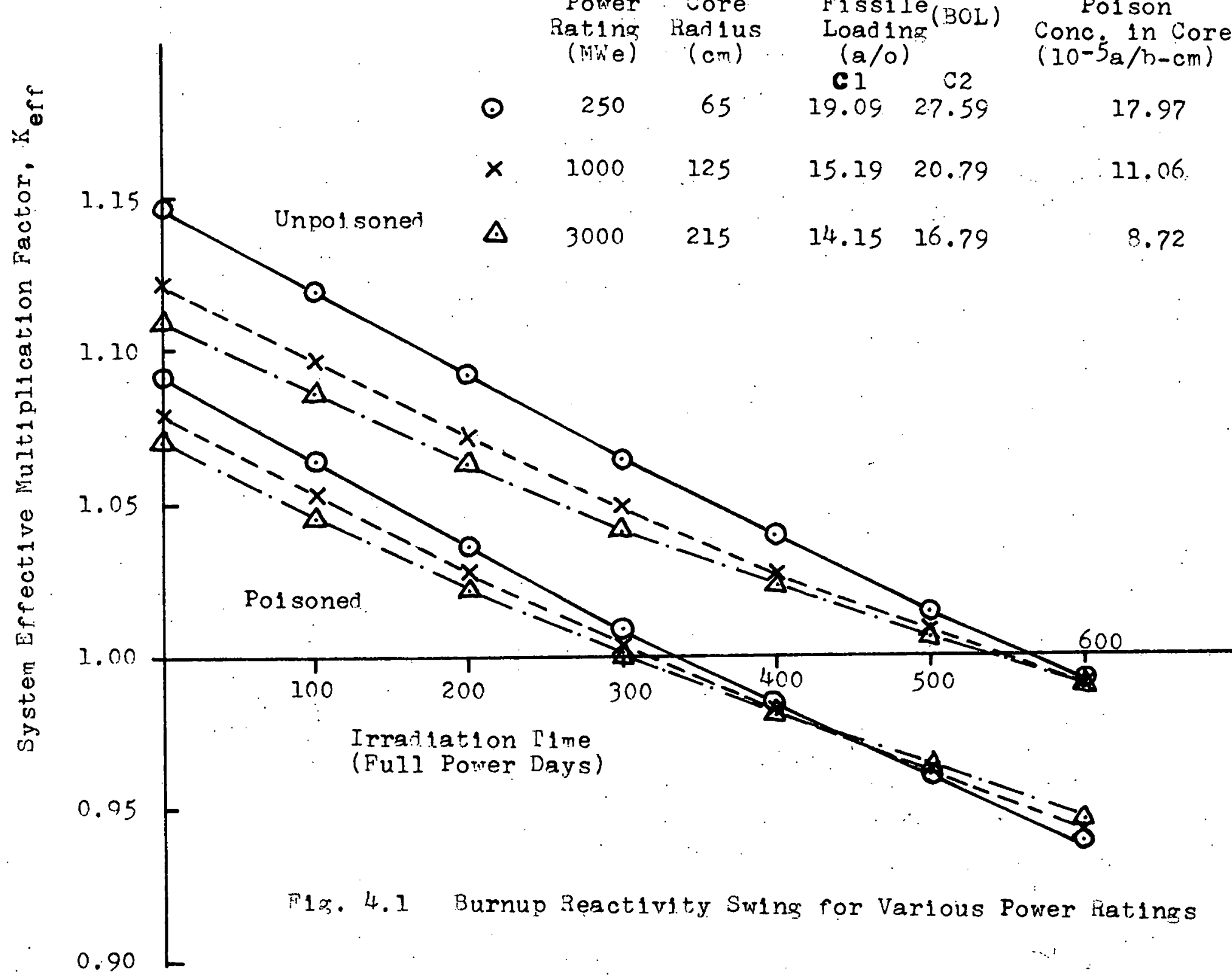

Two-Zone, Power Flattened, Blanketed Cores, Whole System (Core and Blanket) S3urned Up.

\begin{tabular}{|c|c|c|c|}
\hline $\begin{array}{l}\text { Power } \\
\text { Rating } \\
\text { (nke) }\end{array}$ & $\begin{array}{l}\text { Core } \\
\text { Rad 1 us } \\
(\mathrm{cm})\end{array}$ & $\begin{array}{l}\text { Fissile }(\mathrm{BOL}) \\
\text { Loading } \\
(\mathrm{a} / \mathrm{O})\end{array}$ & $\begin{array}{l}\text { Poison } \\
\text { Conc in Core } \\
\left(10^{-5} \mathrm{a} / \mathrm{h}-\mathrm{cm}\right)\end{array}$ \\
\hline
\end{tabular}

$\begin{array}{llllll}-250 & 65 & 19.09 & 27.59 & 17.97\end{array}$

$\begin{array}{lllll}1000 & 125 & 15.19 & 20.79 \quad \ldots 11.06\end{array}$

\begin{tabular}{llllll}
\hline & 3000 & 215 & 14.15 & 16.79 & 8.72
\end{tabular} 


$$
-\frac{\Delta \mathrm{k}}{\mathrm{k}} \cong 0.000437 \Delta \mathrm{B}
$$

where $\Delta B$ is the boron concentration increase in units of $10^{-5}$ atoms/barn-cm.

By trial and error, the final boron concentrations in three cores were determined to be $17.97,11.06$ and $8.72 \times 10^{-5}$ atoms/barn-cm; respectively, as shown in Fig. 4:1. A two-year burnup of the boronpoisoned core is also shown in Fig. 4.1, where $\mathrm{k}_{\text {eff }}$ now equals unity at about 300 full power days. The ratio of the boron concentration in the axial blanket to that in the core was set at $2.3: 1.0$, as discussed in Chapter 2. The use of a time-invariant pois on concentration over the burnup cycle is justified on the basis that there is no significant effect of boron control poison on the fissile inventory in the radial blanket. Figure 4.2 shows the fissile inventory in row 1 . of the radial blanket for three core sizes $\left(250,1000\right.$ and $3000 \mathrm{MW}_{\mathrm{e}}$ ) with and without boron control poison.

The "equilibrium" core and axial blanket system are defined to consist of the compositions at the $k_{\text {eff }}=1.0,300$-day point. Tables F. 13 (a), (b) and (c) in Appendix F list the nuclide concentrations in the two core zones and the single axial blanket zone (see also.Fig. 2.2) for the $1000-\mathrm{MW}$ e core obtained in this manner. The "equilibrium" core and axial blanket system for the other core sizes considered here, $250 \mathrm{MW}$ and $3000 \mathrm{MW}_{\mathrm{e}}$, were determined in the same manner.

Figure 4.3 shows the variation of the radial power flatness with burnup for the cores described above. As is shown, all of the BOL "equilibrium" core systems satisfy our arbitrary $\pm 5 \%$ criterion on 


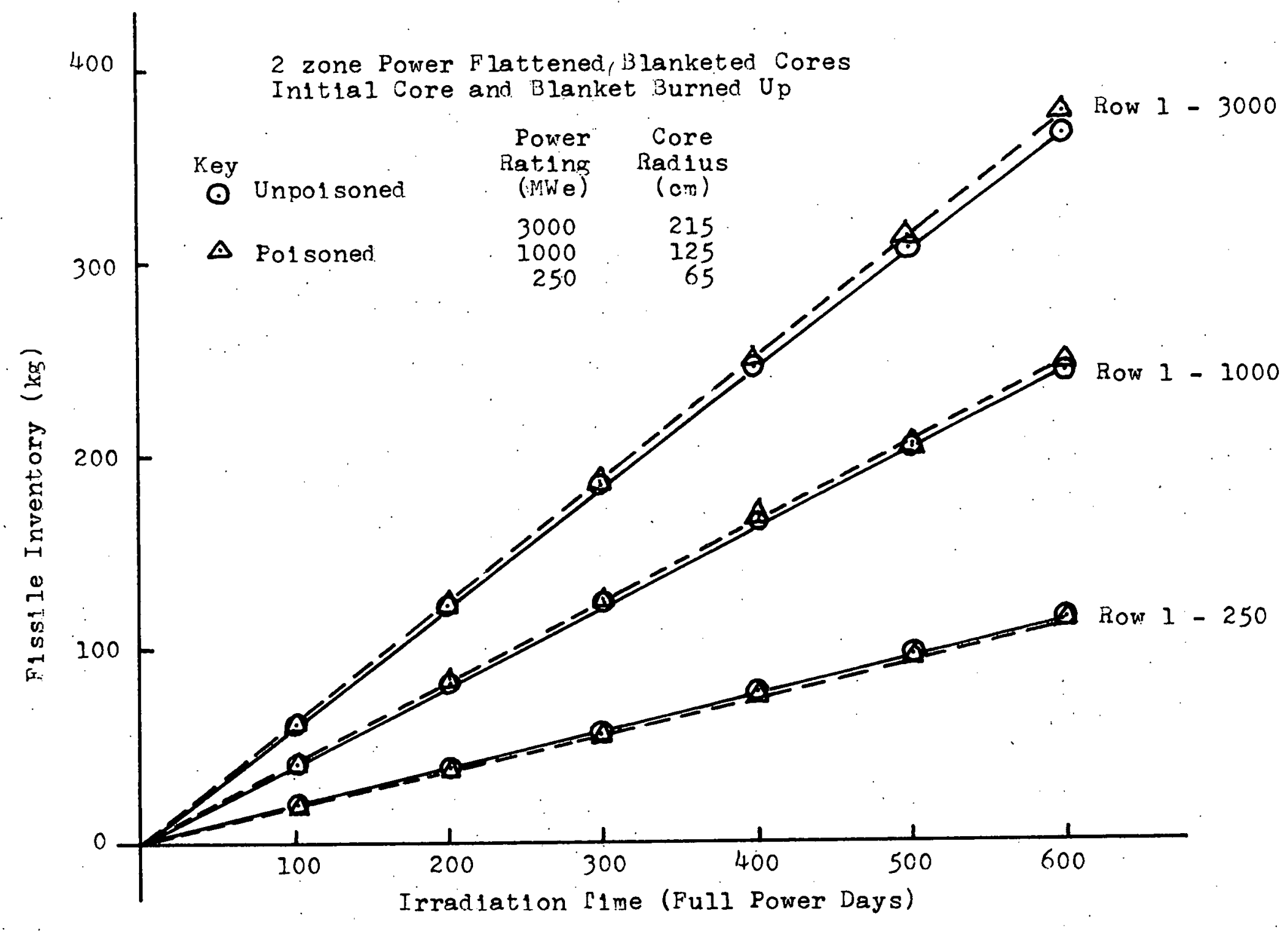

F1g. 4.2 The Effect of Boron Control Polson on the Fissile Inventory in Rom 1 of the Radial Blanket 


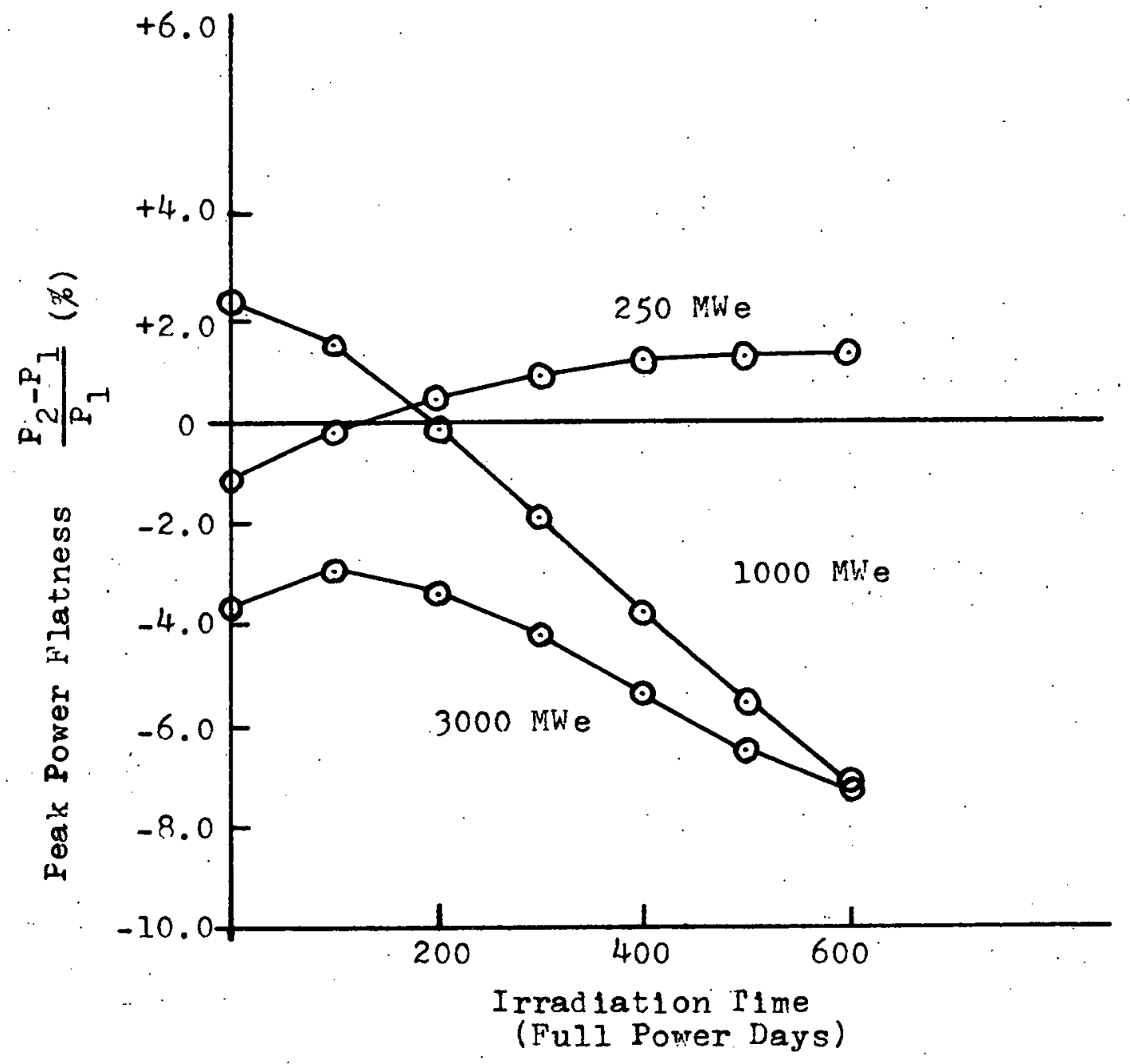

F1g. 4.3 Peak Power Flatness Changes Due To Irradiation for Various Power Ratines 
power flatness. However, since the larger cores violate this criterion at EOL, it would be necessary in practice to adjust the control poison to balance the zone power split. This was not done in the present case. Thus the sensitivity of blanket performance to power flatness must be examined. The "equilibrium" core and axial blanket system has been compared with three other core options: "Beginning of Life (BOL)", "End of Life (EOL)" and "Power-Flattened End of Life (EOL-PF)". Figure 4.4 shows the fissile inventory in the radial blanket driven by these four different cores. Figure 4.5 shows the fuel cycle cost contribution of row 1 in the radial blanket driven by these four different cores. As shown, the radial blanket driven by the "equilibrium" core (option $M-L$ in the figure) can simulate the behavior of the fissile inventory and the fuel cycle cost contribution in the radial blanket, row 1 , driven by any burnup-state of the core within $\pm 24 \mathrm{~kg}$ for the fissile inventory, and \pm 0.02 mills $/ \mathrm{kwhr}$ for the fuel cycle cost contribution, for the physical lifetime of the fuel assembly (here assumed to be 1800 full power days). For the local optimum point for row 1, the "equilibrium" core can predict the fissile inventory within $\pm 24 \mathrm{~kg}$, and the optimum irradiation time within 150 days (i.e., within half of a refueling interval) and the fuel cost within $\pm 0.02 \mathrm{mills} / \mathrm{kwhr}$, as shown in Table 4.1 .

The "Mid-Life" core with its peak power flattened within 5\% has therefore been adopted as the "Equilibrium" core, which is fixed in composition during the blanket burnup period (here assumed to be 1800 full power days). 


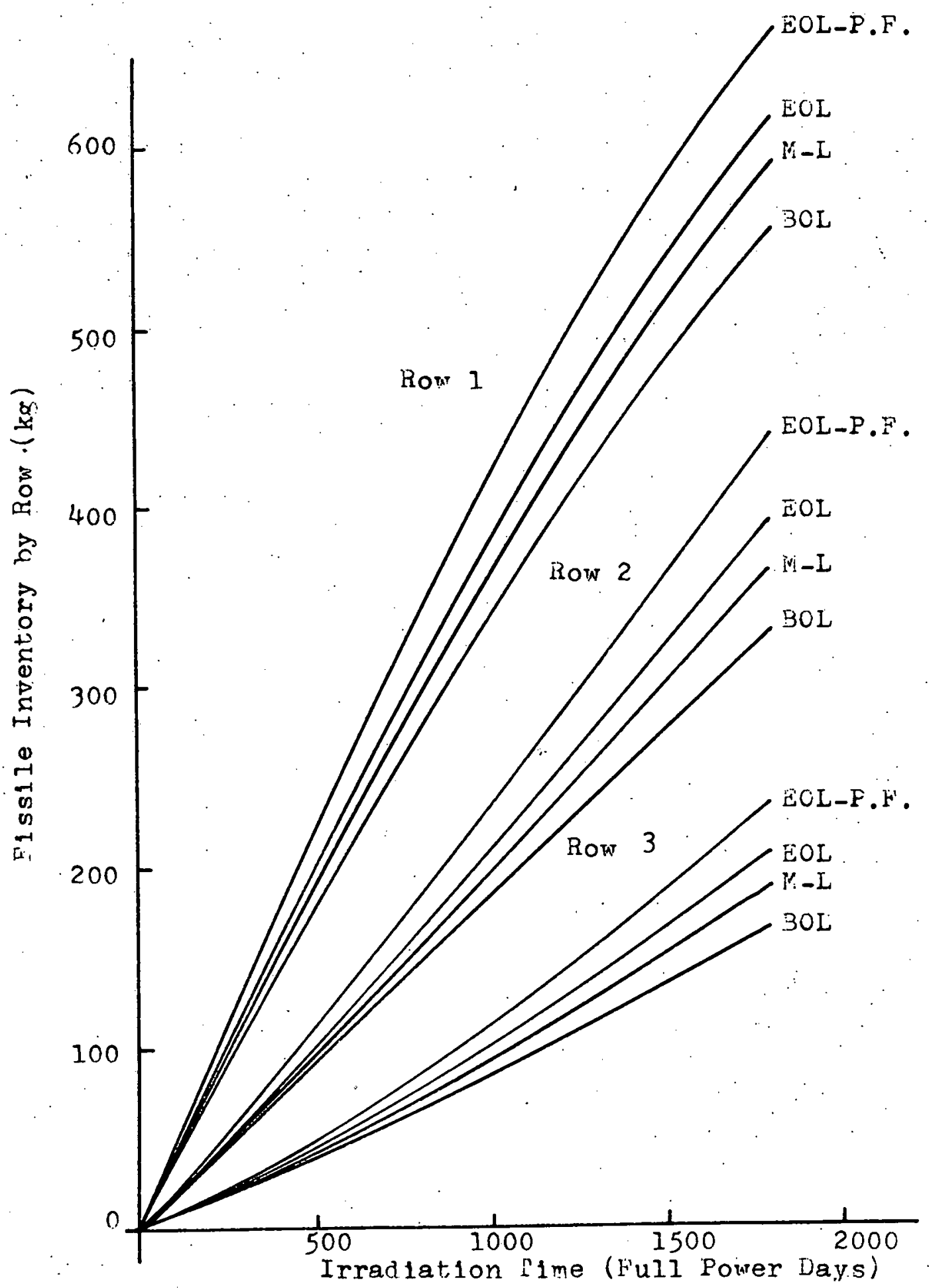

Fix. 4.4 The Effect of Core Conditions on the kow-by-Row Fissile Inventory of the Radial Blanket 


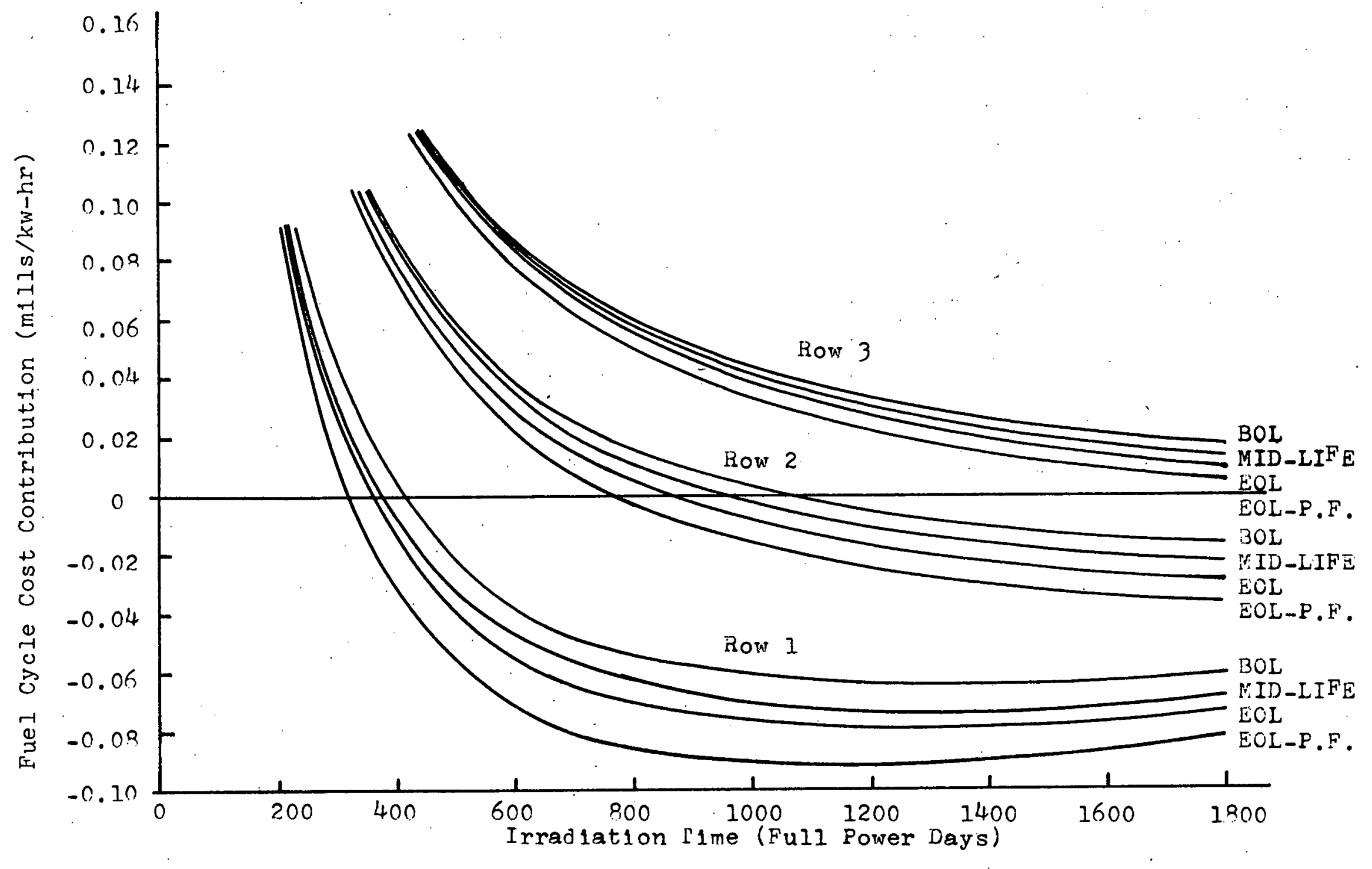

Fig. 4.5 The Effect of Core Conditions on the Fuel Cycle Cost Contribution 


\begin{tabular}{|c|c|c|c|c|}
\hline $\begin{array}{l}\text { Frozen Core Type } \\
\text { Items }\end{array}$ & "Equilibrium" & BOL & EOL & $\begin{array}{c}\text { EOL } \\
\text { Power-Flattened }\end{array}$ \\
\hline $\begin{array}{l}\text { Optimum } \\
\text { Irradiation Time } \\
\text { (Full Power Days) } \\
\text { (Difference)* }\end{array}$ & 1290 & $\begin{array}{l}1347 \\
(+57)\end{array}$ & $\begin{array}{l}1246 \\
(-44)\end{array}$ & $\begin{array}{c}1147 \\
(-143)\end{array}$ \\
\hline $\begin{array}{l}\text { Enrichment at } \\
\text { optimum } \\
\text { Irradiation Time (\%) } \\
\text { (Difference) }\end{array}$ & 4.44 & $\begin{array}{l}4.29 \\
(-915)\end{array}$ & $\begin{array}{l}4.50 \\
(+0.06)\end{array}$ & $\begin{array}{l}4.93 \\
(+0.49)\end{array}$ \\
\hline $\begin{array}{l}\text { Minimum Fuel } \\
\text { Cycle Cost } \\
\text { (mills/KwHr) } \\
\text { (Difference) }\end{array}$ & -0.0728 & $\begin{array}{l}-0.0655 \\
(-0.0073)\end{array}$ & $\begin{array}{l}-0.0790 \\
(-0.0062)\end{array}$ & $\begin{array}{l}-0.0910 \\
(-0.0182)\end{array}$ \\
\hline $\begin{array}{l}\text { Fissile Inventory } \\
\text { (KG) at Optimum } \\
\text { Irradiation Time } \\
\text { (Difference) }\end{array}$ & 453.7 & $\begin{array}{c}441.5 \\
(-12.2)\end{array}$ & $\begin{array}{l}463.2 \\
(+9.5) \\
\end{array}$ & $\begin{array}{l}477.1 \\
(+23.4)\end{array}$ \\
\hline
\end{tabular}

Table 4.1 Comparison of the optima for Row 1 of the

Radial Blanket for Various Frozen Composition cores 
4.2.2 Model of Fissile Material Buildup in the Blanket

Fissile material in the blanket, driven by a radially powerflattened (2-zone) "equilibrium" core, builds up at a nearly uniform rate at first, and then at a changing rate, depending on the location (i.e., at a very slowly decreasing rate for row 1 , at an essentially uniform rate for row. 2 , and at a very slowly increasing rate for row 3). Figures 4.6 and 4.7 show the 2DB-BRECON results for the fissile inventory history in each row of the radial blanket, which indicate that:

1). The fissile specific inventories ( $\mathrm{gPu} / \mathrm{kgHM}$ ) at $1800 \mathrm{full}$ power days are $50,30,13$ for rows 1,2 and 3 . In other words, the enrichment is $5 \%, 3 \%, 1.3 \%$, respectively.

2) The fissile specific buildup rate, $S_{0},(g P u / k g H M-y r)$ at $B O L$ are $10,4.5$ and 1.7 for rows $1, .2$ and 3 , which will determine the capability of producing net profit according to the criterion that $\mathrm{S}_{\mathrm{O}} \geqslant 2 \mathrm{gPu} / \mathrm{kgHM}-\mathrm{yr}$.

3) The fissile specific buildup rate at a given location in the radial blanket and at a given exposure time is essentially the same for all core sizes. (The moderate mismatch shown can be attributed to imperfect power-flattening over lifetime and the use of finite zoning instead of more nearly continuous fissile loading variations.) On the whole, the 2DB-BRECON calculations confirm that the fissile buildup rate in corresponding rows of the radial blanket is always the same for all radially power-flattened cores, not only at BOL but also over the whole lifetime of the blanket. 


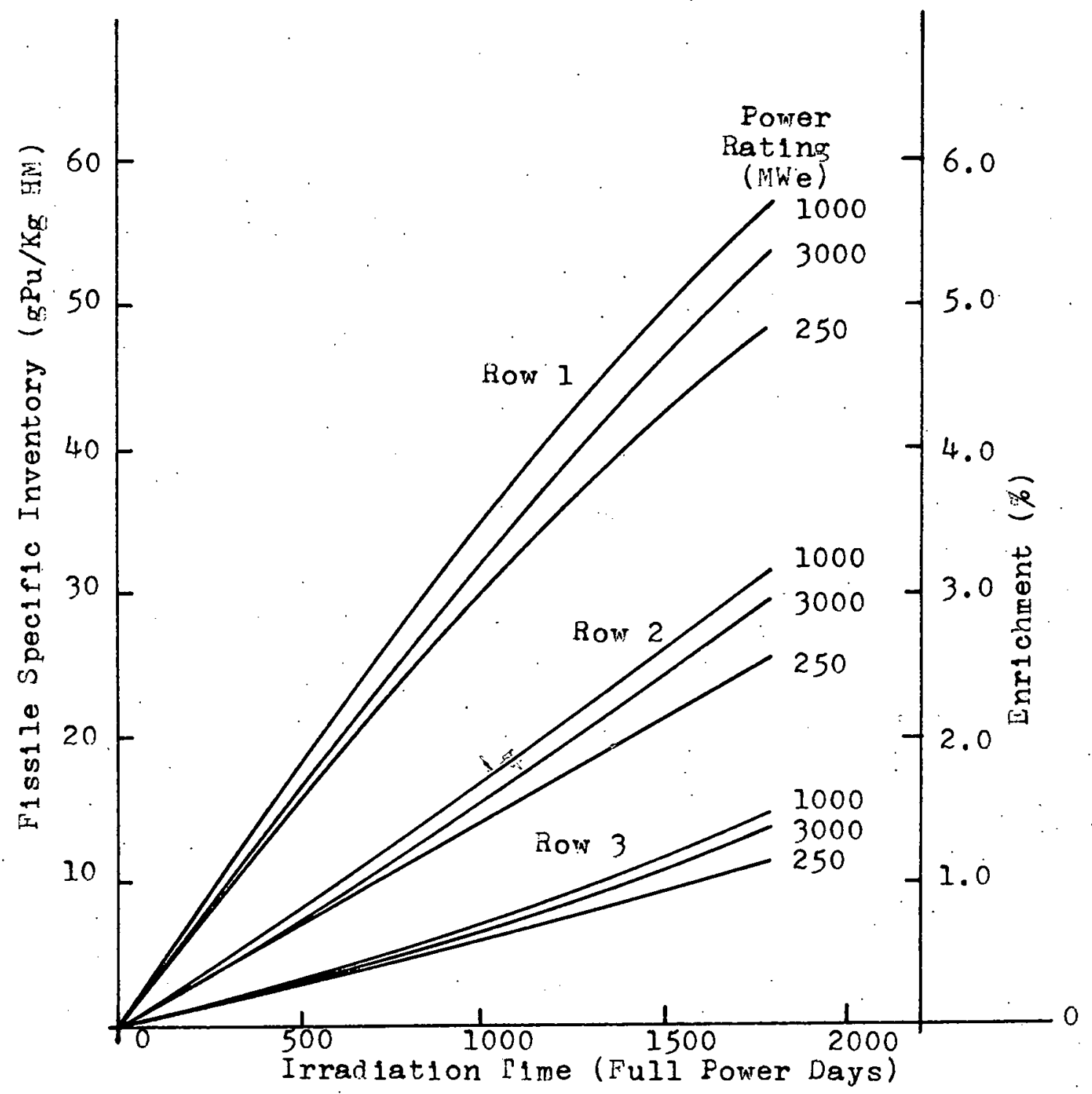

F1.9. 4.6 The Effect of Core Radius on the Row-by-Row Fissile Specific Inventory of the Radial Blanket 


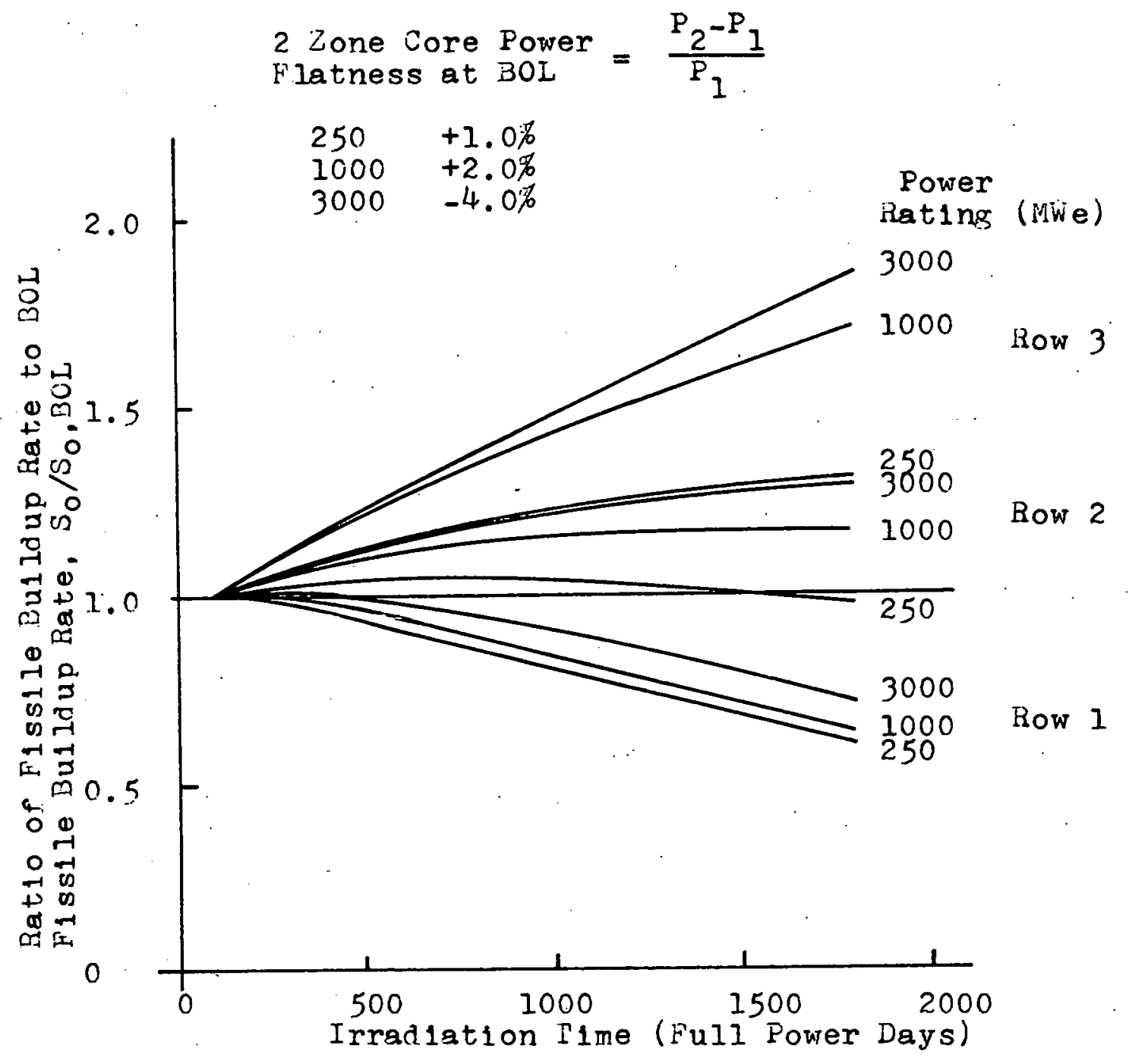

F1. 4.7 Burnup Dependence of the BOL-Normalized Fissile Buildup Rate Ratio for Various Power Ratings 
Some investigators (B4, W2) have approximated this behavior by a linear buildup model as shown in Fig. 4.8 (here applied to row 1 of the radial blanket driven by a $1000-\mathrm{MW}_{\mathrm{e}}$, 2-zone core). The linear buildup model can predict a qualitatively useful result, as discussed in the next section, but it fails to determine an accurate optimum ir radiation time (i.e., the observed difference of about 500 full power days for the optimum irradiation time violates the criterion that key times be determined within half a refueling interval $\simeq 150$ full power days):

It should be noted that the "fissile" material cited in this report does not include $\mathrm{Pu}^{241}$. This approximation is acceptable because the inventory of $\mathrm{Pu}^{241}$ in any row is less than $0.4 \%$ of $\mathrm{Pu}^{239}$ at 1800 full power days, as shown in Fig. 4.9.

\section{3 ECONOMIC ANALYSIS}

\section{3.1 Local Breakeven and Optimum Irradiation Times}

Figure 4.10 shows the row-by-row (designated as. "local") fuel cycle cost contribution as a function of irradiation for a typical radial blanket driven by a $1000-\mathrm{MW}_{\mathrm{e}}, 2-z$ one, radially power-flattened core. As shown, each row has its own breakeven irradiation time, which increases as the row is moved farther away from the core. Also, each : row has its own optimum irradiation time, which also increases as the row is moved farther from the core. The optimum point for row 3 does not occur until beyond 3000 full power days burnup. The minimum local cost is less (the profit is higher) in the row closest to the core. Many interesting questions are raised: What is the relation of the breakeven 


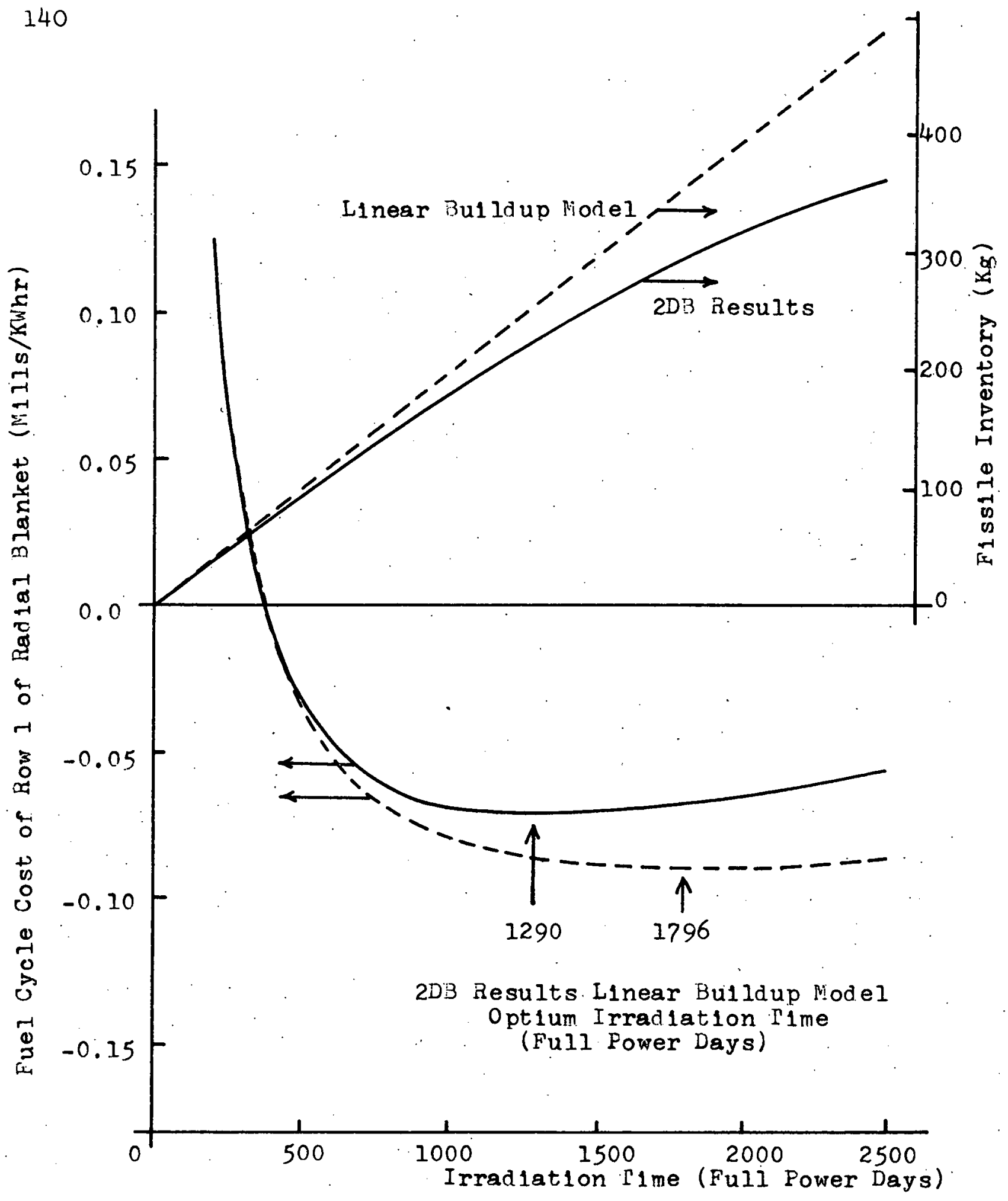

Fig. 4. 9 Comparison of 2DB-BRECON and Linear Models of Fissile Inventory Buildup and Fuel Cycle

Cost of Row 1 of the Radial Blanket ( 1000 MWe) 


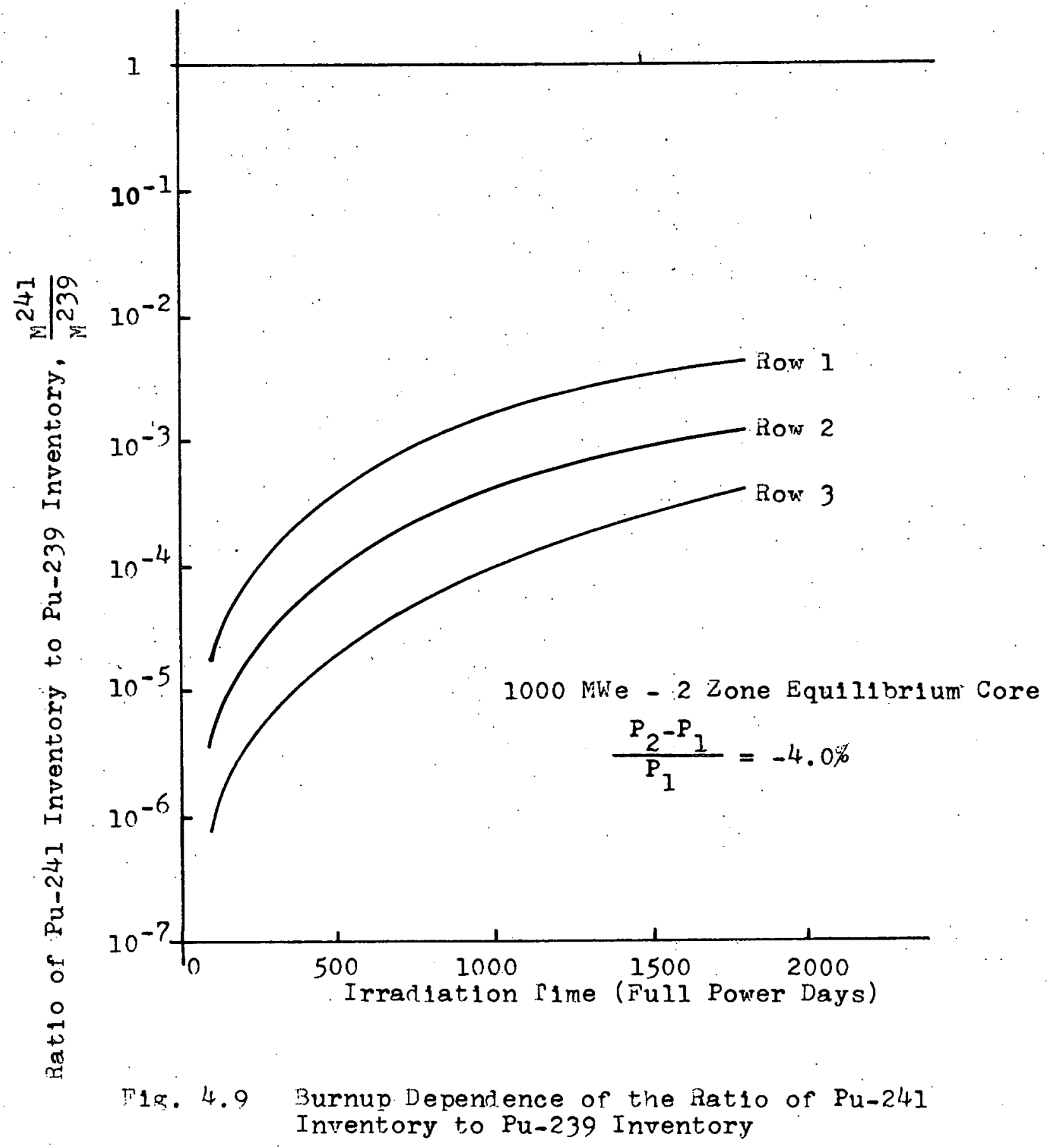




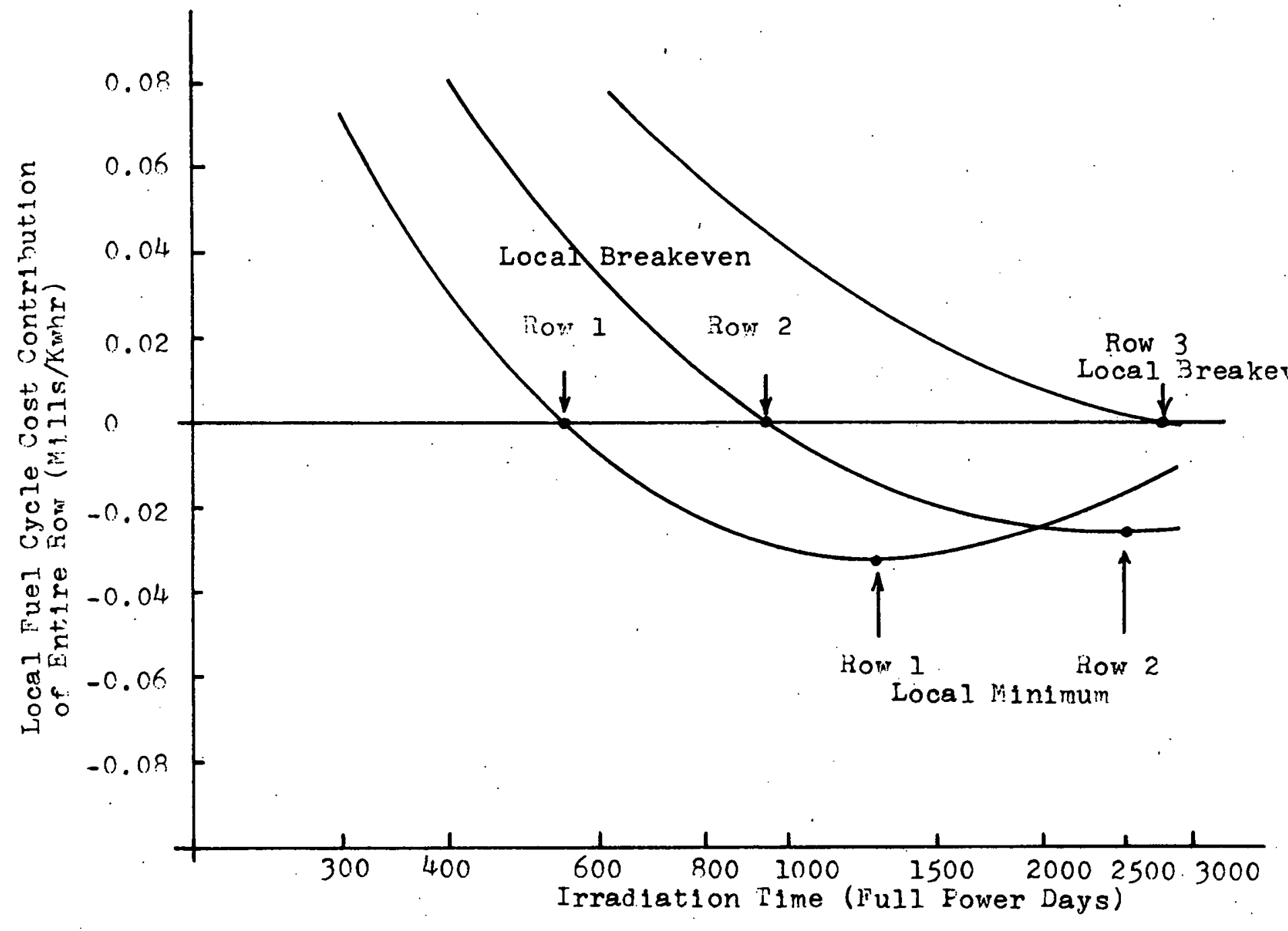

P1s. 4.10 The Effect of Blanket Row Position on Local Fuel Cycle Cost Contribution 
time and row position, the relation of the optimum time and row position, and the minimum local and whole blanket (designated as "total") costs? Each point will be addressed subsequently. We will consider first the effect of core radius on the breakeven and the optimum times and improve upon a correlation developed by Wood (W2) relating these parameters.

The observations in Chapter 3 that the BOL radial blanket fissile buildup rate density stays the same as core radius increases (for the idealized case of the radially power-flattened core), and the observation in the preceding section that the fissile specific buildup rate at a given location in the radial blanket and at a given exposure time is essentially the same for all core sizes, lead to the conclusion that the local breakeven and optimum irradiation time is the same for all core ratings. Figure 4.11 shows the effect of core radius on the local optimum irradiation time, which confirms that the local optimum irradiation time is independent of core radius within \pm half of a refueling interval (here assumed to be 300 full power days). Figure 4.11 also shows the effect of core radius on the local breakeven irradiation time, which indicates that the local breakeven irradiation time is also independent of core radius, again within \pm half of a refueling interval. The local optimum irradiation time for rows 2 and 3 and the local breakeven irradiation time for row 3 were not reached within 1500 full power days under the economic environment shown in Table 2.14. The reason for this will be explained later.

An approximate expression for the optimum irradiation time was derived in section 2.2.2.2, culminating in Eq. 2.26. Because of the 


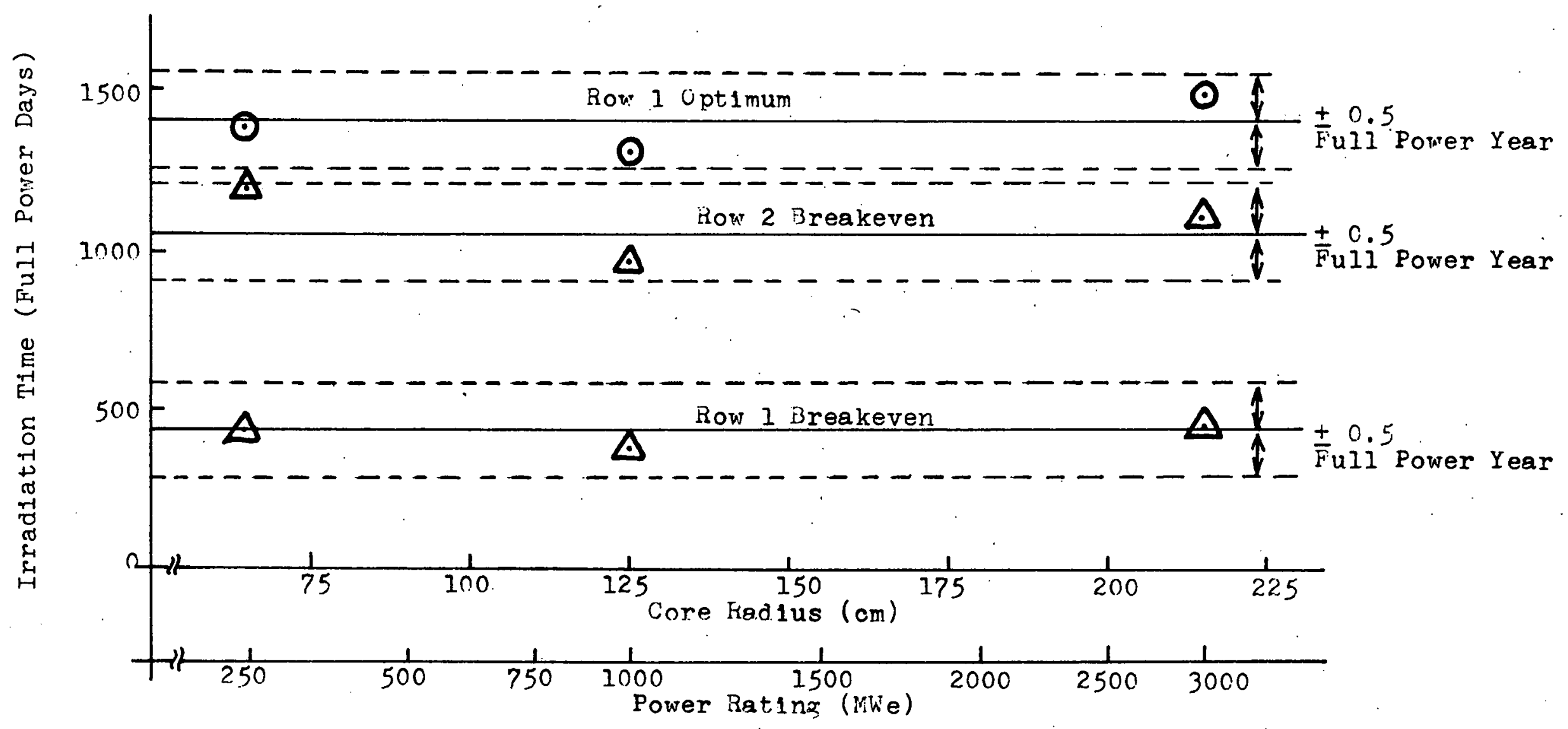

F13:4.11 The Effect of Core-Radius on the Optimum Irradiation Pime for Row 1 , and the Breakeven Irradiation Time for kows 1 and 2 , of the Radial Blanket 
large number of assumptions and omissions used in developing Eq. 2. 26, the actual equation would not be expected to apply on a quantitative basis. However, all of the more important economic parameters are included within Eq. 2.26. As a result, following the same line of reasoning as suggested by Wood (W2), one might expect that the optimum irradiation time would correlate against economic parameters such as:

$$
\mathrm{W}=\left[\frac{\mathrm{C}_{1} \mathrm{~F}_{1}\left(-\Delta \mathrm{T}_{1}\right)+\mathrm{C}_{2} \mathrm{~F}_{2}\left(\Delta \mathrm{T}_{2}\right)}{\mathrm{C}_{3} \mathrm{~F}_{3}\left(\Delta \mathrm{T}_{3}\right)}\right]
$$

and the discount rate, $X$. Because of the form of Eq. 2.26, this correlation might also be expected to be in the form:

$$
\mathrm{T}_{\text {opt }}=\mathrm{a}_{j} \mathrm{w}^{\mathrm{b}_{\mathrm{j}}} \mathrm{c}^{\mathrm{c}} \text {, }
$$

where $a_{j} b_{j}$ and $c_{j}$ are constants for the $j$-th region, to be obtained by correlating 2DB-BRECON output. The parameter, W, which characterizes the economic environment, differs slightly from Wood's parameter $\mathrm{N}_{\mathrm{E}}$ (W2) in that the discount rate has been separated out as a second independent variable. One has $\mathrm{N}_{\mathrm{E}} \mathrm{X}=\mathrm{W}$. As shown in Table 4.2, Wood did not consider a significant variation in discount rate, $X$, in his parameter studies. In the present work, checking the effect of a large change in discount rate on the correlation was considered worthwhile because of the recent large escalation in interest rates.

The variation in the discount rate was obtained by changing the bondholder's rate of return, $r_{b}$, and stockholder's rate of return, $r_{s}$, (with fixed values for their fractional contributions of $f_{b}=0.5$ and $\mathrm{f}_{\mathrm{S}}=0.5$, and for the income tax, $\tau=0.5$ ) as shown in Table 4. 3 . 


\begin{tabular}{|c|c|c|}
\hline PARAMETER (UNITS) & THIS STUDY & WOOD (W2) \\
\hline Value of fissile $\mathrm{P}_{\mathrm{u}}\left(\$ / \mathrm{gP} \mathrm{u}^{\prime}\right.$ & 6.0 to 14.0 & 6.0 to 16.0 \\
Fabrication charges $(\$ / \mathrm{Kg} \mathrm{HM})$ & 69 to 140 & 69 to 140 \\
Preprocessing charges $(\$ / \mathrm{Kg} \mathrm{HM})$ & 50 to 100 & 50 to 100 \\
Discount Rate (Year & \\
\hline
\end{tabular}

Table 4.2 Range of Variation of Economic Parameters 
4.3(A) Discount Rate

\begin{tabular}{|lllll|l|}
\hline$z$ & $r_{b}$ & $f_{b}$ & $r_{s}$ & $f_{s}$ & $x^{*}$ \\
\hline$\uparrow$ & 0.04 & $\uparrow$ & 0.06 & $\uparrow$ & 0.04 \\
& 0.07 & 0.5 & 0.125 & 0.5 & 0.08 \\
& 0.12 & $\downarrow$ & 0.18 & $\downarrow$ & 0.12 \\
& 0.16 & $\downarrow$ & 0.24 & $\downarrow$ & 0.16 \\
\hline
\end{tabular}

* Discount Rate: $x=(1-\tau) r_{b} f_{b}+r_{s} f_{s}$

4.3(B) Wood's Economic Parameter; $N_{E}$

$$
N_{E} \equiv\left[C_{1} F_{1}\left(-\Delta T_{1}\right)+C_{2} F_{2}\left(\Delta T_{2}\right)\right] /\left[C_{3} F_{3}\left(\Delta T_{3}\right) X\right]
$$

\begin{tabular}{|c|c|c|c|c|c|c|}
\hline बे/ & $C_{1}=69$ & $d c_{2}=50$ & SgHM & $C_{1}=14$ & and $\mathrm{C}_{2}$ & 100 \\
\hline$x \quad y / g \beta_{a}$ & 6 & 10 & 14 & 6 & 10 & 14 \\
\hline 0.04 & 0.5306 & 0.3184 & 0.2274 & & N.A & \\
\hline 0.08 & $0: 2653$ & 0.1592 & 0.1137 & 0.5353 & 0.3211 & 0.2294 \\
\hline 0.12 & 0.1990 & 0.1061 & 0.0788 & & N.A. & \\
\hline 0.16 & 0.1327 & 0.0796 & 0.0569 & & N.A. & \\
\hline
\end{tabular}

4.3(C) Modified Economic Parameter Used In Present Work, $\mathrm{W}=\mathrm{N}_{\mathrm{E}} \mathrm{X}$

\begin{tabular}{|c|ccc|ccc|}
\hline \multirow{2}{*}{$C_{1}, C_{2}$} & \multicolumn{3}{|l|}{$C_{1}=69$ and $C_{2}=50$} & \multicolumn{3}{|c|}{$C_{1}=140$ and $C_{2}=100$} \\
\cline { 2 - 7 } & 6 & 10 & 14 & 6 & 10 & 14 \\
\hline All $x$ & 0.02123 & 0.01274 & 0.0091 & 0.04282 & 0.02569 & 0.01835 \\
\hline
\end{tabular}

Table 4.3 Discount Rate, Wood's Economic Parameter and Modified Economic Parameter 
A series of economic analyses were made using the financial parameters appropriate for a typical private utility, as summarized in Table 4. 3 .

Economic optimum irradiation times for all cases were determined by fitting a parabola through the three points bracketing the minimum, differentiating with respect to irradiation time, setting the derivative equal to zero and solving the resulting linear equation for the irradiation time at which the fuel cycle cost contribution was a minimum. The optimum irradiation times for row 1 were then least-square fit to Eq. 4.4 to give:

$$
\mathrm{T}_{\text {opt }-1}=\left(9.22 \times 10^{3}\right) \cdot \mathrm{W}^{0.54} \mathrm{X}^{-0.15} \quad \text { (full power days). (4.5) }
$$

In a similar manner, a correlation for row 2 was obtained:

$$
\mathrm{T}_{\text {opt-2 }}=\left(7.75 \times 10^{3}\right) \mathrm{W}^{0.40} \mathrm{X}^{-0.24} \text { (full power days). (4.6) }
$$

The exponents, 0.54 and 0.40 , are in good agreement with the value 0.5 predicted by the simplified model of Chapter 2\% Figures 4.12 and 4.13 compare the optimum irradiation times predicted by Eqs. 4.5 and 4.6 to those generated by 2DB-BRECON. The agreement is excellent.

A similar procedure was followed in the case of the local breakeven ir radiation time except that linear interpolation was used to find the zero cost point using the two points on either side of zero. In this case, for rows 1 and 2 of the radial blanket, one obtains:

$$
\begin{aligned}
& \mathrm{T}_{\mathrm{BE}-1}=\left(8.75 \times 10^{4}\right) \mathrm{W}^{1.14} \mathrm{X}^{0.17} \text { (full power days), } \\
& \mathrm{T}_{\mathrm{BE-2}}=\left(8.55 \times 10^{5}\right) \mathrm{W}^{1.28} \mathrm{X}^{0.46} \quad \text { (full power days). }
\end{aligned}
$$

Figures 4.12 and 4.13 compare the "exact". BRECON results and Eqs. 4.5 and 4.6 for rows 1 and 2 of the radial blanket driven by the $1000-M W_{e}, 2-z o n e$ core. Again agreement is good. 


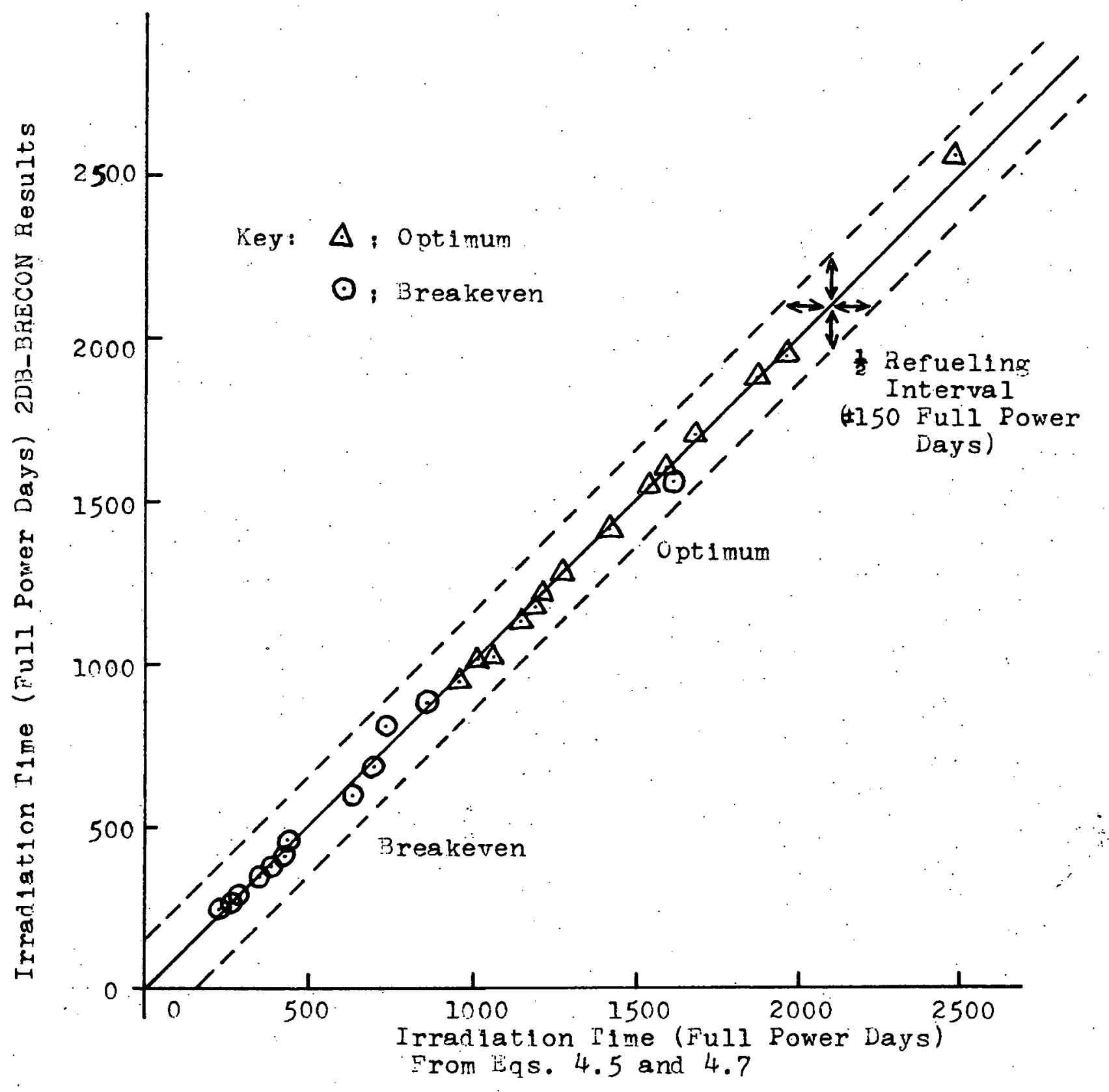

Fig. 4.12 Comparison of Opt1mum and Breakeven Irradiation Times for Radial Blanket - Row 1 Fredicted by Correlation and 2DB-BiECON 


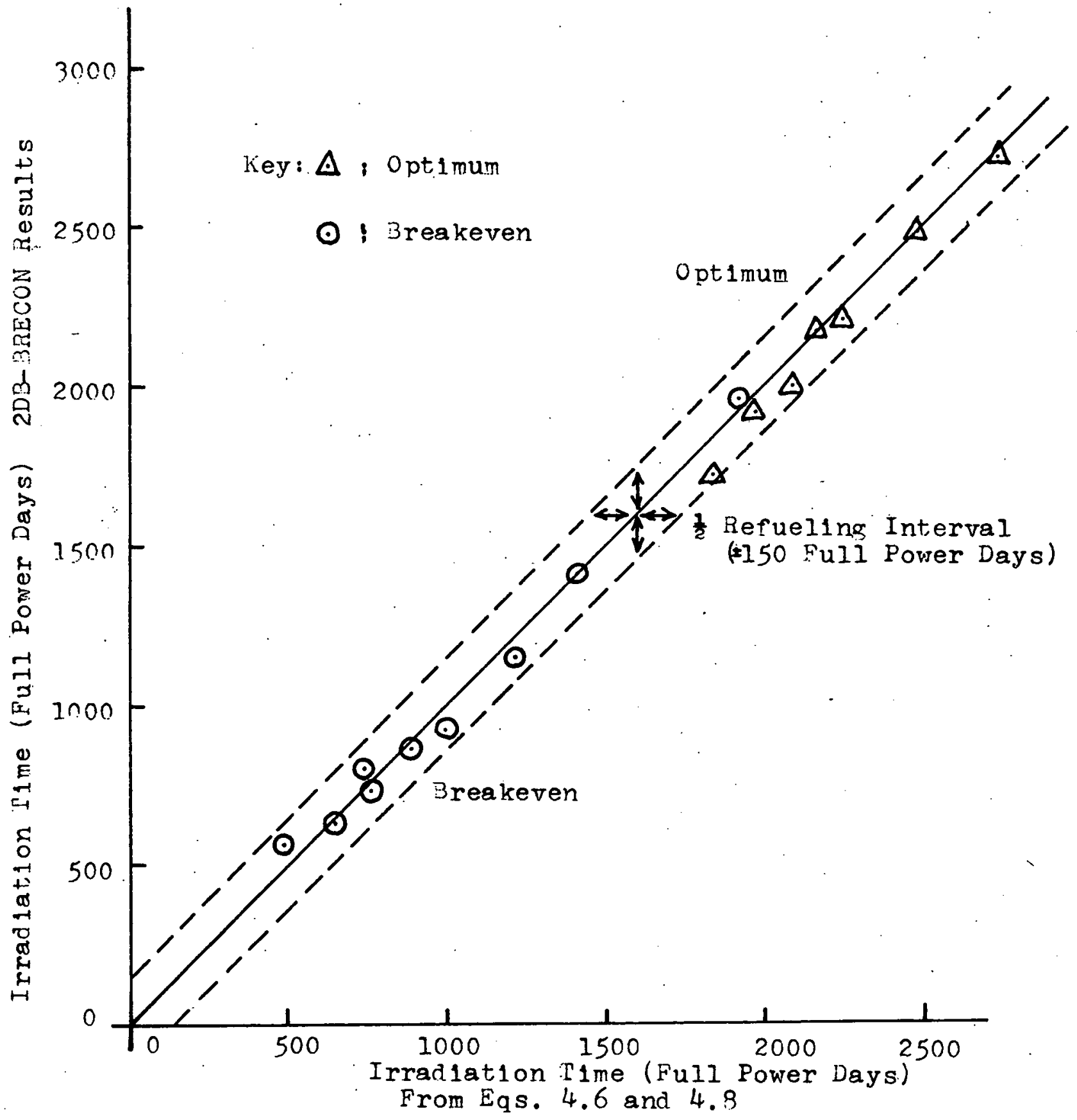

T1\%. 4.13 Comparison of Optimum and Breakeven Irradiation imes for Radial 3lanket - Row 2 Predicted by Correlation and 2D.3-9RECON 
The relationships between the local breakeven and the local optimum irradiation times obtained from Eq. 4.5 and Eq. 4.7 for row 1 and from Eq. 4.6 and Eq. 4.8 for row 2 are:

$$
\begin{aligned}
& \mathrm{T}_{\mathrm{BE}-1}=\left(3.73 \times 10^{-4}\right) \mathrm{T}_{\text {opt }} 2.11 \mathrm{X}^{0.49}, \\
& \mathrm{~T}_{\mathrm{BE}-2}=\left(3.06 \times 10^{-7}\right) \mathrm{T}_{\text {opt }} 3.20 \mathrm{X}^{1.23} .
\end{aligned}
$$

Again this is in good qualitative agreement with the approximate model derived in Chapter 2 and Appendix E. An a.lternate form can be derived in which the discount rate is eliminated:

$$
\begin{aligned}
& \mathrm{T}_{\mathrm{BE}-1} \cdot \mathrm{T}_{\text {opt-1}} \cong\left(8.07 \times 10^{8}\right) \mathrm{W}^{1.68} \quad{\text { (full power days })^{2}} \\
& \mathrm{~T}_{\mathrm{BE}-2} \cdot \mathrm{T}_{\text {opt-2 }} \cong\left(6.63 \times 10^{9}\right) \mathrm{W}^{1.68} \quad(\text { full power days })^{2}
\end{aligned}
$$

\subsubsection{Local Minimum Fuel Cycle Cost Contribution}

The local minimum fuel cycle cost contribution, which occurs at the optimum irradiation time (by definition) or at the end of the useful life of the fuel assembly (here taken to be 1800 full power days $\simeq 6$ calendar years) is shown in Fig. 4.14, which indicates that the local minimum power cost contribution from an entire blanket row decreases as the core radius increases. This is in good qualitative agreement with the predictions of the one-group model in section 2.2 . It should be noted that the local minimum fuel cycle cost contribution from row 1 is smaller (the profit is larger) than that from row 2 and so on, because the fissile buildup rate in the blanket rows near the core is larger than. for those farther away from the core. In the example shown, row 3 


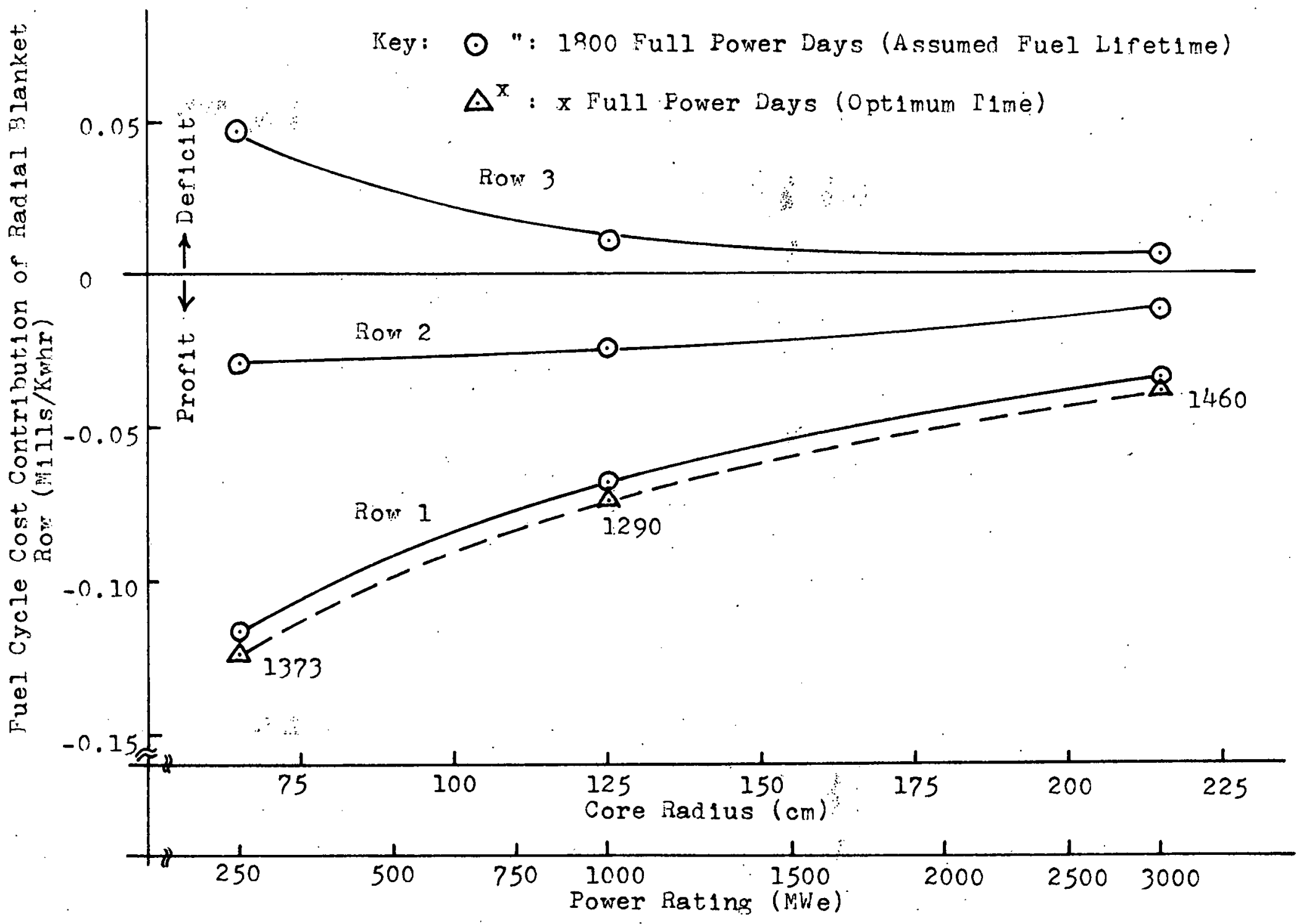

Fig. 4.14 The Effect of Core Radius on the Minimum Fuel Cycle Cost Contribution From the Radial Blanket 
never becomes profitable. Also interesting is that the absolute value of the local minimum fuel cycle cost contribution from each profitable row of the radial blanket surrounding a core of large radius is smaller than that for the corresponding row of a similar blanket on a core of smaller radius.

Figure 4.15 shows the revenue per unit mass of heavy metal (i. e., $\$ / \mathrm{kgHM}$, hence per assembly) for each row as a function of core radius. As expected, the revenue per assembly is the same for all radii.

Figure 4.16 shows the local cost for an entire row as a function of distance into the blanket for given irradiation times. As expected, the local cost increases (the profit decreases) as the distance increases. This trend holds true as irradiation time increases, except that the slope gradually changes. The intersection of this curve and the zero local cost line defines the local breakeven and batchirradiated whole-blanket optimum irradiation conditions .

Figure 4.17 shows the variation of the local breakeven and optimum irradiation times with position, which indicates that the local irradiation time increases exponentially as the distance into the blanket increases. For a given irradiation time, this "local breakeven" curve gives the total optimum thickness in the sense that a batchmanaged blanket having this thickness has the minimum total cost (the profit is a maximum) at this irradiation time.

The intersection of the "local breakeven" curve and the abscissa (i.e., at the core/blanket interface) is the local breakeven irradiation time of the innermost slice of the blanket, which we have designated as 


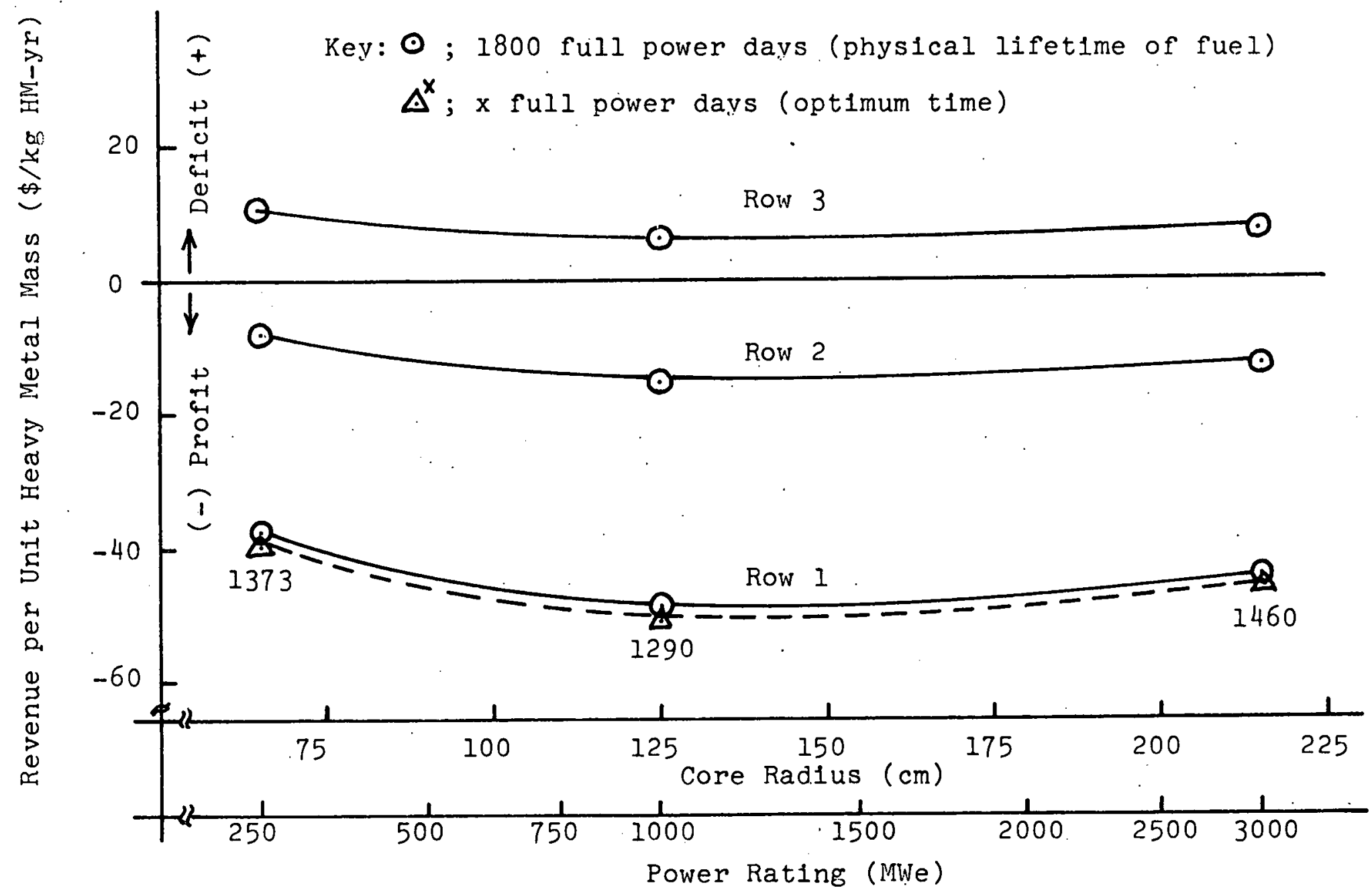

Fig. 4.15 The Effect of Core-Radius on Revenue (Def1c1t) per Assembly in the Radial Blanket 


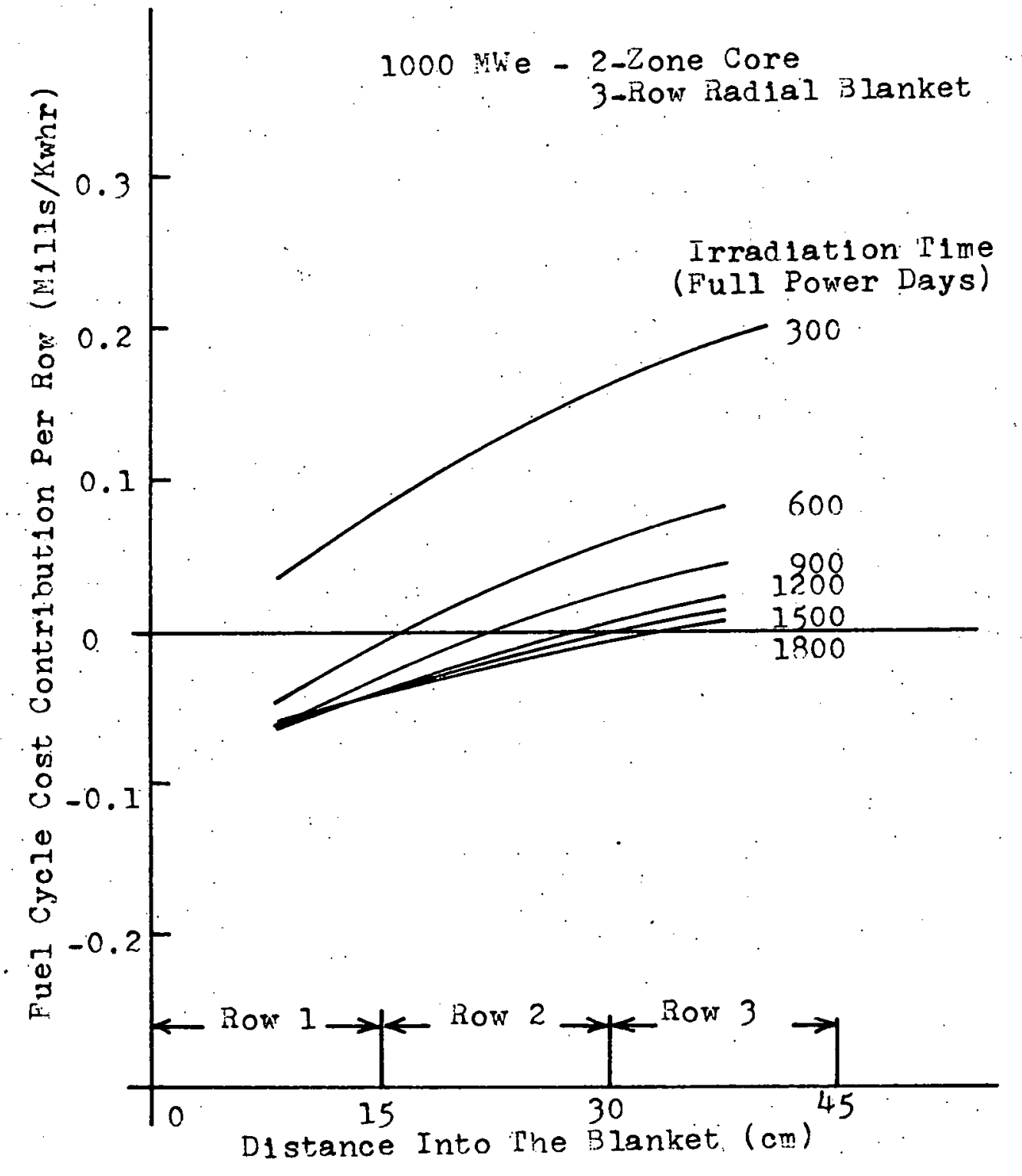
Fir. 4.16 Fuel Cycle Cost Contribution Per Row
as a Function of Blanket Thickness 


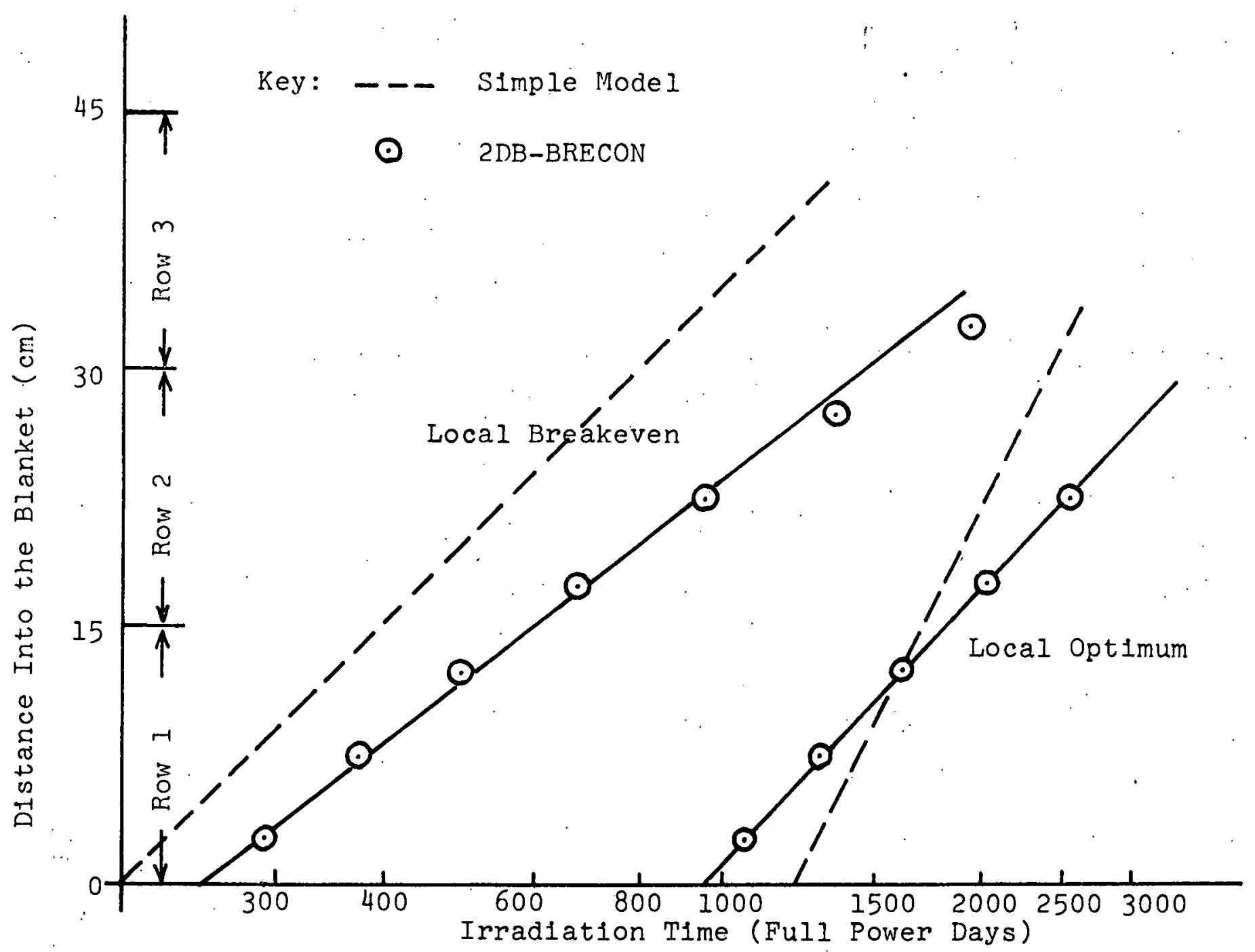

Fig. 4.17 Local Breakeven and Local Optimum Positions as a Function of Irradiation. Time 
point $P$ in Appendix $E$, where a simple analytical model is employed to. derive the approximate relation:

$$
\mathrm{T}_{\mathrm{BE}, \mathrm{P}}=\frac{\mathrm{W}}{\mathrm{S}_{\mathrm{O}}(0)}
$$

Using the data for a reference economic environment of Table 2.14, one has $T_{B E, P}=196$ full power days, which compares favorably to the $2 \mathrm{DB}-\mathrm{BRECON}$ result of 245 full power days, considering the unsophisticated nature of the model.

As shown in Fig. 4.10, a row is most profitable (the minimum. local cost) at the local optimum irradiation time: both before and beyond that time, the profit is less. This local optimum time also increases as distance into the blanket increases. Figure 4.17 also shows the local optimum irradiation time as a function of distance into the blanket, which indicates that the local optimum irradiation time also increases exponentially as the distance increases. Again this has been predicted by the analysis outlined in Chapter 2 and Appendix C. The semi-log gradient of the "local optimum" curve is 1.2 and that of the "local breakeven" curve is 0.8 , which are comparable with the predicted values of 2.0 and 1.0 from the analysis discussed earlier. The intersection of the "local optimum" curve and the abscissa, called point $Q$ in the present work, can be estimated as:

$$
T_{\text {opt }, Q} \cong \sqrt{\frac{2 W}{S_{o}(0) X}}
$$

Using the data for a reference economic environment of Table 2.14, one obtains $T_{\text {opt }, Q} \cong 1211$ full power days, which agrees fairly well with the 2DB-BRECON result of 950 full power days. 
Figure 4:18 shows the local minimum fuel cycle cost contribution of each row (solid line) or per unit volume (dotted line). As can be seen, the local minimum cost for an inner row is less than that for an outer row (the profit is higher), as expected. While this figure resembles Fig. 4.16 in some respects, it should be noted that the irradiation time for each row is different on this figure (i.e., all points correspond to optimum times).

The intercept of this local minimum cost-distance curve and the zero local cost line, which is designated point $M$ in the present work, does not occur within the irradiation interval considered (1800 full power days) under a representative economic environment (discount rate, $\mathrm{X}=0.08 ; \mathrm{Pu}$ price, $\left.\mathrm{C}_{3}=10 \$ / \mathrm{gPu}\right)$. As described in Appendix $\mathrm{E}$, the location of point $\mathrm{M}$ can be approximated as:

$$
\begin{aligned}
& \mathrm{T}_{\mathrm{M}}=\frac{1}{\mathrm{X}}, \\
& \tau_{\mathrm{M}}=\frac{1}{\gamma} \ln \left[\frac{\mathrm{S}_{\mathrm{o}}(0)}{2 \mathrm{WX}}\right] .
\end{aligned}
$$

Using the data for the reference economic condition of Table 2.14, one can obtain $T_{M}=12.5$ full power years and $\tau_{M}=45.2 \mathrm{~cm}$.

In order to realize a net profit from a given zone of the blanket, the fissile specific buildup rate in that zone, $\bar{S}_{0}$, should be greater than a certain amount, which is determined for a given set of economic conditions by the following formula, derived in Appendix $\mathrm{E}$ :

$$
\bar{S}_{0} \geqslant 2 W X
$$

where

$\overline{\mathrm{S}}_{\mathrm{O}}$ is the fissile specific buildup rate (gPu/kgHM-yr).

$\mathrm{W}$ is the economic index defined in Eq. 4. 3

$\mathrm{X}$ is the discount rate defined in Eq. 2.56. 
Key: $\mathcal{\odot}$; per row basis

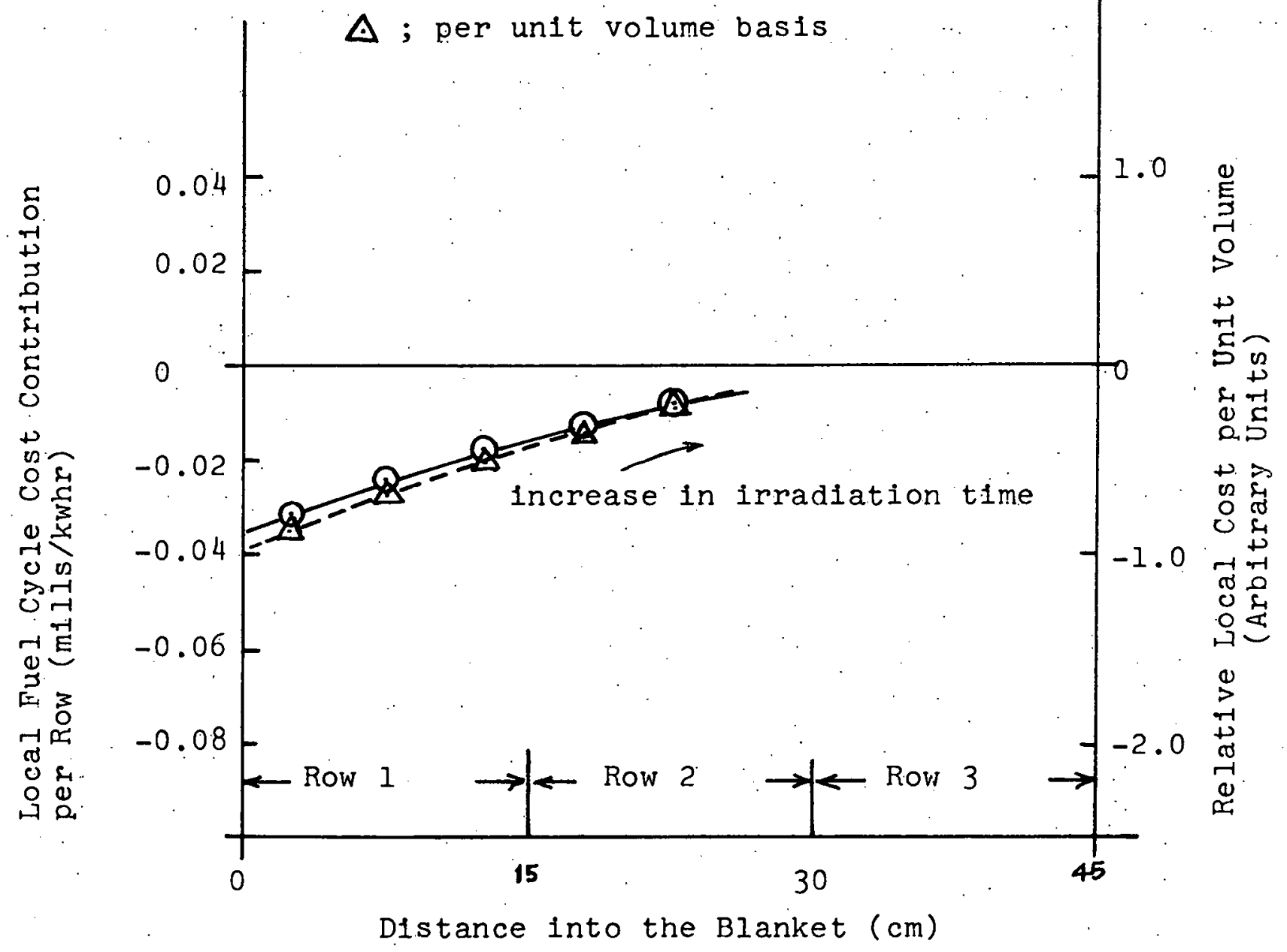

Fig. 4.18 Minimum Local Fuel Cycle Cost Contribution as a Function of Blanket Thickness 
Using the data in Table 2.14 , one can obtain $\overline{\mathrm{S}}_{\mathrm{o}} \geqslant 2(\mathrm{gPu} / \mathrm{kgHM}-\mathrm{yr})$. As seen from Fig. 4.19, the fissile specific buildup rates for rows 1 and 2 are greater than this minimum required fissile specific buildup rate of $2(\mathrm{gPu} / \mathrm{kgHM}-\mathrm{yr})$, but the rate for 3 is not. This helps to explain why rows 1 and 2 can achieve breakeven within a reasonable time interval, while row 3 cannot, as was shown in Fig. 4.10. It should be noted, however, that row 3 could achieve breakeven at 2800 full power days since the fissile specific buildup rate eventually exceeds the minimum rate at somewhat over 500 full power days. As can be seen from Eq. 4.16, the minimum profitable fissile specific buildup rate, which occurs at the position of optimum batch-irradiated blanket thickness, is determined by economic conditions. For example, the minimum profitable fissile specific buildup rate decreases as $\mathrm{W}$ decreases ( $\mathrm{Pu}$ price increases or fabrication and reprocessing costs decrease) or the discount rate increases; one can then afford to deploy thicker blankets.

\section{3. 3 Breakeven and Optimum Irradiation Times of an Entire Blanket}

Figure 4.20 shows the variation of the whole-blanket (called "total") fuel cycle cost contribution with irradiation, to be contrasted with Fig. 4.10, which applies to local (i.e., row) costs: otherwise, both curves are similar in appearance. Blankets having different thicknesses have their own total breakeven and total optimum batch irradiation times. Hence, in the same manner as for the local breakeven and optimum times, one can correlate total blanket breakeven and optimum irradiation times as functions of the economic parameter, $\mathrm{W}$, and the discount rate, $X$. 


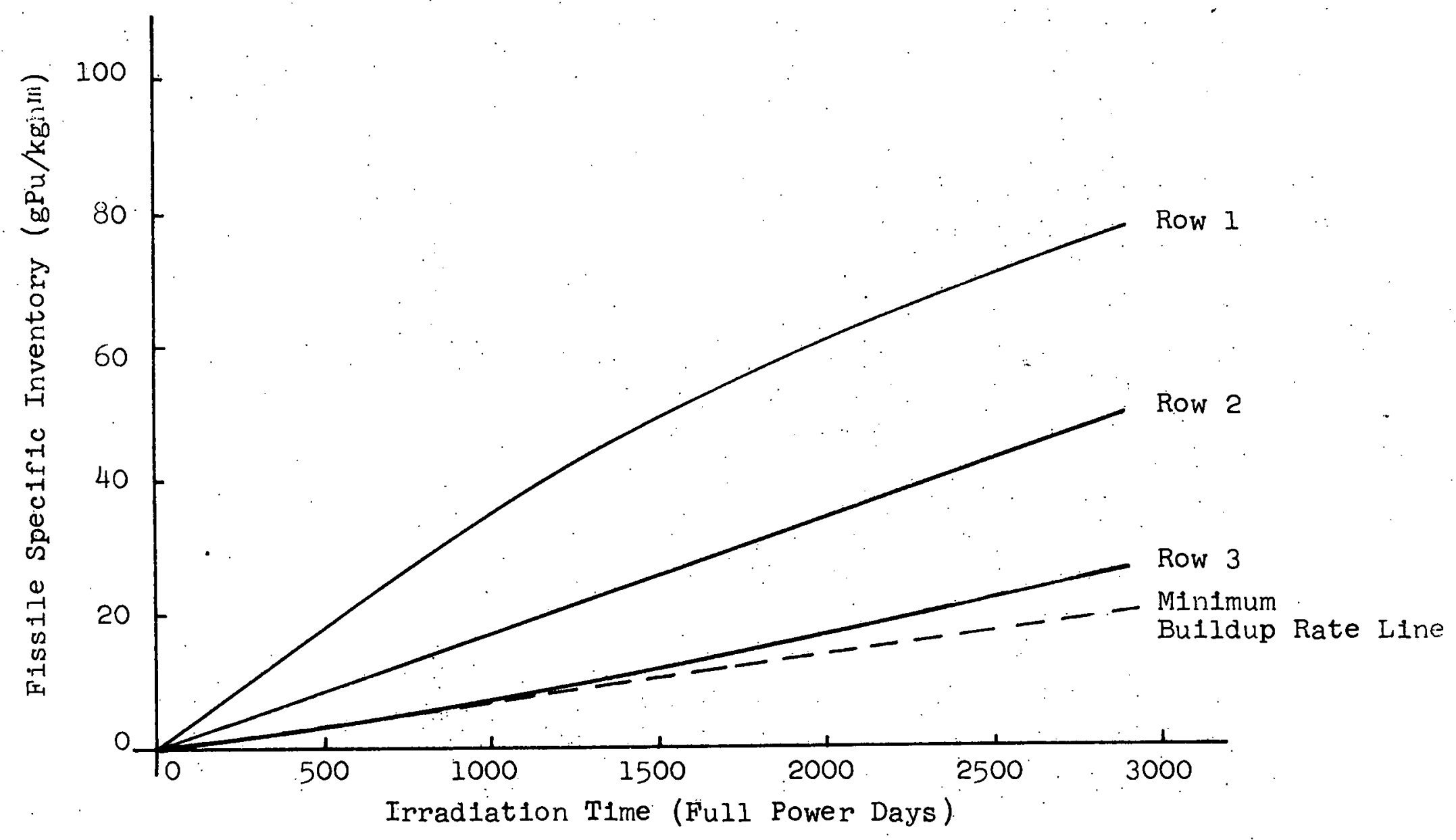

Fig. 4.19 Row-by-Row Fissile Specific Inventory and Minimum Profitable Fissile Specific Bulldup Rate 


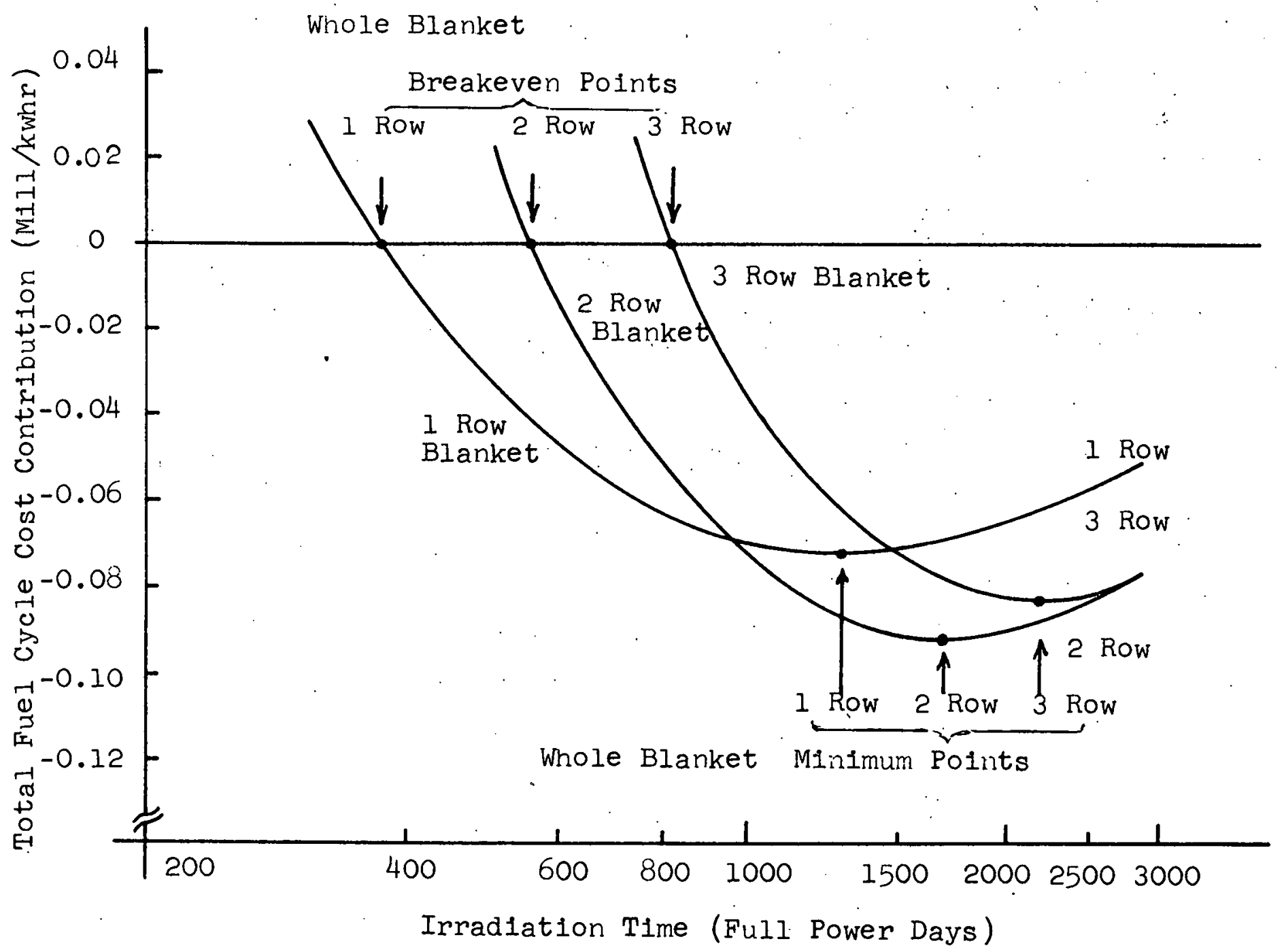

Fig. 4.20 The Effect of Blanket Thickness on the Total Full Cycle Cost Contribution (Reference Case of Table 2.14). 
For a given thickness, the total blanket optimum irradiation time, $\mathrm{T}_{\text {opt }}$, which is defined as the time when the total fuel cycle cost contribution of the entire blanket is the minimum (the total profit is the maximum), can be expressed in the form:

$$
\begin{aligned}
& \mathrm{T}_{\text {opt-2 }}=\left(1.03 \times 10^{4}\right) \mathrm{W}^{0.52} \mathrm{X}^{-0.18} \text { for the 2-row blanket, } \\
& \mathrm{T}_{\text {opt-3 }}=\left(1.02 \times 10^{4}\right) \mathrm{w}^{0.50} \mathrm{X}^{-0.24} \text { for the 3-row blanket. }
\end{aligned}
$$

The one-row blanket result is, of course; the same as the "local" row 1 result, Eq. 4. 5. A similar procedure was followed in the case of the breakeven irradiation time to obtain:

$$
\begin{aligned}
& \mathrm{T}_{\mathrm{BE}-2}=\left(3.46 \times 10^{5}\right) \mathrm{W}^{1.30} \mathrm{X}^{0.28} \text { for the 2-row blanket, } \\
& \mathrm{T}_{\mathrm{BE}-3}=\left(7.53 \times 10^{5}\right) \mathrm{W}^{1.34} \mathrm{X}^{0.40} \text { for the 3-row blanket. }
\end{aligned}
$$

Figures 4.21 and 4.22 compare the total optimum and breakeven irradiation times predicted by Eqs. 4.17 and 4.19 for the two-row blanket and by Eqs. 4.18 and 4.20 for the three-row blanket, respectively. The agreement is excellent.

The points outside the dotted lines in Figs. 4.21 and 4.22 are. breakeven points for high discount rate $\left(X=0.12 \mathrm{yr}^{-1}\right)$ and low $\mathrm{Pu}$ price $\left(\mathrm{C}_{3}=6 \$ / \mathrm{gPu}\right)$ and for very high discount rate $\left(\mathrm{X}=0.16 \mathrm{yr}^{-1}\right)$ and reference Pu price $\left(\mathrm{C}_{4}=10 \$ / \mathrm{gPu}\right)$ (see Table F.23 in Appendix F). Table 4.4 summarizes the coefficients $a_{j}, b_{j}$ and $c_{j}$ of the correlation in the general formula:

$$
T=a_{j} w^{b_{j}} c_{j}
$$




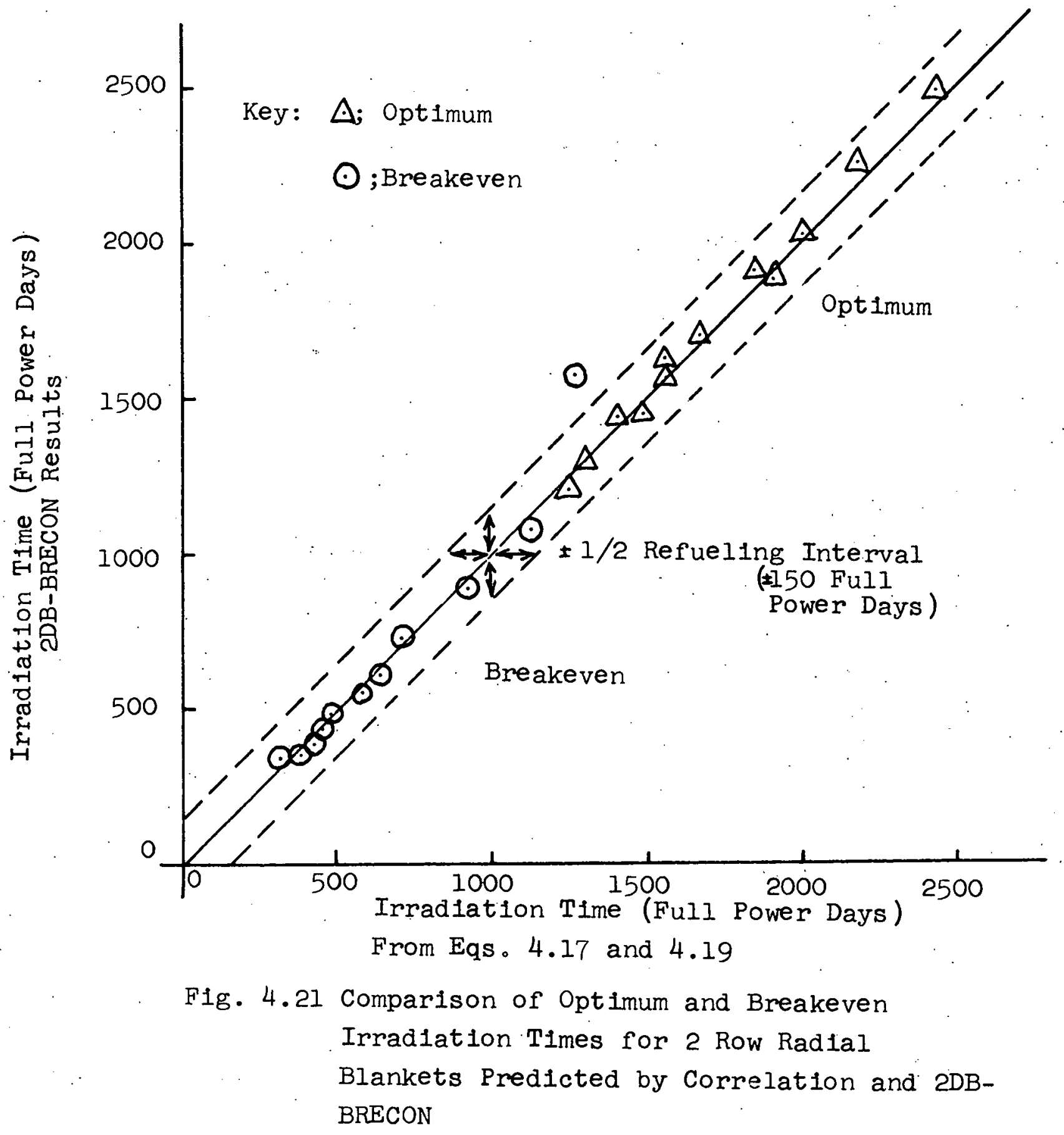




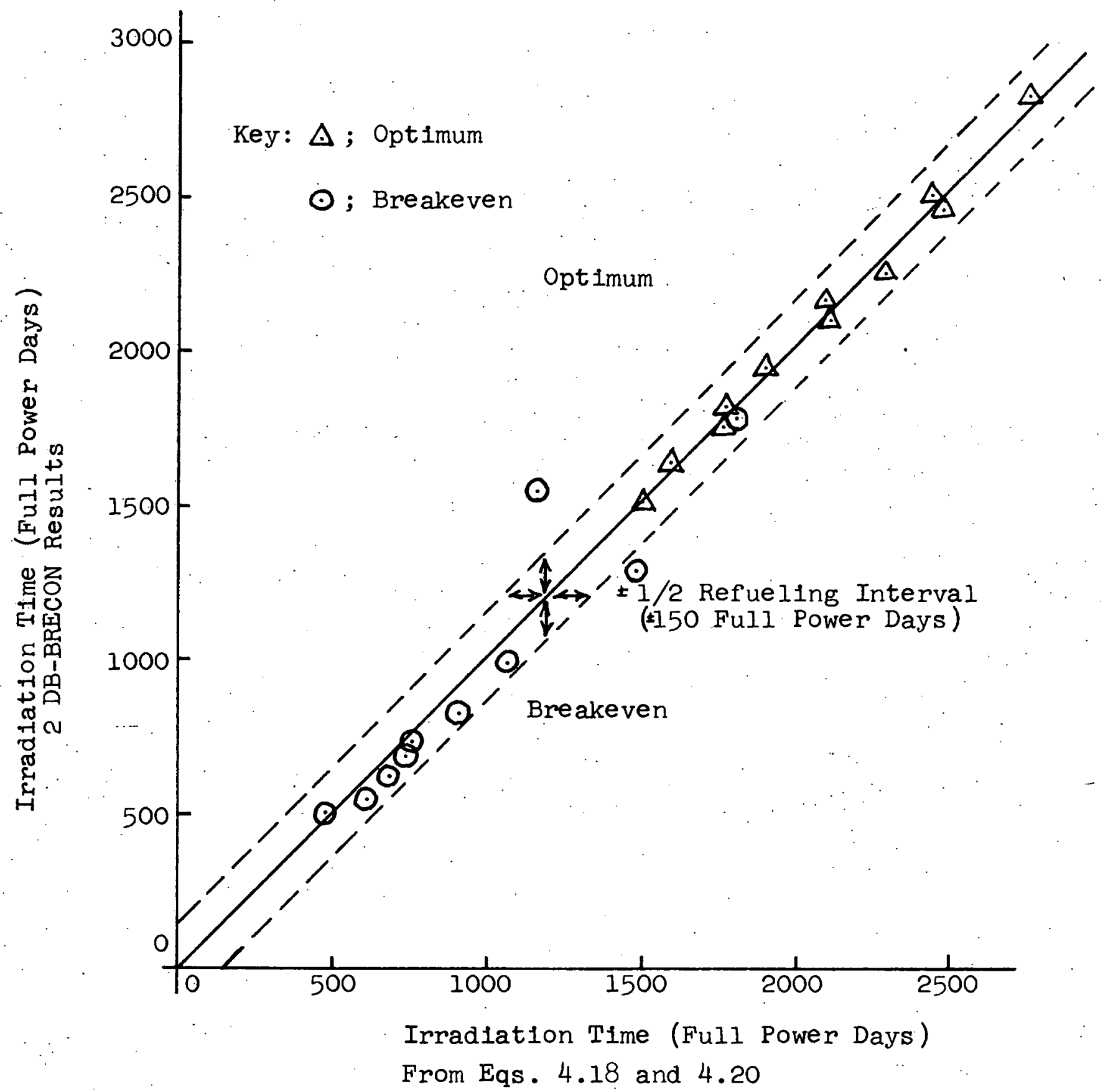

Fig. 4.22 Comparison of Optimum and Breakeven Irradiation Times for 3 Row Radial Blankets Predicted by Correlation and $2 \mathrm{DB}-\mathrm{BRECON}$ 


\begin{tabular}{|c|c|c|c|c|c|c|c|c|}
\hline & \multicolumn{3}{|c|}{ Simplified Model } & \multicolumn{3}{|c|}{ 2DB-BRECON } \\
\hline & & & & $b_{j}$ & $c_{j}$ & $a_{j}$ & $b_{j}$ & $c_{j}$ \\
\hline \multirow{2}{*}{ 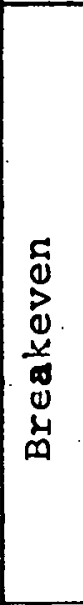 } & $\begin{array}{l}7 \\
0 \\
0 \\
0\end{array}$ & $\begin{array}{ll}\text { Row } & 1 \\
\text { Row } & 2 \\
\text { Row } & 3\end{array}$ & \multirow{2}{*}{$\begin{array}{l}\quad \times 10 \\
2.64 \\
6.38 \\
10.8 \\
2.64 \\
38.2 \\
53.4 \\
\end{array}$} & \multirow{2}{*}{1.0} & \multirow{2}{*}{0.0} & $\begin{array}{r}x] \\
8.75 \\
85.5\end{array}$ & $\begin{array}{l}1.14 \\
1.28\end{array}$ & $\begin{array}{l}0.17 \\
0.46\end{array}$ \\
\hline & 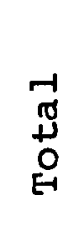 & $\begin{array}{ll}1 & \text { Row } \\
2 & \text { Row } \text { Blanket } \\
3 & \text { Row } \\
\end{array}$ & & & & $\begin{array}{l}8.75 \\
34.6 \\
75.3 \\
\end{array}$ & $\begin{array}{l}1.14 \\
1.30 \\
1.34 \\
\end{array}$ & $\begin{array}{l}0.17 \\
0.28 \\
0.40 \\
\end{array}$ \\
\hline \multirow{2}{*}{ 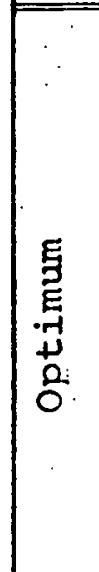 } & $\begin{array}{l}-17 \\
0 \\
0 \\
0\end{array}$ & $\mid \begin{array}{ll}\text { Row } & 1 \\
\text { Row } & 2 \\
\text { Row } & 3\end{array}$ & \multirow{2}{*}{\multicolumn{2}{|c|}{$\begin{array}{c}\times 10^{3} \\
3.98 \\
6.19 \\
10.0\end{array}$}} & \multirow{2}{*}{-0.5} & $\begin{array}{r}x] \\
9.22 \\
7.75\end{array}$ & $\begin{array}{l}0.54 \\
0.40\end{array}$ & $\begin{array}{l}-0.15 \\
-0.24\end{array}$ \\
\hline & $\begin{array}{l}7 \\
0 \\
+1 \\
0 \\
0\end{array}$ & $\begin{array}{l}\text { I Row Blanket } \\
2 \text { Row Blanket } \\
3 \text { Row Blanket }\end{array}$ & & & & $\begin{array}{l}9.22 \\
10.3 \\
10.2\end{array}$ & $\begin{array}{l}0.54 \\
0.52 \\
0.50\end{array}$ & $\begin{array}{l}-0.15 \\
-0.18 \\
-0.24\end{array}$ \\
\hline
\end{tabular}

Table 4.4 Comparison of the Correlations:

$\mathbf{T}=a_{j}{ }^{b^{j}} \times{ }^{c_{j}}$

Predicted by the Simplified Model to those obtained by Curve Fitting 2DB-BRECON Results 
It should be noted that the correlation for row 1 has the same form for the "local" and "total" cases.

The relations between the total breakeven and the total optimum irradiation times obtained from Eq. 4.17 and Eq. 4.19 for row 2 and from Eq.“4.18 and Eq . 4.20 for row 3 are:

$$
\begin{aligned}
& \mathrm{T}_{\mathrm{BE}-2}=\left(3.21 \times 10^{-6}\right)\left(\mathrm{T}_{\text {opt }-2}\right)^{2.50} \mathrm{X}^{0.73} \\
& \mathrm{~T}_{\mathrm{BE}-3}=\left(1.36 \times 10^{-5}\right)\left(\mathrm{T}_{\text {opt }-3}\right)^{2.68} \mathrm{X}^{1.04}
\end{aligned}
$$

In a similar manner, an alternative form can be derived in which the discount rate is eliminated:

$$
\begin{aligned}
& \mathrm{T}_{\mathrm{BE}-2} \cdot \mathrm{T}_{\text {opt }-2} \cong\left(3.56 \times 10^{8}\right) \mathrm{W}^{1.82}{\text { (full power days })^{2},} \\
& \left.\mathrm{~T}_{\mathrm{BE}-3} \cdot \mathrm{T}_{\text {opt }-3} \cong\left(7.68 \times 10^{9}\right) \mathrm{W}^{1.84} \text { (full power days }\right)^{2} .
\end{aligned}
$$

Table 4.5 summarizes the coefficients $p_{j}, q_{j}$ and $r_{j}$ of the correlation in the general form:

$$
T_{B E}=p_{j} T_{o p t}{ }^{q_{j}} x^{r_{j}}
$$

As shown, thicker blankets have larger breakeven and optimum batch irradiation times. Figure 4.23 shows the relationship between the total blanket breakeven and optimum irradiation times and the blanket thickness, demonstrating that both times increase exponentially as the blanket thickness increases.

The semilog slope for the "optimum" curve is 3.1 and that for the: "breakeven". curve is 2.3 , which compare fairly well with the predicted values of 4.0 and 2.0 from the analysis discussed in Appendix E. 


\begin{tabular}{|c|c|c|c|c|c|}
\hline \multicolumn{3}{|c|}{ Coefficients } & $\underline{p}_{j}$ & $q_{j}$ & $r_{j}$ \\
\hline \multicolumn{3}{|c|}{ Model Prediction } & $1.67 \times 10^{-3}$ & 2.0 & 1.0 \\
\hline \multirow{2}{*}{ 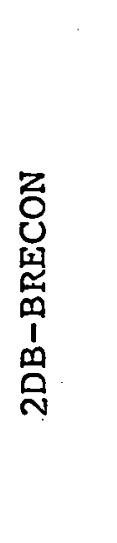 } & $\begin{array}{l}\overrightarrow{1} \\
\text { ठ } \\
\text { ○ }\end{array}$ & $\begin{array}{l}\text { Row } 1 \\
\text { Row } 2 \\
\text { Row } 3\end{array}$ & $\begin{array}{c}3.73 \times 10^{-4} \\
3.06 \times 10^{-7} \\
\mathrm{NA}\end{array}$ & $\begin{array}{l}2.11 \\
3.20 \\
\mathrm{NA}\end{array}$ & $\begin{array}{c}0.49 \\
1.23 \\
\text { NA }\end{array}$ \\
\hline & 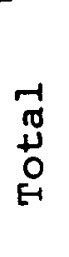 & $\begin{array}{l}1 \text { Row } \\
2 \text { Row } \\
3 \text { Row }\end{array}$ & $\begin{array}{l}3.73 \times 10^{-4} \\
3.21 \times 10^{-6} \\
1.36 \times 10^{-5}\end{array}$ & $\begin{array}{l}2.11 \\
2.50 \\
2.68\end{array}$ & $\begin{array}{l}0.49 \\
0.73 \\
1.04\end{array}$ \\
\hline
\end{tabular}

Table 4.5 Comparison of the Correlations:

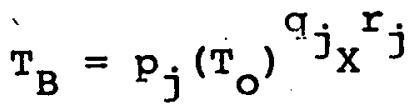

predicted by the Simplified Model and 2DB - BRECON 


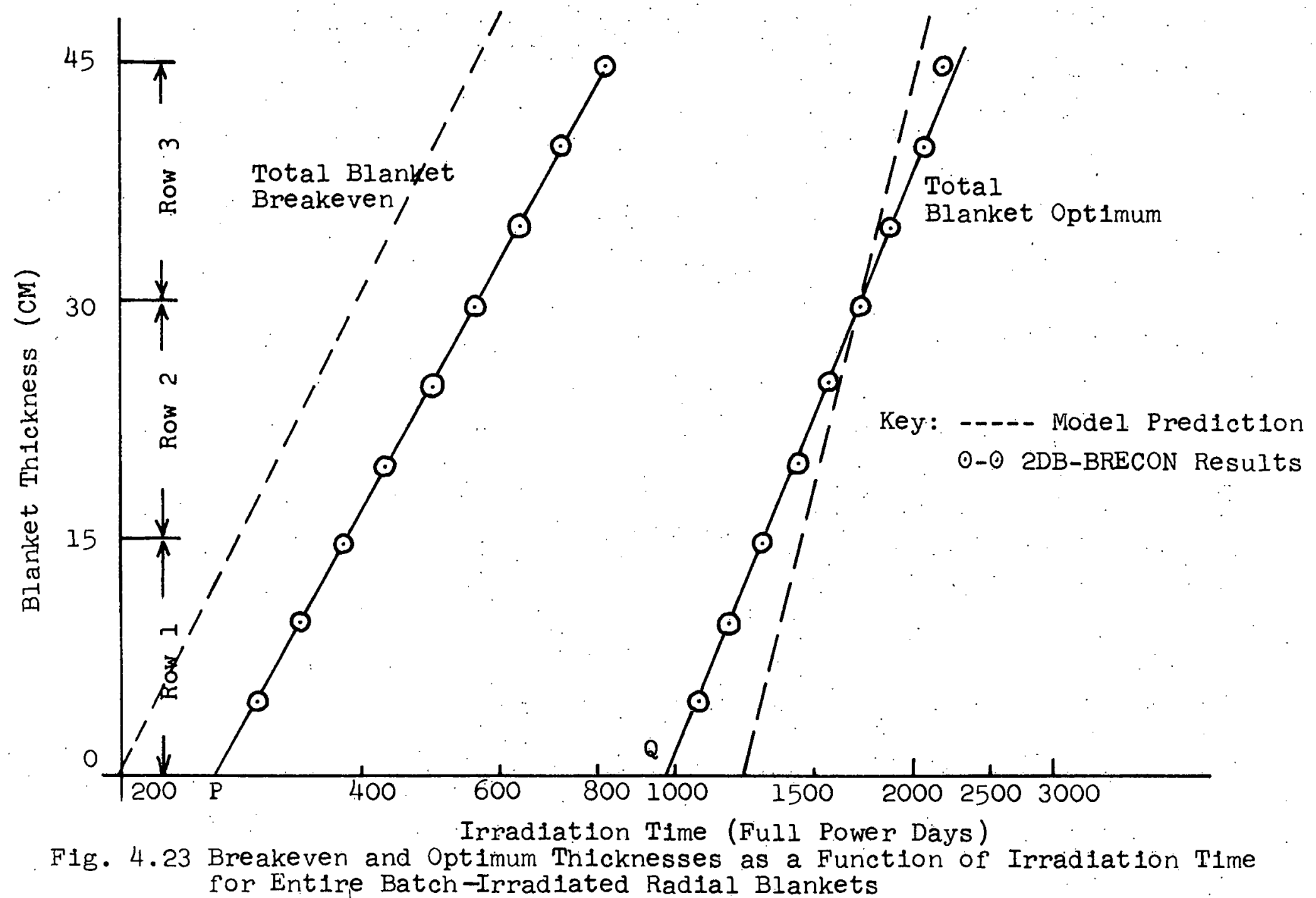


By definition, the intercept of the "total blanket breakeven" curve and the abscissa, point $P$, occurs at the same point as for the local breakeven curve discussed previously. A similar identity holds true for point $Q$, which is the intercept of the "total blanket optimum" curve and the abscissa. The intersection of the "total blanket breakeven" curve and the "total optimum" curve is called point $\mathrm{N}$ '. Physically, point $\mathrm{N}^{\prime}$ is replaced by point $\mathrm{N}$ as shown in Fig. 2.11 and discussed in Chapter 2 and Appendix E. At point $\mathrm{N}$, the total fuel cycle cost contribution for a blanket of thickness $\tau_{\mathrm{N}}$ is zero at irradiation time $\mathrm{T}_{\mathrm{N}}$; thicker blankets cannot produce any profit even if burnup were continued indefinitely. The location of point $\mathrm{N}$ depends on the economic environment and does not occur under the typical economic conditions of Table 2. 14 .

\section{3.4 Minimum Fuel Cycle Cost Contribution of an Entire Blanket}

Figure 4.24 shows the total fuel cycle cost contribution for an entire blanket as a function of thickness for given irradiation times. As expected, the total cost for a given irradiation time decreases and then increases through a minimum value as the blanket thickness increases. This trend is well approximated by a parabolic function of the blanket thickness, as discussed in Appendix $\mathrm{E}$, and also holds true as irradiation time increases, except that the bottom of the parabola (i.e.; the minimum total cost and hence the batch-optimum thickness for a given irradiation time) moves lower as the thickness increases. This behavior corresponds to the slope change of the "local costdistance" curve in Fig. 4.16. Thus, the projection of the locus of 


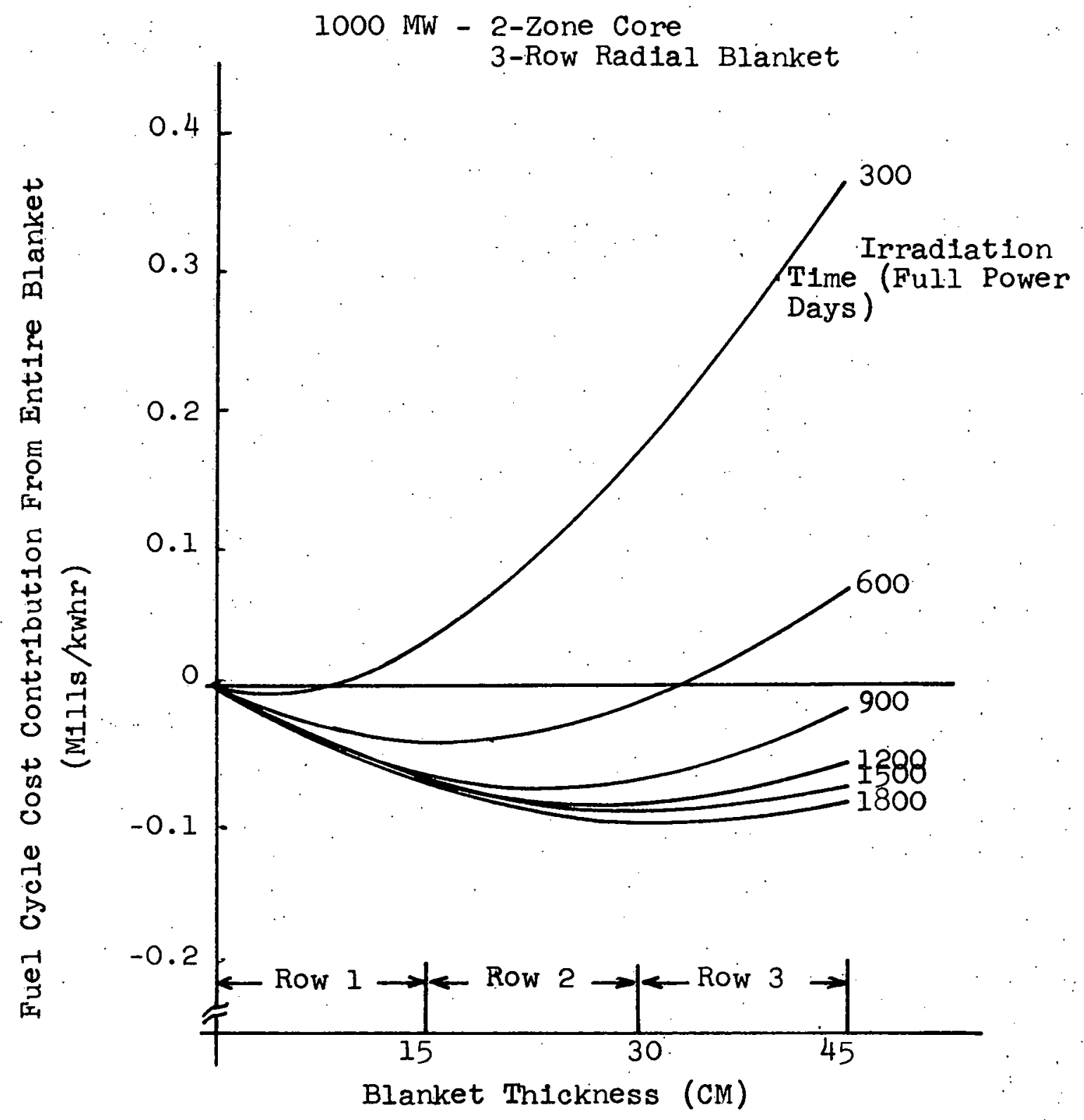

Fig. 4.24 Fuel Cycle Cost Contribution From Entire Batch Irradiated Radial Blankets as a Function of Blanket Thickness 
the "parabola-bottom" point on the "irradiation time-thickness" plane (i.e., the zero total cost line) is the same as that of the intercept of the "local cost-distance" curve and the zero cost line. This relation for a given irradiation time (here 1500 full power days) is shown in Fig. 4.25, which also indicates that the batch-optimum thickness for a given irradiation time (here around $30 \mathrm{~cm}$ for 1500 full power days) is the same for all core radii, as discussed in Chapter 2. In other words, the two-row blanket is the optimum configuration for the reference economic conditions of Table 2.14. The minimum cost of the entire radial blanket decreases as the core radius increases, which has been predicted in Chapter 2. The decrease is approximately inversely proportional to core radius. Figure 4.26 confirms this relationship, in which the 1 -row blanket is irradiated to the optimum irradiation time, and the 2-row and 3-row blankets are irradiated for the physical lifetime of the fuel assembly (here assumed to be 1800 full power days).

These results show that the radial blanket has a smaller relative effect on the fuel cycle cost in large LMFBR's primarily because there are fewer blanket assemblies per core assembly. On the other hand, absolute revenue dollars per blanket assembly in a given row is the same for all core sizes; hence all cores will have the same number of blanket rows and the same economic optimum assembly refueling schedules, whether on a row-by-row or entire blanket basis.

Agairi the Iocus of the "parabola bottom" (i.e., the minimum total cost) point is important to determine the "global" optimum point, which will be discussed next. 


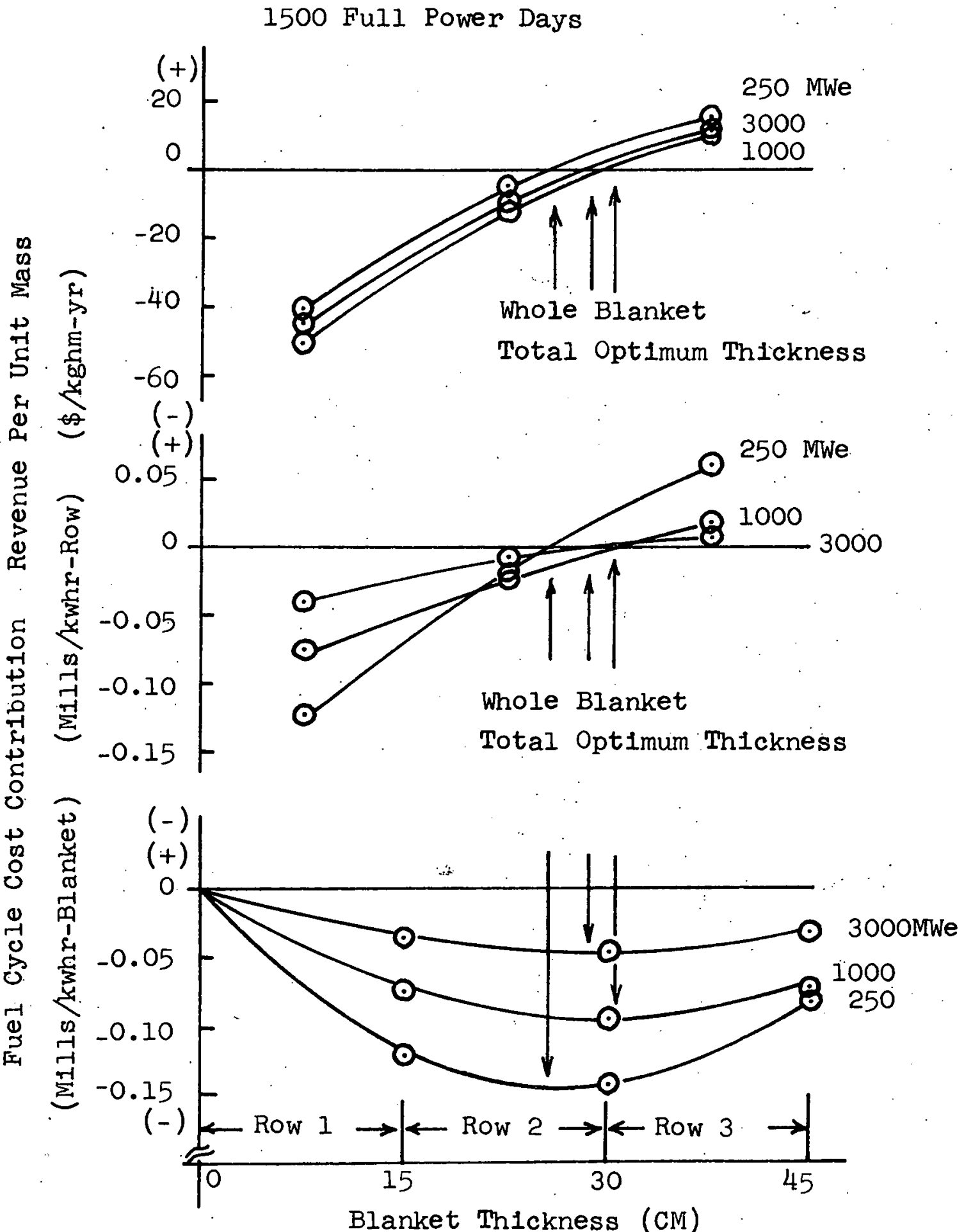

Fig. 4.25 Revenue Per Blanket Assembly and Fuel Cycle Cost Contribution Per Row or Per Entire Batch-Irradiated Radial Blanket as a Function of Blanket Thickness (for a Given Irradiation Time) 


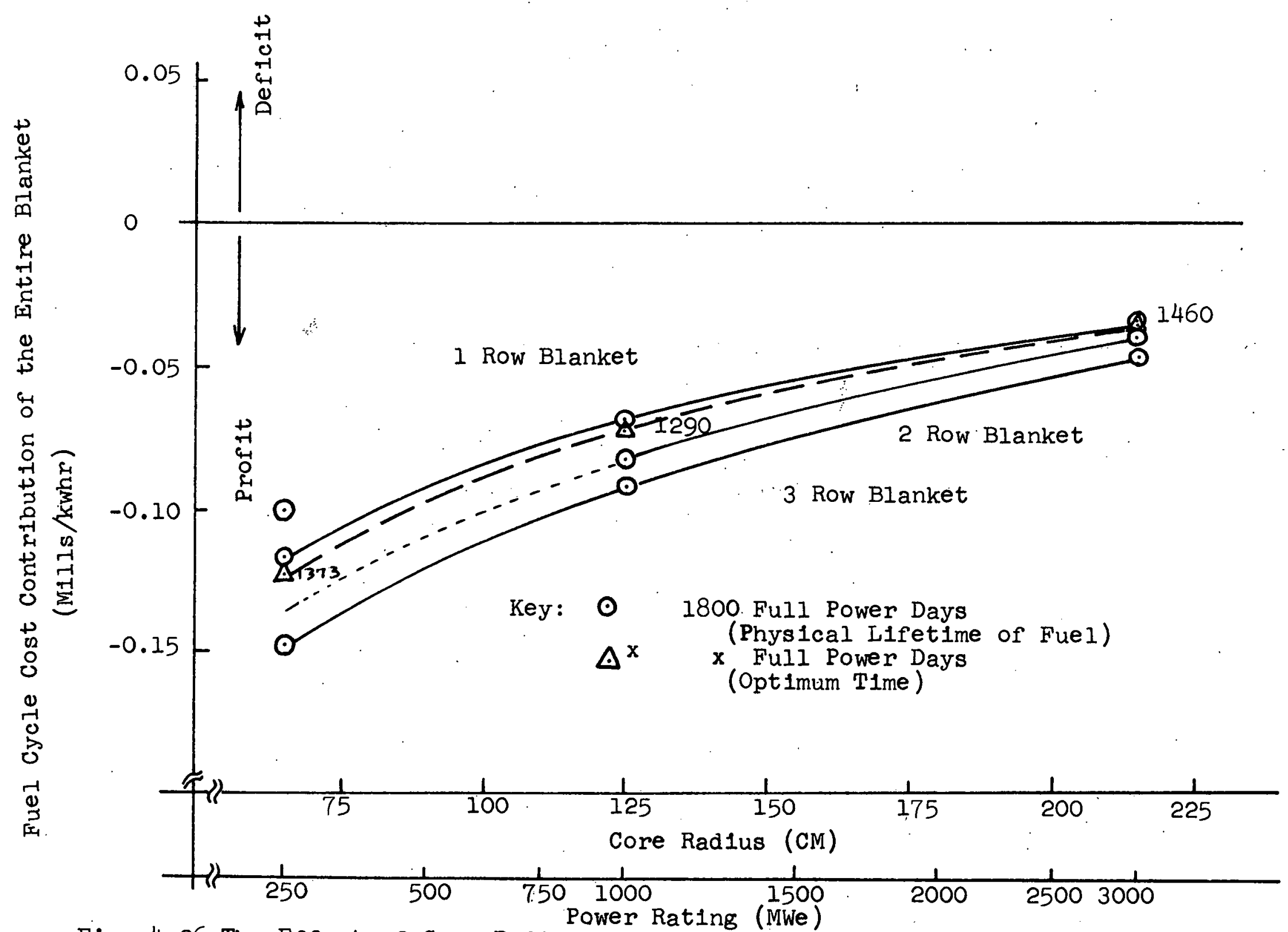

F1g. 4.26 The Effect of Core Radius on the Minimum Fuel Cycle Cost Contribution of the Entire Batch-Irradiated Radial Blanket 


\subsubsection{Global Optimum Thickness and Irradiation Time and} Global Minimum Cost

Figure 4.27 shows the minimum fuel cycle cost contribution of the entire blanket as a function of blanket thickness (i.e., the loci of the "parabola bottom" in Fig. 4.24 as discussed in the previous section). Notice again that the irradiation time varies along this locus in the same manner as in Fig. 4.18. The minimum point of the "total blanket minimum cost-thickness" curve, designated point $\mathrm{Z}$ or the "global minimum" point in the present work, occurs at that combination of thickness and irradiation time (here $31 \mathrm{~cm}$ and 1744 full power days), where the maximum-maximum profit is achieved. In other words, under the reference economic conditions of Table 2.14, a two-row radial blanket can produce the most profit at about 6 full power years using batch fuel management. Since Wood (W2) has shown that other fuel management schemes do not give significantly different results in terms of the net profit realized, the methods outlined in this section can also be used to estimate the economic prospects for blankets managed according to other fuel management schemes. Even more specifically, local row optimum correlations can be used to derive a zone-scatter type of refueling program.

Next consider another aspect of point $Z$. By superimposing Fig. 4.17 and Fig. 4.23, one can see the relationships between the four key curves: "local breakeven," "local optimum," "total breakeven" and "total optimum," as shown in Fig. 4.28. The intercept of the "local breakeven" (i.e., optimum thickness for a given irradiation time) and "total optimum" (i.. e., optimum irradiation time for a given thickness) curves, designated as point $S$, coincides with point $Z$. 


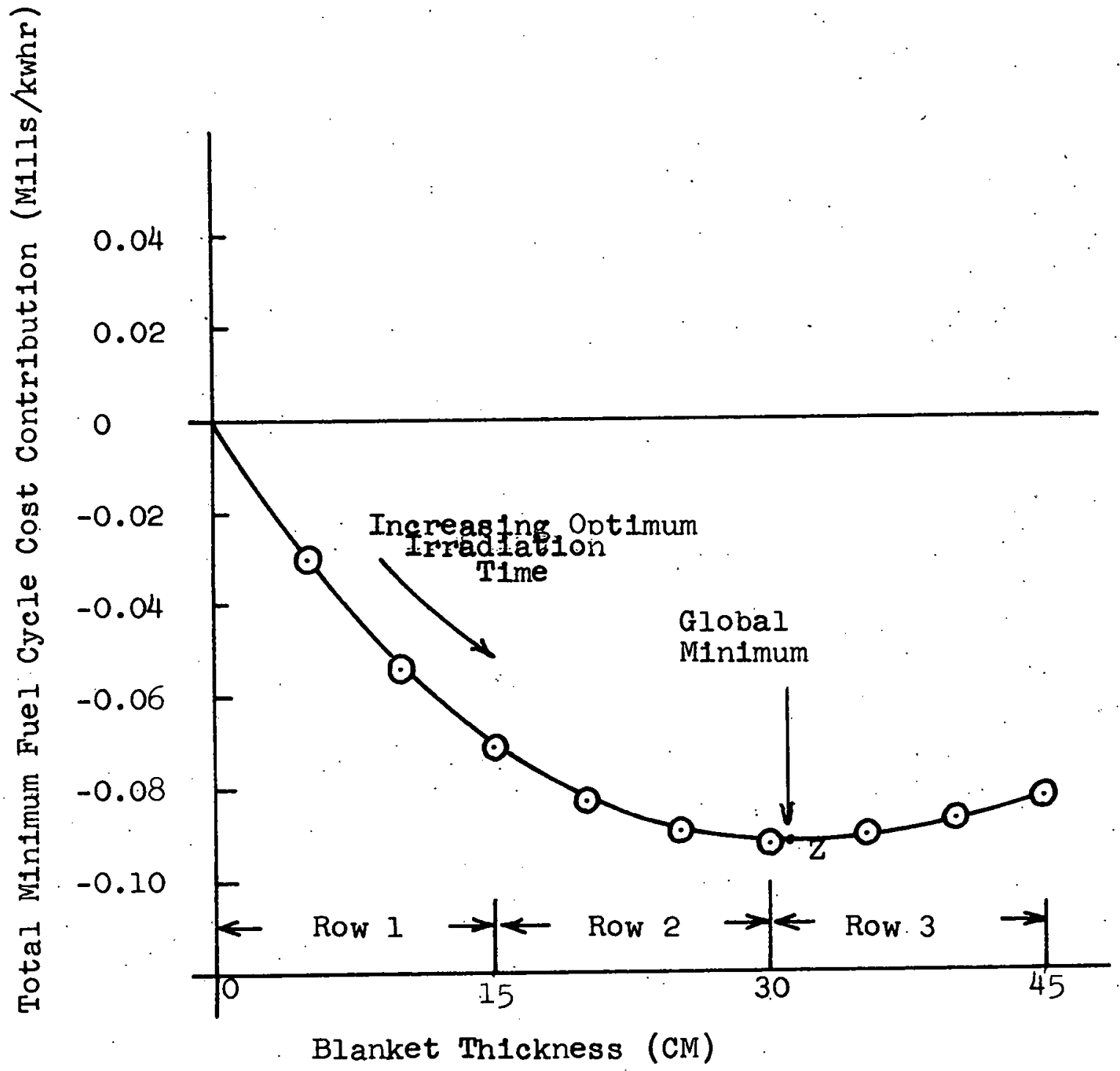

Fig. 4.27 Minimum Fuel Cycle Cost Contribution as a Function of Blanket Thickness 


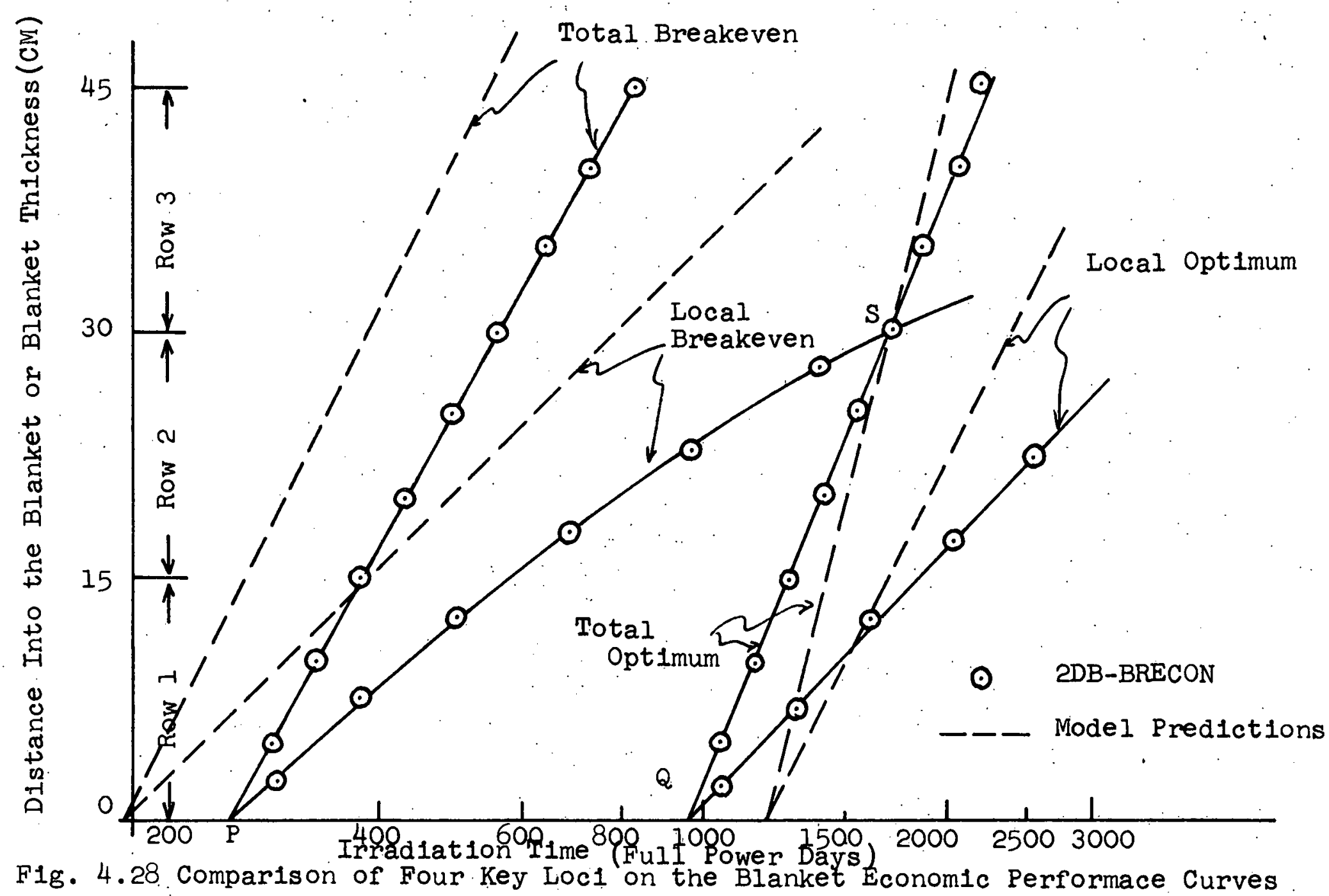


Finally; the correlation locating the $Z$ point (i.e., $S$ point) is expressed in the form:

$$
\begin{aligned}
& \mathrm{T}_{\mathrm{s}}=\left(1.53 \times 10^{3}\right) \mathrm{W}^{0.23} \mathrm{x}^{-0.45} \quad \text { (full power days) } \\
& \tau_{\mathrm{S}}=\frac{1}{\gamma} \ln \left[\left(1.38 \times 10^{-2}\right) \mathrm{W}^{0.86} \mathrm{x}^{-0.82}\right] \quad(\mathrm{cm}) \\
& \mathrm{e}_{\mathrm{S}}=\left(-1.50 \times 10^{-7}\right) \mathrm{W}^{-2.46} \mathrm{x}^{-0.94} \quad(\text { mills } / \mathrm{kwhr})
\end{aligned}
$$

Table 4.6 summarizes the coefficients of the above correlations in comparison with the model prediction; the agreement is fairly good considering the simple nature of the model.

Figure 4.29 shows a comparison of the correlated and original 2DB-BRECON global optimum thicknesses and irradiation times, which indicates that the correlations can predict the global optimum thickness within the half thickness of a row (here $7.5 \mathrm{~cm}$ ) and the global optimum ir radiation time within half a refueling interval (here $\frac{1}{2} \times 300=150$ full power days).

Figure 4.30 shows a comparison of global minimum costs: the correlated results and the original $2 \mathrm{DB}-\mathrm{BRECON}$ results. In general, the cost can be correlated to within \pm 0.02 mills $/ \mathrm{kwhr}$. The point outside the dotted line in Fig. 4.30 is the extreme case which has low discount rate $\left(\mathrm{X}=0.04 \mathrm{yr}^{-1}\right)$ and high $\mathrm{Pu}$ price $\left(\mathrm{C}_{3}=14 \$ / \mathrm{gPu}\right)$ and thus the lowest cost (the highest profit $\mathrm{e}_{\mathrm{S}} \cong-0.2 \mathrm{mills} / \mathrm{kwhr}$ ).

Correlations of this type should prove extremely useful in determining the nature and extent of changes in parameters such as blanket thickness, irradiation time and fuel cycle cost contribution of the radial blanket in batch fuel management as the economic environment changes. 


\begin{tabular}{|c|c|c|c|c|c|c|}
\hline & \multicolumn{3}{|c|}{ Simplified Model } & \multicolumn{3}{|c|}{ 2DB-BRECON } \\
\hline & $a_{j}$ & $b_{j}$ & $c_{j}$ & $a_{j}$ & $\mathrm{~b}_{j}$ & $c_{j}$ \\
\hline $\mathrm{T}_{\mathrm{s}}$ (Full power davs) & $1.07 \times 10^{3}$ & +0.33 & -0.67 & $1.53 \times 10^{3}$ & +0.23 & -0.45 \\
\hline$\tau_{s}(\mathrm{~cm})$ & $1.15 \times 10^{-1}$ & -0.67 & -0.67 & $1.38 \times 10^{-2}$ & -0.86 & -0.82 \\
\hline $\mathrm{e}_{\mathrm{s}}(\mathrm{mills} / \mathrm{kw} \mathrm{hr})$ & & & & $-1.50 \times 10^{-7}$ & -2.46 & -0.94 \\
\hline
\end{tabular}

Table 4.6 Comparison of Correlation, Coefficients for Global

optima Predicted by the Simplified Model and 2DB-BRECON 

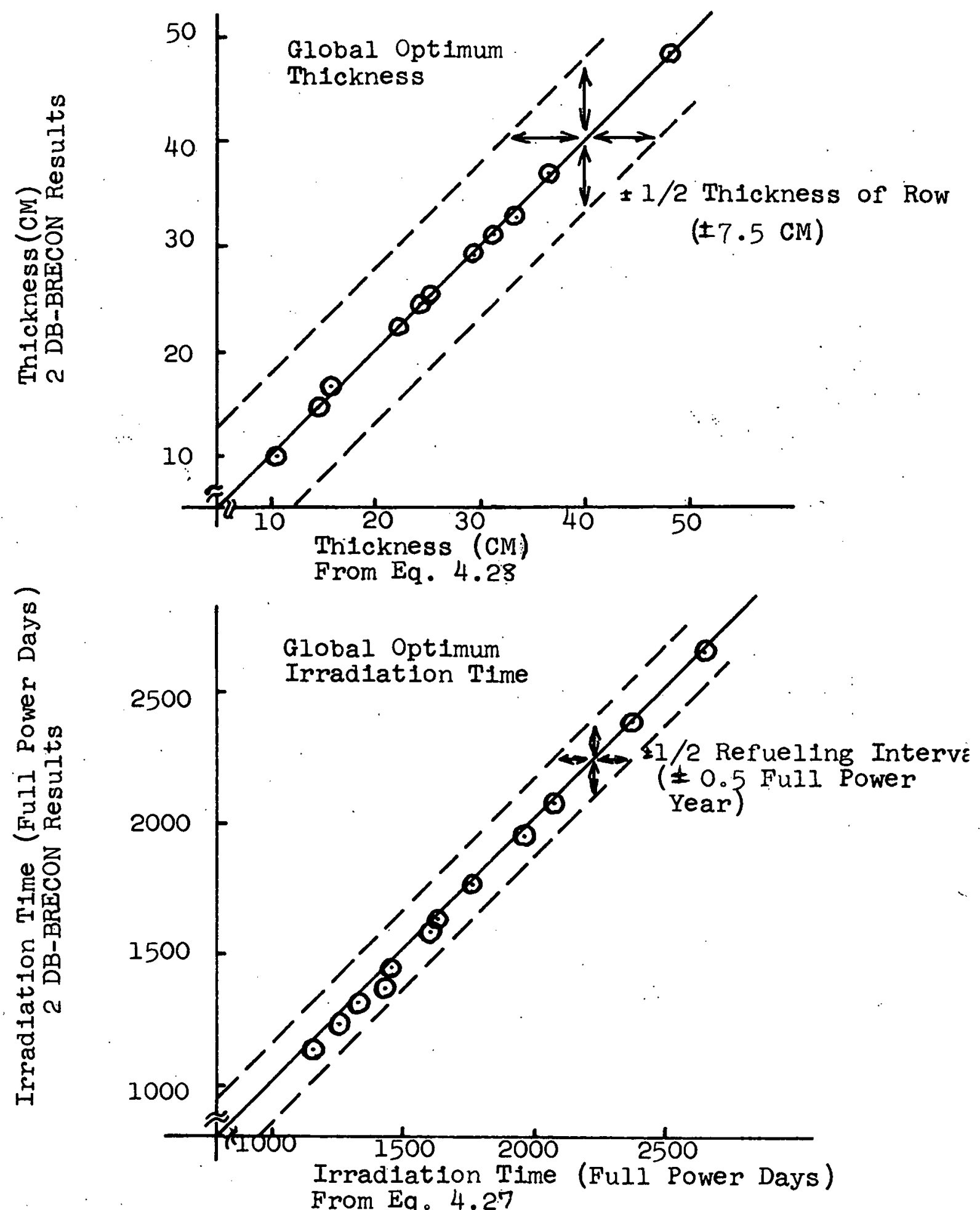

Fig. 4.29 Comparison of Global Optima Predicted by Correlations and $2 \mathrm{DB}-\mathrm{BRECON}$ 


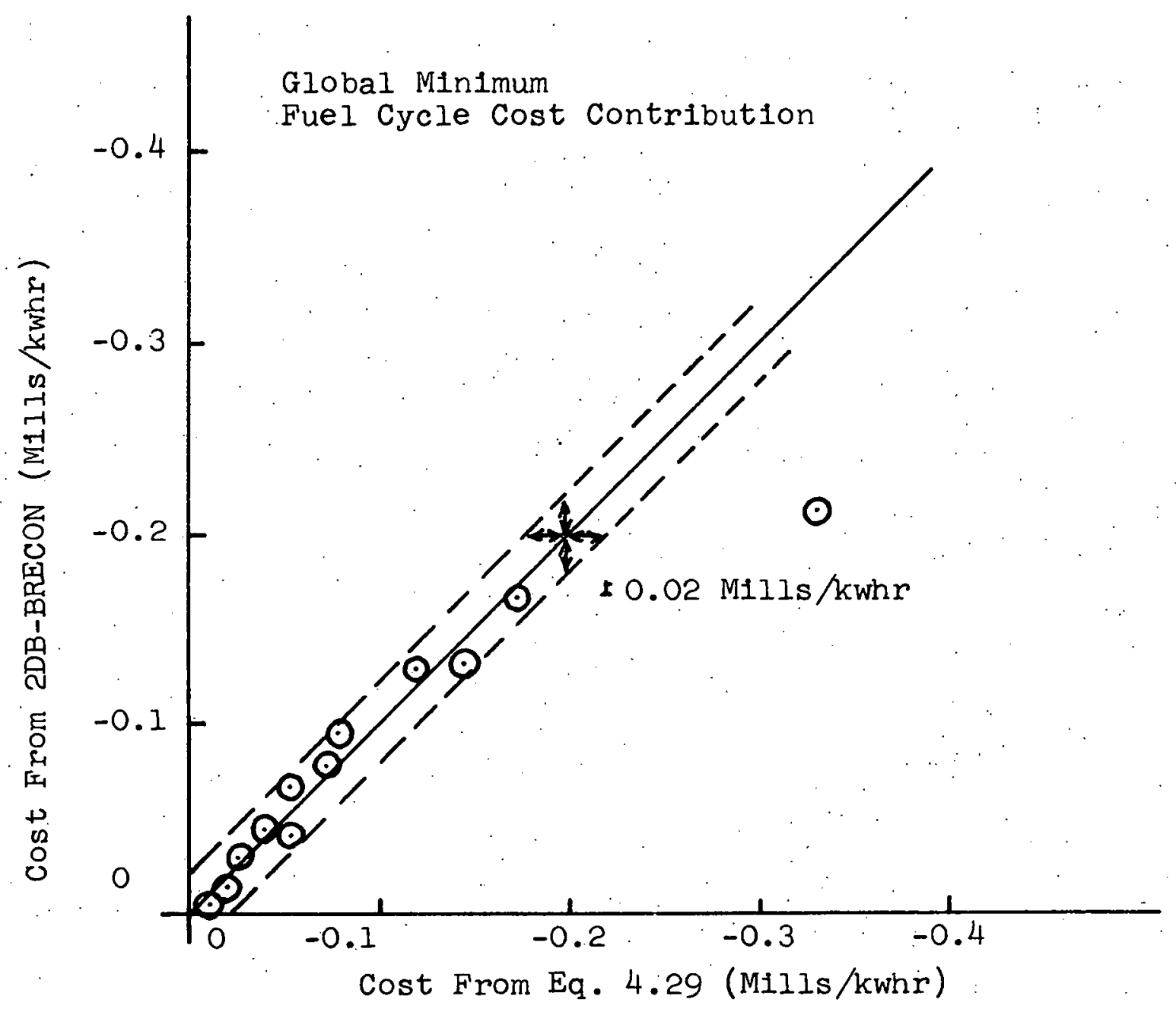

Fig. 4.30 Comparison of Global Minimum Cost Predicted by Correlation and 2DB-BRECON 


\section{4 CONCLUSIONS}

Good agreement between the predictions of simplified analyses and 2DB-BRECON calculations has been obtained for the depletioneconomics performance of LMFBR blankets in the sense that the simplified analyses have correctly predicted the functional dependence of all important parameters, permitting the development of highly accurate correlations for all burnup/economics results.

Useful correlations of blanket-breeding-performance characteristics, such as breakeven and optimum irradiation times and thicknesses, have been formulated using $2 \mathrm{DB}-\mathrm{BRECON}$ calculations correlated against the parameters singled out in the simplified analysis. Finally, it is concluded from the observations in this and the previous chapters that these correlations are applicable to an entire class of LMFBR core/blanket combinations characterized by constant core height and radial-core-power-flattening. 
Chapter 5

SUMMARY, CONCLUSIONS AND RECOMMENDATIONS.

\subsection{INTRODUCTION}

Commercialization of the LMFBR will require a continuous escalation in unit size to keep pace with the scale-up of competing nuclear or fossil alternatives: power ratings as large as $3000 \mathrm{MW}$ are projected by the year 2000. The purpose of the investigation reported here has been to examine the effects of the required core size increases on the neutronic and economic performance of the breeding blanket region surrounding these cores. The approach used throughout has been to employ simple reactor physics and economics models to predict trends and develop correlations, and then to employ more sophisticated state-of-the-art computer methods to confirm the results for realistic system designs.

Figure 5.1 depicts the major material subdivisions in a twodimensional representation of a $1000-M_{e}$ LMFBR used as a reference design for burnup calculations. The main features to note in this cylindrically symmetric layout are two approximately equalvolume core enrichment zones (for radial power-flattening), a 40-. $\mathrm{cm}$-thick axial blanket on the top and bottom of the core, and a threerow, 45-cm-thick radial blanket surrounded by a steel reflector. Tables 5.1 and 5.2 summarize the pertinent data for this reference configuration, which closely resembles other $1000-\mathrm{MW}$ e $\mathrm{LMFBR}$ blanket studies (B3, W2). This basic design was varied to examine. 


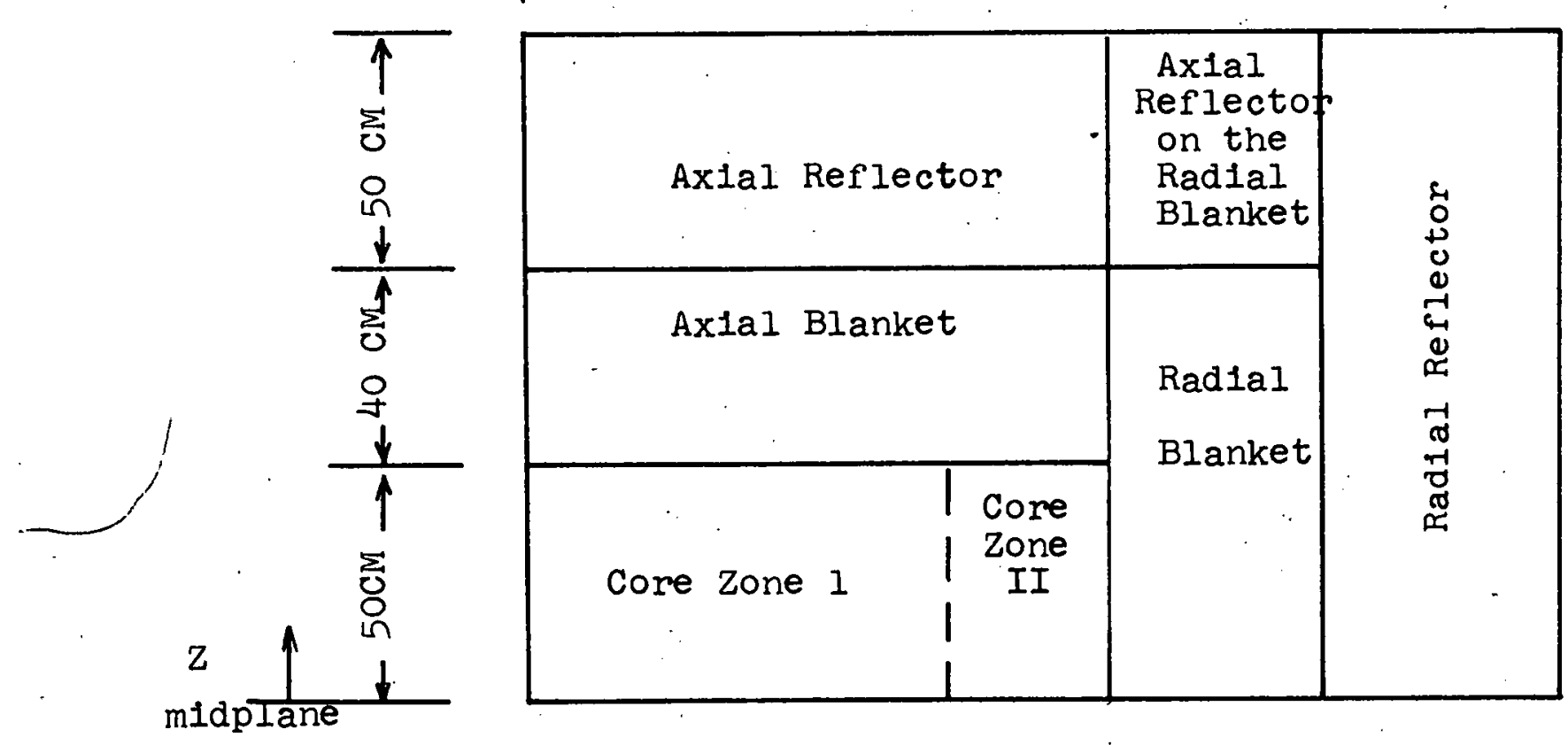

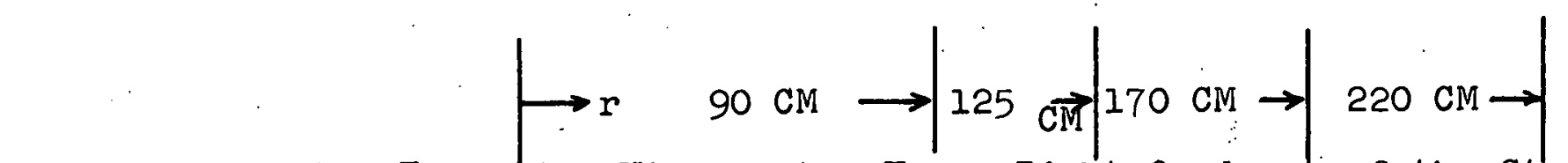

F1g. 5.1 Schematic Elevation View of the Upper Right Quadrant of the Standard 1000 MWe Reactor System 
Table 5.1 Characteristics of the Standard 1000 Mwe Reactor

\begin{tabular}{|c|c|c|}
\hline Parameter & Dimension & Value \\
\hline HeIght & $\mathrm{cm}$ & 100 \\
\hline Diameter & $\mathrm{cm}$ & 250 \\
\hline Volume & Iiters & 4906 \\
\hline Axial Blanket Thickness & $\mathrm{cm}$ & 40 \\
\hline Radial Blanket Thickness & $\mathrm{cm}$ & 45 \\
\hline Core Averaged Power Dens 1ty & kwth/liter & $\sim 500$ \\
\hline Core Peak Power Density & kwth/1iter & $\sim 730$ \\
\hline Core Zone I. O.D. & $\mathrm{cm}$ & 90 \\
\hline Core Zone I Volume & liters & 2540 \\
\hline Core Zone II O.D. & $\mathrm{cm}$ & 125 \\
\hline Core Zone II Volume & liters & 2366 \\
\hline Rated Thermal Power ${ }^{*}$ & MWt & 2500 \\
\hline Rated Electrical Power ${ }^{* *}$ & MWe & 1000 \\
\hline
\end{tabular}

* Core Plus Blankets

* Assumed System Efficiency $=40 \%$ 
Table 5.2 Standard 1000 MWe Reactor Parameters

\begin{tabular}{|c|c|c|c|c|c|}
\hline & \multirow{2}{*}{$\stackrel{\mathrm{Ht}}{(\mathrm{cm})}$} & \multirow{2}{*}{$\begin{array}{l}\text { Rad. } \\
\text { Th1ck. } \\
(\mathrm{cm})\end{array}$} & \multicolumn{3}{|c|}{ Percent by Volume } \\
\hline & & & Fuel ${ }^{c}$ & Coolant ${ }^{d}$ & Structure \\
\hline Core & & & & & \\
\hline Zone 1 & 100 & 90 & $30(85 \%$ t.d. $)$ & 50 & 20 \\
\hline Zone 2 & 100 & $\therefore 35$ & $30(85 \%$ t.d. $)$ & 50 & 20 \\
\hline $\begin{array}{l}\text { Axlal } \\
\text { Blanket } \\
\text { Radial } \\
\text { Blanket b }\end{array}$ & 80 & 125 & $30(85 \%$ t.d. $)$ & 50 & 20 \\
\hline Row 1 & 180 & 15 & $50(95 \%$ t.d. $)$ & 30 & 20 \\
\hline Row 2 & 180 & 15 & $50(95 \%$ t.d. $)$ & 30 & 20 \\
\hline Row 3 & 180 & 15 & $50(95 \%$ t.d.) & 30 & 20 \\
\hline
\end{tabular}


Table 5.2 : Standard 1000 MWe Reactor Parameters (continued)

\begin{tabular}{|c|c|c|c|c|c|}
\hline & \multirow{2}{*}{$\stackrel{\mathrm{Ht}}{(\mathrm{cm})}$} & \multirow{2}{*}{$\begin{array}{l}\text { Rad. } \\
\text { Th1ck. } \\
(\mathrm{cm})\end{array}$} & \multicolumn{3}{|c|}{ Percent by Volume } \\
\hline & & & Fue $1^{c}$ & Coolant ${ }^{\mathrm{d}}$ & Structure ${ }^{e}$ \\
\hline \multicolumn{6}{|l|}{$\begin{array}{l}\text { Axtal } \\
\text { Reflector }\end{array}$} \\
\hline $\begin{array}{c}\text { For axtal } \\
\text { blanket }\end{array}$ & 50 & 125 & - & 50 & 50 \\
\hline $\begin{array}{l}\text { For radial } \\
\text { blanket }\end{array}$ & 50 & 45 & - & 30 & 70 \\
\hline $\begin{array}{l}\text { Radlal } \\
\text { Reflector }\end{array}$ & 140 & 50 & & 10 & 90 \\
\hline
\end{tabular}

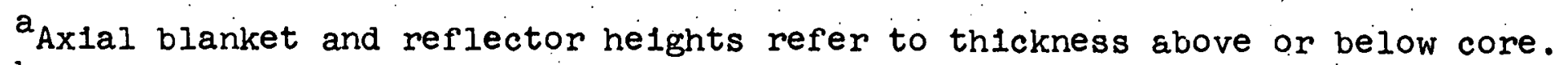
${ }^{b}$ Assumes hexagonal assemblies $15 \mathrm{~cm}$ across the flats.

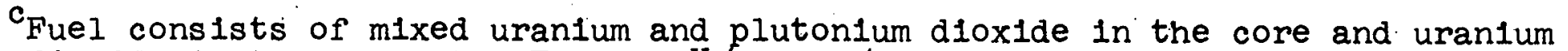
dloxide in the blanket. The $100 \mathrm{v} \%$, 100\% t.d. molecular density. is taken as 0.02447 atoms $/$ bam $-\mathrm{cm}$. Plutonfum is assumed to be typical light water reactor discharge $\mathrm{Pu}$ at 30,000 MWD/T: 63\%. Pu-239/27.3\% Pu-240/5.9\% Pu-241/3.8\% Pu-242(D4).

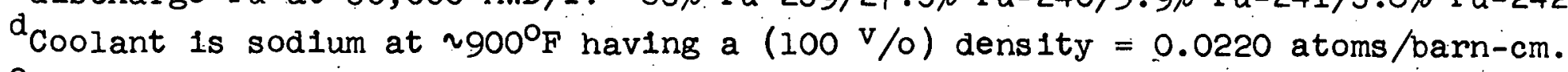

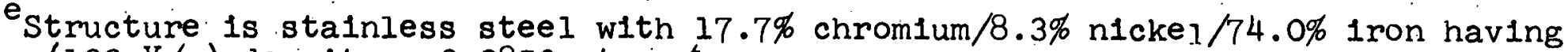
a $(100 \mathrm{v} / 0)$ density $=0.0850$ atoms $/$ barn $-\mathrm{cm}$. 
reactor ratings in the range from $250 \mathrm{MW}_{\mathrm{e}}$ to $3000 \mathrm{MW} \mathrm{e}$. Most of the variations involved changing the core radius (from $6.5 \mathrm{~cm}$ to $215 \mathrm{~cm}$ ) at constant core height $(100 \mathrm{~cm})$ while achieving an acceptable degree of radial power-flattening by means of radial enrichment zoning. For completeness, some studies were also carried out in which height was varied at constant radius. In all cases the blanket thickness was held constant. Tables 5.3 and 5.4 show the power ratings, the corresponding core radii and the enrichment zone configurations examined.

In all of the above cases, the blanket thickness and the irradiation time were optimized according to economic criteria determined by evaluating the levelized fuel cycle cost contribution of each blanket region, taking into account the burnup/economic parameters (including fissile revenue and fabrication, reprocessing and carrying charges).

Batch blanket management was selected for this study due to. its simplicity of implementation (i.e., blanket elements see only one position in the reactor, minimizing reactor down-time devoted to blanket refueling and/or repositioning) and due to the fact that approximately the same amount of plutonium is bred in an equivalent number of blanket elements regardless of management scheme $(\cdot e . g .$, out-in. or in-out management) over the same time interval (see B.3, W.1 or W2). 


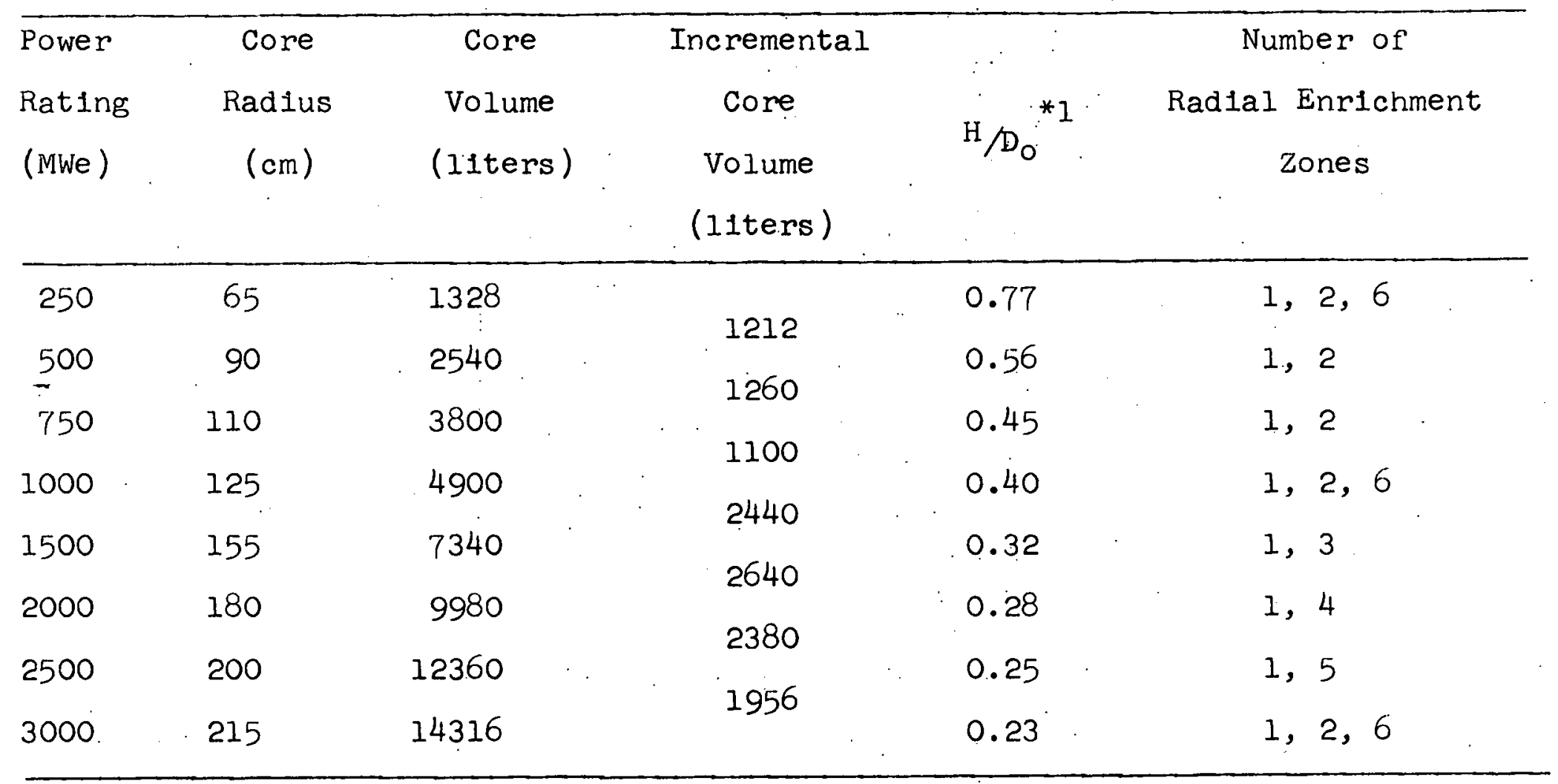

${ }^{*} 1$ Core Height $=100 \mathrm{~cm}$

Table 5.3 Key Characterist1cs of Reactor S1zes Examined (Constant Core Height) 
Table 5.4 Key Characteristics of Reactor Sizes Examined

(Constant Core Radius)

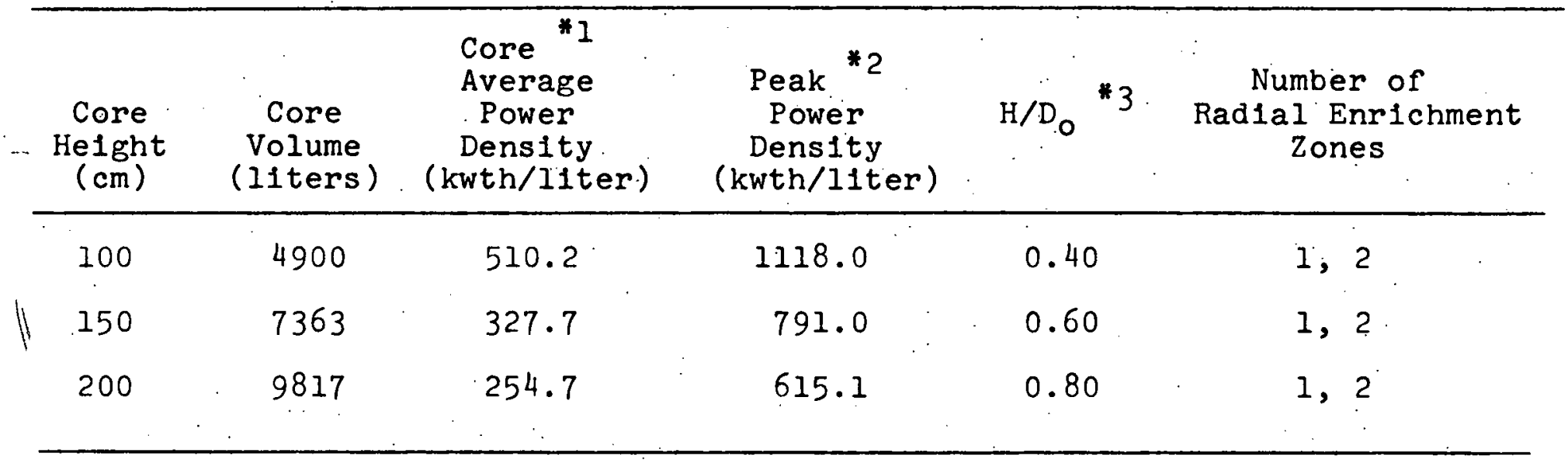

*. Total Reactor Thermal Power $=2500 \mathrm{MWth}$

Power Rating. $\quad=1000 \mathrm{MW}_{\mathrm{e}}$

Assumed Thermal Efflciency $=40 \%$

*2 One Zone Core

* 3 Constant Core Diameter $=250 \mathrm{~cm}$ 


\subsection{COMPUTER AND ANALYTIC MODELS}

\subsubsection{Method of Burnup}

The primary calculational tool used in comparing the neutronic performance of the cases studied was the two-dimensional diffusion theory burnup code $2 \mathrm{DB}$ (L1). A 4-group, regionwise cross-section set was employed. This set was prepared by collapsing the 26-group ABBN Type FTR-200 cross-section set (A3, N1, W2) over spectra appropriate to the various reactor regions using the one-dimensional transport theory code ANISN (E2). Regionwise 4-group cross sections have been shown to give results which compare favorably to multigroup many-region calculations, especially in the inner regions of the blanket which contribute most of the blanket plutonium production (H1).

Since long burnups (around six years) were performed in studying the blanket burnup behavior, an "equilibrium" core and axial blanket were defined which remained fixed in time. Constant core and axial blanket material concentrations (including fission product and control poison concentrations) at the time-averaged values expected in these regions were used, obviating the need to fuel-manage the core. It should be noted that although considerable care was taken to define a realistic core and axial blanket composition around which the radial blanket was irradiated, other investigators ( $\mathrm{B} 5, \mathrm{H} 1, \mathrm{~W} 2)$ have looked into the effect of different core-management methods on radial blanket economics and have concluded that there is an insignificant effect. Furthermore, since the same core treatment is used for all cases studied, any systematic bias (however small) should cancel out so long as relative comparisons are emphasized. 


\subsubsection{Depletion-Economics Model}

The depletion-economic analysis was performed utilizing the cash flow method (CFM). contained in the computer code BRECON, developed by Brewer (B3) and modified by Wood (W2) to permit direct use of $2 \mathrm{DB}$ burnup results as input:. This method capitalizes, and consequently depreciates for tax purposes, the material purchases and fabrication charges; whereas reprocessing charges and material credit are treated as an expensed cost and taxable revenue, respectively.

The economic results generated by BRECON are the local levelized fuel component of the energy cost (mills/kwhr) which can be applied to an entire region (e.g., radial blanket) or subregion (e.g., radial blanket row). This facilitates the determination of the minimum fuel cycle cost contribution (i.e.;, optimum irradiation time) for a blanket row or for the entire blanket.

Table 5.5 lists the basic economic parameters used in this study of radial and axial blanket burnup fuel economics. The conditions are the same as those employed by Brewer (B3) and Wood (W2) and are within the range projected for the mature U.S. nuclear fuel cycle economy (W1).

\subsubsection{One-Group Model}

Simplified models were used to examine both the neutronic and economic performance of fast reactor blankets. Reactor physics properties were investigated using one-group diffusion theory and a representative set of fast reactor cross sections; economic 
Tabie 5.5 Reference Economic Environment

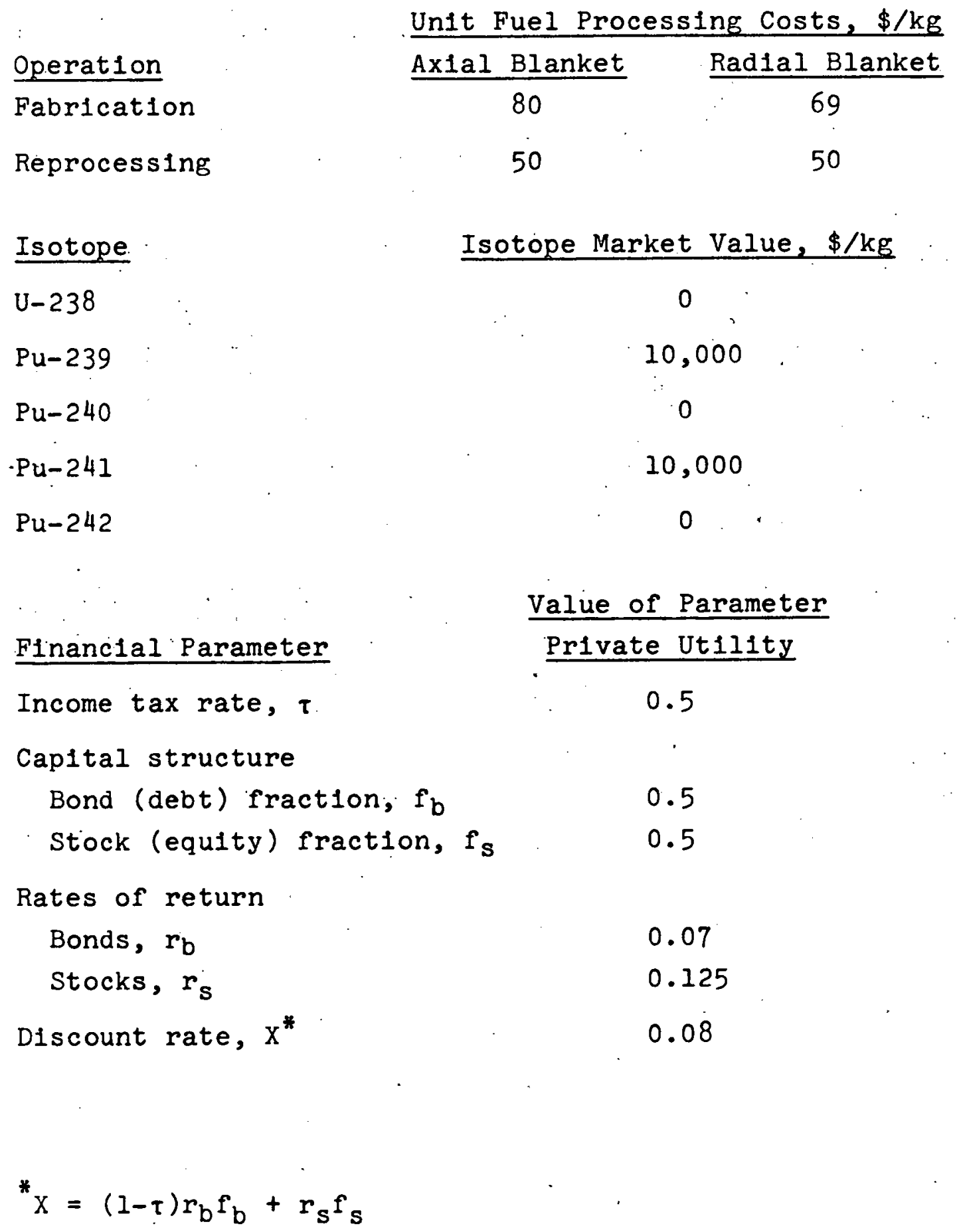


performance was approximated using a simplified version of the cashflow model employed in the detailed computer studies.

One-group diffusion theory was employed to pitedict the effect of changes in core size on both the radial and axial blankets. In each case, two types of cores were examined - uniformly enriched and radially power-flattened by enrichment gradation; and two independent variations in size were considered - increasing radius at constant core height, and increasing height at constant core radius.

The analysis of single-enrichment-zone cores is an elementary exercise dealt with in depth by all reactor physics texts; radially power-flattened systems are seldom discussed, despite their practical importance, and therefore the approximations required to permit an analytic solution are worthy of mention, the most important being that the core diffusion coefficient, the linear extrapolation distances into the blankets, and the core-averaged fertile-to-fissile fission ratio are essentially independent of local enrichment. Two-dimensional multigroup calculations were carried out to confirm each of these key assumptions and other common hypotheses, such as the spatial separability of the axial and radial flux dependence.

The subject reactor physics model was employed to develop the following'conclusionș:

1) 1. For radially power-flattened (RPF) cores, both central and peripheral enrichments remain essentially the same as the core radius (hence power rating) increases for constant core height.

2. The magnitude of the peripheral core flux and leakage current $\left(\mathrm{n} / \mathrm{cm}^{2}-\mathrm{sec}\right)$ into the radial blanket remains the same as 
core radius increases; because the peripheral enrichment is the same, one also expects the energy spectrum to be the same.

3. The core-averaged enrichment (hence critical mass) for single-enrichment and RPF cores having the same height and radius (hence volume) are very nearly the same, and as expected, average enrichment decreases gradually with increasing core size.

4. Axial leakage is essentially the same for the RPF and onezone cores.

Based on these observations, a number of important conclusions were drawn in regard to the rate of production of new fissile material in three blanket volumes of interest: the entire blanket, a single row, and per blanket assembly. Tables 5.6 through 5.8 summarize these results. The most important single conclusion is that per blanket. assembly the fissile material bred per unit time is independent of core radius for $\mathrm{RPF}$ cores, but decreases rapidly for single-zone cores. Hence, in the more realistic RPF cores of commercial interest, the blankets will tend to have similar optimum thicknesses and optimum irradiation schedules and equal dollar revenue on a per assembly basis. On the other hand, the effect of an assembly row or an entire blanket on the total fuel cycle cost in mills/kwhr decreases as core size increases. 
Table 5.6 Summary of the Effect of Changing Core Radius at Constant Core Helght on the Neutronic and Economic Performance of the Radial Blanket (Predictions of Simple One-Group Model)

\begin{tabular}{|c|c|c|c|}
\hline \multicolumn{2}{|c|}{ Items } & $\begin{array}{c}\text { Radially-Power-Flattened } \\
\text { Core }\end{array}$ & $\begin{array}{l}\text { Uniformly-L oaded } \\
\text { Core }\end{array}$ \\
\hline \multirow{3}{*}{ 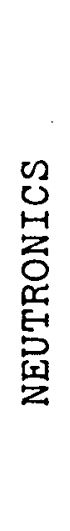 } & $\begin{array}{c}\text { Whole Blanket (or Row) } \\
\text { Fissile Bulidup Rate, } \\
R_{0}(\mathrm{kgP} / \mathrm{yr})\end{array}$ & $\alpha a$ & Constant $\cdot\left(1+\frac{\delta_{r}}{a}\right)^{-2}$ \\
\hline & $\begin{array}{l}\text { Specific Inventory } \\
\text { Buildup Rate } \\
\text { So(kgP } / \mathrm{kgHM} \text { yr) }\end{array}$ & Constant & $a a^{-2}\left(1+\frac{\delta_{r}}{a}\right)^{-2}$ \\
\hline & $\begin{array}{c}\text { Breeding Ratio } \\
\text { bxr }\end{array}$ & $\alpha a^{-1}$ & $\alpha a^{-2}\left(1+\frac{\delta_{r}}{a}\right)^{-2}$ \\
\hline
\end{tabular}

$a=$ Core Radius

$\delta_{r}=$ Extrapolation Distance 
Table 5.6 Summary of the Effect of Changing Core Radius at Constant Core Helght on the Neutronic and Economic Performance of the Radial Blanket

(Predictions of Simple One-Group Model)

(Continued)

\begin{tabular}{|c|c|c|c|}
\hline \multicolumn{2}{|c|}{ Items } & $\begin{array}{c}\text { Radially-Power-Flattened } \\
\text { Core }\end{array}$ & $\begin{array}{l}\text { Uniformly-Loaded } \\
\text { Core }\end{array}$ \\
\hline \multirow{5}{*}{ 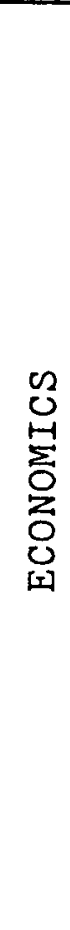 } & $\begin{array}{c}\text { Revenue per Blanket Row } \\
(\$)\end{array}$ & $\alpha a$ & Constant $\left(1+\frac{\delta}{a}\right)^{-2}$ \\
\hline & $\begin{array}{c}\text { Revenue per Blanket } \\
\text { Assembly } \\
(\$)\end{array}$ & Constant & $\alpha a^{-1}\left(1+\frac{\delta_{r}}{a}\right)^{-2}$ \\
\hline & $\begin{array}{c}\text { Contribution to Fuel } \\
\text { Cycle Cost } \\
\text { (mills/kwhr) }\end{array}$ & $\alpha a^{-1}$ & $\alpha a^{-2}\left(1+\frac{\delta}{a}\right)^{-2}$ \\
\hline & $\begin{array}{l}\text { Optimum Irradiation } \\
\text { Time } \\
\text { (Full Power Days) }\end{array}$ & Constant & Increases \\
\hline & $\begin{array}{l}\text { Optimum Thickness } \\
(\mathrm{cm})\end{array}$ & Constant & Decreases \\
\hline
\end{tabular}

$a=$ Core Radius

$\delta_{r}=$ Extrapolation Distance 


\begin{tabular}{|c|c|c|}
\hline \multicolumn{2}{|c|}{ Items } & \begin{tabular}{|c|} 
Large \\
Radially-Powe r-Flattened \\
or \\
Uniformly Loaded \\
Cores
\end{tabular} \\
\hline \multirow{3}{*}{ 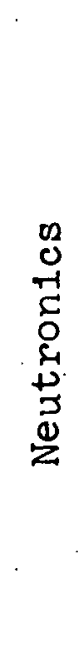 } & $\begin{array}{l}\text { Whole Blanket } \\
\text { Fissile Buildup Rate } \\
\left.\text { Ro( } \mathrm{kgP}_{\mathrm{u}} / \mathrm{yr}\right)\end{array}$ & $\alpha a^{2}$ \\
\hline & $\begin{array}{l}\text { Special Inventory } \\
\text { Buildup Rate } \\
\text { So }\left(\mathrm{kgP}_{\mathrm{u}} / \mathrm{kgHM} \text { yr }\right)\end{array}$ & Constant \\
\hline & $\begin{array}{c}\text { Breeding Ratio } \\
\text { bxa }\end{array}$ & Constant \\
\hline $\begin{array}{r}02 \\
0 \\
-1 \\
E \\
0 \\
0 \\
0 \\
0 \\
01\end{array}$ & $\begin{array}{l}\text { Revenue per Blanket Zone } \\
\text { ( } \$ / B \text { lanket Zone) } \\
\text { Revenue per Blanket Assembly } \\
\text { ( } \$ / B l a n k e t \text { Assembly) } \\
\text { Contribution to Fuel Cycle } \\
\text { Cost } \\
\text { (mills/kwhr) }\end{array}$ & $\begin{array}{c}\alpha a^{2} \\
\text { Constant } \\
\text { Constant }\end{array}$ \\
\hline
\end{tabular}

* See Appendix $B$ and section 2.2.1.3

$a=$ Core Radius

Table 5.7 Summary of the Effect of Changing Core Radius at Constant Core Height on the Neutronic and Economic Performance of the Axial Blanket (predictions of simple one-group model) 


\begin{tabular}{|c|c|}
\hline Core & $\begin{array}{c}\text { Radially-Power-Flattened } \\
\text { or } \\
\text { Uniformly-Loaded } \\
\text { Cores }\end{array}$ \\
\hline $\begin{array}{l}\text { Radial Breeding } \\
\text { Rat1o } \\
b_{\mathrm{xr}}\end{array}$ & Constant \\
\hline $\begin{array}{c}\text { Axial Breeding } \\
\text { Rat1o } \\
b_{x a}\end{array}$ & $\alpha \frac{1}{H_{e}^{2} \varepsilon_{c}}$ \\
\hline
\end{tabular}

$$
\begin{aligned}
\mathrm{H}_{\mathrm{e}} & =\mathrm{H}+2 \delta_{\mathrm{a}} \\
\mathrm{H} & =\text { Core Height } \\
\delta_{\mathrm{a}} & =\text { Linear Extropolation Distance }
\end{aligned}
$$

Table 5.8 Summary of the Effect of Changing Core Height at Constant Core Radius on the Breeding Performance of the Radial and Axial Blankets (Predictions of Simple One-Group Model) 


\subsubsection{Simplified Economic Analysis}

The cash-flow model for the fuel cycle cost contribution of a given region of LMFBR blanket is of the form (B3, W2):

$$
\mathrm{e}(\mathrm{T}) \propto \frac{\mathrm{C}_{1} \mathrm{~F}_{1}\left(-\mathrm{T}_{1}\right)+\mathrm{C}_{2} \mathrm{~F}_{2}\left(-\mathrm{T}_{2}\right)-\mathrm{C}_{3} \mathrm{~F}_{3}\left(-\mathrm{T}_{3}\right) \varepsilon(\mathrm{T})}{\mathrm{T}}
$$

where

$$
\begin{aligned}
& \mathrm{C}_{1}=\text { fabrication charge, } \$ / \mathrm{kg} \text { heavy metal } \\
& \mathrm{C}_{2}=\text { reprocessing charge, } \$ / \mathrm{kg} \text { heavy metal } \\
& \mathrm{C}_{3}=\text { fissile value, } \$ / \mathrm{kg} \text { fissile }
\end{aligned}
$$

and the present worth factors are:

$$
\begin{aligned}
& \mathrm{F}_{1}(-\mathrm{T}) \text { on the fabrication charges } \\
& \mathrm{F}_{2}\left(-\mathrm{T}_{2}\right) \text { on the reprocessing charges } \\
& \mathrm{F}_{3}\left(-\mathrm{T}_{3}\right) \text { on the material credit }
\end{aligned}
$$

The various times appearing in this relation are shown in Fig. 5.2, and a typical $\mathrm{e}(\mathrm{T})$ curve is displayed in Fig. 5.3. Breakeven conditions occur when $\mathrm{e}=0$, and optimum performance results when $\mathrm{de} / \mathrm{dT}=0$, as shown in the figure.

The computer code BRECON (B3, W2) employs Eq. 5.1 to calculate regionwise cost contributions given time-dependent heavy metal inventories from a burnup code. Simple analytic solutions can be obtained, however, by series expansion (and truncation) of the present worth factors and by assuming a fissile buildup which increases linearly with time and decreases exponentially with distance from the core/blanket interface - assumptions amply confirmed by multigroup calculations. By means of this approximate 


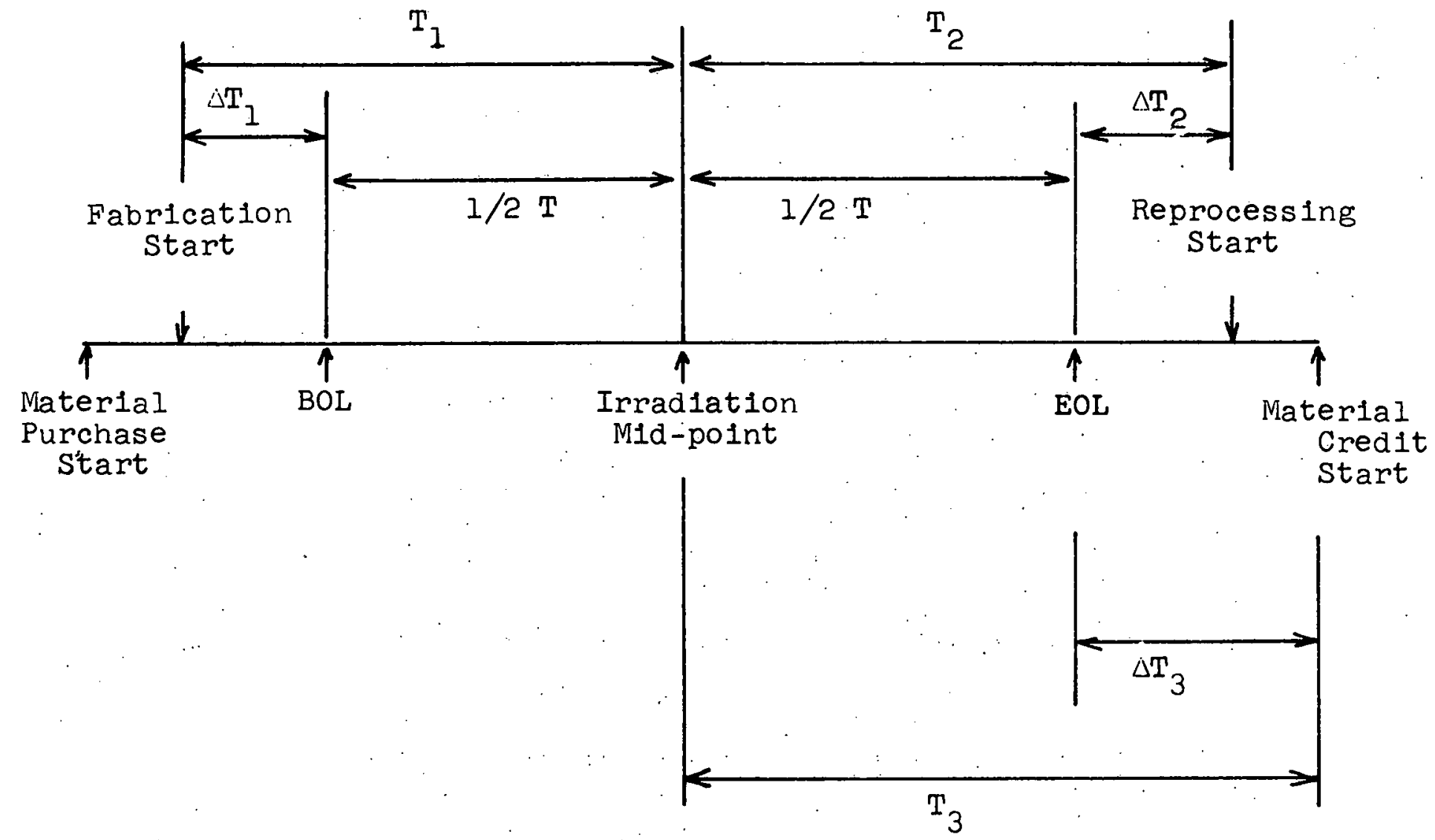

F1g. 5.2 Timing of Cash Flows for Fuel Cycle Cost Calculations 


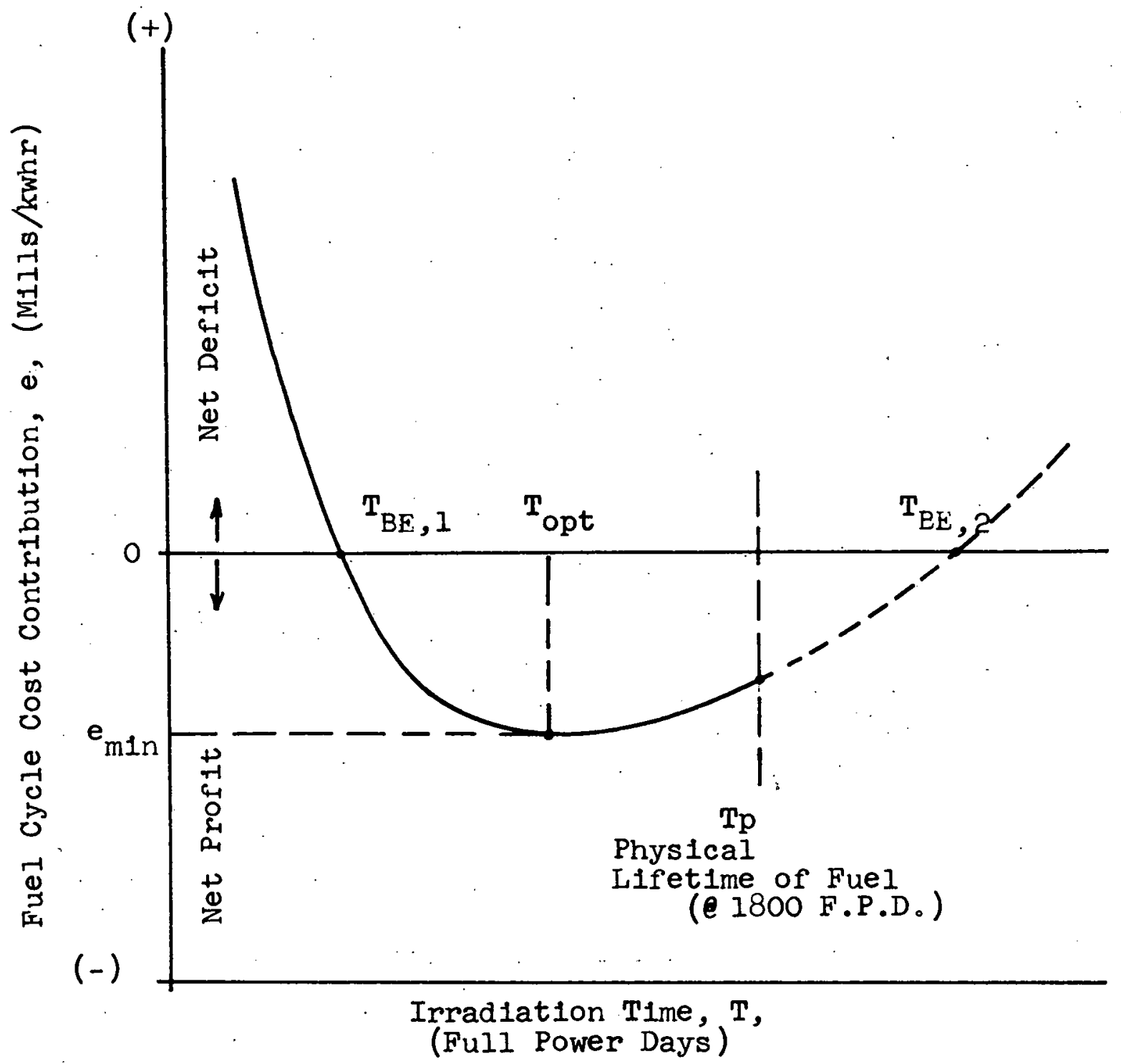

F1g. 5.3 Typical Variation of Fuel Cycle Cost Contribution from a Fast Reactor Blanket 
treatment, it is possible to derive analytic expressions for the breakeven and optimum irradiation times for local slices or entire regions of a blanket. Quite often the results are quantitatively correct, but their major interest here is as the starting point for the development of correlation methods to systematize the results obtained from the BRECON program.

Tables 5.9 and 5.10 summarize the analytic expressions developed in this simplified approach. Figure 5.4 illustrates the network of linearized relations developed. The most important result is the simple power-law dependence of optimum and breakeven times and enrichments on but two parameters, W. and X, which completely characterize the economic environment.

\section{3 BEGINNING-OF-LIFE BREEDING PHYSICS RESULTS}

\section{3.1 Physics-Related Parameters}

As has been noted, the approach employed in the present investigation was to develop hypotheses using simplified analytic models, and then to use the results of more sophisticated state-of-the-art computations to test assumptions and conclusions. In the paragraphs which follow, the results of this verification process are summarized for all of the major points at issue.

Figure 5.5 compares the critical enrichments predicted by the one-group model ( $1 \mathrm{GM}$ ) and the 4-group $2 \mathrm{DB}$ calculations to provide a general picture of the degree to which the 1GM results can be relied upon. The figure also shows the close correspondence between singleand multi-zone, core-averaged critical enrichments. 


\begin{tabular}{|l|c|c|}
\hline & Local & Total \\
\hline Breakeven & $\tau=\frac{1}{\gamma}\left(\operatorname{lnT}-\ln \mathrm{T}_{\mathrm{B}}\right)$ & $\tau=\frac{2}{\gamma}\left(\ln \mathrm{T}-\ln \mathrm{T}_{\mathrm{B}}\right)$ \\
\hline pptimum & $\tau=\frac{2}{\gamma}\left(\operatorname{lnT}-\ln \mathrm{T}_{\mathrm{O}}\right)$ & $\tau=\frac{4}{\gamma}\left(\ln \mathrm{T}-\ln \mathrm{T}_{0}\right)$ \\
\hline
\end{tabular}

\footnotetext{
$\mathrm{T}_{\mathrm{B}}=$ The Interfacial Breakeven Time Point $\mathrm{P}$ in Table 5.10

$\mathrm{T}_{0}=$ The Interfacial Optimum Time Point $Q$ in Table 5.10

$\gamma=$ Reciprocal Diffusion Length of the Blanket
}

Table 5.9 Summary of Relations Between Local Blanket Region Positions or Total Blanket Thickness and Irradiation Time 
Table 5:10 Summary of the S1x Key Intercepts Predicted by Simplified CFM Analysis

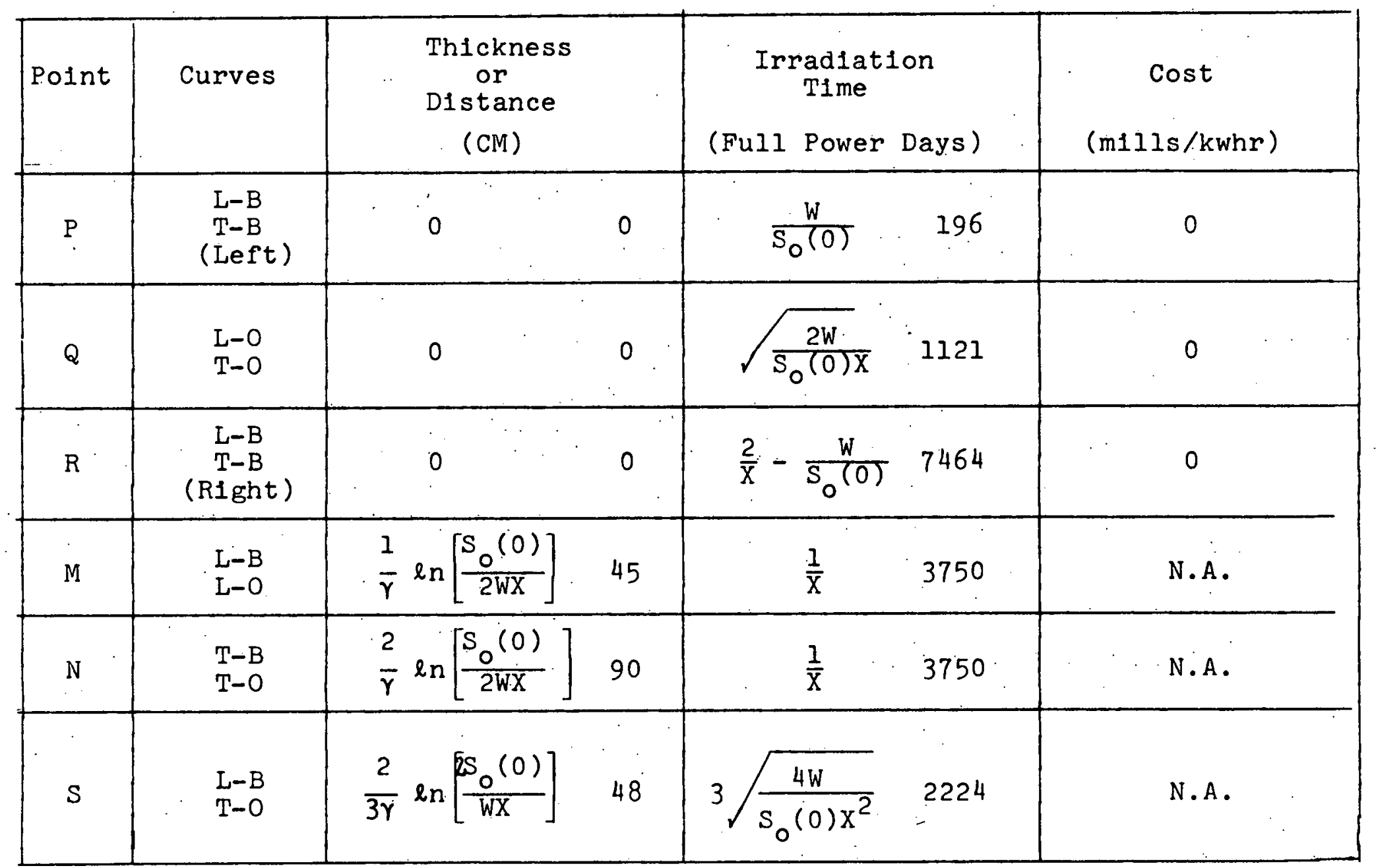




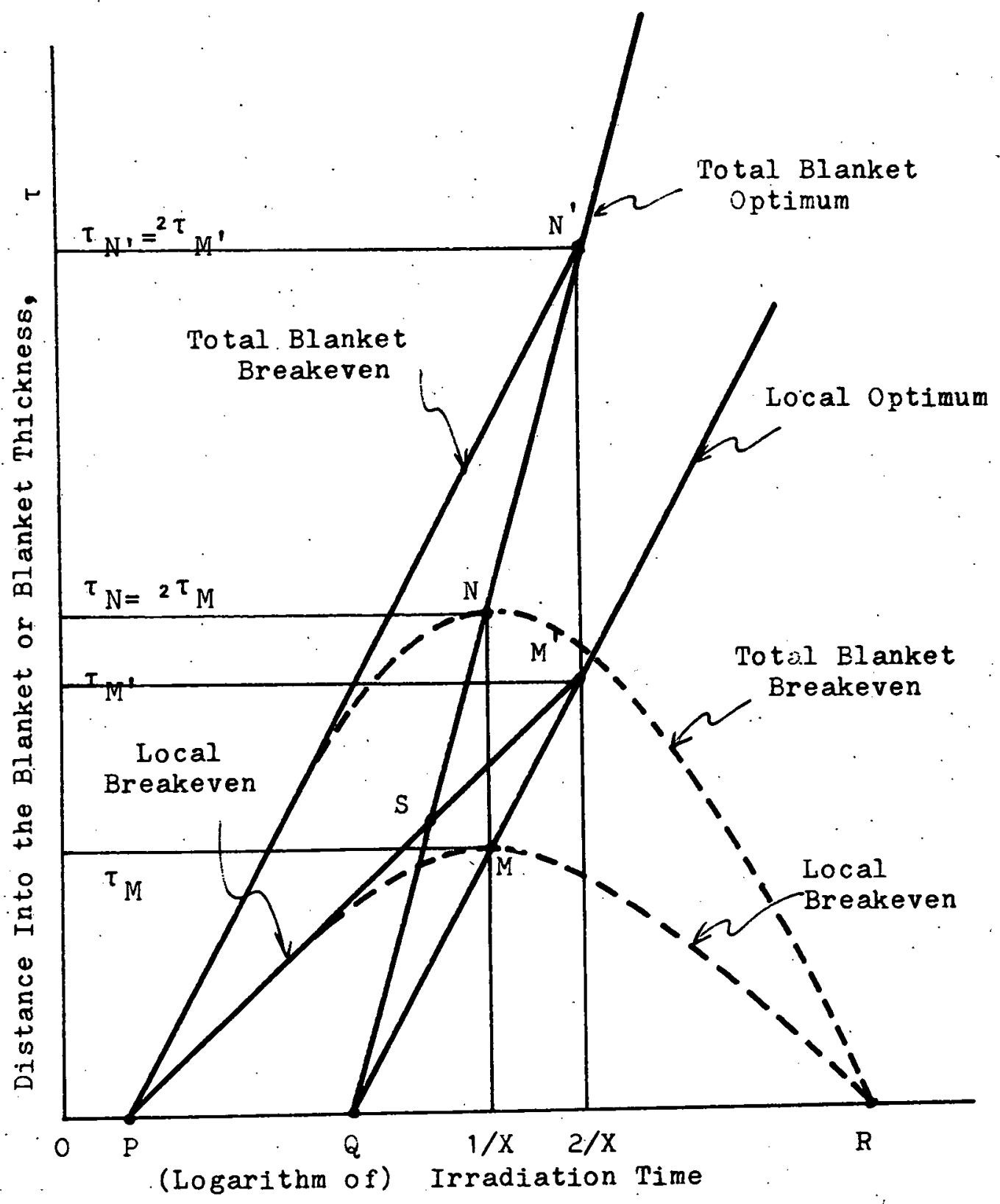

Fig. 5.4 Schematic Diagram of Breakeven and Optimum Loci as a Function of Irradiation Time 


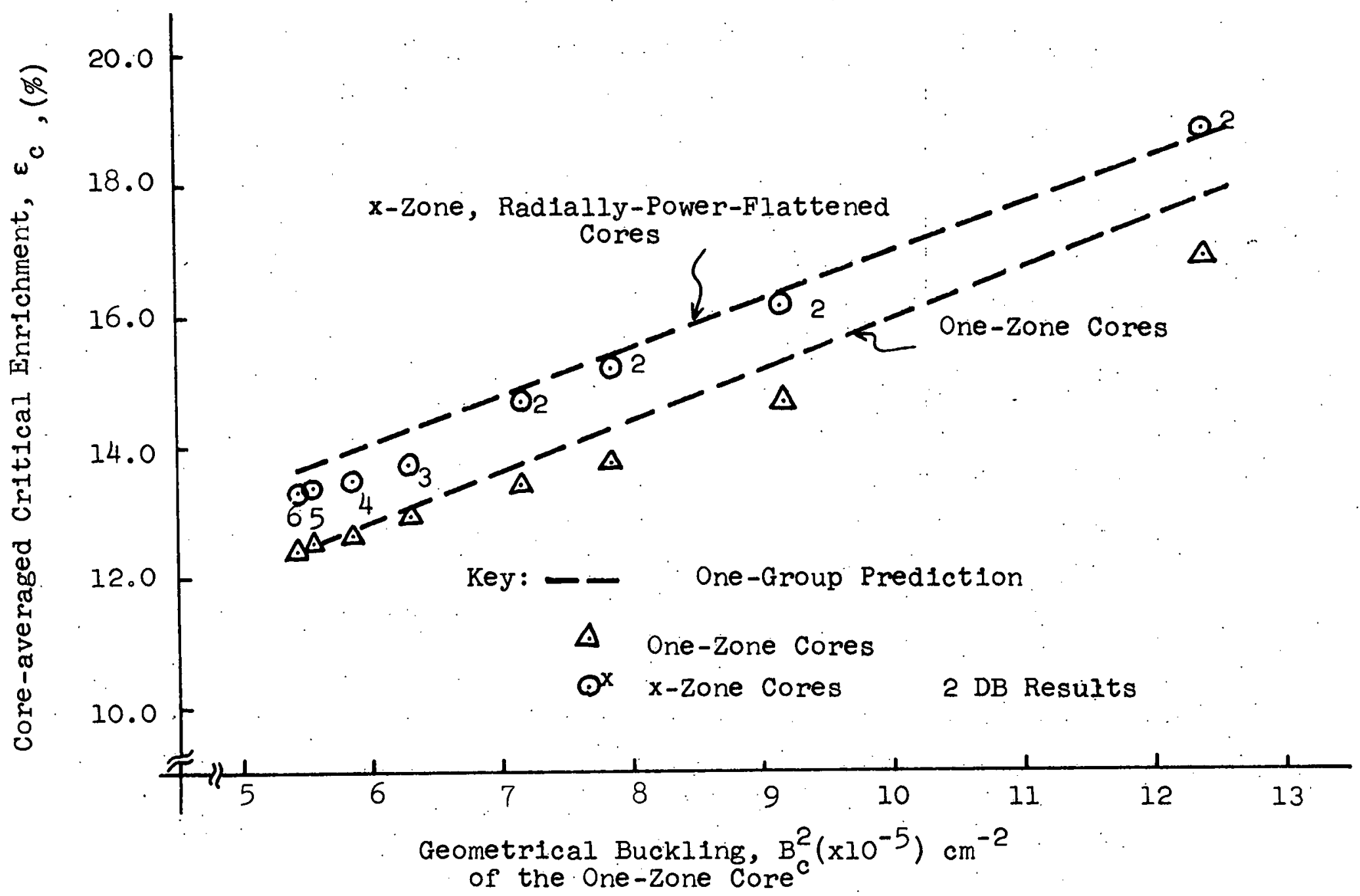

F1g. 5.5 Core-averaged Critical Enrichment as a Function of Core-size 
In the analytic 1.G.M, perfect radial power-flattening was achieved by continuous enrichment gradation: in the multigroup calculations, a finite number of enrichment zones were employed. Table 5.11 summarizes the cases investigated. The various zones were selected to have roughly equal volumes, and zone enrichment was adjusted to match peak power densities in all of the zones to within \pm 5 percent.

Figure 5.6 confirms that the central and peripheral enrichments of multizone cores tend to be the same within fairly narrow bounds. The conclusion that equal enrichment implies similar neutron spectra is confirmed by Fig. 5.7 which compares the peripheral neutron spectra of the 2-zone, 250-MWe $\mathrm{e}$ and 6-zone, $3000-\mathrm{MW} \mathrm{e}$ cores.

\subsubsection{Effect of Changing Core Radius at Constant Core Height on Blanket Performance}

\subsubsection{Radial Blanket}

Figure 5.8 shows the BOL-specific fissile inventory buildup rate, $\overline{\mathrm{S}}_{\mathrm{O}}$, (gPu/kgHM-yr) of each row of the radial blanket driven by radially power-flattened cores, which substantiates the important conclusion that $\bar{S}_{o}$ is the same for all core radii (ratings) - hence the absolute economic performance of the radial blanket assemblies is the same for all cores.

It should also be noted that the $\overline{\mathrm{S}}_{0}$ 's for rows 1 and 2 (but not 3 ) are larger than the minimum profitable fissile buildup rate, which is defined as the rate beyond which a non-negative profit can be produced: here $2 \mathrm{gPu} / \mathrm{kgHM}-\mathrm{yr}$. The same results can also be rearranged to show that the percentage of the total blanket fissile material bred in a given 


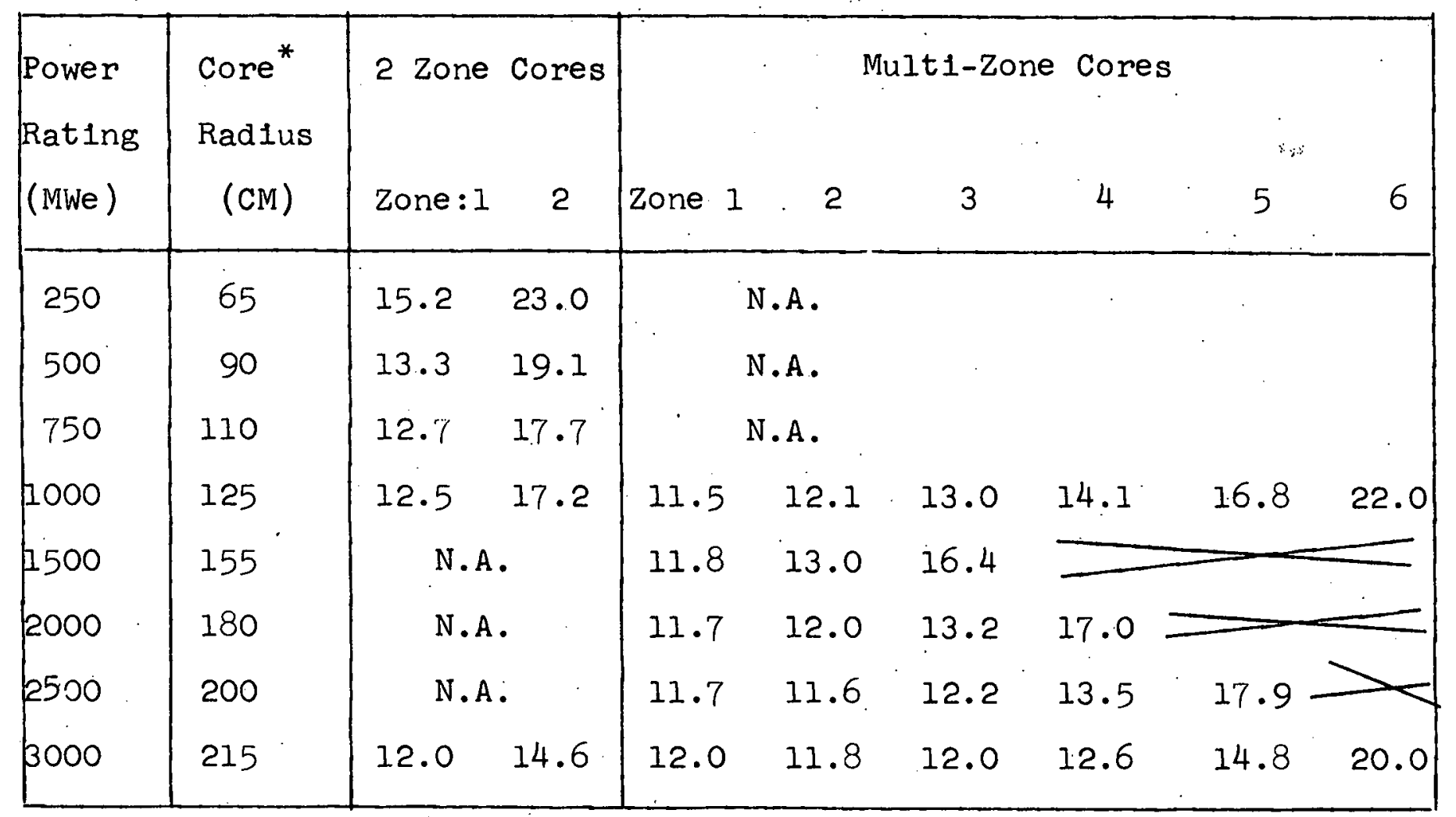

* Constant Core Height=100CM, Ail Cases

$x_{z, x}$

Table 5.11 Zone-Averaged Enrichments for Critical Beginning-Of-Life Cores of Various Ratings (2DB Calculations) 


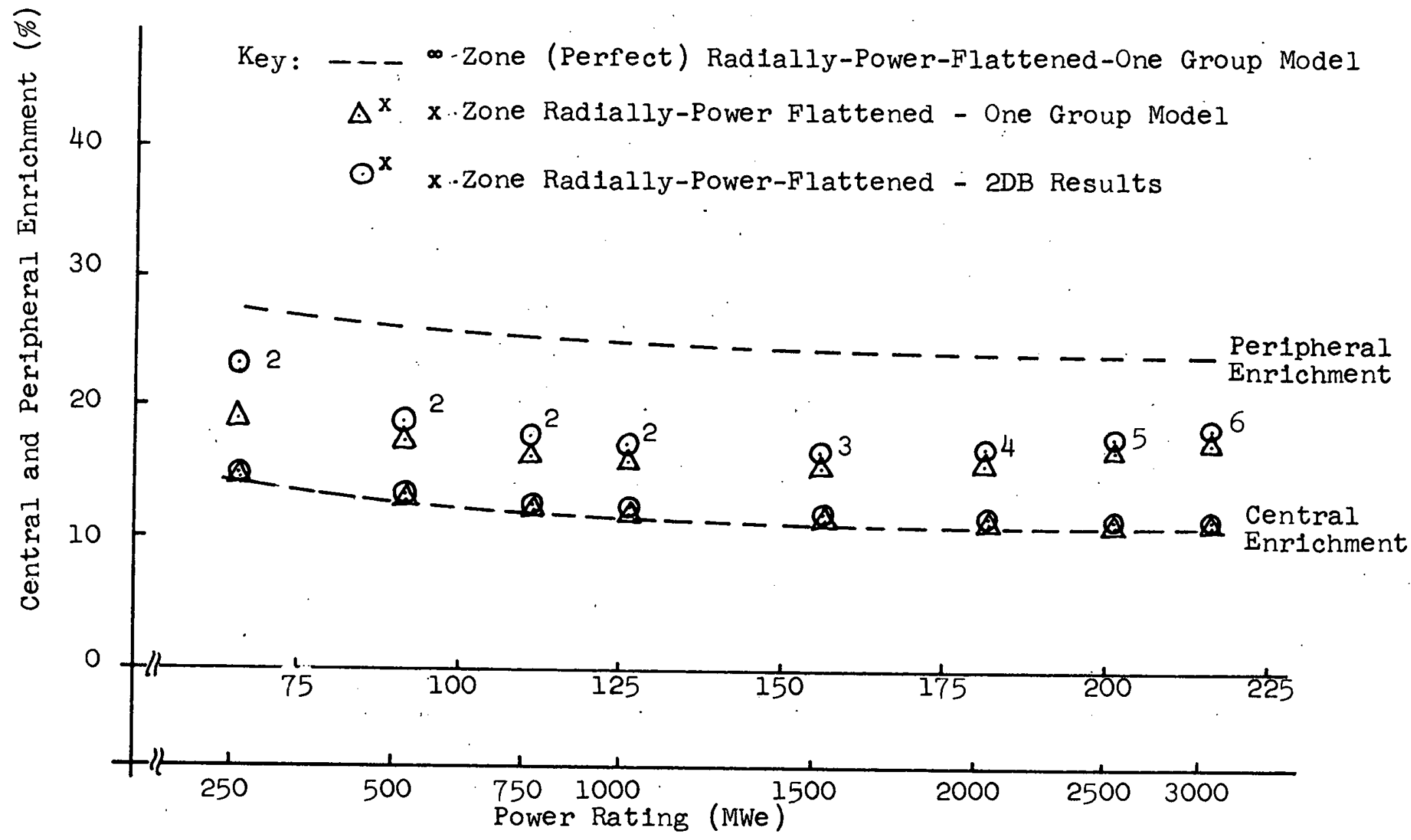

Fig. 5.6 The Effect of Core-Radius on Central and Peripheral or Central-Zone and Outermost-Zone Enrichment 


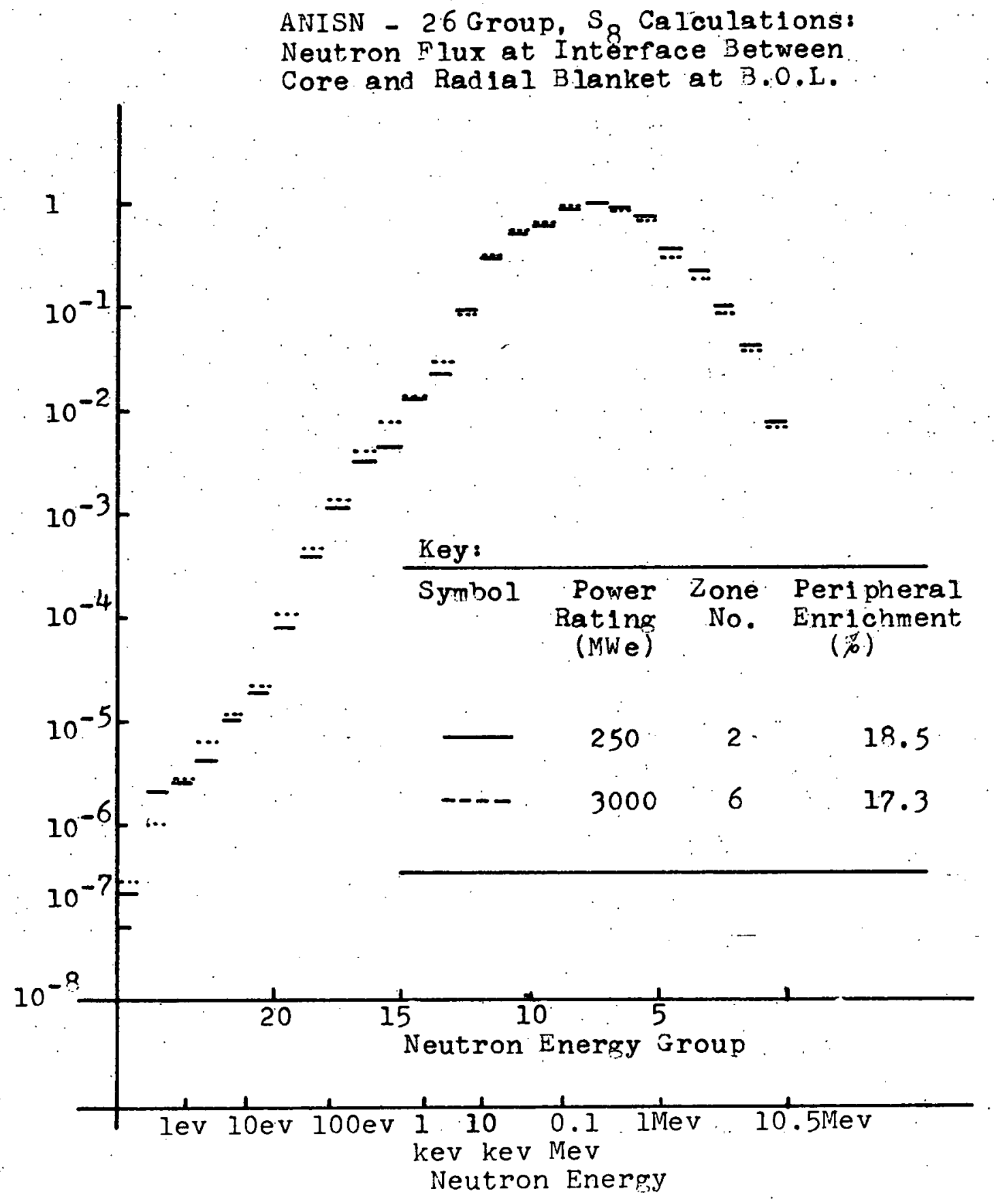

F1g. 5.7 Comparison of Peripheral Neutron Energy Spectra 


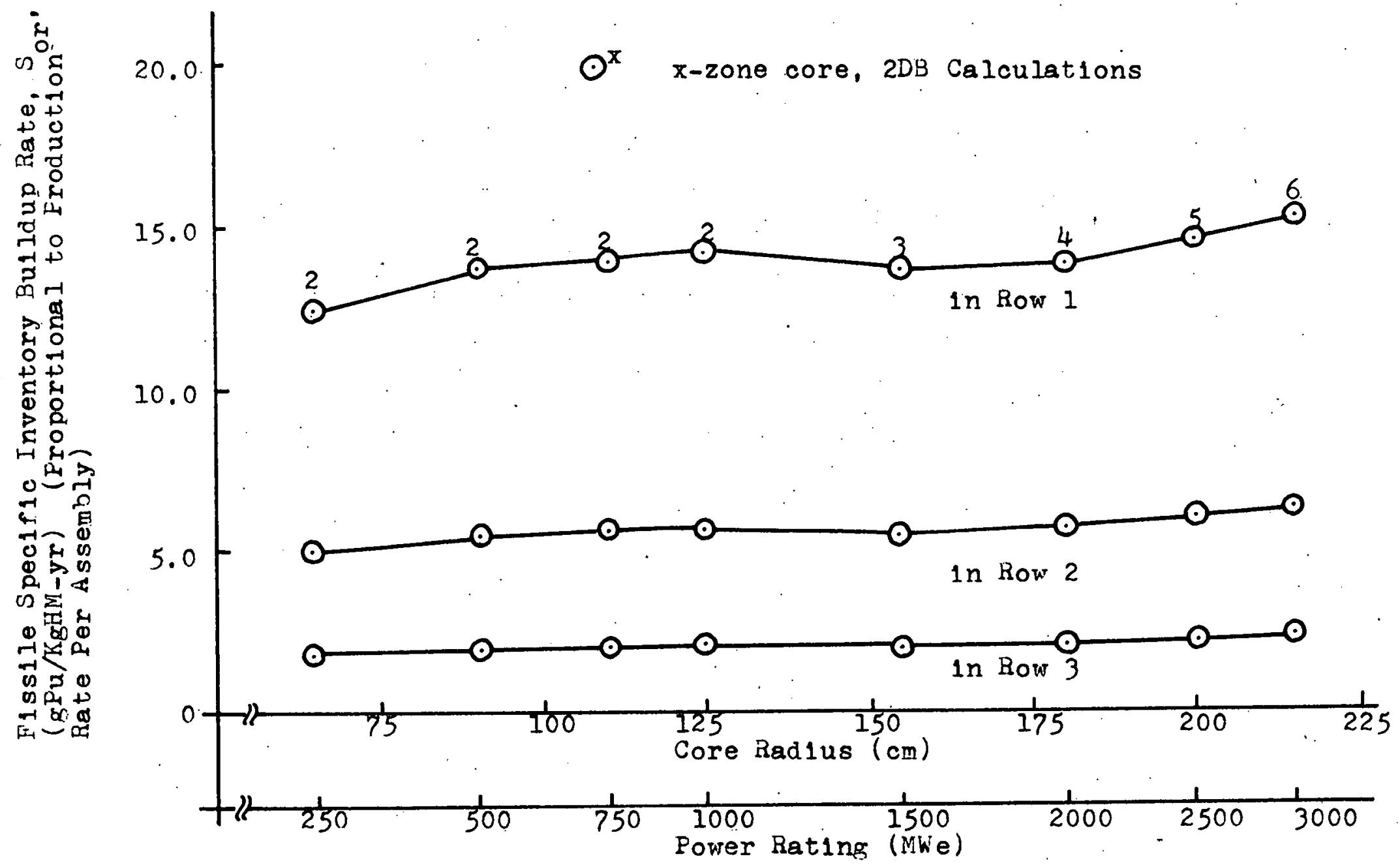

Fig. 5.8 The Effect of Core-Radius on the BOL Fissile Specific Inventory Bulldup Rate in the Radial Blanket 
row is the same regardless of core radius: approximately $60 \%$ for row $1,30 \%$ for row 2 and $10 \%$ for row 3 , which is compatible with the equivalent-slab-geometry exponential-flux approximation used for the radial blanket in deriving some of the simple model results.

Figure 5.9 shows a $\log -\log$ plot of the radial blanket breeding ratio as a function of core radius, which indicates that the log-log slope of the curve is -1.0 , and thus the radial blanket breeding ratio is inversely proportional to core radius for RPF cores, as predicted by the simple 1GM. This implies that the relative importance of the radial blanket in fissile breeding decreases as the core radius increases, as expected. The more rapid decrease in blanket breeding ratio for one-zone cores is also illustrated.

\subsubsection{Axial Blanket}

Figure 5.10 shows the product of the core-averaged critical enrichment, $\varepsilon_{C}$, and the BOL-fissile specific inventory buildup rate, $\overline{\mathrm{S}}_{\mathrm{O}}$; of the axial blanket driven by either radially power-flattened or uniformly loaded cores, which indicates that the product $\left(\bar{S}_{O} \varepsilon_{c}\right)$ is essentially constant, as predicted by the 1GM when one allows for the decrease in core-averaged enrichment with reactor size. The figure also shows that $\overline{\mathrm{S}}_{\mathrm{o}}$ increases slightly with the core radius but is very nearly constant for the larger cores investigated.

Figure 5.11 shows the product of the core-averaged critical enrichment and the axial blanket breeding ratio as a function of core radius, which indicates that the product is constant and the axial 


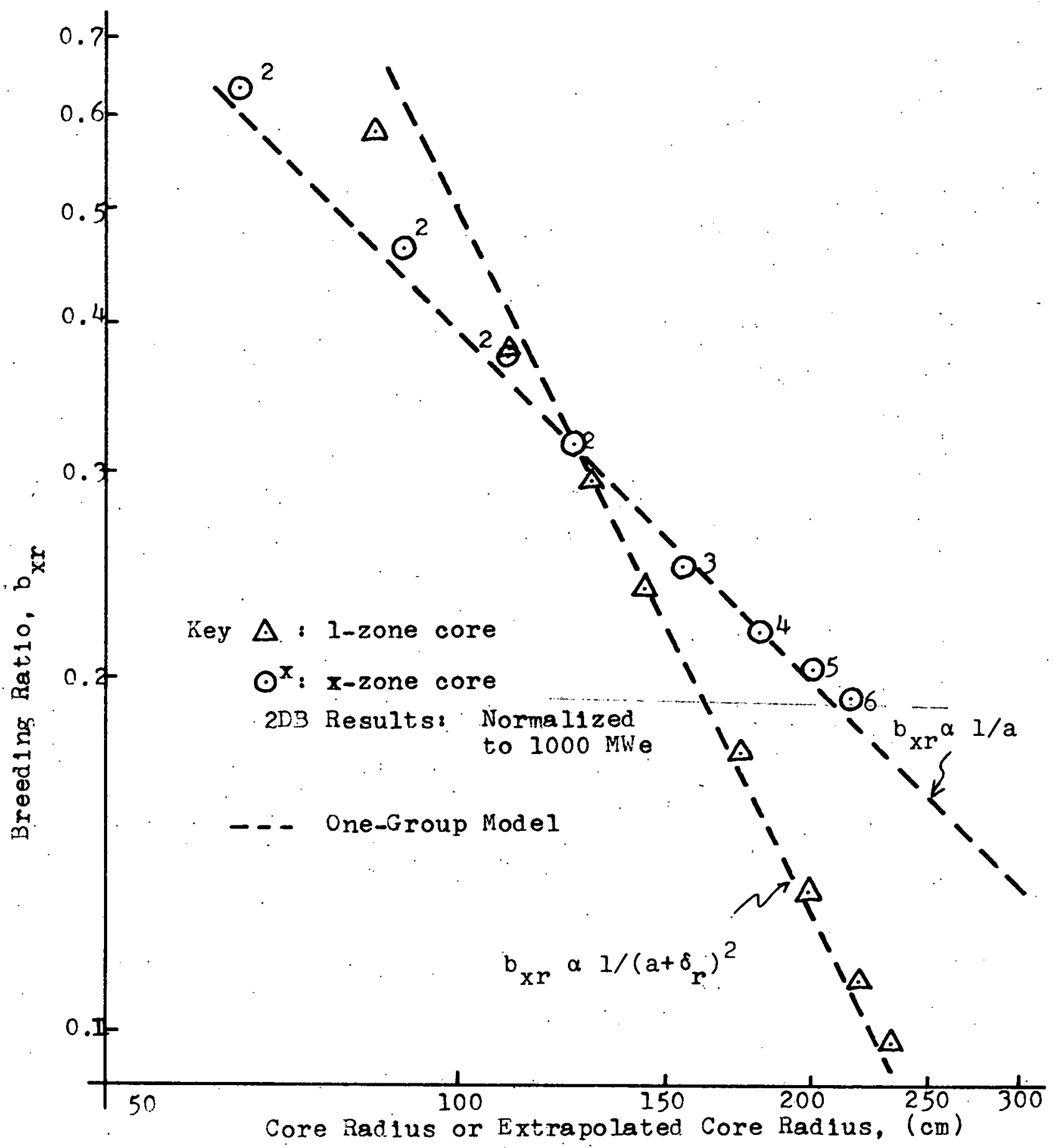

F19. 5.9 The Effect of Core Radius on Radial Blanket Breed Ing Rat1o 


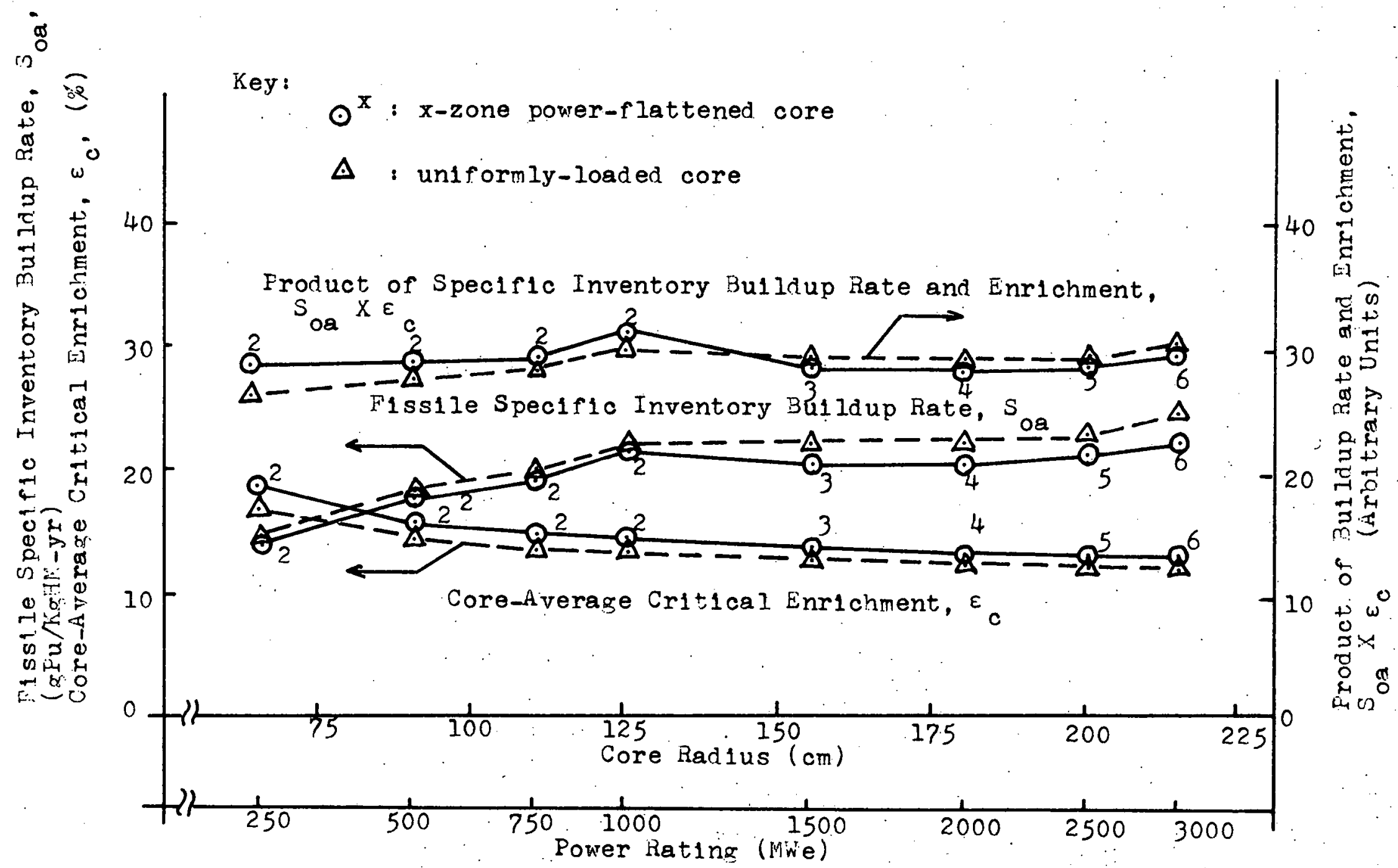

Fig. 5.10 rine Effect of Core-Radius on ine 30L Fissile specific Inventory Bulldup Rate in the Axial Blanket 


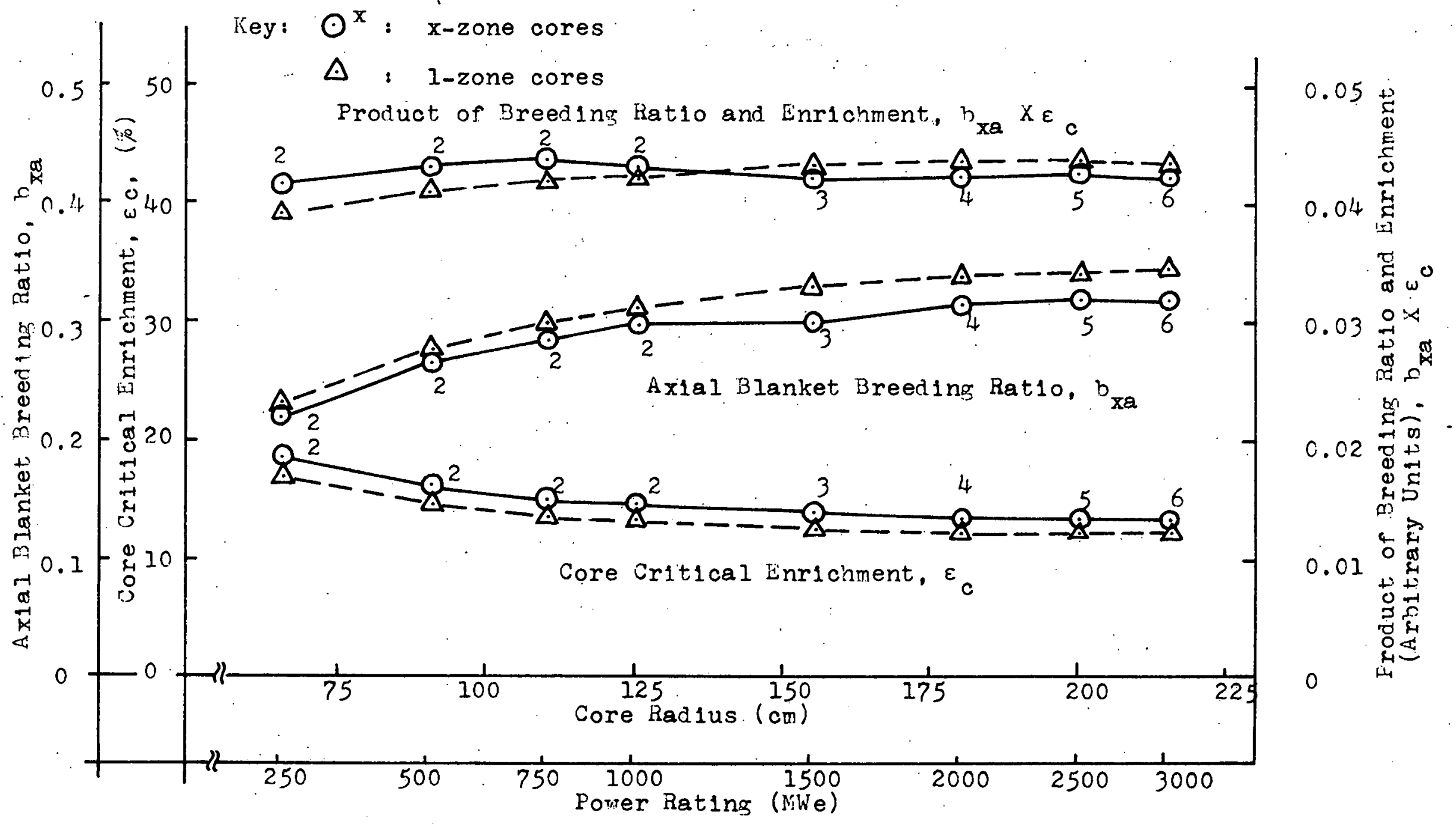

Pig. 5.11 Product of Axial Blanket Breeding Ratio and Core-Averaged Critical Enrichment as a Function of Core-Radius 
blanket breeding ratio increases slightly with the core radius but is : again very nearly constant for the larger cores examined.

\subsubsection{Combined System Breeding Performance}

Figure 5.12 shows the internal (core) breeding ratio, the blanket breeding ratio (sum of axial and radial blankets) and the total breeding ratio (core plus blanket) as a function of core radius for either radially power-flattened or uniformly loaded cores, which illustrates several interesting points in agreement with the predictions of the $1 \mathrm{GM}$ :

1) The internal (core) breeding ratio increases but does not exceed unity, even in the largest cores; the blanket breeding ratio decreases as core radius increases; the total breeding ratio remains very nearly the same. The total breeding ratio appears to be anomolously high $(\sim 1.5)$ because the results are for a BOL clean core without control pois on or excess enrichment to compensate for burnup.

2) The internal breeding ratio for radially power-flattened cores is slightly less than for uniformly loaded cores because of slightly higher critical mass in the former.

3) The blanket breeding ratio for radially power-flattened cores is higher than that for uniformly loaded cores because of the higher radial breeding ratio due to radial power-flattening. 


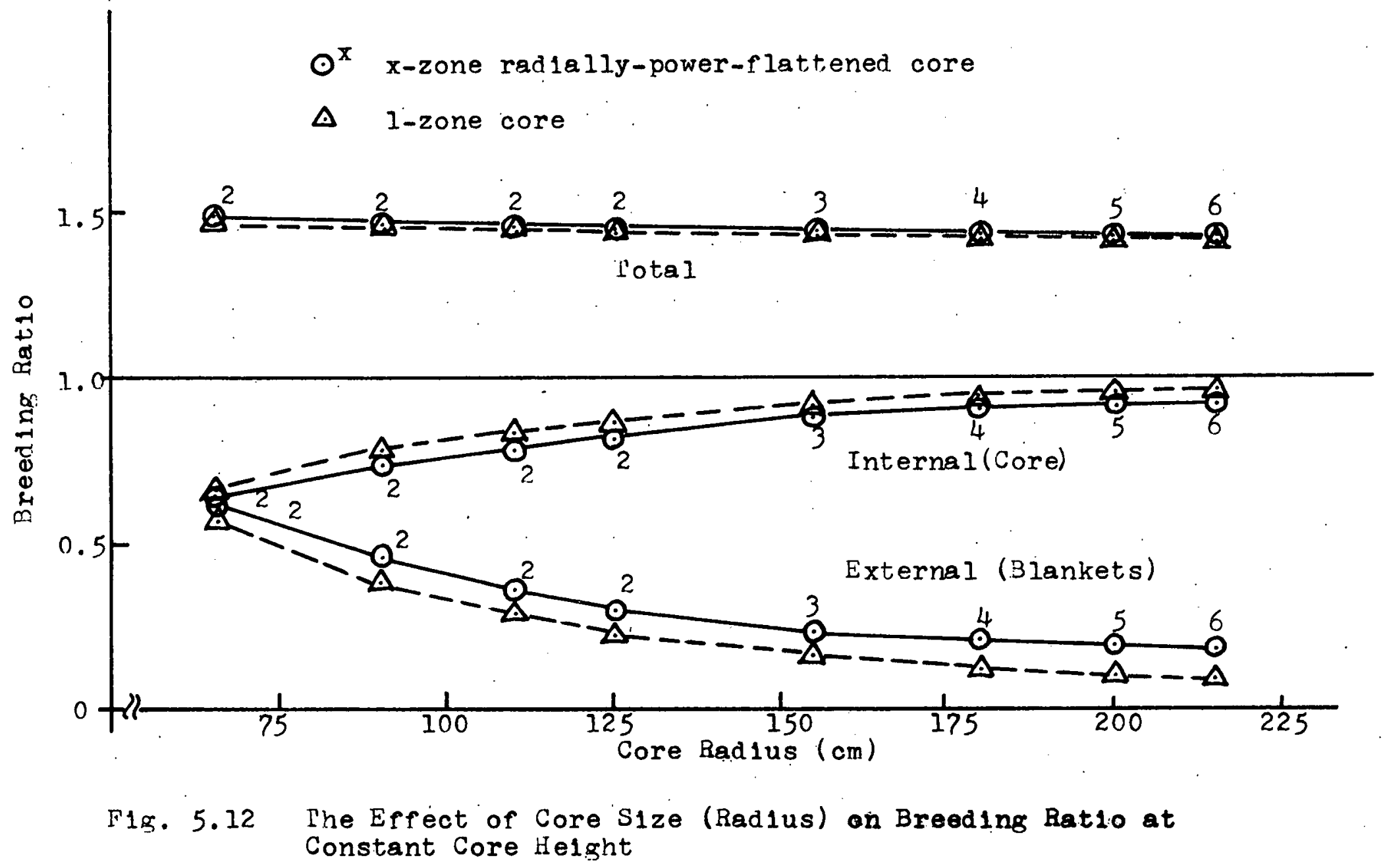




\section{3. 3 Effect of Changing Core Height at Constant Core Radius} on Breeding Performance

Although most reactor designers evidently prefer to scale-up LMFBR designs by increasing core radius at constant core height, for completeness, and as a further test of the 1GM predictions, a series of core height variations at constant radius were studied starting with the reference design 1000-MW $\mathrm{e}$ 2-zone core.

Figure 5.13 shows the radial blanket breeding ratio driven by either radially power-flattened or uniformly loaded cores as a function of core height, which indicates that the breeding ratio is the same regardless of core height. The predictions of the one-group model are in good agreement with the $2 \mathrm{DB}$ results.

Figure 5.14 shows the axial blanket breeding ratio driven by either radially power-flattened or uniformly loaded cores as a function of core height. The 2DB results confirm the 1GM prediction of a variation proportional to $\left(\mathrm{H}+2 \delta_{\mathrm{a}}\right)^{-2} \varepsilon_{\mathrm{c}}^{-1}$.

Figure 5.15 shows the internal breeding ratio, the blanket breeding ratio and the total breeding ratio as a function of core height, which indicates that:

1) The internal breeding ratio increases as core height increases, and ultimately exceeds unity; the blanket breeding ratio decreases as core height increases and the total breeding ratio remains very nearly constant.

2) The internal breeding ratio for radially power-flattened cores is less than that for uniformly loaded cores because of the higher critical mass of the former. 


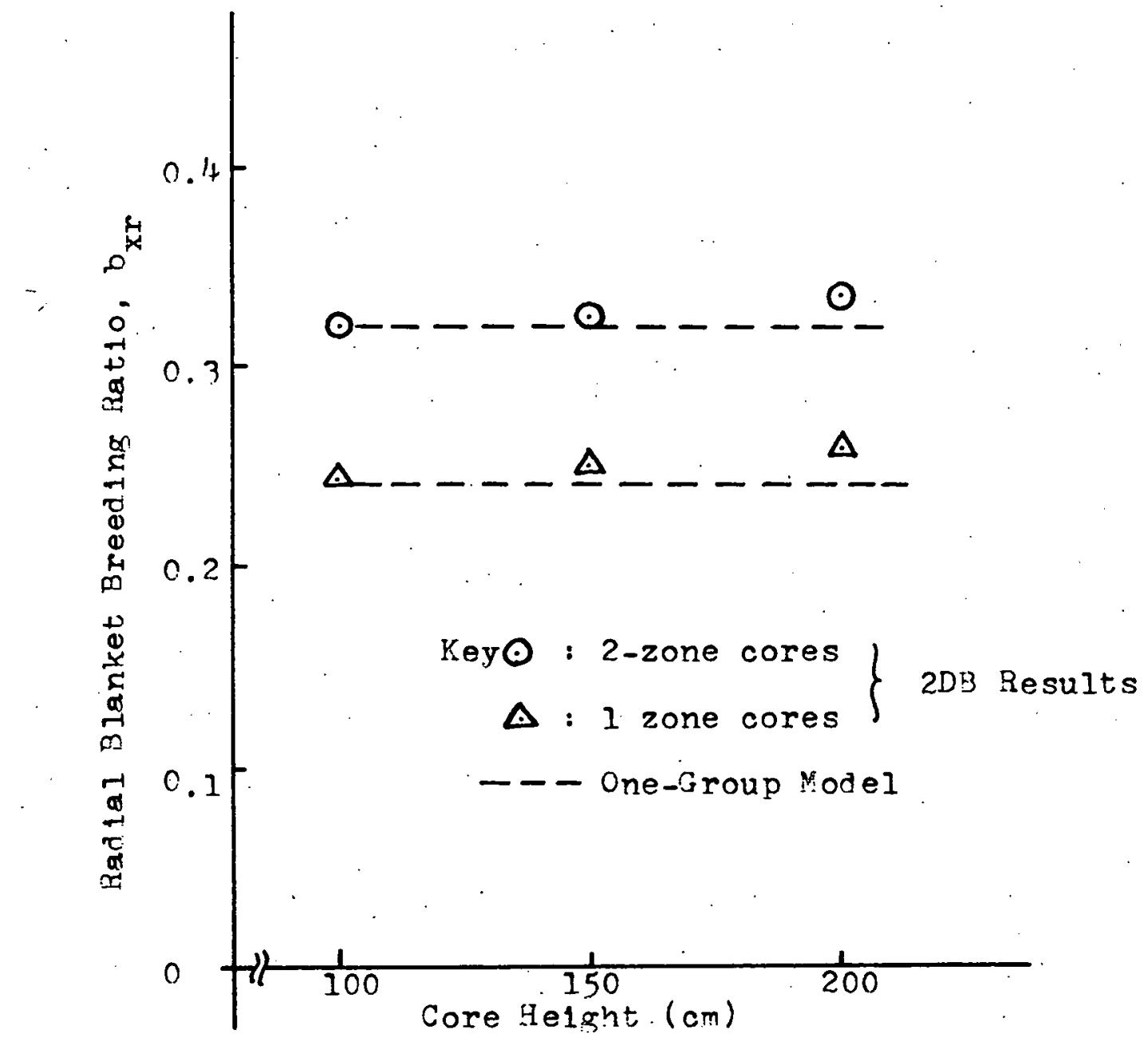

F1. 5.13 The Effect of Chang1ng Core Helght at Constant Core hadtus on the Radial 3 lanket Breeding Ratio 


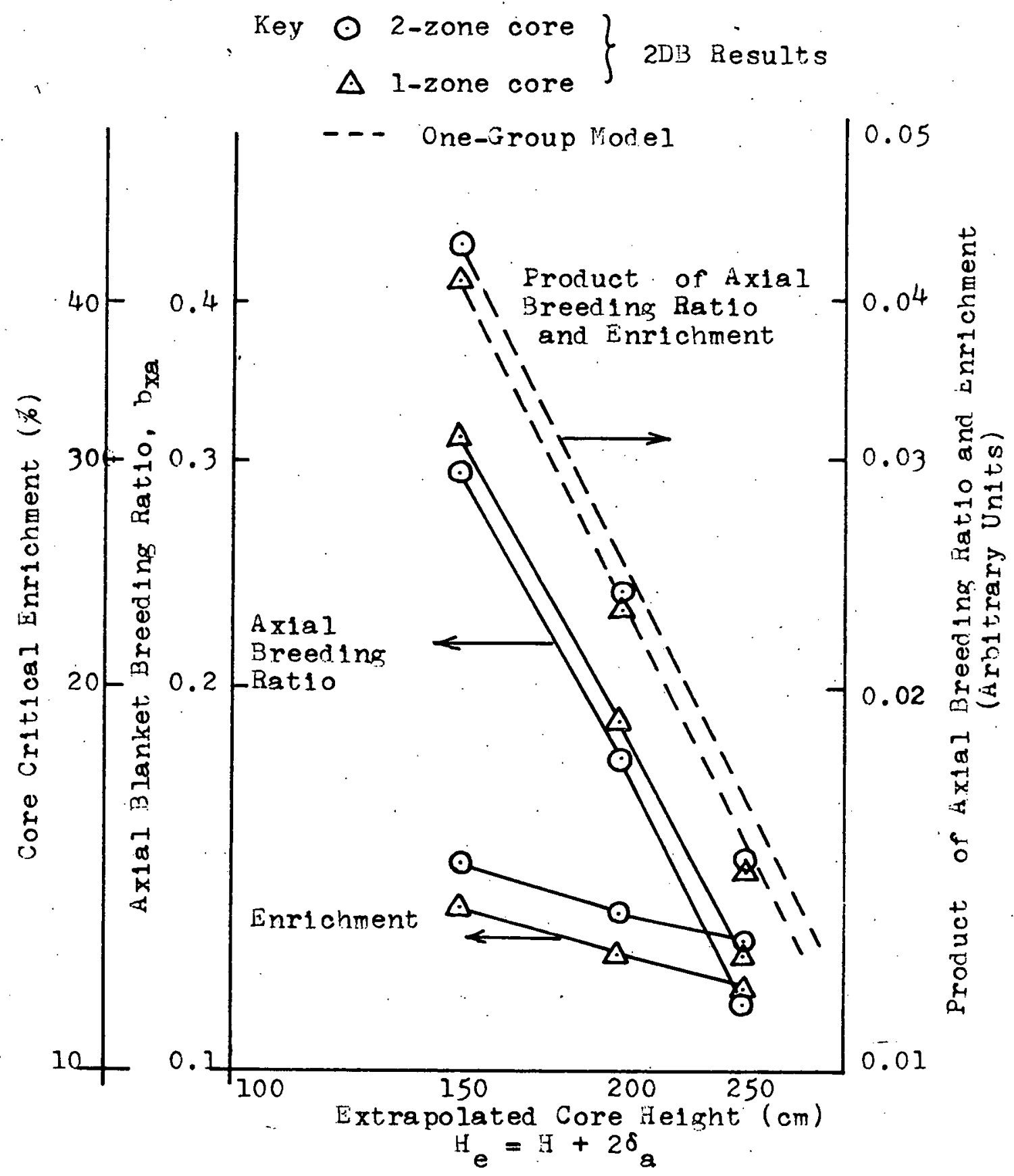

F19. 5.14 The Effect of Changing Core leight at Constant Core Radius on Axial Blanket Breeding Performance 


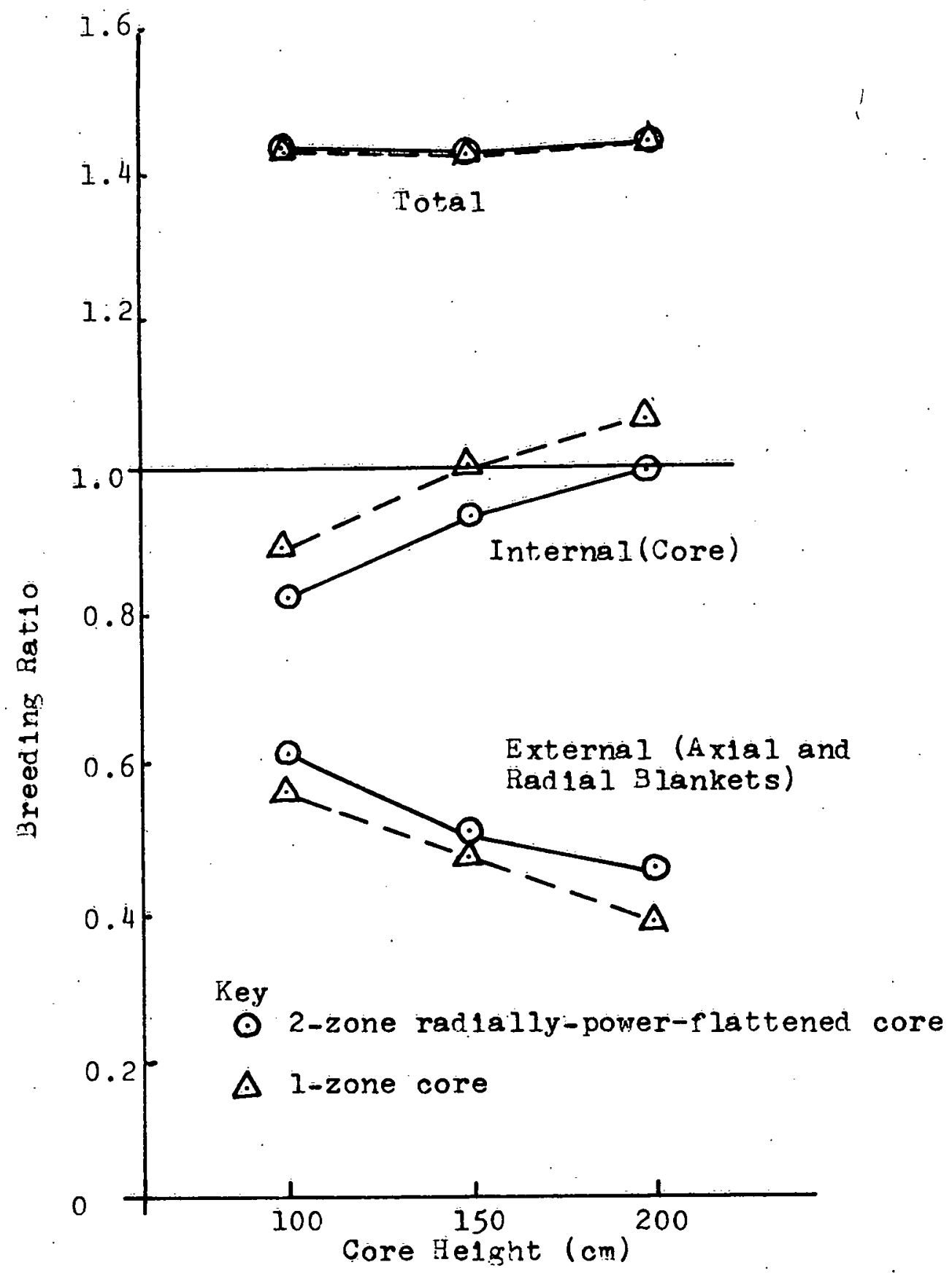

Fig. 5.15 The Effect of Changing Core Height at Constant Core Radius on the Breeding Rat10 
3). The blanket breeding ratio for radially power-flattened cores is higher than that for uniformly loaded cores, but the total breeding ratio is the same regardless of the type of core loading.

Thus an increase in core height at constant core radius does not lead to an improvement in overall breeding performance.

\section{4 DEPLETION-ECONOMICS RESULTS}

Good agreement between the predictions of simplified analyses and 2DB-BRECON calculations has been obtained for the depletioneconomics performance of LMFBR blankets. Useful correlations of blanket-breeding-performance characteristics, such as breakeven and optimum irradiation times and thicknesses, have been formulated using $2 \mathrm{DB}-\mathrm{BRECON}$ calculations correlated against the parameters singled out in the simplified analysis.

Figure 5. 16 shows the breakeven irradiation times for rows 1 and 2 and the optimum irradiation time for row 1 of the radial blanket as a function of core radius, which indicates that both breakeven and optimum times are, the same for all core radii (power ratings) within half a refueling interval (assumed to be $\frac{1}{2} \times 300=150$ full power days).

- The agreement with the predictions of the simple model is therefore good on this important point.

Figure 5.17 shows the revenue per unit mass of blanket; the local (per blanket-row basis) and the total (entire-radial blanket) fuel cycle cost contribution as a function of the distance into the blanket 


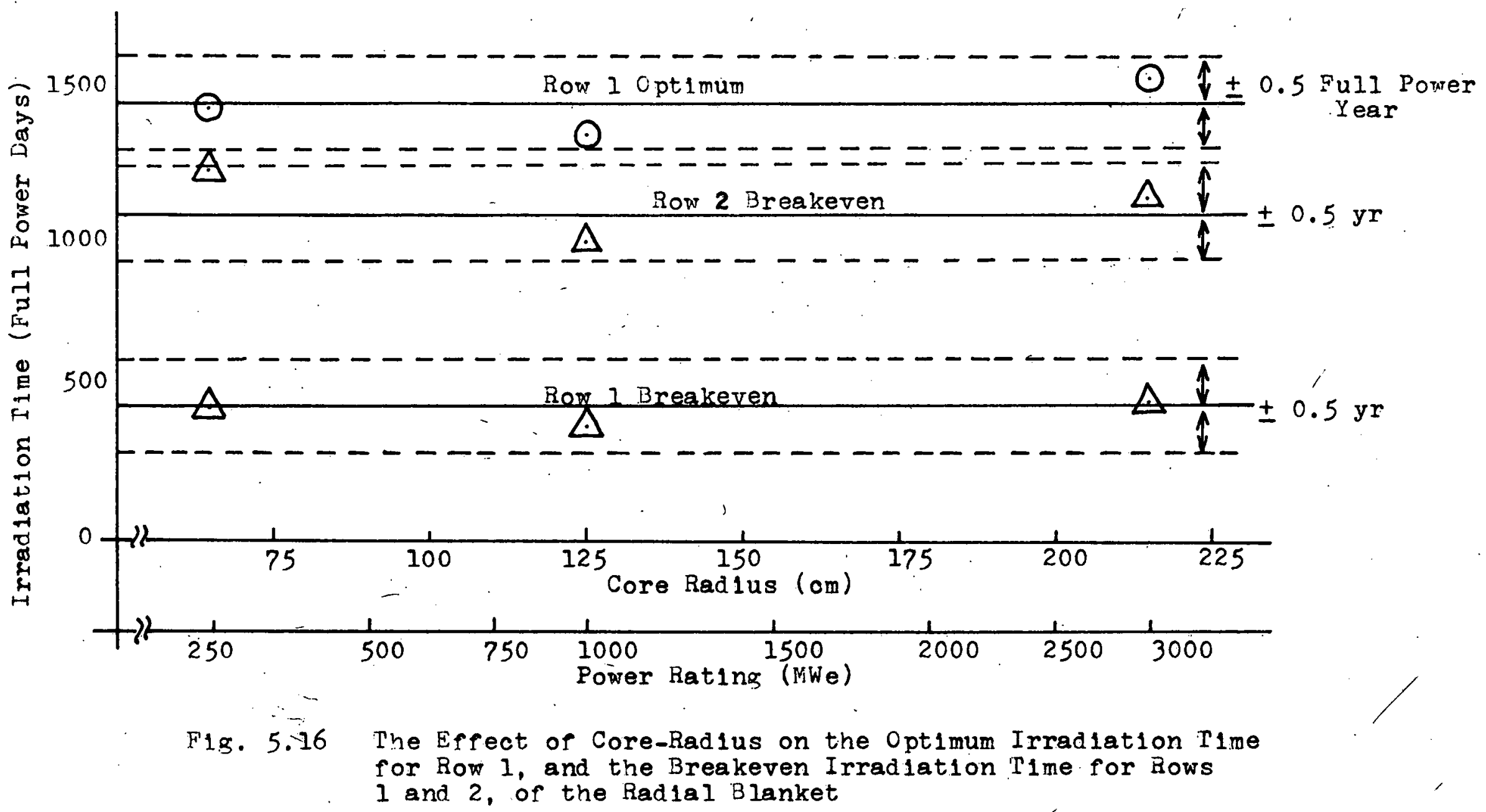




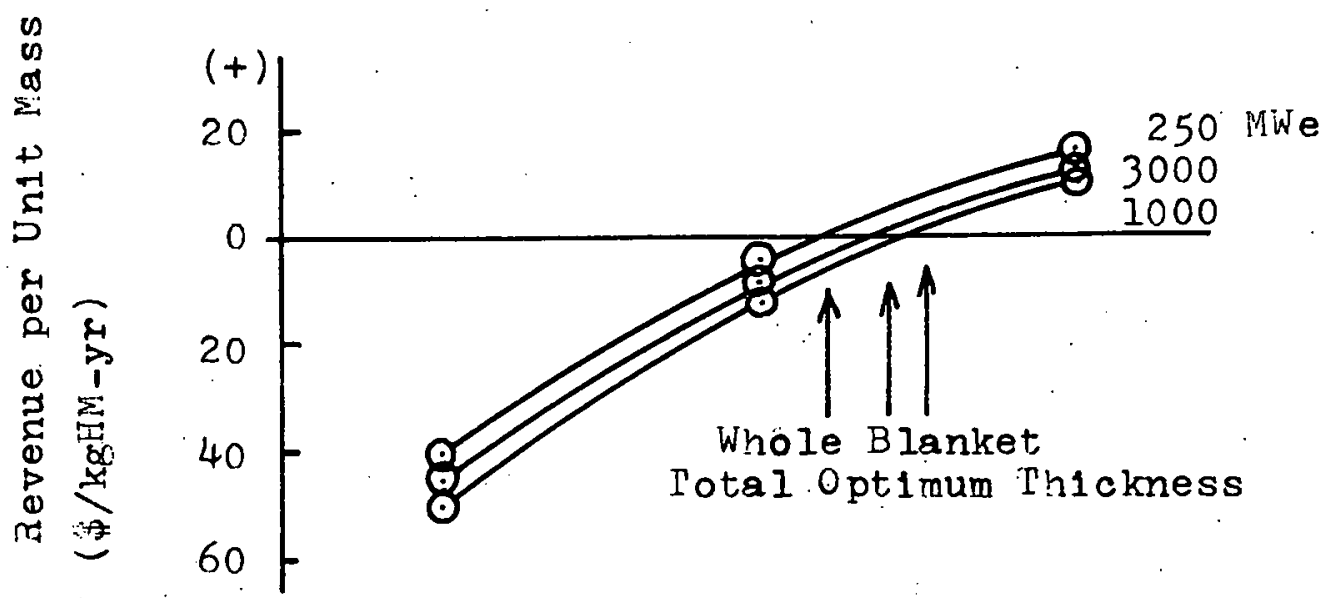

$$
(-)
$$

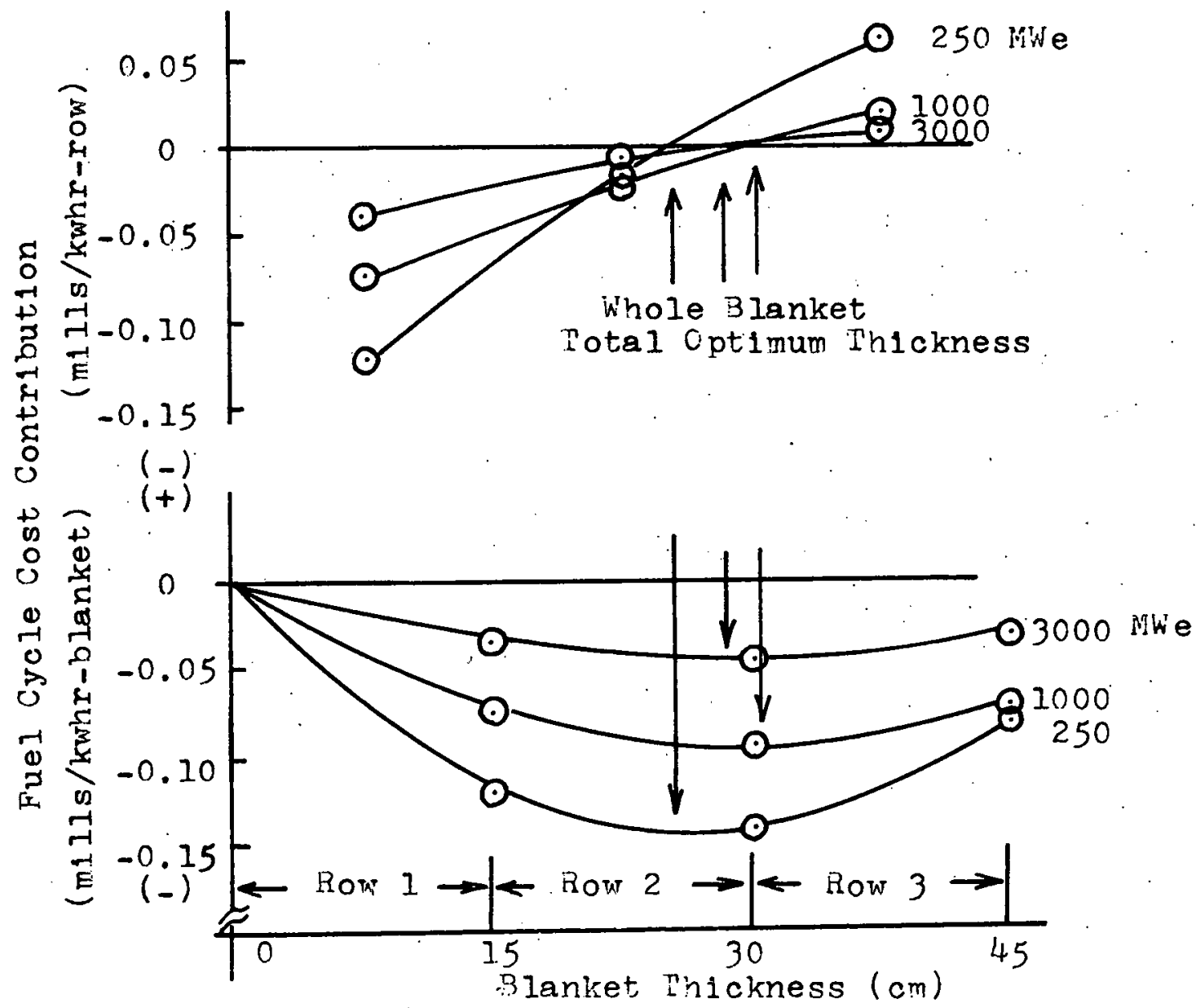

Fio. 5.17 Revenue per Blanket Assembly and Fuel Cycle Cost Contribution per Row or per Entire Batch-Irradiated Radial 3lanket as a Function of Blanket Thickness (for a Given Irradiation Time) 
(or the blanket thickness) for a given irradiation time, which indicates that the optimum thickness is the same for all core radii (power ratings) within half of a blanket assembly thickness (assumed to be $\frac{1}{2} \times 15=7.5 \mathrm{~cm}$ ).

Figure 5.18 shows the minimum fuel cycle cost contribution for each row as a function of core radius, which indicates that the minimum cost for a given irradiation time decreases approximately according to $\mathrm{a}^{-1}$, i.e:, inversely with core radius.

Table 5. 12 summarizes the correlation coefficients for region $\mathrm{j}$ :

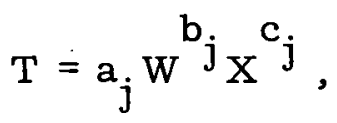

comparing the predictions of the simplified model and the original results from the state-of-the-art computations using $2 \mathrm{DB}-\mathrm{BRECON}$. The range of parameters characterizing the economic environment used in obtaining the correlation is shown in Table 5.13. The utility of the : simplified model in singling out the important parameters ( $W$ and $X)$ for use in the correlations is evident. Figure 5.19 shows a typical comparison of correlated and original 2DB-BRECON results for the optimum and breakeven irradiation times for row 1 in the radial blanket driven by a radially power-flattened core (1000-MW, 2 -zone). The correlation can predict the optimum and breakeven irradiation times within half of the refueling interval (here $\frac{1}{2} \times 300=150$ full power days).

Figure 5.20 compares for the four key correlation curves, predictions of the simplified model and the $2 \mathrm{DB}-\mathrm{BRECON}$ results. The semilog linear relation between thickness and time is shown to be an excellent approximation, except for the "local breakeven" curve, which curves downward for large thicknesses and long irradiation time. 


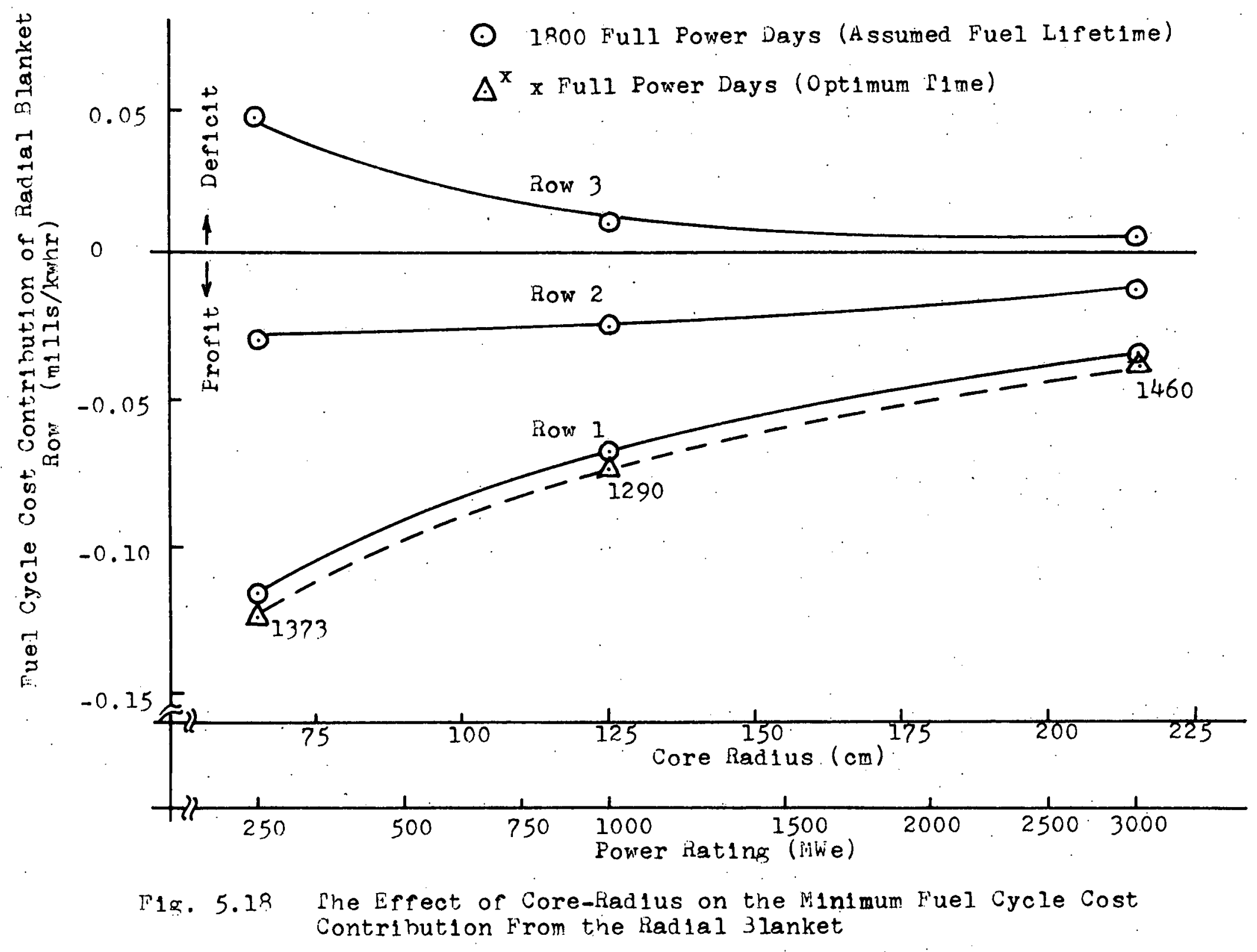




\begin{tabular}{|c|c|c|c|c|c|c|c|c|}
\hline & & $\bullet$ & SImpI & If led Mo & & $2 \mathrm{DB} B R$ & $\mathrm{CON}$ & \\
\hline & & & & $b_{j}$ & $c_{j}$ & $a_{j}$ & $\mathrm{~b}_{j}$ & $c_{j}$ \\
\hline & & Row 1 & 2.64 & $\times 10^{4}$ & & $8.75 \times 10$ & 1.14 & 0.17 \\
\hline & 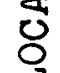 & Row 2 & 6.38 & 1.0 & 0.0 & 85.5 & 1.28 & 0.46 \\
\hline 叒 & & Row 3 & 10.8 & & & & & \\
\hline 気 & $\theta$ & 1 Row Blkt & 2.64 & & & 8.75 & 1.14 & 0.17 \\
\hline & 由े & 2 Row B1kt & 38.2 & & & 34.6 & 1.30 & 0.28 \\
\hline & & 3 Row Blkt & 53.4 & & & 75.3 & 1.34 & 0.40 \\
\hline & & Row 1 & 3.98 & $x 10^{3}$ & & $9.22 \times 10^{\circ}$ & 0.54 & -0.15 \\
\hline & 8 & Row 2 & 6.19 & 0.5 & -0.5 & 7.75 & 0.40 & -0.24 \\
\hline & & Row 3 & 10.0 & & & & & \\
\hline 总 & $\theta$ & 1 Row Blkt & 3.98 & & & 9.22 & 0.54 & -0.15 \\
\hline 통 & 봉 & 2 Row Blkt & 4.79 & & & 10.3 & 0.52 & -0.18 \\
\hline & & 3 Row Blkt & 5.66 & & & 10.2 & 0.50 & -0.24 \\
\hline
\end{tabular}

Table 5.12 Comparison of Correlation Coefficlents Predicted by the Simplified Model to Those Obtained by Curve-Fitting 2 DB-BRECON Results 


\begin{tabular}{|l|l|l|}
\hline Parameter (Units) & Th1s Study & Wood (W2) \\
\hline Value of F1ssile $\mathrm{P}_{\mathrm{u}}\left(\$ / \mathrm{gP}_{\mathrm{u}}\right)$ & 6.0 to 14.0 & 6.0 to 16.0 \\
69 to 140 & 69 to 140 \\
Fabrication Charges $(\$ / \mathrm{kgHH})$ & 50 to 100 \\
Reprocessing Charges $(\$ / \mathrm{kgHH})$ & 50 to 100 & 0.075 to 0.085 \\
\hline Discount Rate $\left(\right.$ Year $\left.^{-1}\right)$ & 0.04 to 0.16 &
\end{tabular}

Table 5.13 Range of Varlation of Economic Parameters 


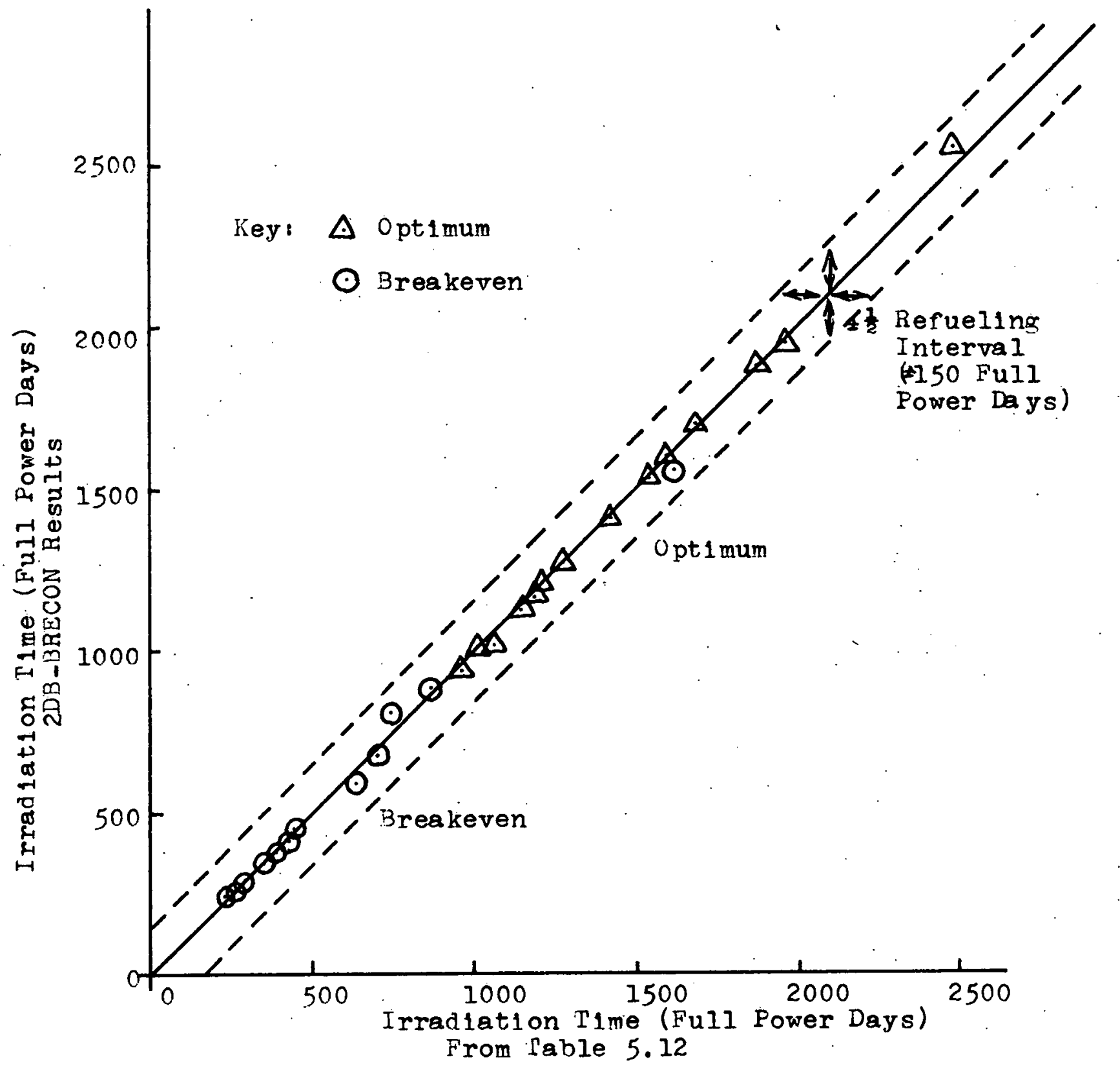

Fig. 5.19 Comparison of Optimum and Breakeven Irradiation Times for Radial Blanket - Row I Predicted by Correlation and $2 \mathrm{DB}-\mathrm{BRECON}$ 


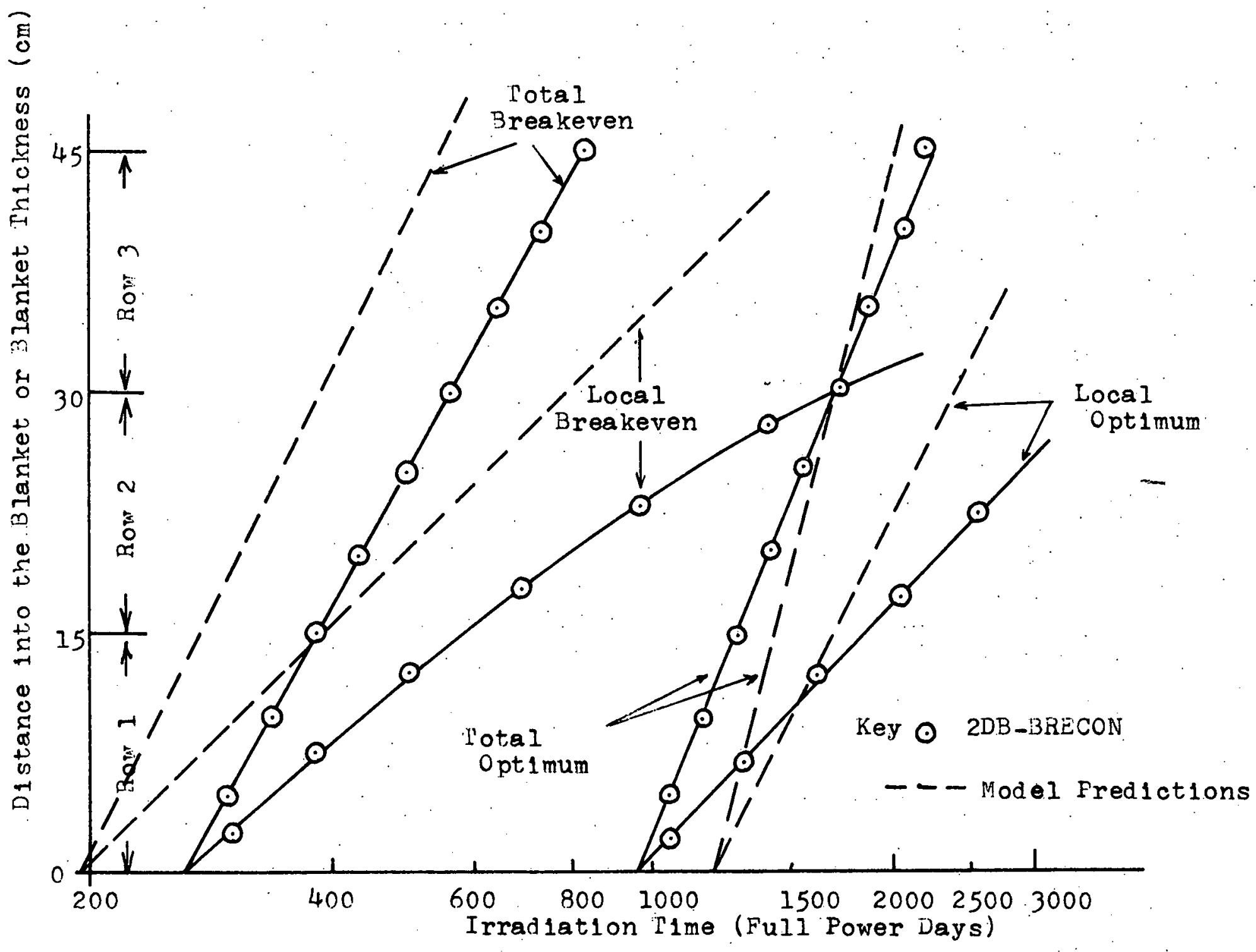

F1g. 5.20 Burnup Econamics Correlation Lines Showlng Key Loc1 
Table 5.14 compares the global optimum-point correlation coefficients predicted by the simplified model and those extracted by curvefitting the data, indicating that the model can again be used to formulate useful correlations.

Figure 5.21 compares correlated and original 2DB-BRECON results for the global optimum thickness and the optimum irradiation time for various economic environments. The correlation can predict the global optimum thickness within a half-thickness (here $7.5 \mathrm{~cm}$ ) of a blanket assembly, and the global optimum irradiation time within half of a refueling interval (here $\frac{1}{2} \times 300=150$ full power days).

Figure 5.22 compares correlated and original 2DB-BRECON results for the global minimum fuel cycle cost contribution. The agreement is good except for one point corresponding to an extreme economic environment (high $\mathrm{Pu}$ price and low discount rate).

Finally, it is concluded from the observations in this and the previous chapters that these correlations are applicable to an entire class of LMFBR core/blanket combinations characterized by constant core height and radial-core-power-flattening. 
Table 5.14 Comparison of Correlation Coefficlents for the Global Optimum: Simplifled Model vs. 2DB-BRECON

\begin{tabular}{|c|c|c|c|c|c|c|}
\hline & \multicolumn{3}{|c|}{ Simplified Model } & \multicolumn{3}{|c|}{ 2DB-BRECON } \\
\hline & $\dot{a}_{j}$ & $b_{j}$ & $c_{j}$ & $a_{j}$ & $b_{j}$ & $c_{j}$ \\
\hline $\mathrm{T}_{\mathrm{s}}$ (Full Power Days) & $1.77 \times 10^{3}$ & +0.33 & -0.67 & $1.53 \times 10^{3}$ & +0.23 & -0.45 \\
\hline$\tau_{s}(\mathrm{CM})$ & $1.15 \times 10^{-1}$ & -0.67 & -0.67 & $1.38 \times 10^{-2}$ & -0.86 & -0.82 \\
\hline$e_{s}(\mathrm{mills} / \mathrm{kwhr})$ & & & & $-1.50 \times 10^{-7}$ & -2.46 & -0.94 \\
\hline
\end{tabular}



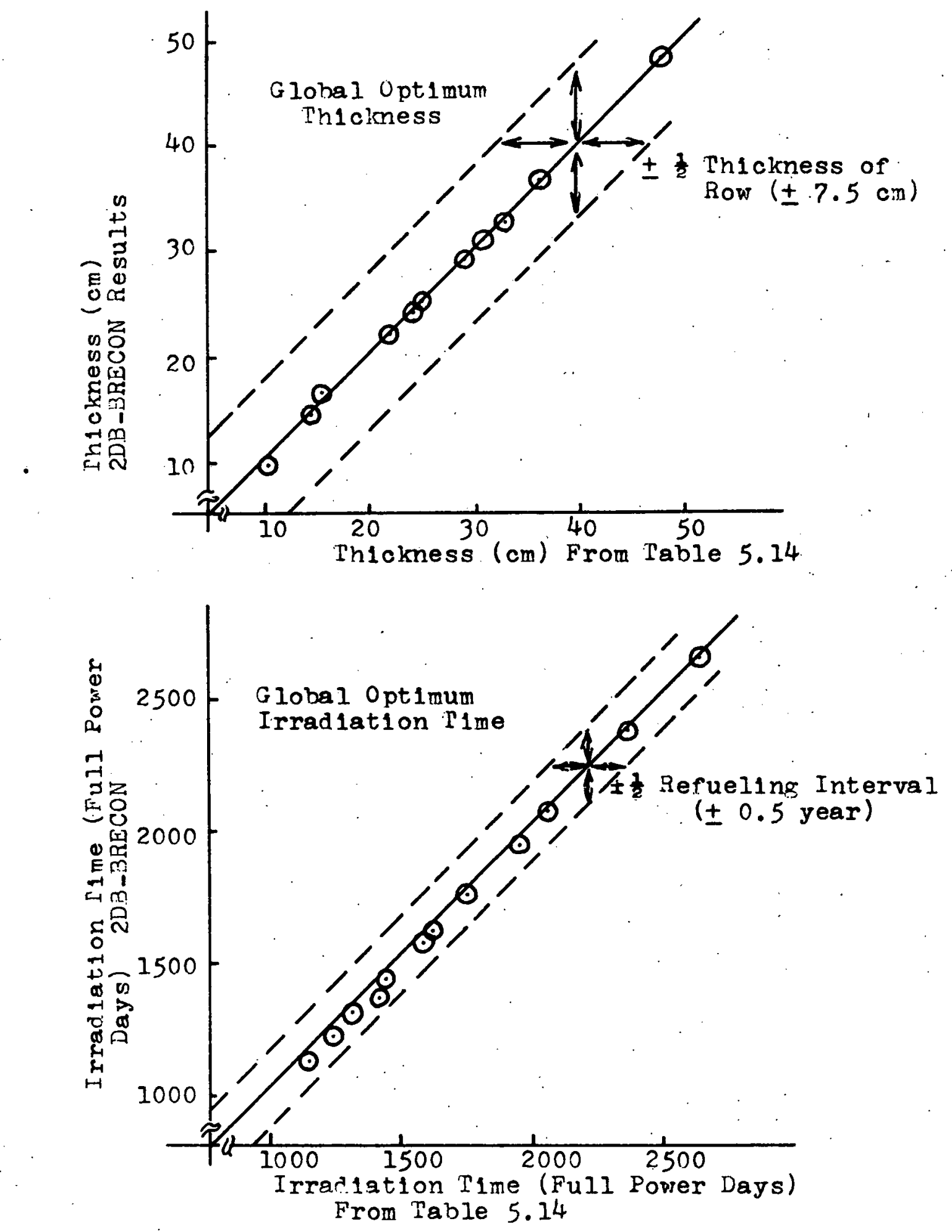

Fig. 5.21 Comparison of G.lobal Optima Predicted by Correlation and $2 \mathrm{DB}-\mathrm{BRECON}$ 


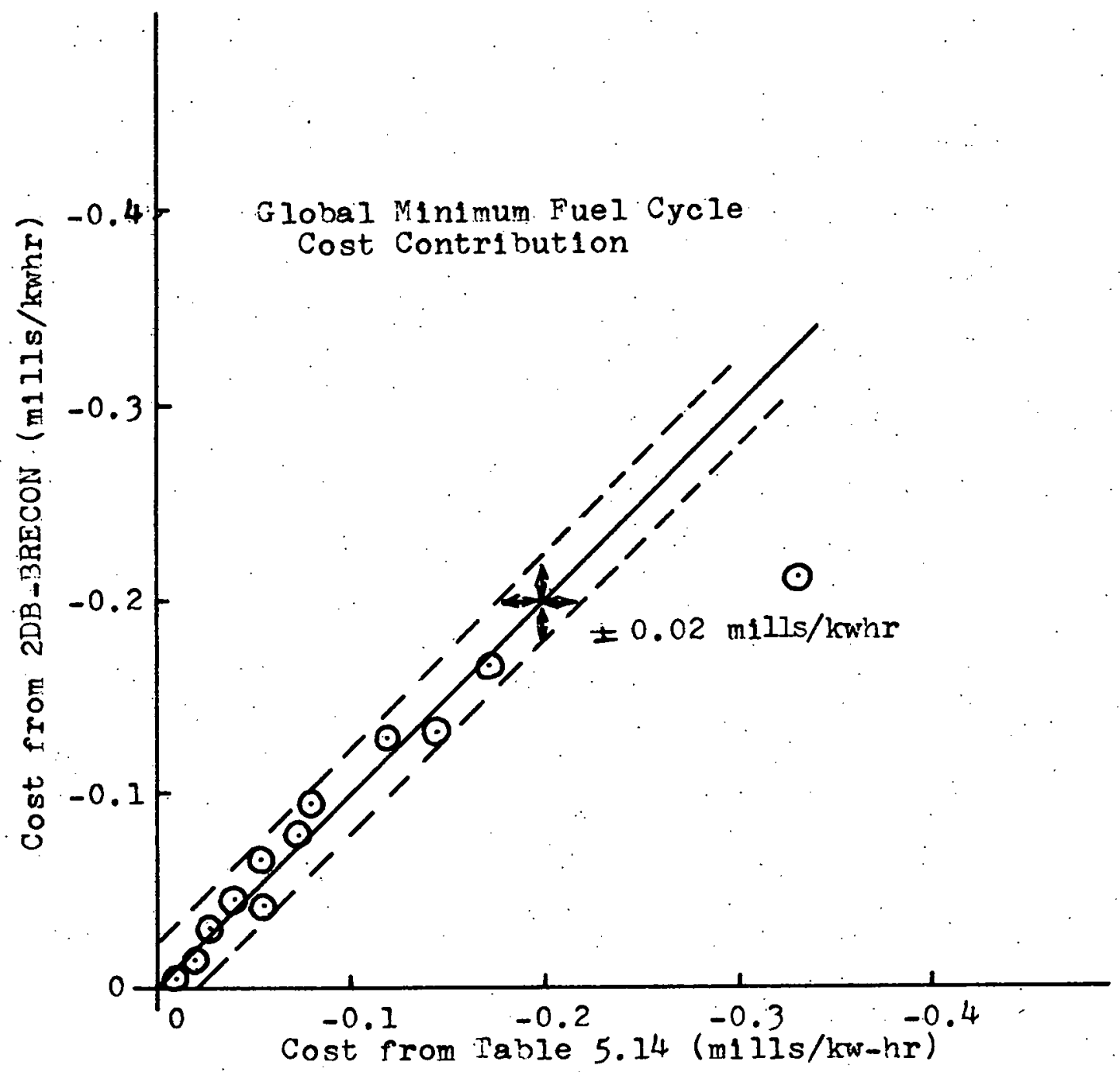

F1g. 5.22 Comparison of Globel Cptimum Costs Predicted by Correlation and $2 \mathrm{DB}-3 \mathrm{RECON}$ 


\section{5 CONCLUSIONS}

The purpose of this work - to examine the effect on blanket breeding economics of projected increases in core size in future commercial fast reactors - has been achieved using both simple models to elucidate general principles and state-of-the-art computer methods to provide realistic examples.

A one-group diffusion theory analysis of the radially powerflattened core behavior was employed to show that:

(a) The breeding ratio of the radial blanket is, to a very good approximation, inversely proportional to the core radius for constant-height cores.

(b) The fissile buildup rate per unit volume (hence per unit fertile mass or per blanket assembly) in the radial blanket remains constant as core size increases.

(c) The total fissile production rate of the entire radial blanket increases as core size increases.

(d) The peripheral core enrichment remains very nearly constant as the core radius increases. Hence the energy spectrum of neutrons leaking into the blanket will also not change significantly.

Translating these neutronic findings into their economic consequences, one finds that:

(a) Total dollar revenue per radial blanket assembly in a given row of the blanket remains constant as core size increases.

(b) Optimum blanket thickness remains constant as core size increases. 
(c) Optimum blanket assembly irradiation time remains the same as core size increases.

(d) Total blanket dollar revenue increases as core size increases.

(e) The fuel.cycle cost contribution of the radial blanket, in mills/kwhr, decreases as core size increases. Hence the blanket does become a relatively less important economic entity.

Correlations for the breakeven and optimum irradiation times for a given row or for an entire blanket under batch fuel management, and the optimum blanket thickness have been developed which can predict time within half of a refueling interval and thickness within half of an assembly thickness. These correlations involve variables, and take the form, suggested by application of a simplified economics model:

$$
\begin{aligned}
& T=a_{j} w^{b_{j}}{ }_{x}{ }^{j} \\
& \tau=\frac{1}{\gamma} \ln \left[a_{j} w^{b_{j}} x^{c_{j}}\right]
\end{aligned}
$$

where

$$
\begin{aligned}
& a_{j}, b_{j} \text { and } c_{j} \text { are the correlation coefficients of } \\
& \text { the } j \text {-th region of the blanket, } \\
& \gamma \text { is the inverse diffusion length of the blanket, } \\
& W \text { is an economic parameter, and } \\
& X \text { is the discount rate. }
\end{aligned}
$$

These conclusions wère all tested against state-of-the-art burnup-economics calculations carried out on cores in the range 
250 to $3000 \mathrm{MW}_{\mathrm{e}}$ using the $2 \mathrm{DB}$ depletion program and a 4 -group cross section set, and the BRECON cash-flow-economics program. Realistic multizone cores were examined: 2 radial enrichment zones up to 1000 $\mathrm{MW}_{\mathrm{e}}$ and progressively more for the larger ratings. The simple model predictions were all confirmed to within practically significant accuracy: for example, as the core radius was increased, optimum blanket assembly irradiation times remained constant to within plus or minus half of a core refueling interval.

Similar analyses were carried out for axial blanket performance and for the effect on both the axial and radial blankets of changing core height at constant radius, and generally similar conclusions were reached. We also showed that for the single-enrichment-zone cores the optimum radial blanket thickness would decrease with core size.

These results are significant because they indicate that on a per assembly basis, radial blanket performance on demonstration-size units will be an excellent simulation of blanket performance on future commercial units, even in very large reactors. Likewise, fuel management schemes developed now for the smaller units will be directly applicable to the larger units; designers will not have to continuously reoptimize blanket design as fast breeder reactors grow in size to take advantage of the economics of scale.

\section{6 RECOMMENDATIONS}

In fulfilling the goal of the present work, several areas have been identified in which further analysis is merited, namely: 
(1) The simple correlations developed here for the radial blanket; relating breakeven and optimum irradiation times and blanket thicknesses to the economic parameters. $\mathrm{W}$ and $\mathrm{X}$; should be extended to:

(a) Facilitate their extension to different core and blanket designs (e.g. , carbide fuel, different fuel fractions, axial blankets). with the minimum of new calculations at the 2DB-BRECON level. For example, a BOL snapshot calculation of the breeding ratio may suffice to properly normalize the correlations. It would also be extremely interesting to determine whether the exponents $(b, c)$ in the time-thickness-economics correlations involving $\mathrm{aW}^{\mathrm{b}} \mathrm{X}$ are universal in the sense that they remain invariant for different core and blanket types, with the entire difference being accommodated in the " $a$ " coefficient.

(b) Develop a better correlation for the fuel cycle cost contribution e, mills/kwhr. This would eliminate the need for a detailed economics program (e.g., BRECON). This should be feasible since the purely empirical version examined in this report is already quite successful.

(c) Deal with core economic performance. If this can be done, then it should also be possible to generalize the treatment to handle LWR or HTGR cores as well.

(2) A comparative analysis of different blanket fuel management options (e.g., zone-scatter, in-out, out-in) should be carried out using the methods of this report. The demonstration that blanket assembly performance will be independent of core size creates considerable 
incentive to devote more attention to the fine points of blanket management now, since the results will not become outdated.

(3) The results of the present analysis have important implications for experimental programs such as those carried out on blanket mockups at MIT. For example, it does not appear very useful to study blankets driven by a variety of different (simulated) cores: as we have seen, the spectrum driving the radial blanket does not change significantly with core size, and that driving the axial blanket is bracketed by the essentially fixed central and peripheral spectra. On the other hand, this work motivates even more attention to in-depth analysis of a small number of representative blankets, which can serve as models for essentially all future applications.

(4) The methods of this report should be applied to cores in which some of the radial power-flattening is achieved by radial control poison gradation, as this approach is likely to be used in addition to, or even in lieu of, extensive radial enrichment zoning.

(5) This report has concentrated on the neutronic and economic aspects of blanket breeding performance. Some further consideration of other aspects of blanket design, should be reviewed in light of its conclusions. For example, the finding that the magnitude and energy spectrum of the neutron flux in the radial blanket remains invariant as the core radius is increased also implies that assembly bowing due to stainless steel swelling will remain the same in the blanket (since swelling is roughly proportional to flux squared) - in contrast to the core 
where the average flux increases as core size increases (due to the concurrent decrease in average enrichment). In another area; Brown (B3) has shown that an economic penalty should be assigned to blanket overcooling, to account for the resulting decrease in the coreaveraged mixed-mean coolant temperature. As core radius increases, the ratio of the number of blanket to core assemblies decreases; hence the relative impact of blanket overcooling is also less.

(6) Throughout this analysis, we have employed Brewer's accounting method " $\mathrm{A}$ " in which material purchases and fabrication. charges were capitalized and consequently depreciated for tax purposes; whereas reprocessing charges and material credit were treated as an expensed cost and taxable revenue, respectively. More work needs to be done in this area of dealing with appreciating assets such as the blanket and, if method $A$ cannot be agreed on as a definitive convention, Brewer's method " $\mathrm{B}$ " should also be applied, and the results correlated using the methods of this report to determine whether blanket design and management options such as optimum thickness and irradiation time are significantly affected when compared to method A.

Finally, while an appreciable menu of future tasks has been suggested, it should not be considered as detracting from the conclusive nature of the demonstration presented here that large commercial fast reactors will have blankets which are in all essential respects the same as those found to be optimum for smaller demonstration reactors. 
Appendix A

NOMENCLATURE

\section{English Symbols}

a $=$ the core radius

$a_{j}=a$ coefficient in the economic correlation for the $j$-th region

$\mathrm{b}_{\mathrm{j}}=$ the exponent of $\mathrm{W}$ in the economic correlation for the $j$-th region

$\mathrm{b}_{\mathrm{i}} \quad=\quad$ the internal (core) breeding ratio

$\mathrm{b}_{\mathrm{x}} \quad=\quad$ the external (blanket) breeding ratio

$\mathrm{b}_{\mathrm{xr}} \quad=$, the radial blanket breeding ratio

$\mathrm{b}_{\mathrm{xa}}=\quad=$ the axial blanket breeding ratio

$\mathrm{B}_{\mathrm{r}}^{2}=$ the radial geometrical buckling, $\mathrm{cm}^{-2}$

$\mathrm{B}_{\mathrm{z}}^{2} \quad=$ the axial geometrical buckling, $\mathrm{cm}^{-2}$

$\mathrm{B}_{\mathrm{C}}^{2}=$ the core material buckling, $\mathrm{cm}^{-2}$

$\Delta \mathrm{B}=$ the boron concentration increase, $10^{-5}$ atoms $/$ barn $-\mathrm{cm}$

$\mathrm{C}_{1} \quad=$ fabrication charge, $\$ / \mathrm{kg}$ heavy metal

$\mathrm{C}_{2}=$ reprocessing charge, $\$ / \mathrm{kg}$ heavy metal

$\mathrm{C}_{3}=$ fissile value, $\$ / \mathrm{kg}$ fissile 


$$
\begin{aligned}
& \begin{aligned}
c_{j}= & \text { the exponent of } X \text { in the economic correlation for } \\
& \text { the } j \text {-th region }
\end{aligned} \\
& D_{B}=\text { the blanket diffusion coefficient, } \mathrm{cm} \\
& \mathrm{D}_{\mathrm{c}} \quad=\quad \text { the core diffusion coefficient, } \mathrm{cm} \text {. } \\
& \mathrm{D}_{\mathrm{O}} \quad=\quad \text { the core diameter, } \mathrm{cm} \\
& \text { D. }=\text { the diffusion coefficient in the core, } \mathrm{cm} \text {. } \\
& \text { e } \quad=\text { the fuel cycle cost contribution, mills } / \mathrm{kwhr} \\
& e_{L}(\tau, T)=\text { the fuel cycle cost contribution distribution at distance } \\
& \tau \text { into the blanket and at time } \mathrm{T} \text {, mills/kwhr-cm } \\
& \mathrm{e}_{\mathrm{T}}(\tau, \mathrm{T}) \quad=\quad \text { the fuel cycle cost contribution for thickness } \tau \text { and } \\
& \text { time } \mathrm{T} \text {, mills / kwhr } \\
& \mathrm{e}_{\mathrm{MIN}}=\text { the minimum fuel cycle cost contribution, mills/kwhr } \\
& \text { E } \quad=\text { the total electricity generated from the entire reactor, } \\
& \text { kwhr } \\
& \mathrm{F}=\text { power density factor, fissions } / \mathrm{cm}^{3}-\mathrm{sec} \\
& \mathrm{F}_{1} \quad=\quad \text { the present worth factor on fabrication charges } \\
& \mathrm{F}_{2} \quad=\quad \text { the present worth factor on reprocessing charges } \\
& \mathrm{F}_{3} \quad=\quad \text { the present worth factor on material credit } \\
& \mathrm{f}_{\mathrm{b}} \quad=\quad \text { fraction of capital from bondholders } \\
& \mathrm{f}_{\mathrm{S}} \quad=\quad \text { fraction of capital from stockholders }
\end{aligned}
$$


[FOB] = the "economic figure-of-merit" function, $\$ / \mathrm{kgHM}$

$G_{1}(T)=$ a fabrication cost function at time $T$

$\mathrm{G}_{2}(\mathrm{~T}) \quad=\quad$ a material credit function at time $\mathrm{T}$

$\mathrm{H}=$ the core height, $\mathrm{cm}$

$\mathrm{H}_{\mathrm{e}} \quad=\quad$ the extrapolation core height, $\mathrm{cm}$

$\mathrm{I}_{\mathrm{O}}(\kappa \mathrm{r}) \quad=\quad$ Bessel function

$I_{1}(\kappa r) \quad=\quad$ Bessel function

$\mathrm{J}_{\mathrm{O}} \quad=\quad$ Bessel function

$J(a)=$ the neutron current density, neutrons $/ \mathrm{cm}^{3}-\mathrm{sec}$

$\mathrm{k}_{\text {eff }} \quad=\quad$ the effective multiplication factor

$\mathrm{K}_{\mathrm{L}}(\tau, \mathrm{T})=$ the revenue per unit heavy metal mass at the distance $\tau$ into the blanket and at irradiation time $\mathrm{T}, \$ / \mathrm{kgHM}$

$\Delta \mathrm{k} / \mathrm{k}=$ the reactivity loss

$\mathrm{L}_{\mathrm{r}} \quad=\quad$ the radial neutron leakage rate, neutrons $/ \mathrm{cm}^{2}-\mathrm{sec}$

$\mathrm{L}_{\mathrm{a}} \quad=\quad$ the axial neutron leakage rate, neutrons $/ \mathrm{cm}^{2}-\mathrm{sec}$

$\mathrm{M}^{49}=$ the mass of fissile material, $\mathrm{kg}$

$\mathrm{M}_{\mathrm{HM}}(\mathrm{T})=$ the mass of heavy metal at time.T, $\mathrm{kgHM}$

$\dot{\mathrm{M}}_{\mathrm{HM}} \quad=\quad$ the mass of heavy metal at BOL, kgHM 


$$
\begin{aligned}
& \Delta \mathrm{M} / \mathrm{M}=\text {. the change in the fissile loading } \\
& \mathrm{N}_{\mathrm{E}} \quad=\quad \text { Wood's economic parameter } \\
& \mathrm{N}_{\mathrm{j}} \quad=\quad=\text { the atom number density for the } \mathrm{j} \text {-th nuclide, atoms } / \mathrm{cm}^{3} \\
& \mathrm{~N}_{\mathrm{O}}=\text { the atom number density of heavy metal, atoms } / \mathrm{cm}^{3} \text {. } \\
& \mathrm{p}=\text { fission rate per unit volume, fissions } / \mathrm{cm}^{3}-\mathrm{sec} \\
& \mathrm{p}_{\mathrm{i}}=\text { the peak power density in the } \mathrm{i} \text {-th zone of the core, } \\
& \mathrm{kwth} / \text { liter } \\
& \mathrm{p}_{1}=\text { the peak power density in the central zone of the core, } \\
& \text { kwth/liter } \\
& \mathrm{p}_{\mathrm{j}}=\text { the coefficient of the } \mathrm{T}_{\mathrm{BE}} \mathrm{T}_{\text {opt }} \text { correlation for the } \\
& j \text {-th region } \\
& \mathrm{q}_{\mathrm{j}}=\text { the exponent on } \mathrm{W} \text { in the } \mathrm{T}_{\mathrm{BE}} \mathrm{T}_{\text {opt }} \text { correlation for } \\
& \text { the } j \text {-th region } \\
& r_{j}=\text { the exponent on } X \text { in the } T_{B E}-T_{\text {opt }} \text { correlation for } \\
& \text { the } j \text {-th region }
\end{aligned}
$$

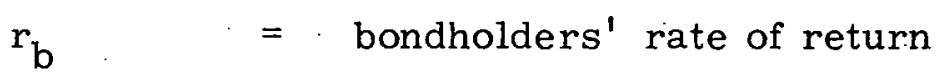

$$
\begin{aligned}
& \mathrm{r}_{\mathrm{s}} \quad=\text { stockholders' rate of return } \\
& R_{\text {or }}=\text { the fissile buildup rate in the radial blanket, } g P u / y r \\
& \mathrm{R}_{\text {oa }}=\text { the fissile buildup rate in the axial blanket, } \mathrm{gPu} / \mathrm{yr}
\end{aligned}
$$




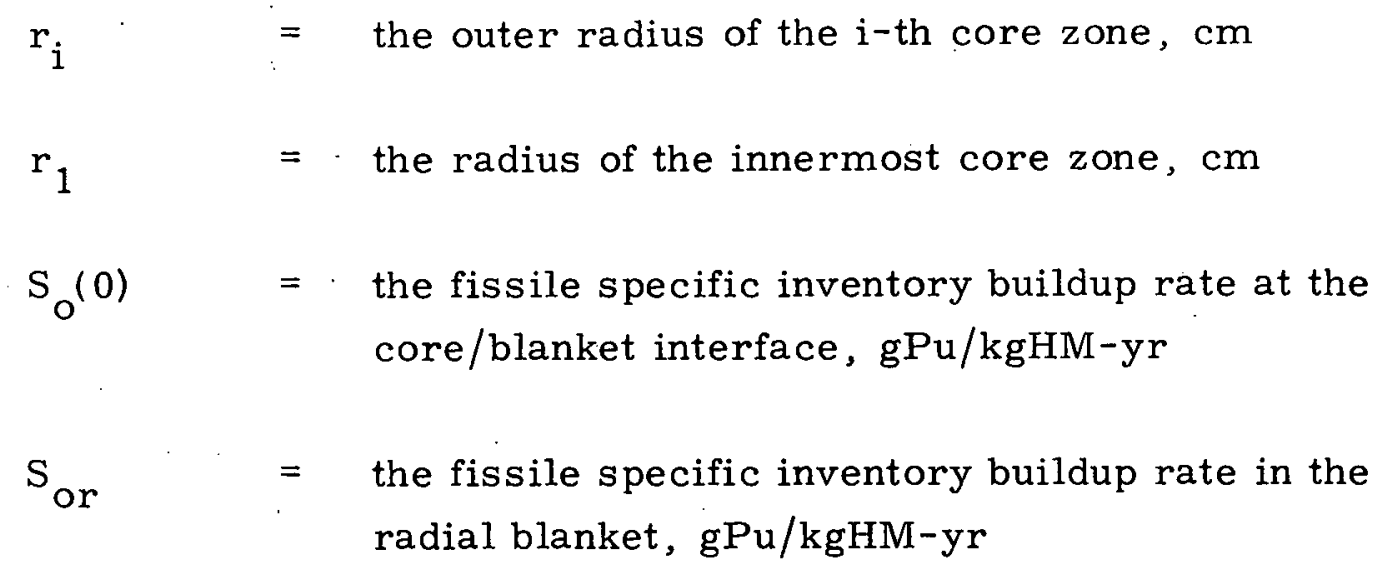

$\mathrm{S}_{\mathrm{Oa}} \quad=\quad$ the fissile specific inventory buildup rate in the axial blanket, $\mathrm{gPu} / \mathrm{kgHM}-\mathrm{yr}$

$\mathrm{S}_{\mathrm{O}, \mathrm{BOL}}=$ the fissile specific inventory buildup rate at $\mathrm{BOL}$, $\mathrm{gPu} / \mathrm{kgHM}-\mathrm{yr}$

$\overline{\mathrm{S}}_{\mathrm{O}, \mathrm{t}}=\quad$ the entire-blanket fissile buildup rate, $\mathrm{gPu} / \mathrm{kgHM}-\mathrm{yr}$

$\overline{\mathrm{S}}_{\mathrm{O}, \ell}=$ the blanket-row fissile buildup rate, $\mathrm{gPu} / \mathrm{kgHM}-\mathrm{yr}$

$\mathrm{T}, \quad=\quad$ the length of the irradiation, years or full power days

$\mathrm{T}_{1} \quad=\quad$ the time from fabrication to the midpoint of the irradiation, years

$\mathrm{T}_{2}=$ the time from reprocessing to the midpoint of the irradiation, years

$\mathrm{T}_{3}=$ the time from material credit to the midpoint of the irradiation, years

$\Delta \mathrm{T}_{1}=$ the time span between fabrication and loading, years

$\Delta \mathrm{T}_{2}=$ the time span between discharge and reprocessing, years 


$$
\begin{aligned}
& \Delta \mathrm{T}_{3} \quad=\text { the time span between discharge and sale, years } \\
& \mathrm{T}_{\mathrm{BE}-1}, \mathrm{~T}_{\mathrm{B}}=\text { the first breakeven irradiation time, full power days } \\
& \mathrm{T}_{\mathrm{BE}-2} \quad=\text { the second breakeven irradiation time, full power days } \\
& \mathrm{T}_{\mathrm{opt}}, \mathrm{T}_{\mathrm{O}}=\text { the optimum irradiation time, full power days } \\
& \mathrm{T}_{\mathrm{p}} \quad=\text { the physical lifetime of a fuel assembly, full power } \\
& \mathrm{U}_{\mathrm{O}} \quad=\text { the fissile buildup rate per unit volume, } \mathrm{gP}_{\mathrm{u}} / \mathrm{liter}-\mathrm{yr} \\
& \mathrm{V}_{\mathrm{B}} \\
& \mathrm{V}_{\mathrm{C}} \quad=\text { the blanket volume per unit height, } \mathrm{cm}^{2} \\
& \mathrm{~W} \\
& \mathrm{X} \quad=\text { the modified economic parameter } \\
& \quad=\text { the discount rate, years }
\end{aligned}
$$

\section{Greek Symbols}

$\bar{\alpha}=$ the average capture-to-fission ratio

$\beta(\kappa a)=$ Bessel function term

$\gamma=$ the inverse diffusion length in the blanket, $\mathrm{cm}^{-1}$

$\delta_{28}=$ fertile-to-fissile fission ratio

$\delta_{\mathrm{R}} \quad=\quad$ the linear extrapolation length in the radial direction, $\mathrm{cm}$

$\delta_{\mathrm{a}}=$ the linear extrapolation length in the axial direction, $\mathrm{cm}$ 
$\vec{\varepsilon}_{\mathbf{i}}$

$\varepsilon(r)$

$\varepsilon_{\infty}(0)$

$\dot{\varepsilon}_{0}$

$\varepsilon(T)$

$\varepsilon_{c}$

$\eta_{i}$

$\theta_{\circ B}$

$\theta_{\text {oc }}$

$\kappa$

$\lambda(\mathrm{X})=$ the hyperbolic function term

$v \quad=$ the average number of neutrons produced per fission

$v_{\mathrm{o}}=$ the fundamental eigenvalue of $\mathrm{J}_{\mathrm{O}}$

$\rho_{\text {OC }}$

$=$ the $i$-th zone averaged enrichment

$=$ the enrichment at position $r, \%$

$=$ the central enrichment for a core, $\%$

$=$ the enrichment buildup rate in the blanket, $\% / \mathrm{yr}$

$=$ the enrichment in the blanket at irradiation time $\mathrm{T}, \%$

$=$ the core-averaged critical enrichment, $\%$

$=$ the number of fission neutrons produced per neutron absorbed in isotope $i$

$=$ the fractional volume occupied by the fuel in the blanket

$=$ the fractional volume occupied by the fuel in the core

$=$ the "pseudo" reciprocal-diffusion length, $\mathrm{cm}^{-1}$
$\rho_{\mathrm{OB}}=\quad=\quad$ the density of the heavy metal oxide fuel in the blanket, kgHM-oxide/liter HM-oxide kght-oxide/1iter HM-oxide

$=$ the density of the heavy metal oxide fuel in the core, kgHM-oxide/liter HM-oxide 


$$
\begin{aligned}
& \sigma_{j}=\quad \text { the microscopic cross section for the } j \text {-th nuclide, } \\
& =\text { the microscopic fission cross section for the } j-\text { th } \\
& \text { nuclide, barns } \\
& \begin{aligned}
& \sigma_{i}= \\
& \text { nuclide, barns }
\end{aligned} \\
& \sigma_{\mathrm{tr}, \mathrm{j}}=\text { the microscopic transport cross section for the } j \text {-th } \\
& \text { nuclide, barns } \\
& \bar{\sigma}_{\mathrm{tr}, \mathrm{j}}=\quad=\text { the average micros copic transport cross section for } \\
& \text { the } j \text {-th nuclide, barns } \\
& \nu \Sigma_{\mathrm{f}, \mathrm{B}}=\text { the blanket macroscopic neutron production cross } \\
& \text { section, } \mathrm{cm}^{-1} \\
& \Sigma_{\mathrm{a}, \mathrm{B}}=\text { the blanket macroscopic absorption cross section, } \mathrm{cm}^{-1} \\
& \Sigma_{\text {tr, B }}=\text { the blanket macroscopic transport cross section, } \mathrm{cm}^{-1} \\
& \begin{aligned}
& \nu \Sigma_{\mathrm{f}, \mathrm{c}}= \text { the core macroscopic neutron production cross section, } \\
& \mathrm{cm}^{-1}
\end{aligned} \\
& \Sigma_{\text {tr }, \mathrm{c}}=\text { the core macroscopic transport cross section, } \mathrm{cm}^{-1} \\
& \Sigma_{\mathrm{a}, \mathrm{c}}=\text { the core macroscopic absorption cross section, } \mathrm{cm}^{-1} \\
& \dot{\Sigma}_{\mathrm{a}, \mathrm{c}, \mathrm{p}}=\text { the non-fuel absorption cross section, } \mathrm{cm}^{-1} \\
& \Sigma_{f}^{49}(r)=\text { macroscopic fission cross section for fissile isotopes, } \\
& \mathrm{cm}^{-1}
\end{aligned}
$$




$\begin{array}{ll}\Sigma_{\mathrm{f}}(\mathrm{r}) & =\text { macroscopic fission cross section, } \mathrm{cm}^{-1} \\ \Sigma_{\mathrm{a}}(\mathrm{r}) & =\text { macroscopic absorption cross section, } \mathrm{cm}^{-1} \\ \Sigma_{\mathrm{n}} & =\text { the pseudo-macroscopic cross section, } \mathrm{cm}^{-1} \\ \tau & =\text { the blanket thickness or the distance into the blanket, cm } \\ \hat{\tau} & =\text { income tax rate } \\ \phi(\mathrm{x}, \mathrm{y}) & =\text { the neutron flux at the radial position } \mathrm{y} \text { of the core } \\ & =\text { having radius } \mathrm{x}, \text { neutrons } / \mathrm{cm}^{2}-\mathrm{sec} \\ \phi(\mathrm{r}) & =\text { neutron group flux for } \mathrm{i}-\mathrm{th} \text { group, neutrons } / \mathrm{cm}^{2}-\mathrm{sec} \\ & =\end{array}$




\section{Appendix B \\ NEUTRONICS OF UNIFORMLY LOADED CORES}

In this appendix the various relations needed to perform a neutron balance in a reactor core having uniform fissile enrichment will be summarized, with particular emphasis on the breeding ratio. The presentation will be brief because one-group diffusion theory is dealt with at great length in all elementary reactor physics texts.

\section{B. 1 CRITICAL CORE ENRICHMENT}

An expression relating critical core enrichment, $\varepsilon_{c}$, and critical core buckling, $\mathrm{B}_{\mathrm{C}}^{2}$, is developed below.

The diffusion equation, for a homogeneous critical one-region core, is

$$
\mathrm{D}_{\mathrm{c}} \nabla^{2} \phi-\Sigma_{\mathrm{a}, \mathrm{c}} \phi+\nu \Sigma_{\mathrm{f}, \mathrm{c}} \phi=0
$$

where

$D_{c}$ is the diffusion coefficient,

$\Sigma_{f, c}$ is the macroscopic fission cross section,

$\Sigma_{a, c}$ is the macroscopic absorption cross section,

$\nu$ is the neutron yield per fission,

and the subscript $c$ indicates that core properties are involved.

Equation B. 1 can be rearranged as:

$$
\nabla^{2} \phi+\mathrm{B}_{\mathrm{c}}^{2} \phi=0
$$

where 


$$
\mathrm{B}_{\mathrm{c}}^{2}=\frac{\nu \Sigma_{\mathrm{f}, \mathrm{c}}-\Sigma_{\mathrm{a}, \mathrm{c}}}{\mathrm{D}_{\mathrm{c}}}
$$

or

$$
-\mathrm{DB}_{\mathrm{c}}^{2}-\Sigma_{\mathrm{a}, \mathrm{c}}+\nu \Sigma_{\mathrm{f}, \mathrm{c}}=0
$$

Separating the production term into fertile production, $\nu_{28} \Sigma_{\mathrm{f}, \mathrm{c}, 28}$, and fissile production, $v_{49} \Sigma_{\mathrm{f}, \mathrm{c}, 49}$, gives

$$
\begin{aligned}
\nu \Sigma_{\mathrm{f}, \mathrm{c}} & =\nu_{28} \Sigma_{\mathrm{f}, \mathrm{c}, 28}+\nu_{49} \Sigma_{\mathrm{f}, \mathrm{c}, 49} \\
& =\eta_{28} \Sigma_{\mathrm{a}, \mathrm{c}, 28}+\eta_{49} \Sigma_{\mathrm{a}, \mathrm{c}, 49}
\end{aligned}
$$

Separating the absorption term into fertile absorption; $\Sigma_{a}, c, 28$, fissile absorption, $\Sigma_{a}, c, 49$, and non-fuel absorption, $\Sigma_{a}, c, p$,

$$
\Sigma_{a, c}=\Sigma_{a, c, 28}+\Sigma_{a, c, 49}+\Sigma_{a, c, p}
$$

Substituting Eqs. B. 5 and B. 6 into B. 4, one obtains

$$
\left(\eta_{28}-1\right) \Sigma_{a, c, 28}+\left(\eta_{49}-1\right) \Sigma_{a, c, 49}=\Sigma_{a, c, p}+D_{c} B_{c}^{2} \text {. }
$$

The macroscopic cross sections of the fissile and fertile material may be expressed in terms of enrichment, as follows:

$$
\begin{aligned}
& \Sigma_{a, c, 49}=N_{o} \varepsilon_{o} \bar{\sigma}_{a, 49^{\prime}} \\
& \Sigma_{a, c, 28}=N_{o}\left(1-\varepsilon_{0}\right) \bar{\sigma}_{a, 28},
\end{aligned}
$$

where

$\mathrm{N}_{\mathrm{o}}$ is the number density of total heavy metal nuclide, atoms/barn-cm,

$\varepsilon_{c}$ is the critical core enrichment, defined as

$$
\begin{array}{r}
\varepsilon_{\mathrm{c}} \equiv \text { fissile number density/(fissile number density }+ \\
\text { fertile number density) }
\end{array}
$$




$$
\begin{aligned}
& \bar{\sigma}_{a, 49} \begin{array}{l}
\text { is the fissile microscopic absorption cross } \\
\text { section, barns, and }
\end{array} \\
& \bar{\sigma}_{a, 28} \begin{array}{l}
\text { is the fertile microscopic absorption cross } \\
\text { section, barns. }
\end{array}
\end{aligned}
$$

Substituting.Eqs. B. 8 and B. 9 into B. 7 and solving for critical core enrichment,

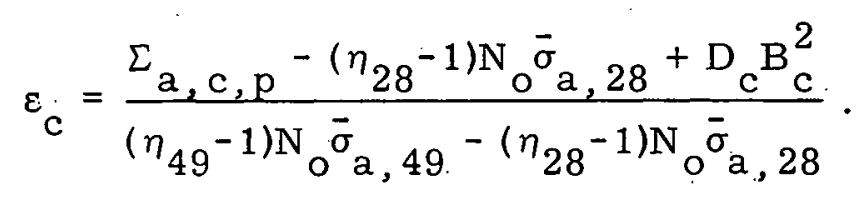

Using the one-group data of Table 3.1 in Chapter 3, Eq. B. 11 becomes

$$
\varepsilon_{c}=0.0829+76.8 \mathrm{~B}_{\mathrm{c}}^{2} \text {. }
$$

Figure 3.3 in Chapter 3 shows a comparison of $2 \mathrm{DB}$ results and Eq. B. 12, which agree within $\sim 5$ percent.

Table B. 1 shows the neutron balance for a BOL, 1000-MW e, 1-zone core, which indicates that:

1) The $\mathrm{k}_{\text {eff }}=\nu \Sigma_{f} /\left(\Sigma_{\mathrm{a}}+\mathrm{DB}^{2}\right)=1.0093$, which agrees with the $2 \mathrm{DB}$ result of 1.0017 within 1.4 percent.

2) Thus, the one-group cross-section set of Table 3.1 in Chapter 3 has been confirmed to be useful for evaluation of physics parameters.

In this evaluation it has been approximated that:

1) The geometrical bucklings are:

$$
\begin{aligned}
& B_{r}^{2}=\left(\nu_{o} / a+\delta_{R}\right)^{2} \\
& B_{z}^{2}=\left(\pi / H+2 \delta_{a}\right)^{2} .
\end{aligned}
$$




\begin{tabular}{|c|c|c|c|}
\hline Loss & $\begin{array}{l}\times 10^{-3} \\
\left(\mathrm{~cm}^{-1}\right)\end{array}$ & Gain & $\begin{array}{l}\times 10^{3} \\
\left(\mathrm{~cm}^{-1}\right)\end{array}$ \\
\hline $\begin{array}{l}\text { Fission of Fissile } \\
\quad\left(\mathrm{J}^{235}, \mathrm{Pu}^{239}, \mathrm{Fu}^{241}\right)^{\sum} \mathrm{f}, 49\end{array}$ & 1.6423 & Production in Fissile, $v \Sigma_{F, 4 ?}$ & 4.3128 \\
\hline Canture in rissile $\quad \Sigma_{c, 49}$ & 0.4046 & Production in Fertile, $\nu \Sigma_{f}, 28$ & 0.9035 \\
\hline $\begin{array}{l}\text { Fission in Fertile } \\
\quad\left(\mathrm{U}^{238}, \mathrm{Pu}^{240}, \mathrm{Pu}^{242}\right)^{\Sigma_{\mathrm{f}, 28}}\end{array}$ & 0.3147 & & \\
\hline Canture in Fertile $\sum_{C, 28}$ & 1.8279 & - & \\
\hline Capture in Non-Fuel $\Sigma_{a, c, p}$ & 0.2528 & & \\
\hline Lcakage Losses & & . & \\
\hline Radial & 0.4724 & & r \\
\hline $\mathrm{DB}_{\mathrm{z}}{ }^{2}$ & 0.7489 & & \\
\hline Total Loss , $\Sigma_{a}+\mathrm{DB}^{2}$ & 5.6636 & Total Gain, $v \Sigma_{f}$ & 5.7163 \\
\hline
\end{tabular}


2) The linear extrapolation distances as obtained from the $2 \mathrm{DB}$ results are:

$$
\begin{aligned}
& \delta_{\mathrm{R}}=20 \mathrm{~cm} \\
& \delta_{\mathrm{a}}=25 \mathrm{~cm} .
\end{aligned}
$$

\section{B. 2 CRITICAL CORE MASS}

Critical core mass, $\mathrm{M}_{\mathrm{C}, 49}^{\mathrm{o}}$, may be computed from enrichment as follows:

$$
\mathrm{M}_{\mathrm{c}, 49}^{\circ}=\varepsilon_{c} \mathrm{M}_{\mathrm{c}, \mathrm{HM}}=\varepsilon_{\mathrm{c}} \mathrm{V}_{\mathrm{c}} \theta_{0, \mathrm{c}} \rho_{0, \mathrm{c}} \mathrm{C},
$$

where

$\mathrm{M}_{\mathrm{c}, 49}^{\mathrm{O}}$ is the critical core fissile mass $(\mathrm{kg})$,

$\rho_{\mathrm{o}, \mathrm{c}}$ is the oxide density $\simeq 10$ ( $\mathrm{kg} \mathrm{HM}$ oxide/liter HM oxide),

$\mathrm{C}$ is $0.83(\mathrm{~kg} \mathrm{HM} / \mathrm{kg} \mathrm{HM}$ oxide),

$\mathrm{M}_{\mathrm{C}, \mathrm{HM}}$ is the mass of heavy metal in the core $(\mathrm{kg})$,

$\theta_{0, c}$ is the volume fraction of oxide fuel in the core ( 0.30 in the present example),

one obtains,

$$
\begin{aligned}
& M_{c, 49}=2.64 \mathrm{~V}_{\mathrm{c}} \varepsilon_{\mathrm{c}}, \\
& \mathrm{M}_{\mathrm{c}, \mathrm{HM}}=2.64 \mathrm{~V}_{\mathrm{c}},
\end{aligned}
$$

where we have ignored the small difference between atom and weight fraction in the definition of enrichment, $\varepsilon_{\dot{C}}$. 


\section{B. 3 BREEDING RATIO}

The fissile production in core and blanket fuel is to be expressed in terms of internal (core) and external (blanket) breeding ratios, respectively. Internal breeding ratio, $b_{i}$, is defined as:

$$
b_{i} \equiv \frac{\text { Fissile production rate in the core }}{\text { Fissile consumption rate in the core }} \text {. }
$$

Thus

$$
b_{i}=\frac{N_{c, 28} \bar{\sigma}_{c, 28}}{N_{c, 49} \bar{\sigma}_{a, 49}}=\frac{1-\varepsilon_{c}}{\varepsilon_{c}} \frac{\bar{\sigma}_{c, 28}}{\bar{\sigma}_{a, 49}}
$$

where

$$
\begin{aligned}
& \bar{\sigma}_{c, 28}=\text { Fertile micros copic capture cross section, } \\
& \bar{\sigma}_{a, 49}=\text { Fissile micros copic absorption cross section. }
\end{aligned}
$$

Using the cross-section data of Table 3.1 ,

$$
b_{i} \propto 0.1393 \frac{1-\varepsilon_{c}}{\varepsilon_{c}} .
$$

Figure B. 1 shows this relation together with $2 \mathrm{DB}$ results, which indicate that the internal breeding ratio does not exceed unity even for the 3000MW $\mathrm{e}_{\mathrm{e}}$ cores considered (which are somewhat "pancaked," height/diameter « 1). The one-group model predicts the internal breeding ratio within 4 percent of the $2 \mathrm{DB}$ results, when the critical enrichment appropriate to $2 \mathrm{DB}$ is used in Eq. B. 20.

The external breeding ratio, $b_{x}$, is defined as follows:

$$
\mathrm{b}_{\mathrm{x}} \equiv \frac{\text { Fissile production rate in the blanket }}{\text { Fissile consumption rate in the core }} \text {. }
$$




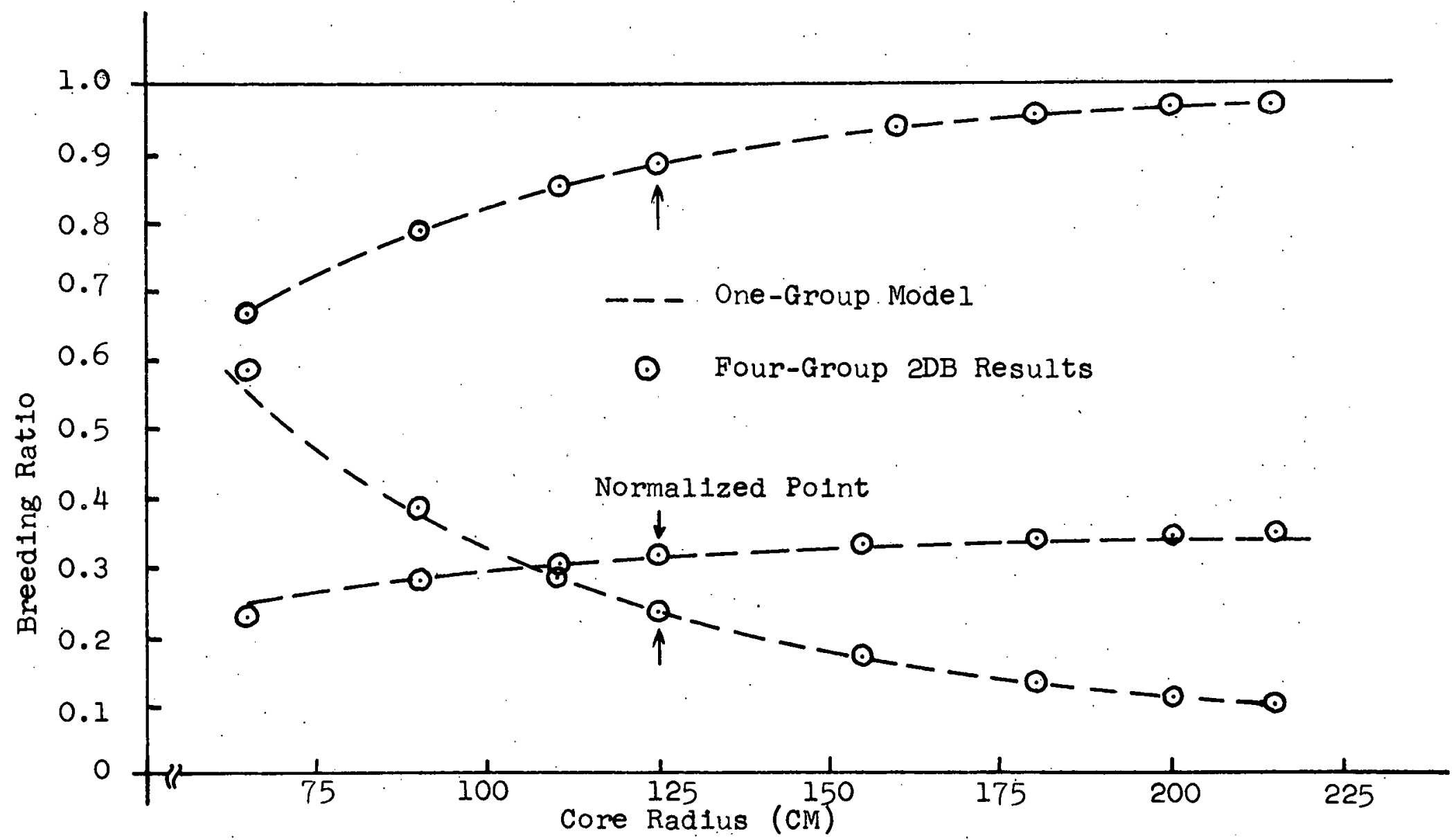

F1g. B.1 Comparison of the Breeding Ratio Predicted by the One-Group Model and $2 \mathrm{DB}$ as a Function of Core Radius (One-Zone Cores) 
Thus,

$$
\begin{aligned}
b_{x}= & \left\{\frac{\text { Core neutron leakage rate }}{\text { Fissile consumption rate in the core }}\right\} \times \\
& \left\{\frac{\text { Fertile capture rate in the blanket }}{\text { Source neutrons fed to blanket }}\right\}:
\end{aligned}
$$

Assuming no leakage from the outer face of the blanket,

$$
b_{x} \propto\left(\frac{D_{c} B_{x}^{2}}{N_{o} \varepsilon_{c} \bar{\sigma}_{a, 49}}\right) \cdot\left(\frac{\Sigma_{c, b, 28}}{\Sigma_{a, b}-\nu \Sigma_{f, b}}\right)
$$

where

$$
\begin{aligned}
& \mathrm{B}_{\mathrm{x}}^{2}=\text { buckling appropriate to radial }(\mathrm{x}=\mathrm{r}) \text { or axial }(\mathrm{x}=\mathrm{a}) \\
& \text { direction, } \\
& \Sigma_{\mathrm{c}, \mathrm{b}, 28} \text { is the fertile macroscopic capture cross section } \\
& \text { in the blanket, } \\
& \Sigma_{\mathrm{a}, \mathrm{b}} \begin{array}{l}
\text { is the total macros copic absorption cross section in } \\
\text { the blanket, }
\end{array} \\
& \nu \Sigma_{\mathrm{f}, \mathrm{b}} \text { is the macroscopic production cross section in the } \\
& \text { blanket, }
\end{aligned}
$$

Using the cross-section data of Tables 3.1 and 3.3 , one can obtain:

$$
\begin{aligned}
& \mathrm{b}_{\mathrm{xa}} \propto \frac{0.04080}{\varepsilon_{\mathrm{c}}}, \\
& \mathrm{b}_{\mathrm{xr}} \propto 93.04 \frac{\mathrm{B}_{\mathrm{r}}^{2}}{\varepsilon_{\mathrm{c}}} .
\end{aligned}
$$

Figure B. 1 also shows these relations for the axial blanket and the radial blanket, respectively. It is interesting to note that the axial 
blanket breeding ratio, $\mathrm{b}_{\mathrm{xa}}$, increases and approaches an asymptotic value as the core radius increases, but the radial blanket breeding ratio, $b_{x r}$, decreases approximately as the inverse of the square of the core radius in accordance with the following equations (where the previously described buckling and enrichment have been substituted into Eq. B. 23):

$$
\mathrm{b}_{\mathrm{xr}} \propto \frac{\left(\frac{\nu_{c}}{\mathrm{a}+\delta_{\mathrm{R}}}\right)^{2}}{\mathrm{~A}+\mathrm{B}\left(\frac{\nu}{\mathrm{a}+\delta_{\mathrm{R}}}\right)^{2}} \propto \frac{1}{\left(\frac{\mathrm{a}+\delta_{\mathrm{R}}}{\nu_{v}}\right)^{2} \mathrm{~A}+\mathrm{B}} .
$$

Using the typical values, $a=125 \mathrm{~cm}, \delta_{\mathrm{R}}=20 \mathrm{~cm}, \nu_{.}=2.4048$, one.finds $A=0.116$; i.e., $\left(\frac{a+\delta_{R}}{v_{c}}\right)^{2} A \simeq 290>B=70$. Thus, one has the rough approximation:

$$
\mathrm{b}_{\mathrm{xr}} \propto \frac{1}{\left(\frac{\mathrm{a}+\delta_{\mathrm{R}}{ }^{2}}{\nu_{v}}\right)}
$$

Figure, 3.11 in Chapter 3 shows this prescription together with $b_{x r}$ for radially power-flattened cores. 


\section{Appendix C \\ NEUTRONICS OF RADIALLY POWER-FLATTENED CORE}

It is well known that radial power-flattening contributes to improve the physics and engineering performance of large reactors (hence minimize the total power cost) and that radial power-flattening is employed in most, if not all, designs of large LMFBR's (for example, two zones for the Westinghouse Demonstration Plant and four zones for the GA-GCFR Demonstration Plant). In this appendix, starting with the steady-state neutron-balance diffusion equation, the neutron flux and the enrichment distribution will be obtained, and then several interesting characteristics of the radially power-flattened core with respect to breeding performance will be presented, with emphasis on the effect of core radius or core height. A detailed derivation of the results used in Chapter 2 will be presented.

\section{1 DERIVATION OF EQUATIONS}

One-group diffusion theory gives the following equation in cylindrical geometry:

$$
D\left(\frac{1}{r} \frac{d}{d r} r \frac{d}{d r}\right) \phi(r)-\Sigma_{a}(r) \phi(r)+\nu \Sigma_{f}(r) \phi(r)=0 .
$$

For a rádially power-flattened core, one has:

$$
\Sigma_{f}(r) \phi(r) \equiv p=\text { constant }
$$

Defining the fertile-to-fissile fission ratio, $\delta_{28}$, as: 


$$
\delta_{28}=\frac{\Sigma_{\mathrm{f}, 28^{(r)}}}{\Sigma_{\mathrm{f}, 49}(\mathrm{r})},
$$

one has

$$
\Sigma_{f}(r)=\Sigma_{f, 49}(r)+\Sigma_{f, 28}(r)=\Sigma_{f, 49}(r)\left(1+\delta_{28}\right)
$$

and

$$
\mathrm{p}=\Sigma_{\mathrm{f}}(\mathrm{r}) \phi(\mathrm{r})=\Sigma_{\mathrm{f}, 49}(\mathrm{r})\left(1+\delta_{28}\right) \phi(\mathrm{r})
$$

where it has been assumed that $1+\delta_{28}$ is constant, which is confirmed in Chapter 3. Similarly, D has been assumed not to vary - a good assumption since $\sigma_{\text {tr }}$ does not vary significantly among heavy metal nuclides.

The absorption term is separated into three components:

$$
\Sigma_{a, p}(r)=\Sigma_{a, \text { fuel }}(r)+\Sigma_{a, p}+D B_{z}^{2},
$$

where:

$\Sigma_{a, f u e l}(r)$ is the fuel macroscopic absorption cross section, $\Sigma_{\mathrm{a}, \mathrm{p}} \quad$ is the non-fuel macroscopic absorption cross section, $\mathrm{DB}_{\mathrm{z}}^{2} \quad$ is the macroscopic destruction cross section due to transverse leakage.

The latter two terms are also assumed to be spatially invariant. Defining the capture-to-fission ratio,

$$
\bar{\alpha} \equiv \frac{\bar{\sigma}_{\gamma, 49}}{\bar{\sigma}_{f, 49}}=\frac{\bar{\sigma}_{a, 49}-\bar{\sigma}_{f, 49}}{\bar{\sigma}_{f, 49}}
$$

or

$$
\frac{\bar{\sigma}_{a, 49}}{\bar{\sigma}_{\mathrm{f}, 49}}=1+\bar{\alpha},
$$


where $\bar{\sigma}_{\gamma, 49}$ is the fissile microscopic capture cross section, one then has:

$$
\begin{aligned}
\Sigma_{a, f \text { fuel }}(\mathrm{r}) & =\Sigma_{\mathrm{a}, 28}(\mathrm{r})+\Sigma_{\mathrm{a}, 49}(\mathrm{r}) \\
& =\frac{\bar{\sigma}_{\mathrm{a}, 28}}{\bar{\sigma}_{\mathrm{f}, 28}} \cdot \frac{\bar{\sigma}_{\mathrm{a}, 28}}{\bar{\sigma}_{\gamma, 28}} \Sigma_{\gamma, 28}(\mathrm{r})+\frac{\bar{\sigma}_{\mathrm{a}, 49}}{\bar{\sigma}_{\mathrm{f}, 49}} \Sigma_{\mathrm{f}, 49}(\mathrm{r}) \\
& =\frac{1+\bar{\alpha}_{28}}{\bar{\alpha}_{28}} \Sigma_{\gamma, 28}(\mathrm{r})+\left(1+\bar{\alpha}_{49}\right) \Sigma_{\mathrm{f}, 49}(\mathrm{r})
\end{aligned}
$$

Since the atomic number density of total heavy metals,

$$
\mathrm{N}_{\mathrm{o}}=\mathrm{N}_{49}(\mathrm{r})+\mathrm{N}_{28}(\mathrm{r}) \text {, }
$$

is constant, one has

$$
\Sigma_{\gamma, 28}(\gamma)=\sigma_{\gamma, 28} \dot{\mathrm{N}}_{28}(\mathrm{r})=\sigma_{\gamma, 28}\left[\mathrm{~N}_{\mathrm{o}}-\mathrm{N}_{49}(\mathrm{r})\right]
$$

Defining $\Sigma_{\gamma \circ, 28} \equiv \sigma_{\gamma, 28} \mathrm{~N}_{0}$, one has

$$
\begin{aligned}
\Sigma_{\gamma, 28}(\mathrm{r}) & =\Sigma_{\gamma 0,28}-\mathrm{N}_{49}(\mathrm{r}) \sigma_{\gamma, 28} \frac{\bar{\sigma}_{\mathrm{f}, 49}}{\bar{\sigma}_{\mathrm{f}, 49}} \\
& =\Sigma_{\gamma 0,28}-\frac{\bar{\sigma}_{\gamma, 28}}{\bar{\sigma}_{f, 49}} \Sigma_{f, 49}(\mathrm{r}) .
\end{aligned}
$$

Substituting Eqs. C. 9 and C. 13 into C. 6 , one obtains

$$
\begin{aligned}
\Sigma_{\mathrm{a}}(r)= & {\left[\frac{1+\bar{\alpha}_{28}}{\bar{\alpha}_{28}} \Sigma_{\gamma 0,28}+\Sigma_{\mathrm{a}, \mathrm{p}}+\mathrm{DB}_{\mathrm{z}}^{2}\right] } \\
& -\left[\frac{1+\bar{\alpha}_{28}}{\bar{\alpha}_{28}} \frac{\bar{\sigma}_{\gamma, 28}}{\bar{\sigma}_{\mathrm{f}, 49}}-\left(1+\bar{\alpha}_{49}\right)\right] \Sigma_{\mathrm{f}, 49}(\mathrm{r}) .
\end{aligned}
$$


Thus, the absorption term is separated into two parts: a spaceindependent term and a space-dependent term. Defining the former as:

$$
\Sigma_{\mathrm{n}} \equiv\left[\frac{1+\bar{\alpha}_{28}}{\bar{\alpha}_{28}} \Sigma_{\gamma 0,28}+\Sigma_{\mathrm{a}, \mathrm{p}}+\mathrm{DB}_{\mathrm{z}}^{2}\right]
$$

and the constant term as:

$$
\xi \equiv\left[\frac{1+\bar{\alpha}_{28}}{\bar{\alpha}_{28}} \frac{\bar{\sigma}_{\gamma, 28}}{\bar{\sigma}_{f, 49}}-\left(1+\bar{\alpha}_{49}\right)\right]
$$

one has:

$$
\Sigma_{a}(r)=\Sigma_{n}+\xi \Sigma_{f, 49}(r)
$$

Substituting Eqs. C. 5 and C. 17 into Eq. C. 1, one obtains:

$$
D\left(\frac{1}{r} \frac{d}{d r} r \frac{d}{d r}\right) \phi(r)-\left[\Sigma_{n}-\xi \Sigma_{f, 49}(r)\right] \phi(r)+\nu p=0
$$

or

$$
\left(\frac{1}{\mathrm{r}} \frac{\mathrm{d}}{\mathrm{dr}} \mathrm{r} \frac{\mathrm{d}}{\mathrm{dr}}\right) \phi(\mathrm{r})-\frac{\Sigma_{\mathrm{n}}}{\mathrm{D}} \phi(\mathrm{r})+\frac{\mathrm{p}}{\mathrm{D}}\left(\nu+\frac{\xi}{1+\delta . \delta 28}\right)=0 .
$$

Defining the terms,

$$
\kappa^{2} \equiv \frac{\Sigma_{\mathrm{n}}}{\mathrm{D}}=\left[\frac{1+\bar{\alpha}_{28}}{\bar{\alpha}_{28}} \Sigma_{\gamma 0,28}+\Sigma_{\mathrm{a}, \mathrm{p}}+\mathrm{DB}_{\mathrm{z}}^{2}\right] / \mathrm{D}
$$

and

$$
\begin{aligned}
F & \equiv \frac{\mathrm{p}}{\mathrm{D}}\left(\nu+\frac{\xi}{1+\delta_{28}}\right) \\
& =\frac{\mathrm{p}}{\mathrm{D}\left(1+\delta_{28}\right)}\left[\nu\left(1+\delta_{28}\right)-\left(1+\bar{\alpha}_{49}\right)+\frac{1+\bar{\alpha}_{28}}{\bar{\alpha}_{28}} \frac{\bar{\sigma}_{\gamma, 28}}{\bar{\sigma}_{\mathrm{f}, 49}}\right]
\end{aligned}
$$

one obtains: 


$$
\left(\frac{1}{r} \frac{d}{d r} r \frac{d}{d r}\right) \phi(r)-\kappa^{2} \phi(r)+F=0,
$$

which has the solution

$$
\phi(r)=\frac{F}{\kappa^{2}}-C I_{0}(\kappa r)
$$

Applying the boundary condition,

$$
\phi(a)+\delta \phi^{\prime}(a)=0
$$

where: $\delta$ is the linear extrapolation distance, which is specified to match $2 \mathrm{DB}$ results, i.e. ,

$$
\delta=20 \mathrm{~cm} \text {, }
$$

one has the neutron flux as a function of radial position and outer radius:

$$
\phi(a, r)=\frac{F}{k^{2}}\left[1-\beta(\kappa a) \cdot I_{o}(\kappa r)\right],
$$

where

$$
\beta(\kappa a)=\left[I_{0}(\kappa a)+\kappa \delta \cdot I_{1}(\kappa a)\right]^{-1}
$$

From Eq. C. 5 one has

$$
p=\Sigma_{f, 49}(r)\left(1+\delta_{28}\right) \phi(r)=\bar{\sigma}_{f, 49} \cdot N_{49}(r) \cdot\left(1+\delta_{28}\right) \phi(r)
$$

Thus, the fissile material profile is

$$
N_{49}(r)=\frac{p}{\bar{\sigma}_{f, 49}\left(1+\delta_{28}\right)} \frac{\kappa^{2}}{F}\left[1-\beta(\kappa a) I_{o}(\kappa r)\right]^{-1}
$$

Using Eq. C.20, one obtains

$$
\mathrm{N}_{49}(\mathrm{r})=\frac{\mathrm{D}{ }^{2}}{\bar{\sigma}_{f, 49}\left[\nu\left(1+\delta_{28}\right)+\xi\right]\left[1-\beta(\kappa a) I_{o}(\kappa r)\right]}
$$


The enrichment profile for a core having radius $=a$ is obtained by dividing Eq. C. 21 by Eq. C. 10 .

$$
\varepsilon(a, r)=\frac{D k^{2}}{\bar{\sigma}_{f, 49} N_{o}\left[\nu\left(1+\delta_{28}\right)+\xi\right]\left[1-\beta(\kappa a) I_{o}(\kappa r)\right]} .
$$

\section{2 COMPARISON WITH UNIFORMLY LOADED CORE}

For a uniformly loaded core, one has from Eq. B.4,

$$
\nu \Sigma_{\mathrm{f}}-\Sigma_{\mathrm{a}}=\mathrm{DB}_{\mathrm{r}}^{2}
$$

Using the same breakdown of the macroscopic cross section; one has:

$$
\nu \bar{\sigma}_{f, 49} \mathrm{~N}_{49, \mathrm{u}}\left(1+\delta_{28}\right)-\left(\Sigma_{\mathrm{n}}-\xi \bar{\sigma}_{\mathrm{f}, 49} \mathrm{~N}_{49, \mathrm{u}}\right)=\mathrm{DB}_{\mathrm{r}}^{2}
$$

Solving for the fissile atom number density for the uniformly loaded core, $\mathrm{N}_{49, \mathrm{u}}$, one has

$$
\mathrm{N}_{49, \mathrm{u}}=\frac{\mathrm{D} \kappa^{2}+\mathrm{DB}_{\mathrm{r}}^{2}}{\bar{\sigma}_{\mathrm{f}, 49}\left[\nu\left(1+\delta_{28}\right)+\xi\right]} .
$$

Therefore; the ratio of local fissile atomic number density in the radially power-flattened core to the uniformly loaded core is, from Eqs. C. 28 and C.21:

$$
\frac{\mathrm{N}_{49}(\mathrm{r})}{\mathrm{N}_{49, \mathrm{u}}}=\left\{\left[1+\frac{\mathrm{B}_{\mathrm{r}}^{2}}{\kappa^{2}}\right]\left[1-\beta(\kappa a) \mathrm{I}_{\mathrm{o}}(\kappa \mathrm{r})\right]\right\}^{-1} .
$$

Figure C. 1 shows Eq. C. 32 for $1000-M W_{e}$ size cores using the crosssection data in Table 3.1. This figure indicates that the fissile atomic number density (hence enrichment) in the radially power-flattened core is lower near the core center but high near the core edge, compared to the enrichment in the uniformly loaded core of the same size. 


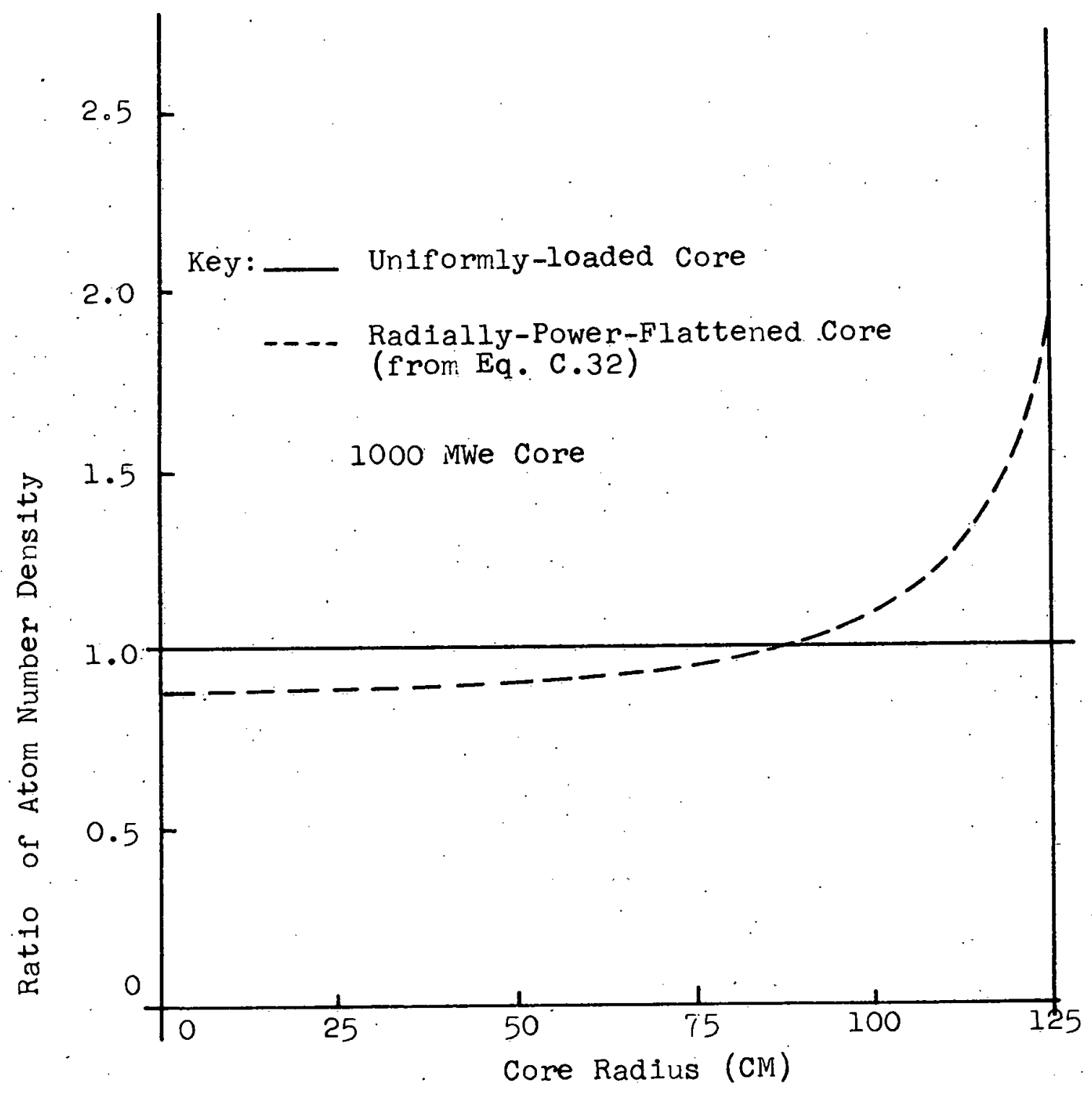

F1g. C.I Fissile Atom Density Distribution for Power-Flattened Cores 


\section{3 CRITICAL MASS RATIO}

The preceding equations can also be used to compute the critical mass ratio between the radially power-flattened and uniformly loaded. cores having the same radius:

$$
\frac{M_{R P F}}{M_{U L}}=\frac{2 \pi \int_{0}^{a} N^{49}(r) r d r}{\pi a^{2} N_{U}^{49}}
$$

The integral in the numerator of $\mathrm{Eq} . \mathrm{C} .33$ can be approximated:

$$
\begin{aligned}
\int_{0}^{a} \frac{r d r}{1-\beta(\kappa a) I_{0}(k r)} & \cong \frac{1}{\kappa^{2}} \int_{0}^{a}(\kappa r) d(\kappa r)\left[1+\beta(\kappa a) I_{0}(\kappa r)+\beta^{2}(k a) I_{o}^{2}(\kappa r)\right] \\
& =\frac{a^{2}}{2}\left\{1+\frac{2 \beta(\kappa a) I_{1}(k a)}{k a}+\beta(\kappa a)^{2}\left[I_{0}^{2}(\kappa a)-I_{1}^{2}(\kappa a)\right]\right\}
\end{aligned}
$$

Thus,

$$
\frac{\dot{M}_{\text {RPF }}}{\mathrm{M}_{\mathrm{UL}}}=\frac{\left\{1+\frac{2 \beta(\kappa a) \mathrm{I}_{\mathrm{o}}(k \mathrm{a})}{\kappa a}+\beta(\kappa a)^{2}\left[\mathrm{I}_{\mathrm{o}}^{2}(\kappa \mathrm{a})-\mathrm{I}_{1}^{2}(\kappa a)\right]\right\}}{\left\{1+\mathrm{B}_{\mathrm{r}}^{2} / \kappa^{2}\right\}}
$$

where

$$
B_{r}=\left(\frac{\nu_{o}}{a+\delta_{R}}\right)
$$

is the approximate solution of the criticality relation for the uniformly loaded core:

$$
{ }^{B} \delta_{R} J_{1}\left(B_{r} a\right)=J_{o}\left(B_{r} a\right)
$$

Given a and $\delta_{R}$, we can solve Eq. C. 37 for $B_{r}$, and then for a given 
$\kappa$, evaluate Eq. C. 35. Using the $1000-\mathrm{MW}_{\mathrm{e}}$ core data in Table 3.1, one can obtain:

$$
\frac{\mathrm{M}_{\mathrm{RPF}}}{\mathrm{M}_{\mathrm{UL}}} \cong 1.09
$$

Thus, in the present case, the critical mass is increased by radial power-flattening (about 9 percent). The critical mass ratio is essentially constant for all core radii (sizes) studied, as discussed in Chapter 3.

\section{4 CENTRAL AND PERIPHERAL ENRICHMENT}

From Eq. C. 29 , and noting that $I(0)=1$, the central enrichment of a core having outer radius $=a$ is:

$$
\varepsilon(a, o)=\frac{D_{k}{ }^{2}}{\bar{\sigma}_{f, 49} N_{o}\left[\nu\left(1+\delta_{28}\right)+\xi\right][1-\beta(\kappa a)]} .
$$

where

$$
\beta(\kappa a)=\left[I_{0}(\kappa a)+\kappa \delta I_{1}(\kappa a)\right]^{-1}
$$

Since

$$
\frac{\mathrm{I}_{1}(\kappa a)}{\mathrm{I}_{0}(\kappa \mathrm{a})} \cong 1-\frac{1}{2 \kappa a}+\ldots .
$$

one has

$$
\begin{aligned}
\beta(\kappa a) & =\frac{1}{I_{0}(\kappa a)\left[1+\kappa \delta \frac{I_{1}(\kappa a)}{I_{0}(k a)}\right]} \\
& \simeq \frac{1}{I_{0}(\kappa a)\left[1+\kappa \delta\left(1-\frac{1}{2 \kappa a}\right)\right]} .
\end{aligned}
$$


Since $I_{0}(\kappa a) \rightarrow \infty$ as $a \rightarrow \infty$, one has

$$
\beta(\kappa a) \rightarrow 0
$$

Thus, the central enrichment approaches an asymptotic value as core radius increases:

$$
\varepsilon(a, o) \rightarrow \frac{D \kappa^{2}}{\bar{\sigma}_{f, 49} \mathrm{~N}_{o}\left[\nu\left(1+\delta_{28}\right)+\xi\right]} \equiv \mathrm{C} .
$$

Using the cross-section data in Table 3.1, one has $\varepsilon(\mathrm{a}, 0) \rightarrow 0.108$, as shown in Fig. C. 2.

From Eq. C.29, the peripheral enrichment, $\varepsilon(a, a)$ is

$$
\varepsilon(a, a)=\frac{C}{1-\beta(\kappa a) I_{o}(k a)}
$$

where

$$
\beta(\kappa a) I_{o}(k a)=\frac{I_{o}(k a)}{I_{0}(k a)+\kappa \delta I_{1}(k a)}
$$

Using the approximation of Eq. C. 41 , one has

$$
\beta(\kappa a) I_{o}(\kappa a) \cong \frac{1}{1+\kappa \delta\left(1-\frac{1}{2 \kappa a}\right)}
$$

Since $\frac{1}{k a} \rightarrow 0$ as a $\rightarrow \infty$, one has

$$
\beta(\kappa a) I_{o}(\kappa a) \rightarrow \frac{1}{1+\kappa \delta} .
$$

Thus, the peripheral enrichment also approaches an asymptotic value as core radius increases:

$$
\varepsilon(a, a) \rightarrow \frac{C}{1-\frac{1}{1+\kappa \delta}} .
$$




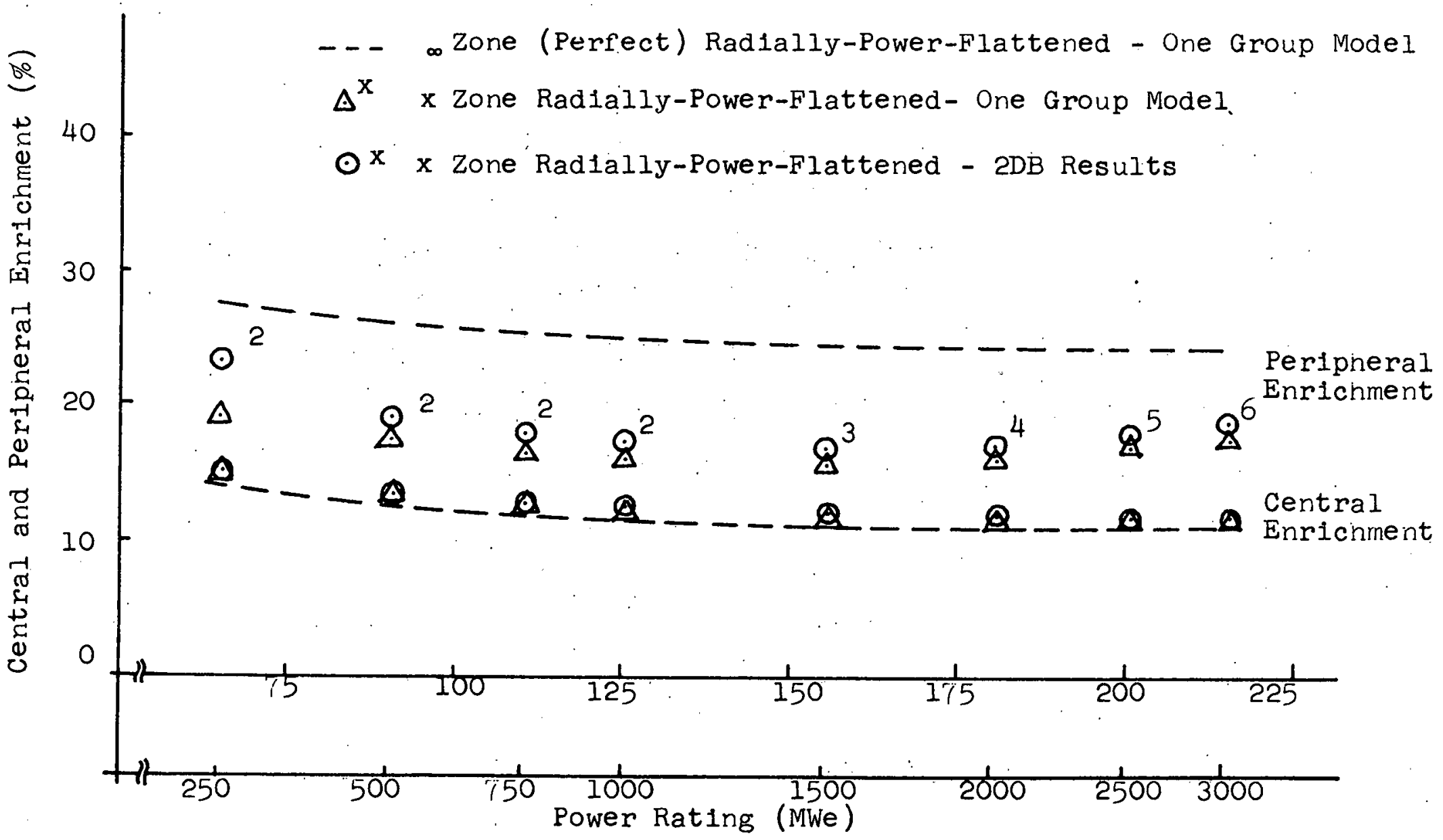

Fig. C.2 The Effect of Core-Radius on Central and Peripheral or Central-Zone and Outermost-Zone Enrichment 
Using the cross-section data in Table 3.1 , one has

$$
\varepsilon(\mathrm{a}, \mathrm{a}) \rightarrow 0.241
$$

Figure C. 2 shows this relation; which indicates that the peripheral enrichment for infinite core radius (at constant core height), $\varepsilon(\infty, \infty)$, approaches 0.241 . Figure C. 2 shows Eq. C. 45 as a function of a, confirming the rapid approach to the asymptotic value of Eq. C. 50. Also shown are outer-zone enrichments of the multizone cores. As illustrated in Fig. C. 1, the zone enrichments are considerably less than the analytical value because the analytical value is an interfacial value.

\section{5 ZONE-AVERAGED ENRICHMENT}

A zone-averaged enrichment, $\bar{\varepsilon}_{i}$, can be obtained by integrating Eq. C. 9 over the annulus bounded by radii $r_{i-1}$ and $r_{i}$ :

$$
\bar{\varepsilon}_{i}=\int_{r_{i-1}}^{r_{i}} \varepsilon(r, a) 2 \pi r d r / \int_{r_{i-1}}^{r_{i}} 2 \pi r d r
$$

The numerator, $\mathrm{N}$, can be evaluated as follows:

$$
N \equiv \int_{r_{i-1}}^{r_{i}} \varepsilon(r ; a) 2 \pi r d r=\int_{r_{i-1}}^{r_{i}} \frac{C}{1-\beta(\kappa a) I_{o}(\kappa r)} \frac{2 \pi(\kappa r) d(\kappa r)}{\kappa^{2}}
$$

where

$$
\mathrm{C} \equiv \frac{\mathrm{D} \kappa^{2}}{\bar{\sigma}_{\mathrm{f}, 49} \mathrm{~N}_{\mathrm{o}}\left[\nu\left(1+\delta_{28}\right)+\xi\right]}
$$


Using the approximation,

$$
\frac{1}{1-\mathrm{X}} \cong 1+\mathrm{X}+\frac{\mathrm{x}^{2}}{2}
$$

one has

$$
\mathrm{N}=\frac{2 \pi \mathrm{C}}{\kappa^{2}} \int_{\mathrm{r}_{i-1}}^{\mathrm{r}_{\mathrm{i}}} \kappa \mathrm{r}\left\{1+\beta(\kappa \mathrm{a}) \mathrm{I}_{\mathrm{o}}(\kappa \mathrm{r})+\frac{\beta^{2}(\kappa a)}{2} \mathrm{I}_{o}^{2}(\kappa r)\right\} \mathrm{d}(\kappa r)
$$

Using the known Bessel function integrals,

$$
\begin{aligned}
& \int X I_{0}(X) d X=X \cdot I_{1}(X) . \\
& \int X I_{O}^{2}(X) d X=\frac{X^{2}}{2}\left[I_{0}^{2}(X)-I_{1}^{2}(X)\right],
\end{aligned}
$$

one can express a set of difference terms as:

$$
\begin{aligned}
& \Delta\left[r^{2}\right] \equiv r_{i}^{2}-r_{i-1}^{2} \\
& \Delta\left[\kappa r I_{1}\right] \equiv\left[\left(\kappa r_{i}\right) I_{1}\left(\kappa r_{i}\right)-\left(\kappa r_{i-1}\right) I_{1}\left(\kappa r_{i-1}\right)\right] \\
& \Delta\left[(\kappa r)^{2}\left(I_{o}^{2}-I_{1}^{2}\right)\right] \equiv\left(\kappa r_{i}\right)^{2}\left\{I_{o}^{2}\left(\kappa r_{i}\right)-I_{1}^{2}\left(\kappa r_{i}\right)\right\}-\left(\kappa r_{i-1}\right)^{2}\left\{I_{o}^{2}\left(\kappa r_{i-1}\right)-I_{1}^{2}\left(\kappa r_{i-1}\right)\right\}
\end{aligned}
$$

Since the denominator of Eq. C. 51 is

$$
\int_{r_{i-1}}^{r_{i}} 2 \pi r d r=\pi\left(r_{i}^{2}-r_{i-1}^{2}\right)=\pi \Delta\left[r^{2}\right]
$$

one has

$$
\bar{\varepsilon}_{i} \cong C\left\{1+\beta(\kappa a) \frac{\Delta\left[\kappa r I_{1}\right]}{\frac{\kappa}{2} \Delta\left[\mathrm{r}^{2}\right]}+\frac{\beta^{2}(\kappa a)}{2} \frac{\Delta\left[(\kappa r)^{2}\left(\mathrm{I}_{\mathrm{o}}^{2}-\mathrm{I}_{1}^{2}\right)\right]}{\frac{\kappa^{2}}{2} \Delta\left[\mathrm{r}^{2}\right]}\right\}
$$

where $\mathrm{C}$ is again the central enrichment for a perfectly radially powerflattened core having an infinite core radius. 
Table C. 1 shows an example of zone-averaged enrichment for a 250- $\mathrm{MW}_{\mathrm{e}}$, 6-zone, power-flattened core, which indicates that the onegroup approach is useful only for developing a first approximation to the required zone loadings. An alternative estimation of zone loadings can be obtained using a formula reported by GA:(pi).

$$
\frac{\vec{\varepsilon}_{i}}{\varepsilon}=\frac{\left(1-0.98 X_{i}\right)^{-0.4}}{\sum_{i=1}^{N} V_{i}\left(1-0.98 X_{i}\right)^{-0.4}}
$$

where

$$
\begin{aligned}
& x_{i}=\sum_{i=1}^{i-1} v_{i} \text { and } x_{1}=0 \\
& v_{i}=\left(\frac{r_{i}}{a}\right)^{2}
\end{aligned}
$$

which is not bad considering that the coefficients of 0.98 and -0.4 used here should really be obtained anew for each reactor design.

\section{Central Zone-Averaged Enrichment}

Putting $i=1$ and then $r_{i-1}=r_{0}=0$ in Eqs. C. $57 \mathrm{a}$, C. $57 \mathrm{~b}$ and $C .57 \mathrm{c}$, one obtains

$$
\begin{aligned}
& \Delta\left[\mathrm{r}^{2}\right]=\mathrm{r}_{1}^{2} \\
& \Delta\left[\kappa \mathrm{rI} \mathrm{I}_{1}\right]=\left[\left(\kappa \mathrm{r}_{1}\right) \mathrm{I}_{1}\left(\kappa \mathrm{r}_{1}\right)\right] \\
& \Delta\left[(\kappa \mathrm{r})^{2}\left(\mathrm{I}_{\mathrm{o}}^{2}-\mathrm{I}_{1}^{2}\right)\right]=\left(\kappa \mathrm{r}_{1}\right)^{2}\left[\mathrm{I}_{\mathrm{o}}^{2}\left(\kappa \mathrm{r}_{1}\right)-\mathrm{I}_{1}^{2}\left(\kappa \mathrm{r}_{1}\right)\right] .
\end{aligned}
$$

The central zone-averaged enrichment can be obtained by using these results in Eq. C. 61 . 


\begin{tabular}{ccccccc}
\hline \multirow{2}{*}{$\begin{array}{c}\text { i-th } \\
\text { Zone }\end{array}$} & $\begin{array}{c}\text { Outer } \\
\text { Radius } \\
(\mathrm{cm})\end{array}$ & $\begin{array}{c}\text { One-Group Prediction } \\
\text { Enrichment }\end{array}$ & $\begin{array}{c}\text { Peak Power } \\
\text { Flatness } \\
(\%)\end{array}$ & & $\begin{array}{c}\text { Zone } \\
\text { Enrichment } \\
(\%)\end{array}$ & $\begin{array}{c}\text { Formula } \\
\text { Peak Power } \\
\text { Flatness } \\
(\%)\end{array}$ \\
\hline 1 & 27.2 & 15.2 & - & 15.2 & - \\
2 & 37.8 & 16.4 & -5.0 & 16.4 & -3.2 \\
3 & 46.9 & 17.7 & -9.2 & 17.9 & -5.9 \\
4 & 54.4 & 19.4 & -15.3 & 20.2 & -8.1 \\
5 & 60.5 & 21.5 & -21.9 & 24.2 & -7.9 \\
6 & 65.0 & 27.0 & -20.7 & 32.3 & -4.5 \\
\hline
\end{tabular}

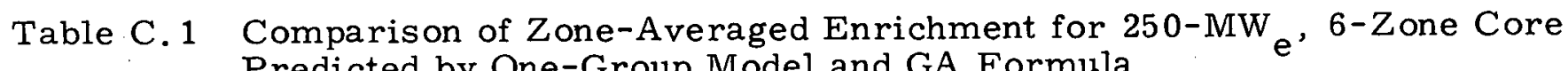
Predicted by One-Group Model and GA Formula. 


\section{Peripheral Zone-Averaged Enrichment}

Putting $i=I$ and then $r_{I} \equiv a$ in Eqs. C. 57a, C. 57b and C.57c, one has

$$
\begin{aligned}
& \Delta\left[\mathrm{r}^{2}\right]=\Delta\left[\mathrm{a}^{2}\right]=\mathrm{a}^{2}-\mathrm{r}_{\mathrm{I}-1}^{2} \\
& \Delta\left[\kappa a I_{1}\right] \equiv\left[\kappa a I_{1}(\kappa a)-\left(\kappa r_{I-1}\right) I_{1}\left(\kappa \dot{r}_{I-1}\right)\right] \\
& \Delta\left[(\kappa a)^{2}\left(I_{o}^{2}-I_{1}^{2}\right)\right]=(\kappa a)^{2}\left[I_{o}^{2}(\kappa a)-I_{1}^{2}(\kappa a)\right] \\
& -\left(\kappa r_{I-1}\right)^{2}\left[I_{o}^{2}\left(\kappa r_{I-1}\right)-I_{1}^{2}\left(\kappa r_{I-1}\right)\right] \text {. }
\end{aligned}
$$

Figure C. 2 also shows these zone-averaged enrichments together with $2 \mathrm{DB}$ results, and indicates good agreement. 


\section{Appendix D}

BLANKET NEUTRONICS

The purpose of this appendix is to obtain the exponential distribution of neutron flux in the radial blanket by solving the one-group diffusion equation and by using reasonable approximations .

\section{1 FLUX DISTRIBUTION IN THE BLANKET}

The blanket diffusion equation is

$$
\mathrm{D}_{\mathrm{B}} \nabla^{2} \phi-\Sigma_{\mathrm{a}, \mathrm{B}} \phi+\nu \Sigma_{\mathrm{f} ; \mathrm{B}} \phi=0 \text {, }
$$

where

$D_{B}$ is the blanket diffusion coefficient,

$\Sigma_{\mathrm{f}, \mathrm{B}}$ is the blanket macroscopic fission cross section,

$\Sigma_{\mathrm{a}, \mathrm{B}}$ is the blanket macroscopic absorption cross section,

$\nu$ is the neutron yield per fission.

Equation D. 1 can be rearranged as

$$
\left(\frac{1}{\mathrm{r}} \frac{\mathrm{d}}{\mathrm{dr}} \mathrm{r} \frac{\mathrm{d}}{\mathrm{dr}}\right) \phi-\gamma^{2} \phi=0,
$$

where

$$
\gamma^{2}=\frac{\Sigma_{a, B}+D_{B} B_{z}^{2}-\nu \Sigma_{f, B}}{D_{B}},
$$

with the solution:

$$
\phi(r)=X K_{o}(\gamma r) .
$$

Applying the boundary condition: 


$$
\phi(a)=\phi(0)=X K_{0}(\gamma a)
$$

or

$$
\mathrm{X}=\frac{\phi(0)}{\mathrm{K}_{\mathrm{o}}(\gamma \mathrm{a})}
$$

one has

$$
\phi(r)=\phi(0) \frac{K_{o}(\gamma r)}{K_{o}(\gamma a)}
$$

Note that we have neglected the effect of the reflector. on the blanket flux based on the observation that multigroup calculations show that in steel-reflected blankets the $U^{238}$ capture rate profile does not differ significantly from that in an infinitely extended blanket (B3).

Since

$$
\left.\mathrm{K}_{\mathrm{o}}(\mathrm{Z}) \cong \sqrt{\frac{\pi}{2 Z}} \mathrm{e}^{-Z} \text { for } \mathrm{Z}=\gamma \mathrm{r} \text { (or } \gamma \mathrm{a}\right) \cong 10
$$

one has

$$
\phi(r)=\phi(0) \sqrt{\frac{a}{r}} e^{-\gamma(r-a)}
$$

Defining a new coordinate, $\tau=r-a$ the distance from the core/blanket interface, one has

$$
\phi(\tau)=\frac{\phi(0)}{\sqrt{1+\frac{\tau}{a}}} \mathrm{e}^{-\gamma \tau}
$$

For a large core which has $\tau=45$ and $a \simeq 125 \mathrm{~cm}$,

$$
1>\frac{\tau}{\mathrm{a}}=\frac{45}{125}=0.36,
$$

one has, very crudely,

$$
\phi(\tau) \rightarrow \phi(0) \mathrm{e}^{-\gamma \tau} .
$$

Equation D. 11 gives a good approximation to the measured or calculated $\mathrm{U}^{238}$ capture rate in LMFBR blankets (W2, B4). 


\section{2 FISSILE MATERIAL BUILDUP RATE}

The local fissile material buildup rate per unit volume at distance $\tau$ into the blanket, $\mathrm{U}_{\mathrm{o}}(\tau)$ (gPu/liter-yr), is proportional to neutron flux which, using Eq. D. 11, gives:

$$
\mathrm{U}_{\mathrm{o}}(\tau) \propto \phi(\tau) \propto \phi(0) \mathrm{e}^{-\gamma \tau}
$$

Since local fissile enrichment buildup rate at distance $\tau$ into the blanket, $\varepsilon_{\mathrm{o}}(\tau)(\mathrm{gPu} / \mathrm{kg} \mathrm{U}-\mathrm{yr})$ is proportional to $U_{\mathrm{o}}(\tau)$, one has

$$
\varepsilon_{0}(\tau) \propto \mathrm{e}^{-\gamma \tau}
$$

which indicates that the fissile enrichment buildup rate decreases exponentially.as the distance into the blanket increases.

\section{3 ROW-BY-ROW FISSILE MATERIAL BUILDUP RATE}

Fissile material buildup rate in a row of the radial blanket, $R_{o_{i}}$, $(\mathrm{gPu} / \mathrm{yr})$ is obtained by integrating Eq. D. 12 over the entire row volume, $\mathrm{V}_{\mathrm{B}}$, as follows:

$$
\mathrm{R}_{\mathrm{o}_{\mathrm{i}}} \propto \int_{\tau_{\mathrm{i}-1}}^{\tau} \mathrm{i} \mathrm{U}_{\mathrm{o}}(\tau) \mathrm{d} \tau=\int_{\tau_{\mathrm{i}-1}}^{\tau} \mathrm{e}^{-\gamma \tau} \mathrm{d} \tau=\frac{1}{\gamma}\left[\mathrm{e}^{-\gamma \tau_{\mathrm{i}}-1}-\mathrm{e}^{-\gamma \tau_{\mathrm{i}}}\right]
$$

The total fissile material buildup rate, $R_{{ }^{\prime}}$, in the entire radial blanket having thickness", $\tau$; is

$$
R_{\mathrm{o}} \propto \int_{0}^{\tau} \mathrm{U}_{\mathrm{o}}(\tau) \mathrm{d} \tau=\frac{1}{\gamma}\left[1-\mathrm{e}^{-\gamma \tau}\right]
$$

Thus, the fractional row-by-row fissile buildup rate is

$$
\frac{\mathrm{R}_{\mathrm{o}_{i}}}{\mathrm{R}_{\mathrm{o}}}=\frac{\left[\mathrm{e}^{-\gamma \tau} \mathrm{i}-1-\mathrm{e}^{-\gamma \tau} \mathrm{i}\right]}{\left[1-\mathrm{e}^{-\gamma \tau}\right]}
$$


It should be noted that fractional row-by-row fissile buildup rate is independent of core radius. Thus fịsile material inventory in each row can be calculated separately. Using the cross-section data of Table 3.1 , the row-by-row fissile material buildup rate is $59 \%$ for row $1,28 \%$ for row 2 and $13 \%$ for row 3 ; in good agreement with $2 \mathrm{DB}$ results as shown in Table D. 1. This row-by-row proportionality does not change very much due to irradiation, as shown by the $2 \mathrm{DB}$ calculations presented in the last column in Table.D. 1. 


\begin{tabular}{|c|c|c|c|}
\hline $\begin{array}{l}\text { Relative } \\
\text { Row-by-Row } \\
\text { Fissile Buildun } \\
\text { Rate }\left(\frac{\%}{6}\right)\end{array}$ & $\begin{array}{l}1 \mathrm{GM} \\
\mathrm{BOL}\end{array}$ & $\begin{array}{l}2 D B \\
\text { BOL }\end{array}$ & $\begin{array}{l}2 \mathrm{DB} \\
\text { EOL * }\end{array}$ \\
\hline$R_{01} / R_{0}$ & 59.0 & 60.5 & 51.8 \\
\hline $\mathrm{R}_{02} / \mathrm{R}_{0}$ & 27.9 & 27.9 & 31.9 \\
\hline$R_{03} / R_{0}$ & 13.1 & 11.6 & 16.3 \\
\hline
\end{tabular}

*EOL for batch-irradiated blanket at 1800 davs surrounding on Equilibrium core.

Table D.1 Comparison of $2 \mathrm{DJ}$ and One-Groun Models for Row-by-Row Fissile Buildup Rate 


\author{
Appendix $\mathrm{E}$ \\ DEPLETION-ECONOMICS ANALYSIS
}

Based on the cost equation derived by Brewer (B3) and the exponential distribution of fissile material buildup in the blanket as discussed in Appendix D, several interesting optima such as local optima (row-by-row basis), total optima (entire blanket basis) and global optima will be presented; their mutual interrelationships will be investigated, and results correlated against the economic parameter originally developed by Wood (W2) and modified in the present work.

\title{
E. 1 OPTIMUM IRRADIATION TIME
}

The local fuel cost contribution equation can be expressed in the form (B3):

$$
e=k \frac{C_{1} F_{1}\left(-T_{1}\right)+C_{2} F_{2}\left(-T_{2}\right)-C_{3} F_{3}\left(-T_{3}\right) \varepsilon(T)}{T}
$$

where

e is the fuel cycle cost contribution

$\mathrm{k}$ is a function which does not depend on the economic environment or time

$C_{1}$ is the fabrication cost component $(\$ / \mathrm{kg})$

$\mathrm{C}_{2}$ is the reprocessing cost component $(\$ / \mathrm{kg})$

$\mathrm{C}_{3}$ is the material credit $(\$ / \mathrm{kg})$

$F_{1}\left(-T_{1}\right)$ is the carrying charge factor for fabrication occurring at time $\mathrm{T}_{1}$. measured from the irradiation midpoint 
$\mathrm{F}_{2}\left(-\mathrm{T}_{2}\right)$ is the carrying charge factor for reprocessing occurring at time $\mathrm{T}_{2}$ measured from the irradiation midpoint

$\mathrm{F}_{3}\left(-\mathrm{T}_{3}\right)$ is the carrying charge factor for material credit occurring at time $\mathrm{T}_{3}$ measured from the irradiation midpoint

in which $\quad X$ is the discount rate

$\tau$ is the tax rate

$\varepsilon(T)$ is the fissile enrichment at time, T

$\mathrm{T}$ is the length of the irradiation period.

Figure E. 1 shows the timing of the cash flow involved. It has been assumed in this relationship that the material purchase is either negligible or included in the fabrication charges. Because a correlation for the optimum irradiation time is desired, the next step in the development is to set the time derivative of the fuel cycle cost contribution equal to zero.

$$
\frac{\mathrm{de}}{\mathrm{dT}}=0
$$

or

$$
\begin{aligned}
0= & \mathrm{TC}_{1} \frac{\mathrm{dF}_{1}\left(-\mathrm{T}_{1}\right)}{\mathrm{dT}}-\mathrm{C}_{1} \mathrm{~F}_{1}\left(-\mathrm{T}_{1}\right)+\mathrm{TC}_{2} \frac{\mathrm{dF_{2 } (}\left(-\mathrm{T}_{2}\right)}{\mathrm{dT}}-\mathrm{C}_{2} \mathrm{~F}_{2}\left(-\mathrm{T}_{2}\right) \\
& -\mathrm{TC}_{3}\left\{\varepsilon(\mathrm{T}) \frac{\mathrm{dF} \mathrm{F}_{3}\left(-\mathrm{T}_{3}\right)}{\mathrm{dT}}+\mathrm{F}_{3}\left(-\mathrm{T}_{3}\right) \frac{\mathrm{d} \varepsilon(\mathrm{T})}{\mathrm{dT}}\right\}+\mathrm{C}_{3} \varepsilon(\mathrm{T}) \mathrm{F}_{3}\left(-\mathrm{T}_{3}\right)=0 .
\end{aligned}
$$

Next, time derivatives are taken of the carrying charge factors. In these operations, series expansions are used where necessary to obtain simple expressions. First, consider $\mathrm{F}_{1}\left(-\mathrm{T}_{1}\right)$. 


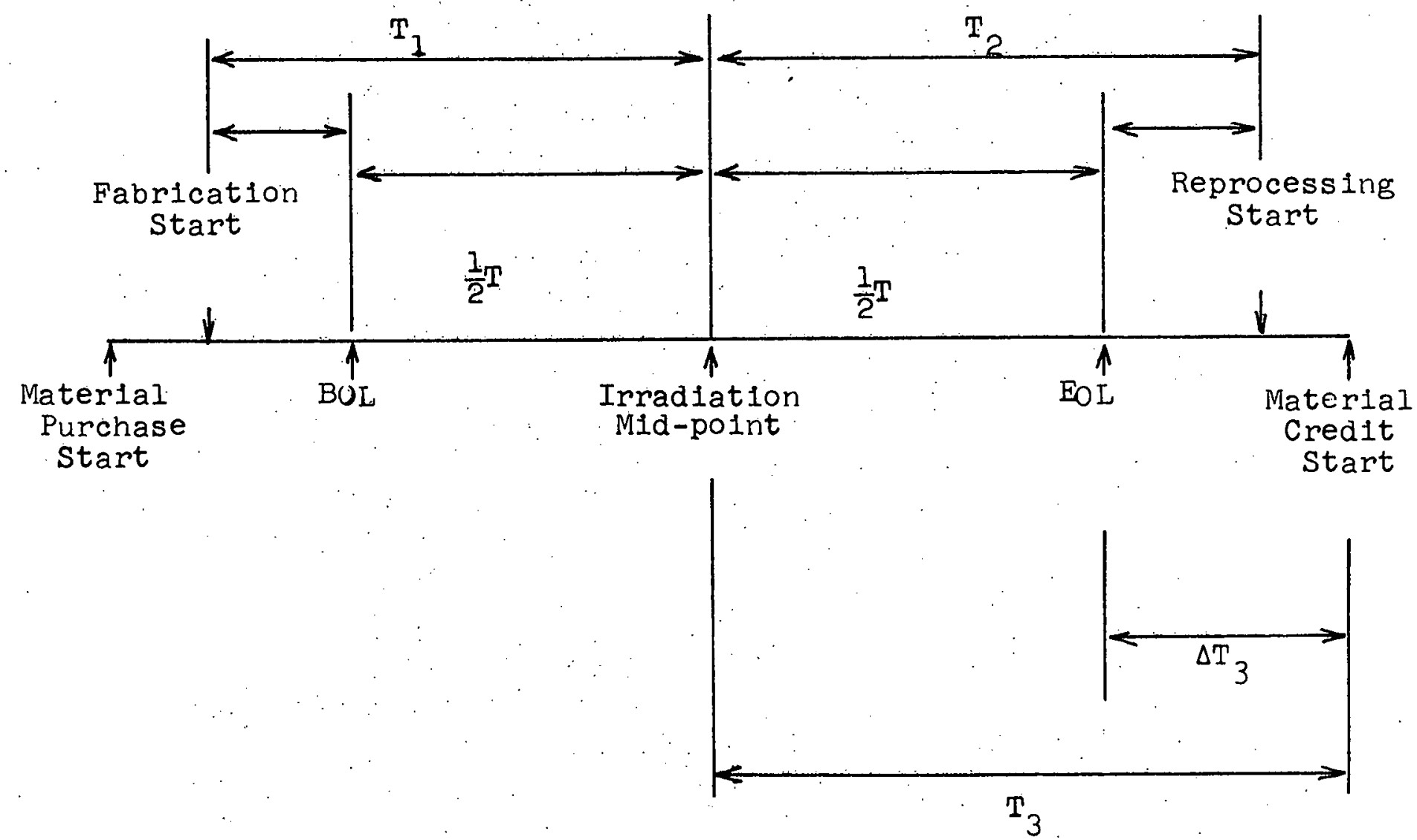

Fig. E.1 Timing of Cash Flows for Fuel Cycle Cost Calculations 


$$
\mathrm{F}_{1}\left(-\mathrm{T}_{1}\right)=\frac{1}{1-\tau} \cdot\left[(1+\mathrm{X})^{\mathrm{T}}{ }^{1}-\tau\right] \cong 1+\left(\frac{\mathrm{X}}{1-\tau}\right) \mathrm{T}_{1}
$$

Consider only a tax rate 0.5 :

$$
\begin{aligned}
& \mathrm{F}_{1}\left(-\mathrm{T}_{1}\right) \cong 1+2 \mathrm{XT} \mathrm{T}_{1} \cong(1+2 \mathrm{X})^{\mathrm{T}} 1 \\
& \frac{\mathrm{dF} \mathrm{F}_{1}\left(-\mathrm{T}_{1}\right)}{\mathrm{dT}} \cong \mathrm{F}_{1}\left(-\mathrm{T}_{1}\right) \ln (1+2 \mathrm{X})\left(\frac{1}{2}\right) \cong \mathrm{F}_{1}\left(-\mathrm{T}_{1}\right) \mathrm{X} .
\end{aligned}
$$

To proceed with this development, the definitions for $\mathrm{T}_{1}, \mathrm{~T}_{2}$, and $\mathrm{T}_{3}$ must be introduced.

$$
\begin{aligned}
& \mathrm{T}_{1}=\Delta \mathrm{T}_{1}+\frac{\mathrm{T}}{2} \\
& \mathrm{~T}_{2}=-\Delta \mathrm{T}_{2}-\frac{\mathrm{T}}{2} \\
& \mathrm{~T}_{3}=-\Delta \mathrm{T}_{3}-\frac{\mathrm{T}}{2}
\end{aligned}
$$

where

$\mathrm{T}$ is the time of the irradiation,

$\Delta \mathrm{T}_{1}$ is the length of time from the fabrication cash flow to the beginning of the irradiation,

$\Delta \mathrm{T}_{2}$ is the length of time from the end of the irradiation to the reprocessing cash flow,

$\Delta \mathrm{T}_{3}$ is the length of time from the end of the irradiation to the material credit cash flow.

Taking derivatives of Eqs. E. 7, E. 8 and E. 9 yields

$$
\begin{aligned}
& \frac{\mathrm{dT}_{1}}{\mathrm{dT}}=\frac{1}{2} \\
& \frac{\mathrm{dT}_{2}}{\mathrm{dT}}=-\frac{1}{2} \\
& \frac{\mathrm{dT}_{3}}{\mathrm{dT}}=-\frac{1}{2} .
\end{aligned}
$$


Combining. Eqs. E. 5, E. 6 and E. 7 yields

$$
\frac{\mathrm{dF}_{1}\left(-\mathrm{T}_{1}\right)}{\mathrm{dT}} \cong \mathrm{X}(1+2 \mathrm{X}) \mathrm{T}_{1}(1+2 \mathrm{X})^{\mathrm{T} / 2} \cong \mathrm{XF}_{1}\left(-\Delta \mathrm{T}_{1}\right)(1+\mathrm{XT})
$$

Consider next the time derivatives of $\mathrm{F}_{2}\left(-\mathrm{T}_{2}\right)$ and $\mathrm{F}_{3}\left(-\mathrm{T}_{3}\right)$.

$$
\frac{\mathrm{dF}_{2}\left(-\mathrm{T}_{2}\right)}{\mathrm{dT}} \cong(1+\mathrm{X})^{\mathrm{T}} 2 \ln (1+\mathrm{X}) \frac{\mathrm{dT}_{2}}{\mathrm{dT}}
$$

Using Eq. E. 11 and expanding the logarithmic term yields

$$
\frac{\mathrm{dF}_{2}\left(-\mathrm{T}_{2}\right)}{\mathrm{dT}} \cong-\frac{\mathrm{X}}{2} \mathrm{~F}_{2}\left(-\mathrm{T}_{2}\right)
$$

Combining Eqs. E. 15 and E. 8 gives

$$
\frac{\mathrm{dF}_{2}\left(-\mathrm{T}_{2}\right)}{\mathrm{dT}}=-\frac{\mathrm{X}}{2} \mathrm{~F}_{2}\left(\Delta \mathrm{T}_{2}\right)(1+\mathrm{X})^{-\mathrm{T} / 2}
$$

expanding the last term produces

$$
\frac{\mathrm{dF}_{2}\left(-\mathrm{T}_{2}\right)}{\mathrm{dT}}=-\frac{\mathrm{X}}{2} \mathrm{~F}_{2}\left(\Delta \mathrm{T}_{2}\right)\left(1-\frac{\mathrm{XT}}{2}\right)
$$

similarly,

$$
\frac{\mathrm{dF}_{3}\left(-\mathrm{T}_{3}\right)}{\mathrm{dT}}=-\frac{\mathrm{X}}{2} \mathrm{~F}_{3}\left(\Delta \mathrm{T}_{3}\right)\left(1-\frac{\mathrm{XT}}{2}\right)
$$

Equations E.13, E.17, and E. 18 can now be substituted into Eq. E. 3 and the carrying charge factors in the resulting expression can be approximated using the following relationships:

$$
\begin{aligned}
& F_{1}\left(-T_{1}\right) \cong F_{1}\left(-\Delta T_{1}\right)\left(1+\frac{X T}{2}\right) \\
& F_{2}\left(-T_{2}\right) \cong F_{2}\left(\Delta T_{2}\right)\left(1-\frac{X T}{2}\right) \\
& F_{3}\left(-T_{3}\right) \cong F_{3}\left(\Delta T_{3}\right)\left(1-\frac{X T}{2}\right)
\end{aligned}
$$


When the terms are collected in the relationship resulting from the above manipulations, the following expression is arrived at:

$$
\begin{aligned}
0= & T^{2}\left\{C_{1} X^{2} F_{1}\left(-\Delta T_{1}\right)+C_{2}\left(\frac{X}{2}\right)^{2} F_{2}\left(\Delta T_{2}\right)+C_{3} \frac{\varepsilon(T)}{T}\left(\frac{X}{2}\right) F_{3}\left(\Delta T_{3}\right)\right\} \\
& -C_{1} F_{1}\left(-\Delta T_{1}\right)-C_{2} F_{2}\left(\Delta T_{2}\right)-T^{2} C_{3} \varepsilon(T)\left(\frac{X}{2}\right)^{2} F_{3}\left(\Delta T_{3}\right) . \quad(E .22)
\end{aligned}
$$

If it is now assumed that the fissile enrichment builds up linearly in the blanket, Eq. E. 22 can be rewritten (neglecting the resulting $\mathrm{T}^{3}$ terms for simplicity):

$$
\begin{gathered}
T^{2}\left\{C_{1} X^{2} F_{1}\left(-\Delta T_{1}\right)+C_{2}\left(\frac{X}{2}\right)^{2} F_{2}\left(\Delta T_{2}\right)+C_{3} S_{o}\left(\frac{X}{2}\right) F_{o}\left(\Delta T_{3}\right)\right\} \\
=C_{1} F_{1}\left(-\Delta T_{1}\right)+C_{2} F_{2}\left(\Delta T_{2}\right)
\end{gathered}
$$

where the fissile enrichment has been approximated by

$$
\varepsilon(T)=S_{0} T
$$

Rearranging Eq. E.23, recalling that the time $\mathrm{T}$ is the optimum irradiation time:

$$
\mathrm{T}_{\text {opt }}=\frac{1}{\mathrm{X}}\left[\frac{\mathrm{C}_{1} \mathrm{~F}_{1}\left(-\Delta \mathrm{T}_{1}\right)+\mathrm{C}_{2} \mathrm{~F}_{2}\left(\Delta \mathrm{T}_{2}\right)}{\mathrm{C}_{1} \mathrm{~F}_{1}\left(-\Delta \mathrm{T}_{1}\right)+\frac{1}{4} \mathrm{C}_{2} \mathrm{~F}_{2}\left(\Delta \mathrm{T}_{2}\right)+\frac{1}{2} \mathrm{C}_{3}\left(\frac{\mathrm{S}_{\mathrm{o}}}{\mathrm{X}}\right) \mathrm{F}_{3}\left(\Delta \mathrm{T}_{3}\right)}\right]^{1 / 2}
$$

Because of the low cost of fabrication $\left(C_{1}=69 \$ / \mathrm{kg}\right)$ and reprocessing $\left(C_{2}=50 \$ / \mathrm{kg}\right)$ relative to the fissile material value $\left(C_{3}=10,000 \$ / \mathrm{kg}\right)$, and noting that $F_{1}(-0.5) \cong F_{2}(0.5) \cong F_{3}(0.5)=1$,

$$
\begin{aligned}
& \mathrm{C}_{1} \mathrm{~F}_{1}\left(-\Delta \mathrm{T}_{1}\right) \cong 69 \\
& \frac{1}{4} \mathrm{C}_{2} \mathrm{~F}_{1}\left(\Delta \mathrm{T}_{2}\right) \cong \frac{50}{4} \cong 13
\end{aligned}
$$




$$
\frac{1}{2} \cdot \mathrm{C}_{3} \mathrm{~F}_{3}\left(\Delta \mathrm{T}_{3}\right) \frac{\mathrm{S}_{\mathrm{o}}}{\mathrm{X}} \cong \frac{1}{2}(10,000) \frac{0.02}{0.08} \cong 1250
$$

Thus, the first two terms in the denominator can be neglected with respect to the last term. The expression resulting from this analysis is:

$$
\mathrm{T}_{\mathrm{opt}} \cong \sqrt{\frac{2}{\mathrm{~S}_{\mathrm{o}}}}\left[\frac{\mathrm{C}_{1} \mathrm{~F}_{1}\left(-\Delta \mathrm{T}_{1}\right)+\mathrm{C}_{2} \mathrm{~F}_{2}\left(\Delta \mathrm{T}_{2}\right)}{\mathrm{C}_{3} \mathrm{~F}_{3}\left(\Delta \mathrm{T}_{3}\right) \mathrm{X}}\right]^{1 / 2}
$$

Because of the large number of assumptions and omissions used in developing Eq. E. 29, the actual equation would not be expected to apply. However, all of the important economic parameters are included within the brackets in Eq. E.29. As a result, one might expect that the optimum irradiation time would correlate against the optimum economic parameter:

$$
\mathrm{W} \equiv\left[\frac{\mathrm{C}_{1} \mathrm{~F}_{1}\left(-\Delta \mathrm{T}_{1}\right)+\mathrm{C}_{2} \mathrm{~F}_{2}\left(\Delta \mathrm{T}_{2}\right)}{\mathrm{C}_{3} \mathrm{~F}_{3}\left(\Delta \mathrm{T}_{3}\right)}\right]
$$

together with the discount rate, $X$. To summarize, the terms in the optimum economic parameter, W, are:

$$
\begin{aligned}
& F_{1}\left(-\Delta T_{1}\right)=\frac{1}{1-\tau}\left[(1+X)^{\Delta T_{1}}{ }^{-\tau}\right] \\
& F_{2}\left(\Delta T_{2}\right)=(1+X)^{-\Delta T_{2}} \\
& F_{3}\left(\Delta T_{3}\right)=(1+X)^{-\Delta T_{3}} \\
& X=(1-\tau) r_{b} f_{b}+r_{s} f_{s},
\end{aligned}
$$

where the terms are defined in Chapter 2. 


\section{E.2 BREAKEVEN IRRADIATION TIME}

Again, one starts with Eq. E. 1 for the fuel cycle cost contribution, e (mills/kwhr), for the blanket:

$$
e \propto \frac{C_{1} F_{1}\left(-T_{1}\right)+C_{2} F_{2}\left(-T_{2}\right)-C_{3} F_{3}\left(-T_{3}\right) \varepsilon(T)}{T}
$$

Using the approximations of Eqs. E.19, E.20, E.21 and Eq. E.24, one has

$$
e \propto \frac{C_{1} F_{1}\left(-\Delta T_{1}\right)\left(1+\frac{X T}{2}\right)+C_{2} F_{2}\left(\Delta T_{2}\right)\left(1-\frac{X T}{2}\right)-C_{3} F_{3}\left(\Delta T_{3}\right)\left(1-\frac{X T}{2}\right) S_{0} T}{T}
$$

To get the breakeven irradiation time, the fuel cycle cost contribution. is set equal to zero. One gets a quadratic equation in $\mathrm{T}(\mathrm{yr})$ :

$$
\begin{gathered}
\mathrm{T}^{2}-\frac{2}{\mathrm{X}}\left[1-\frac{\mathrm{C}_{1} \mathrm{~F}_{1}\left(-\Delta \mathrm{T}_{1}\right)-\mathrm{C}_{2} \mathrm{~F}_{2}\left(\Delta \mathrm{T}_{2}\right)}{\mathrm{C}_{3} \mathrm{~F}_{3}\left(\Delta \mathrm{T}_{3}\right) \mathrm{S}_{0}} \frac{\mathrm{X}}{2}\right] \mathrm{T} \\
+\frac{\mathrm{C}_{1} \mathrm{~F}_{1}\left(-\Delta \mathrm{T}_{1}\right)+\mathrm{C}_{2} \mathrm{~F}_{2}\left(\Delta \mathrm{T}_{2}\right)}{\mathrm{C}_{3} \mathrm{~F}_{3}\left(\Delta \mathrm{T}_{3}\right)} \frac{2}{\mathrm{~S}_{\mathrm{o}} \mathrm{X}}=0 .
\end{gathered}
$$

Since the term

$$
\frac{\mathrm{C}_{1} \mathrm{~F}_{1}\left(-\Delta \mathrm{T}_{1}\right)-\mathrm{C}_{2} \mathrm{~F}_{2}\left(\Delta \mathrm{T}_{2}\right)}{\mathrm{C}_{3} \mathrm{~F}_{3}\left(\Delta \mathrm{T}_{3}\right) \mathrm{S}_{\circ}} \frac{\mathrm{X}}{2}=0.0065 \ll 1
$$

one has,

$$
\mathrm{T}^{2}-\frac{2}{\mathrm{X}} \mathrm{T}+\frac{2 \mathrm{~W}}{\mathrm{~S}_{\mathrm{O}} \mathrm{X}}=0
$$

where the economic parameter,

$$
\mathrm{W} \equiv \frac{\mathrm{C}_{1} \mathrm{~F}_{1}\left(-\Delta \mathrm{T}_{1}\right)+\mathrm{C}_{2} \mathrm{~F}_{2}\left(\Delta \mathrm{T}_{2}\right)}{\mathrm{C}_{3} \mathrm{~F}_{3}\left(\Delta \mathrm{T}_{3}\right)}
$$

has again been used. 
If the discriminant is positive, there are two real solutions which are meaningful.

$$
\mathrm{T}_{\mathrm{BE}}=\frac{1}{\mathrm{X}} \pm \frac{1}{\mathrm{X}} \sqrt{1-\frac{2 \mathrm{WX}}{\mathrm{S}_{\mathrm{O}}}}
$$

The solution with positive sign is the irradiation time beyond which the profit by breeding is cancelled out by accumulation of carrying charges . The solution with negative sign is the case of real interest - the irradiation time beyond which there is a net profit.

Requiring a non-negative discriminant gives

$$
\begin{aligned}
& 1-\frac{2 W X}{S_{O}} \geqslant 0 \\
& \therefore S_{O} \geqslant 2 W X,
\end{aligned}
$$

which indicates that the fissile specific buildup rate must not be less than a certain value, which is determined only by the economic environment. Using reference economic conditions of Table 2.14, one has

$$
\mathrm{S}_{\mathrm{O}} \geqslant 2.04(\mathrm{gPu} / \mathrm{kg} \mathrm{HM}-\mathrm{yr})
$$

which indicates that the fissile specific buildup rate must be larger than about $2(\mathrm{gPu} / \mathrm{kg} \mathrm{HM}-\mathrm{yr})$ under the reference economic environment before the blanket can achieve at least zero profit. The equal sign in Eq. E. 40 gives the minimum profitable fissile specific buildup rate, over which a net profit can be produced, which occurs at:

$$
\mathrm{T}_{\mathrm{M}}=\frac{1}{\mathrm{X}}
$$

Using the reference discount rate $X=0.08\left(\right.$ year $\left.^{-1}\right)$, one obtains

$$
\mathrm{T}_{\mathrm{M}}=12.5 \text { year. }
$$


Since $2 \mathrm{WX} / \mathrm{S}_{\mathrm{O}}=0.116$, one can expand the square root in Eq. E. 39 and obtain:

$$
\mathrm{T}_{\mathrm{BE}} \cong \frac{1}{\mathrm{X}} \pm \frac{1}{\mathrm{X}}\left(1-\frac{\mathrm{WX}}{\mathrm{S}_{\mathrm{O}}}\right)=\left\{\begin{array}{l}
\mathrm{W} / \mathrm{S}_{\mathrm{O}} \\
2 / \mathrm{X}-\mathrm{W} / \mathrm{S}_{\mathrm{o}}
\end{array} .\right.
$$

Thus the first breakeven irradiation time is independent of discount rate. Using reference economic conditions of Table 2.14 and the $2 \mathrm{DB}$ result for zone 1-blanket driven by $1000-\mathrm{MW}_{\mathrm{e}}, 2$-zone core, one obtains:

$$
\mathrm{T}_{\mathrm{BE}-1} \cong 1.12 \text { (full power years) }=336 \text { (full power days). }
$$

This is in reasonably good agreement with the $2 \mathrm{DB}-\mathrm{BRECON}$ results of 376 full power days; however, use of empirical correlations will be needed for more accurate predictions.

The second breakeven irradiation time can also be obtained:

$$
\mathrm{T}_{\mathrm{BE}-2}=23.88^{\circ} \text { (full power years) }
$$

which does not occur within the time span studied.

Figure E.2 shows these relations.

\section{E. 3 RELATION OF OPTIMUM IRRADIATION TIME AND DISTANCE INTO BLANKET}

The local optimum irradiation time of an annular slice of radial blanket at distance, $\tau$, from the core/blanket interface is given in the form:

$$
\mathrm{t}_{\mathrm{opt}}(\tau)=\sqrt{\frac{2 \mathrm{~W}}{\mathrm{x} \overline{\mathrm{S}}_{\mathrm{o}}}}
$$

Using the approximate exponential distribution of bred fissile material 


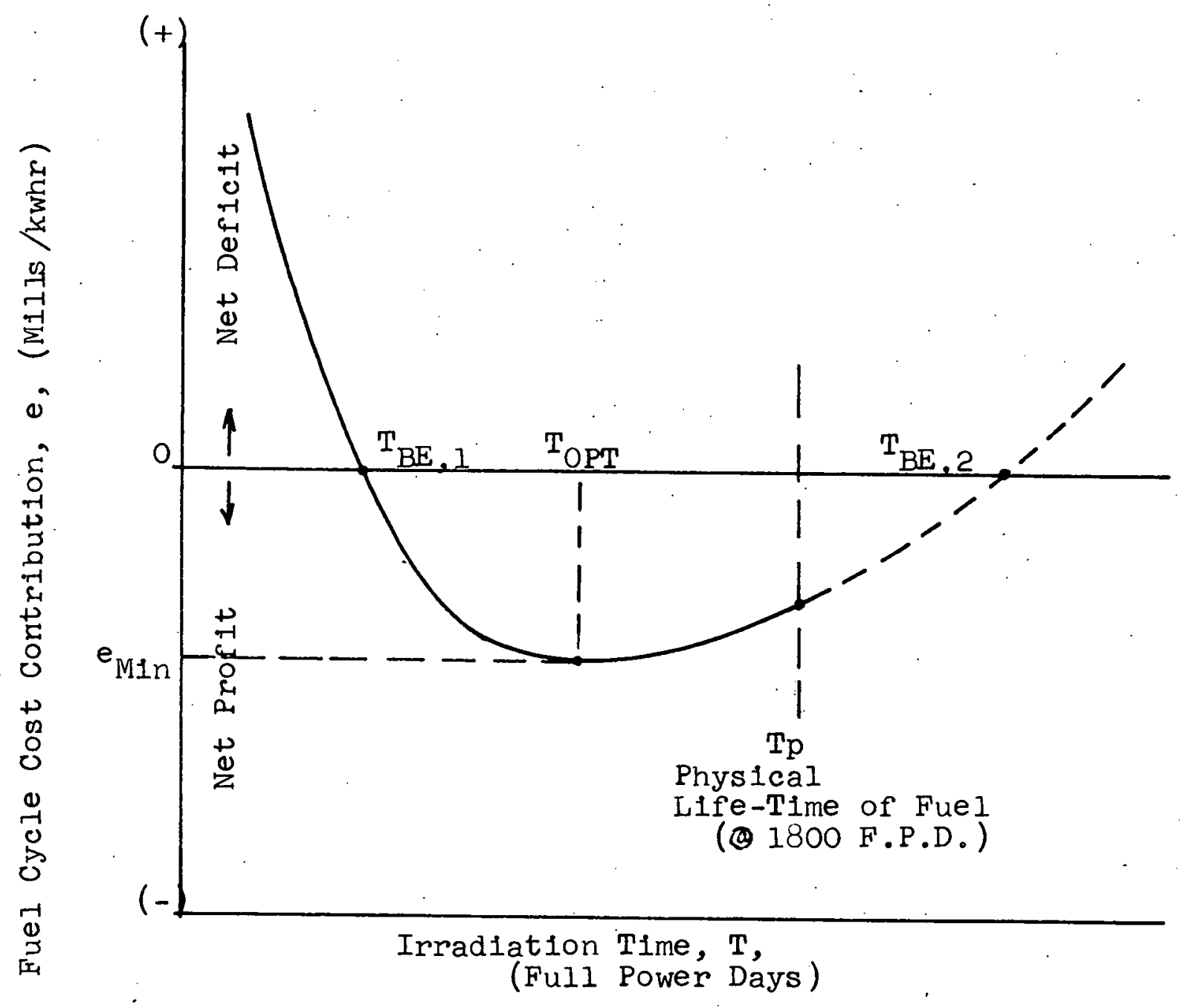

Fig. E.2 Typical Variation of Fuel Cycle Cost Contribution from a Fast Reactor Blanket 
expressed in the form:

$$
S_{0}(\tau)=S_{0}(0) e^{-\gamma \tau}
$$

where $\mathrm{S}_{\mathrm{o}}(0)$ is the fissile buildup rate at the core/blanket interface, one has for the average buildup rate:

$$
\bar{S}_{0}=\frac{\int_{\tau_{i-1}}^{\tau_{i}} S_{o}(\tau) d \tau}{\int_{\tau_{i-1}}^{\tau_{i}} d \tau}=S_{o}(0) \frac{\left(e^{-\gamma \tau} \tau_{i-1}-e^{-\gamma \tau} i\right)}{\gamma \Delta \tau}
$$

Consider a blanket (or blanket row) of thickness $\Delta \tau$ centered about position $\tau$ :

$$
\begin{aligned}
& \tau_{i}-\tau_{i-1}=\Delta \tau \\
& \tau_{i}=\tau+\frac{\Delta \tau}{2} \\
& \tau_{i-1}=\tau-\frac{\Delta \tau}{2}
\end{aligned}
$$

One has

$$
\bar{S}_{\mathrm{O}}=\mathrm{S}_{\mathrm{o}}(0) \mathrm{e}^{-\gamma \tau} \frac{\left(\mathrm{e}^{\gamma \frac{\Delta \tau}{2}}-\mathrm{e}^{-\gamma \frac{\Delta \tau}{2}}\right)}{\gamma \Delta \tau}
$$

or

$$
\bar{S}_{0}^{\prime}=S_{0}(0) e^{-\gamma \tau} \cdot \lambda(X)
$$

where

$$
\lambda(X) \equiv \sinh X / X
$$

is the averaging factor,

$$
\mathrm{X} \equiv \frac{\gamma \Delta \tau}{2} .
$$

Since the averaging factor can be expanded for every $X \neq 0$, 


$$
\lambda(X)=\sinh x / x=1+\frac{x^{2}}{6}+\ldots
$$

one can obtain

$$
\lambda(X) \cong 1
$$

for small $\mathrm{X}=\frac{\gamma \Delta \tau}{2} \cong 0.4$ in the present work where $\gamma=0.05 \mathrm{~cm}^{-1}$ and $\Delta \tau=15 \mathrm{~cm}$. Thus, one has for the average buildup rate:

$$
\bar{S}_{0}=S_{o}(0) e^{-\gamma \tau}
$$

which indicates that the average buildup rate is also expressed as an exponential function of the blanket thickness.

Substituting Eq. E. 51 into Eq. E. 42 , one obtains

$$
t_{o p t}(\tau)=\sqrt{\frac{2 W}{X S_{o}(0)}} e^{\frac{1}{2} \gamma \tau},
$$

which indicates that the local optimum irradiation time increases exponentially as a function of distance from the core/blanket interface, or

$$
\tau=\frac{2}{\gamma}\left[\ln \mathrm{t}_{\mathrm{opt}}(\tau)-\frac{1}{2} \ln \left(\frac{2 \mathrm{~W}}{\mathrm{~S}_{\mathrm{o}}(0) \mathrm{X}}\right)\right]
$$

In a similar manner, the local breakeven irradiation time of the slice of radial blanket at distance $\tau$ into the blanket, is

$$
t_{B E}=\frac{W}{S_{o}(0)} e^{\gamma \tau}
$$

or

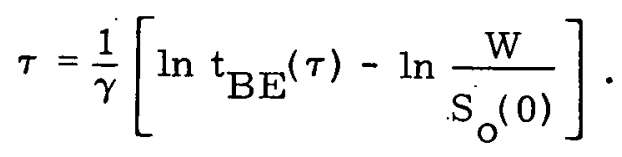

The breakeven irradiation time also increases exponentially with distance into the blanket. These relations are shown in Fig. E. 3. The local breakeven irradiation time can be related to the local optimum 
irradiation time by eliminating the distance; $\tau$, from Eq. E. 53 and Eq. E. 55:

$$
\mathrm{t}_{\mathrm{BE}}=\frac{\mathrm{X}}{2} \mathrm{t}_{\mathrm{opt}}^{2}
$$

or

$$
\ln t_{B E}=2 \ln t_{o p t}+\ln \frac{X}{2}
$$

The intersection of the local breakeven-irradiation-time curve and the local optimum-irradiation-time curve is the point where, for a given irradiation time, $t_{M}$, the local fuel cycle cost contribution of the outermost slice of the blanket at distance into the blanket $\tau_{M^{\prime}}$ is just equal to zero and, at the same time, is the minimum cost. Since any slice of the blanket beyond this distance into the blanket always incurs a positive local cost (loss of profit), the total fuel cycle cost contribution of the entire blanket inboard of this distance, $\tau_{M^{\prime}}$, is the minimum (i.e., profit is the maximum) at the corresponding irradiation time, $t_{M^{p}}$. It should be noted that this irradiation time and thickness $\left(t_{M}{ }^{\prime}, \tau_{M},\right)$ defines a unique point for a given economic environment. Solving Eq. E. 53 and Eq. E. 55 for $t_{M}=t_{B E}=t_{\text {opt }}$ ( $\mathrm{M}^{\prime}$ point in Fig. E. 3), one has

$$
\mathrm{t}_{\mathrm{M}},=\frac{2}{\mathrm{X}}
$$

For the discount rate, $X=0.08\left(\mathrm{yr}^{-1}\right)$, one has $t_{M^{\prime}}=25 \mathrm{yr}$, which approaches the plant design lifetime.

This is a rather longer time than expected. Actually, the semilog linearity cannot persist for a long time at large thicknesses, and the "local breakeven" relation curves downward and intercepts the "local optimum" curve at point $M$ in Fig. E. 3. The point $M$ can be 


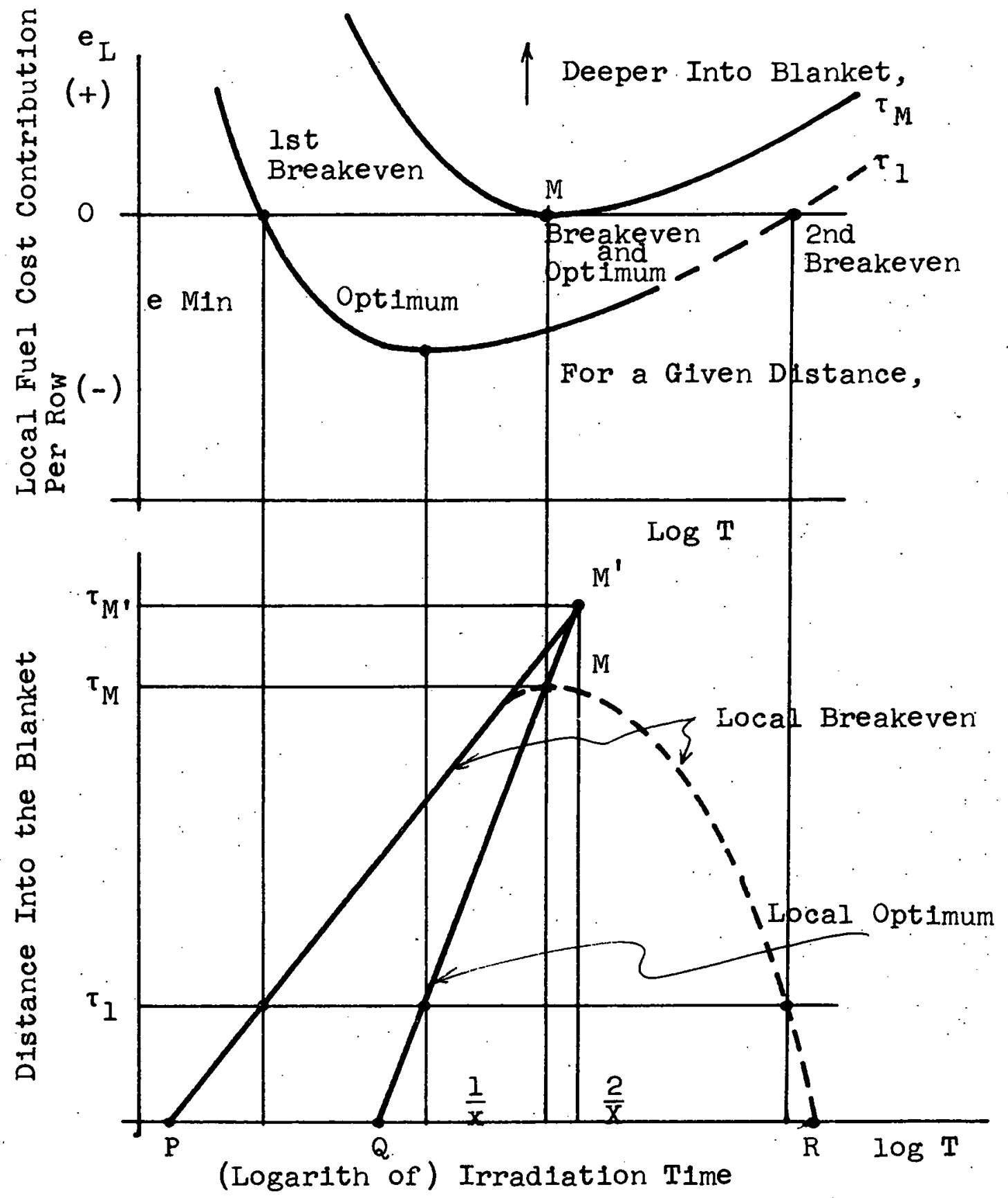

Fig. E.3 Schematic Illustration of Local Cost-TimeThickness Relations 
obtained as the point where the cost equation E. 34 has but one real root (i.e., the usual two breakeven irradiation times for a given thickness degenerate into a single time) as discussed in an earlier section. As obtained before, the coordinates of point $M$ are expressed in the form:

$$
\begin{aligned}
& \mathrm{T}_{\mathrm{M}}=\frac{1}{\mathrm{X}}, \\
& \tau_{\mathrm{M}}=\frac{1}{\gamma} \ln \frac{\mathrm{S}_{\mathrm{o}}(0)}{2 \mathrm{WX}} .
\end{aligned}
$$

It should be noted that the "local breakeven" locus curves downward beyond point $M$ (where point $M$ is at the tangent to the $\tau=\tau_{M}$ line parallel to the abscissa) and decreases monotonically toward the abscissa. In other words, the left-hand branch of the "local breakeven" curve (i.e., the PM branch) corresponds to the first breakeven point, and the right-hand branch (i.e., the MR branch) corresponds to the second breakeven point. This second breakeven point gives the latest time at. which fuel can be discharged without producing a net deficit.

Using the reference economic condition of Table 2.14 and the 2DB results, one can obtain:

$$
\begin{aligned}
& \mathrm{T}_{\mathrm{M}}=12.5 \text { full power years, } \\
& \tau_{\mathrm{M}}=45 \mathrm{~cm} .
\end{aligned}
$$

Thus, the point $M$ does not occur under the reference economic environment. A blanket $45 \mathrm{~cm}$ thick is the most profitable configuration if the entire blanket is to be batch-irradiated for as long as 12.5 years. This would greatly exceed the local optimum exposure for the inner blanket row and probably the physically useful assembly lifetime as well. Thus this point is of more academic than practical interest. However, for the 
unusual condition of high discount rate and low plutonium price (e.g. , $\mathrm{X}=0.16$ year $^{-1}$ and $\left.\mathrm{C}_{3}=6 \$ / \mathrm{gPu}\right)$, useful information on single-row blanket management is provided (i.e., ${ }^{\tau_{M}}=21 \mathrm{~cm}$ and $\tau_{M}=.6 .3 \mathrm{full}$ power years).

\section{E. 4 FUEL CYCLE COST OF THE RADIAL BLANKET}

The local fuel cycle cost contribution distribution, $e_{L}(\tau, T)$, (mills/kwhr-cm) is:

$$
e_{L}(\tau, T) \propto \frac{C_{1} F_{1}\left(-T_{1}\right)+C_{2} F_{2}\left(-T_{2}\right)-C_{3} F_{3}\left(-T_{3}\right) \varepsilon(\tau, T)}{T},
$$

where $\varepsilon(\tau, T) \equiv \mathrm{S}_{\mathrm{o}}(\tau) \mathrm{T}$ is the enrichment distribution (kgPu/kgHM-cm). Defining the time-dependent but distance-independent terms as:

$$
\begin{aligned}
& \frac{\mathrm{C}_{1} \mathrm{~F}_{1}\left(-\mathrm{T}_{1}\right)+\mathrm{C}_{2} \mathrm{~F}_{2}\left(-\mathrm{T}_{2}\right)}{\mathrm{T}} \equiv \mathrm{G}_{1}(\mathrm{~T}), \\
& \mathrm{C}_{3} \mathrm{~F}_{3}\left(-\mathrm{T}_{3}\right) \equiv \mathrm{G}_{2}(\mathrm{~T}),
\end{aligned}
$$

Equation E. 63 is expressed in the form:

$$
\mathrm{e}_{L}(\tau ; T) \propto \mathrm{G}_{1}(T)-\mathrm{G}_{2}(T) \mathrm{S}_{\mathrm{o}}(\tau)
$$

Since $S_{0}(\tau)=S_{0}(0) e^{-\gamma \tau}$

$$
\mathrm{e}_{\mathrm{L}}(\tau, T)=\dot{G}_{1}(\mathrm{~T})-\mathrm{G}_{2}(\mathrm{~T}) \mathrm{S}_{\mathrm{o}}(0) \mathrm{e}^{-\gamma \tau}
$$

For the local breakeven irradiation time, $T=t_{B E}$, at which $e_{L}(\tau, T)=0:$

$$
G_{1}(T)=G_{2}(T) S_{o}(0) e^{-\gamma \tau}
$$


since the batch blanket total thickness is optimum when the outermost fuel reaches its local breakeven irradiation time,

$$
\tau_{B}=\frac{1}{\gamma} \ln \frac{\mathrm{G}_{2}\left(\mathrm{~T}_{\mathrm{B}}\right)}{\mathrm{G}_{1}\left(\mathrm{~T}_{\mathrm{B}}\right)} \mathrm{S}_{\mathrm{o}}(0) .
$$

The total cost of the entire blanket, $e_{T}(\tau, T),($ mills $/ k w h r)$ can be obtained by integrating Eq. E.68:

$$
\mathrm{e}_{\mathrm{T}}(\tau, \mathrm{T})=\mathrm{G}_{1}(\mathrm{~T}) \tau-\frac{\mathrm{G}_{2}(\mathrm{~T}) \mathrm{S}_{\mathrm{o}}(0)}{\gamma}\left(1-\mathrm{e}^{-\gamma \tau}\right)
$$

which indicates that the total cost decreases and then increases, passing through a minimum value as shown in Fig. E.4. The minimum cost (the profit is a maximum) occurs at the point where the derivative of Eq. E.71 (i.e., Eq. E.68 itself) is zero:

$$
\frac{\partial e_{T}}{\partial \tau}=e_{L}=0
$$

which gives exactly Eq. E.69. Thus it is confirmed that the "local breakeven" curve gives the optimum batch-irradiated blanket thickness. It should again be noted that these results hold true for all core radii because of the constant specific inventory buildup rate, $S_{0}(0)$.

Consider an alternate approximation for the cost-thickness curve. Expanding Eq. E.69 in a Taylor series and retaining only the first term:

$$
\mathrm{e}^{-\gamma \tau} \cong \mathrm{e}^{-\gamma \tau} \mathrm{B}\left[1-\gamma\left(\tau-\tau_{\mathrm{B}}\right)\right]
$$

so that

$$
e_{L}(\tau, T) \propto G_{1}(T)-G_{2}(T) S_{o}(0) e^{-\gamma \tau} B\left[1-\gamma\left(\tau-\tau_{B}\right)\right]
$$

Using Eq. E. 69 , it follows that: 

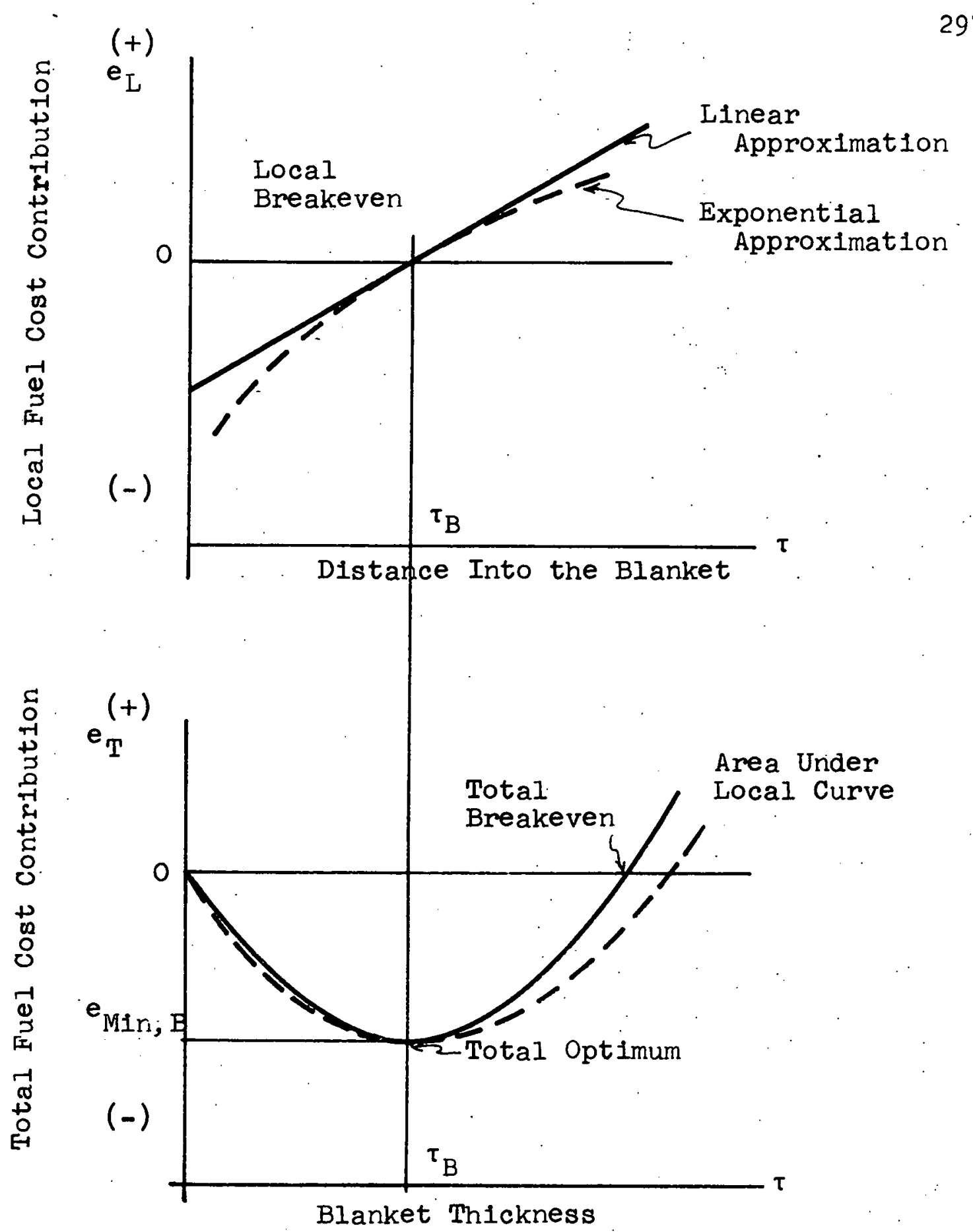

- Fig. E.4 Relation of "Local Cost-Distance" Curve and "Total Cost-Thickness" Curve at a Given. Irradiation Time 


$$
e_{L}(\tau, T) \propto G_{1}(T)\left(\tau-\tau_{B}\right)
$$

which indicates that the fuel cycle cost distribution (i.e., unit cost per unit blanket thickness, mills $/ \mathrm{kwhr}-\mathrm{cm}$ ) is proportional to distance into the blanket in the vicinity of the optimum thickness for a given irradiation time.

The total fuel cycle cost contribution (mills/kwhr) is obtained by integrating Eq. E. 73 over the entire thickness of the blanket:

$$
\mathrm{e}_{\mathrm{T}}(\tau, \mathrm{T})=\int_{0}^{\tau} \mathrm{e}(\tau, \mathrm{T}) \mathrm{d} \tau=\int_{0}^{\tau} \mathrm{G}_{1}(\mathrm{~T})\left(\tau-\tau \mathrm{B}_{\mathrm{B}}\right) \mathrm{d} \tau
$$

or

$$
\mathrm{e}_{\mathrm{T}}(\tau, \mathrm{T}) \propto \frac{\mathrm{G}_{1}}{2} \tau\left(\tau-2 \tau_{\mathrm{B}}\right)
$$

which indicates that the fuel cycle cost (mills/kwhr) is approximated by a parabolic function of $\tau$ in the vicinity of the optimum thickness corresponding to a given irradiation time, $T_{B}$, as shown in Fig. E. 4. This approximation is useful because the "parabola bottom" (i.e., the optimum batch-irradiated blanket thickness) is exactly the same as in the exponential approximation case. It is also interesting that the local breakeven thickness is approximately half of the total breakeven thickness.

\section{E.5 RELATION OF OPTIMUM IRRADIATION TIME AND BLANKET THICKNESS}

The total optimum irradiation time of an entire radial blanket having thickness, $\tau$, is given in the same form as before (i.e., Eq. E. 42 in section E. 3): 


$$
\mathrm{T}_{\mathrm{opt}}(\tau)=\sqrt{\frac{2 \mathrm{~W}}{\mathrm{X} \overline{\mathrm{S}}_{\mathrm{o}, t}}}
$$

Using the approximate exponential distribution of bred fissile material expressed in the form:

$$
S_{o}(\tau)=S_{0}(0) e^{-\gamma \tau}
$$

the entire-blanket-average buildup rate, $\bar{S}_{o, t}$, is:

$$
\bar{S}_{\mathrm{o}, \mathrm{t}}=\frac{\int_{0}^{\tau} \mathrm{S}_{\mathrm{o}}(\tau) \mathrm{d} \tau}{\int_{0}^{\tau} \mathrm{d} \tau}=\frac{\mathrm{S}_{\mathrm{o}}(0)}{\gamma}\left(1-\mathrm{e}^{-\gamma \tau}\right)
$$

Rearranging terms gives:

$$
\bar{S}_{o, t}=S_{o}(0) e^{-\frac{\gamma \tau}{2}} \frac{\sinh \frac{\gamma \tau}{2}}{\frac{\gamma \tau}{2}},
$$

where the hyperbolic function term, designated as the averaging factor, $\lambda(\mathrm{X})$ :

$$
\begin{aligned}
& \lambda(\mathrm{X}) \equiv \frac{\sinh \mathrm{X}}{\mathrm{X}} \\
& \mathrm{X} \equiv \frac{\gamma \tau}{2}
\end{aligned}
$$

in the present work.

Since the averaging factor is approximately equal to unity for the range of $\mathrm{X} \Leftarrow 1.3$ (i.e., $\gamma=0.05 \mathrm{~cm}^{-1}, \tau \gtrless 50 \mathrm{~cm}$ ) in the present work, the entire-blanket-averaged specific buildup rate, $\bar{S}_{o, t}$, is:

$$
\bar{S}_{o, t} \cong S_{o}(0) e^{-\frac{\gamma \tau}{2}}
$$


which indicates that the entire-blanket-average buildup rate also decreases exponentially as the blanket thickness increases - in the same manner as for the row-average buildup rate, $\bar{S}_{0, \ell}$, except that the exponent of the entire-blanket-average buildup rate is half of that of the row-average rate. In other words, the entire-blanketaverage buildup rate decreases less steeply than the row-average rate. $=$ Substituting Eq. E.83 into Eq. E. 75 and eliminating $\bar{S}_{o, t}$, one can obtain:

$$
\mathrm{T}_{\text {opt }}=\sqrt{\frac{2 \mathrm{~W}}{\mathrm{~S}_{\mathrm{o}}(0) \mathrm{X}}} \mathrm{e}^{\frac{\gamma \tau}{4}}
$$

or

$$
\tau=\frac{4}{\gamma}\left\{\ln \mathrm{T}_{\mathrm{opt}}-\frac{1}{2} \ln \left(\frac{2 \mathrm{~W}}{\mathrm{~S}_{\mathrm{o}}(0) \mathrm{X}}\right)\right\}
$$

Again this equation is the same form as for the "local optimum" curve of Eq. E. 53, except the semilog slope is $4 / \gamma$ rather than $2 / \gamma$.

Setting Eq. E. 85 equal to zero, the intercept of the total optimum curve and the abscissa, designated as point $Q$ in the present work, can be obtained:

$$
\mathrm{T}_{\text {opt }}(0)=\sqrt{\frac{2 \mathrm{~W}}{\mathrm{~S}_{\mathrm{o}}(0) \mathrm{X}}}
$$

This point establishes the optimum irradiation time of the zerothickness blanket: an unrealistic extreme case. It is also the intercept of the local optimum curve and the abscissa.

In a similar manner, the total breakeven irradiation time of the entire blanket is: 


$$
\mathrm{T}_{\mathrm{BE}}=\frac{\mathrm{W}}{\mathrm{S}_{\mathrm{O}}(0)} \mathrm{e}^{\gamma \mathrm{T} / 2}
$$

or

$$
\tau=\frac{2}{\gamma}\left\{\ln \mathrm{T}_{\mathrm{BE}}-\ln \frac{\mathrm{W}}{\mathrm{S}_{\mathrm{O}}(0)}\right\}
$$

The following points of similarity are of interest:

1) The intercept of the total breakeven curve and the abscissa. is:

$$
\mathrm{T}_{\mathrm{BE}}(0)=\frac{\mathrm{W}}{\mathrm{S}_{\mathrm{O}}(0)}
$$

which is designated as point $\mathrm{P}$, and is also the intercept of the local breakeven curve and the abscissa.

2) The semilog slope of the total breakeven curve $(2 / \gamma)$ is twice that of the local breakeven $(1 / \gamma)$.

3) The intercept of the "total breakeven"' curve and "total optimum" curve, designated as point $\mathrm{N}^{\prime}$ in the present work; can be obtained by eliminating $\tau$ from Eqs. E. 85 and E. 88 and setting

$$
\begin{aligned}
\mathrm{T}_{\mathrm{N}^{\prime}}=\mathrm{T}_{\text {opt }}=\mathrm{T}_{\mathrm{BE}}: \\
\quad \cdot \mathrm{T}_{\mathrm{N}^{\prime}}=\frac{2}{\mathrm{X}} .
\end{aligned}
$$

For the same reasons as discussed in section $\mathrm{E} .3$, a more realistic intercept, designated as point $\mathrm{N}$ in the present work, can be obtained:

$$
\begin{aligned}
& \mathrm{T}_{\mathrm{N}}=\frac{1}{\mathrm{X}} \\
& \tau_{\dot{N}}=\frac{2}{\gamma} \ln \frac{\mathrm{S}_{\mathrm{o}}(0)}{2 \mathrm{WX}} .
\end{aligned}
$$


Using the reference economic conditions of Table 2.14 and 2DB results, one has:

$$
\begin{aligned}
& { }_{T_{N}}=12.5 \text { full power years } \\
& { }_{\tau_{N}}=90 \mathrm{~cm} .
\end{aligned}
$$

Again this would not represent a practical operating point. Figure E. 5 illustrates these total cost-time-thickness relations.

Combining Fig. E. 4 and Fig. E.5, one can obtain Fig. E.6, which illustrates the relations among three quantities: cost, thickness and time; and also the relations of four curves: the cost-time curve (at constant thickness [graph A in Fig. E.6]), the cost-thickness curve (at constant time [graph.B in Fig. E.6]), and the thickness-time curves (one is the zero cost curve labelled the "total breakeven" curve, and the other is a minimum cost curve labelled the "total optimum" curve [ graph C in Fig. E.6]).

The locus of the parabola bottom (the optimum batch-irradiated blanket thickness for the corresponding time) in graph B of Fig. E. 6 is the "local breakeven" curve in graph C of Fig. E. 7, which can be obtained by combining Fig. E. 3 and Fig. E. 4 in a similar manner. Again there are three quantities: cost; distance and time; and four curves: the cost-time curve (at constant distance [graph A in Fig. E.7]), the cost-distance curve (at constant time [ graph B in Fig. E. 7]) and the distance-time curves (one is the zero cost curve labelled the "local breakeven" curve, and the other is a minimum cost curve labelled the "local optimum" curve [graph C in Fig. E. 7]). 


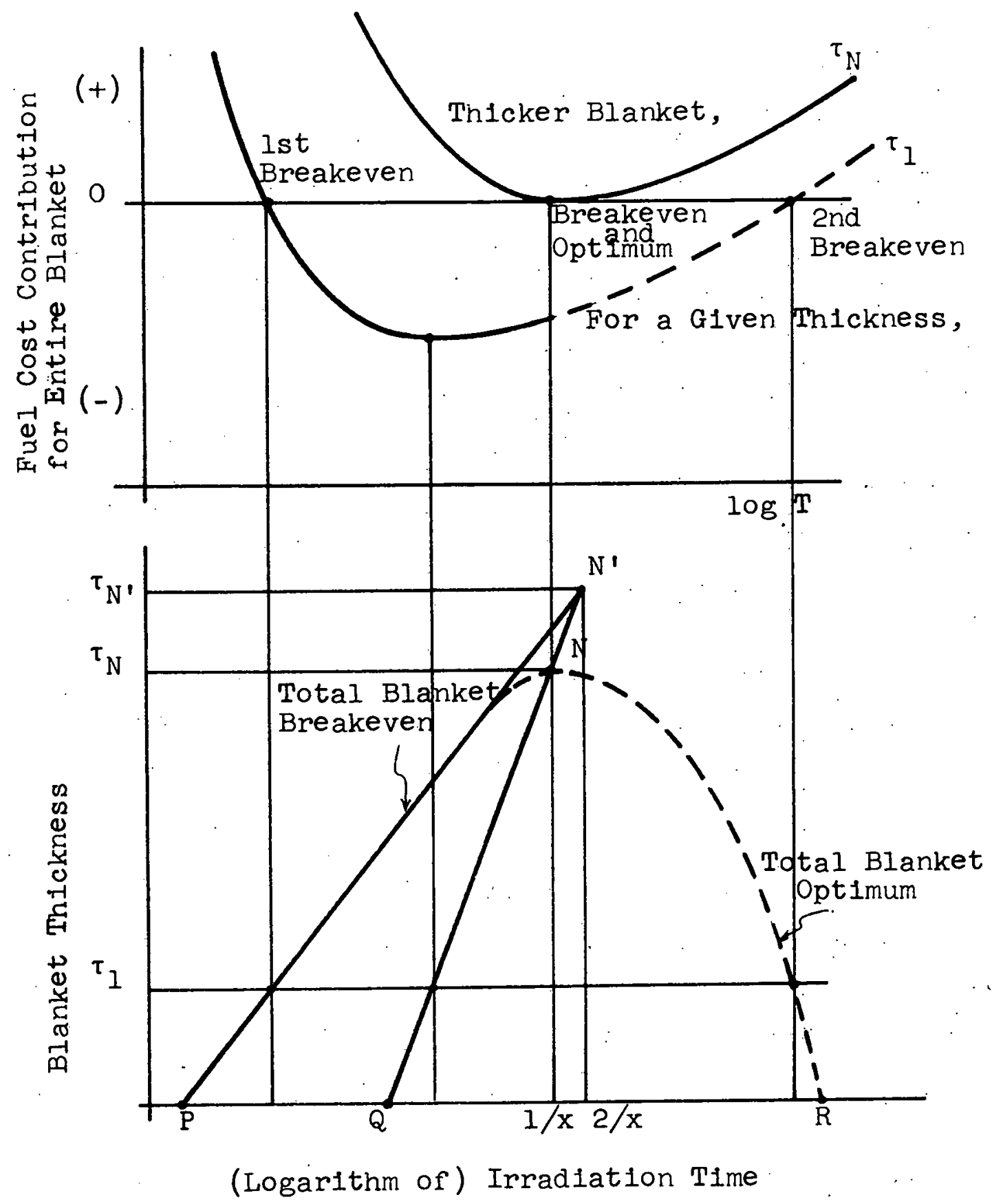

Fig. E.5 Schematic Illustration of Total CostTime-Thickness Relations 


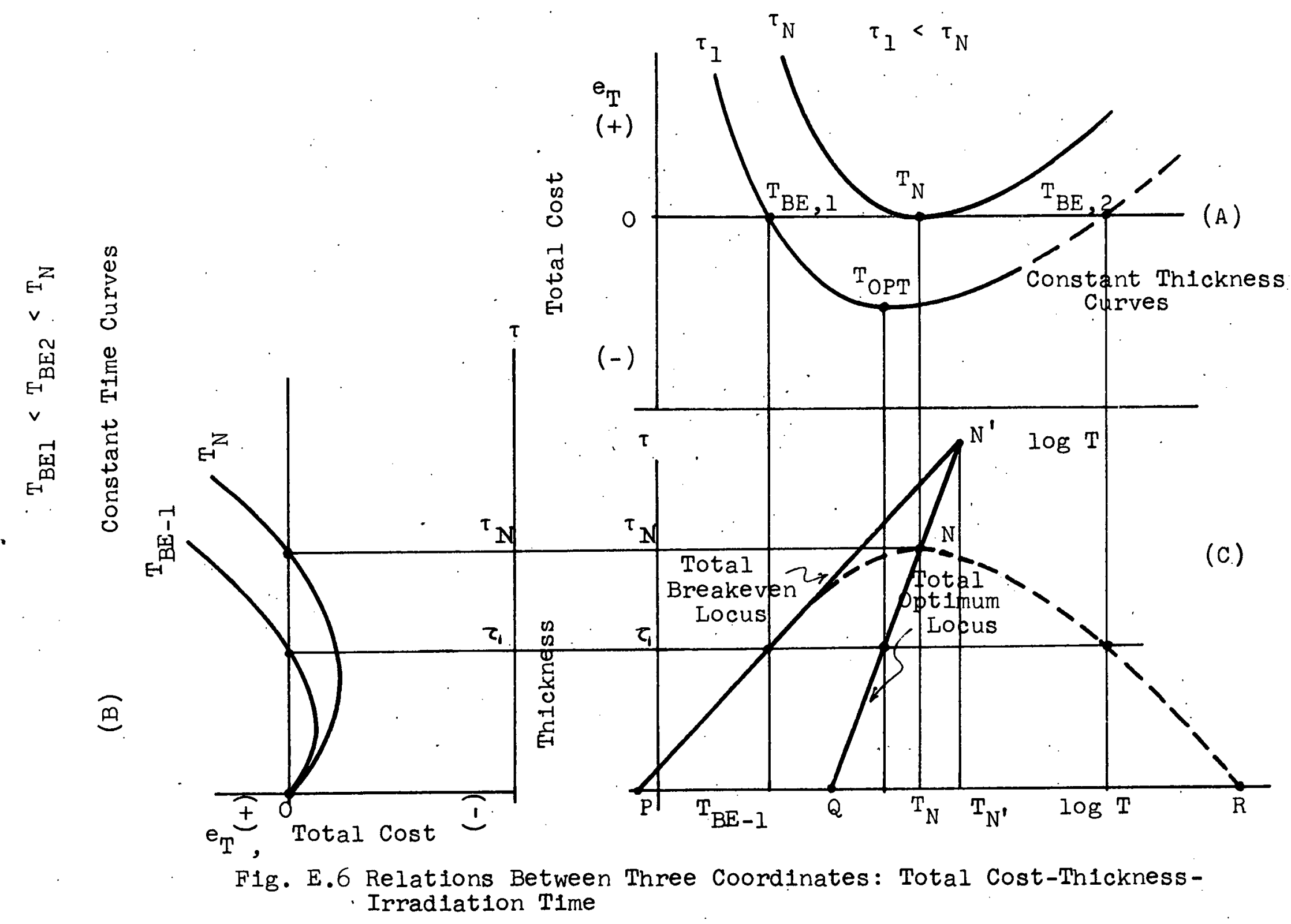

옳 


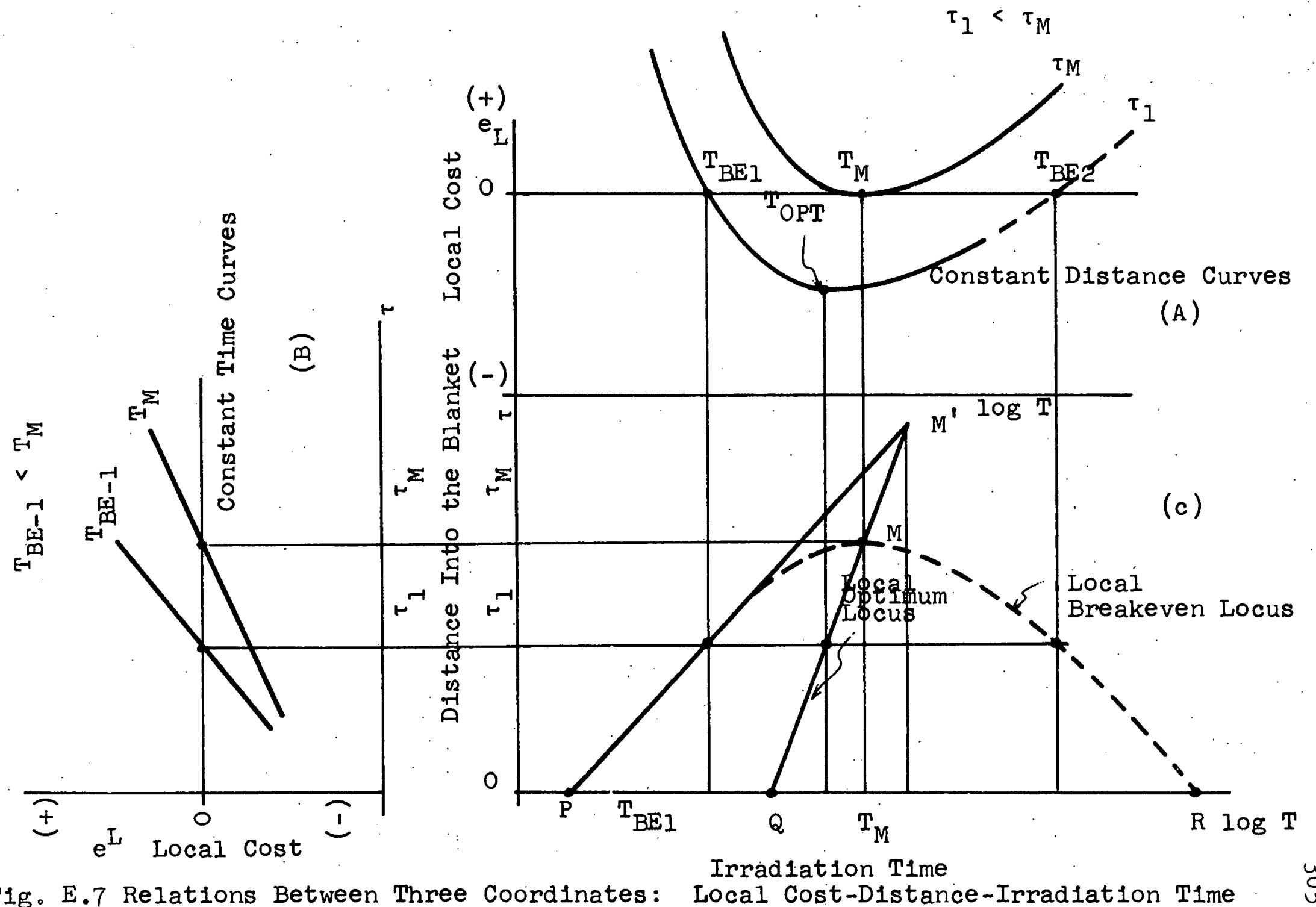

Fig.E.7 Relations Between Three Coordinates: Local Cost-Distance-Irradiation T1me. S 


\section{E. 6 GLOBAL OPTIMA}

By superimposing Figs. E. 3 and E.5, one obtains Fig. E. 8 which displays several items of interest:

1) Four key loci: "local breakeven (LB)," "local optimum ( LO)," "total breakeven (TB)," and "total optimum (TO)"; as summarized in Table E. 1 .

2) Six key points: $P$ is the intersection of the "local breakeven" and "total breakeven" curves, abbreviated as P(LB-TB) in the present work; and then one can also have $Q(L O-T O), R(L B-T B)$, $\mathrm{M}(\mathrm{LO}-\mathrm{LB}), \mathrm{N}(\mathrm{TO}-\mathrm{TB})$ and $\mathrm{S}(\mathrm{LB}-\mathrm{TO})$, as summarized in Table E. 2. The point $S$, which is again the intercept of the "local breakeven" (i.e., optimum batch-irradiated blanket thickness for a given time) locus and the "total optimum" (i: e., optimum irradiation time for a given blanket thickness) locus, is important because this point can give both the optimum batch-irradiated blanket thickness and the optimum irradiation time (hence designated as the "global optimum" in the present work) such that the fuel cycle cost contribution is a minimum (the profit is a maximum). By solving Eqs. E. 55 and E. 85, one can obtain the global optimum thickness and irradiation time:

$$
\begin{aligned}
& \tau_{S}=(2 / 3 \gamma) \ln \left\{2 S_{0}(0) / \mathrm{WX}\right\}, \\
& T_{S}=\left\{\frac{4}{S_{0}(0)}\right\}^{1 / 3} \mathrm{w}^{1 / 3} \mathrm{x}^{-2 / 3} .
\end{aligned}
$$

Thus the global optima can be estimated by using the economic parameter, $W$, and the discount rate, $X$, provided that the interfacial specific 


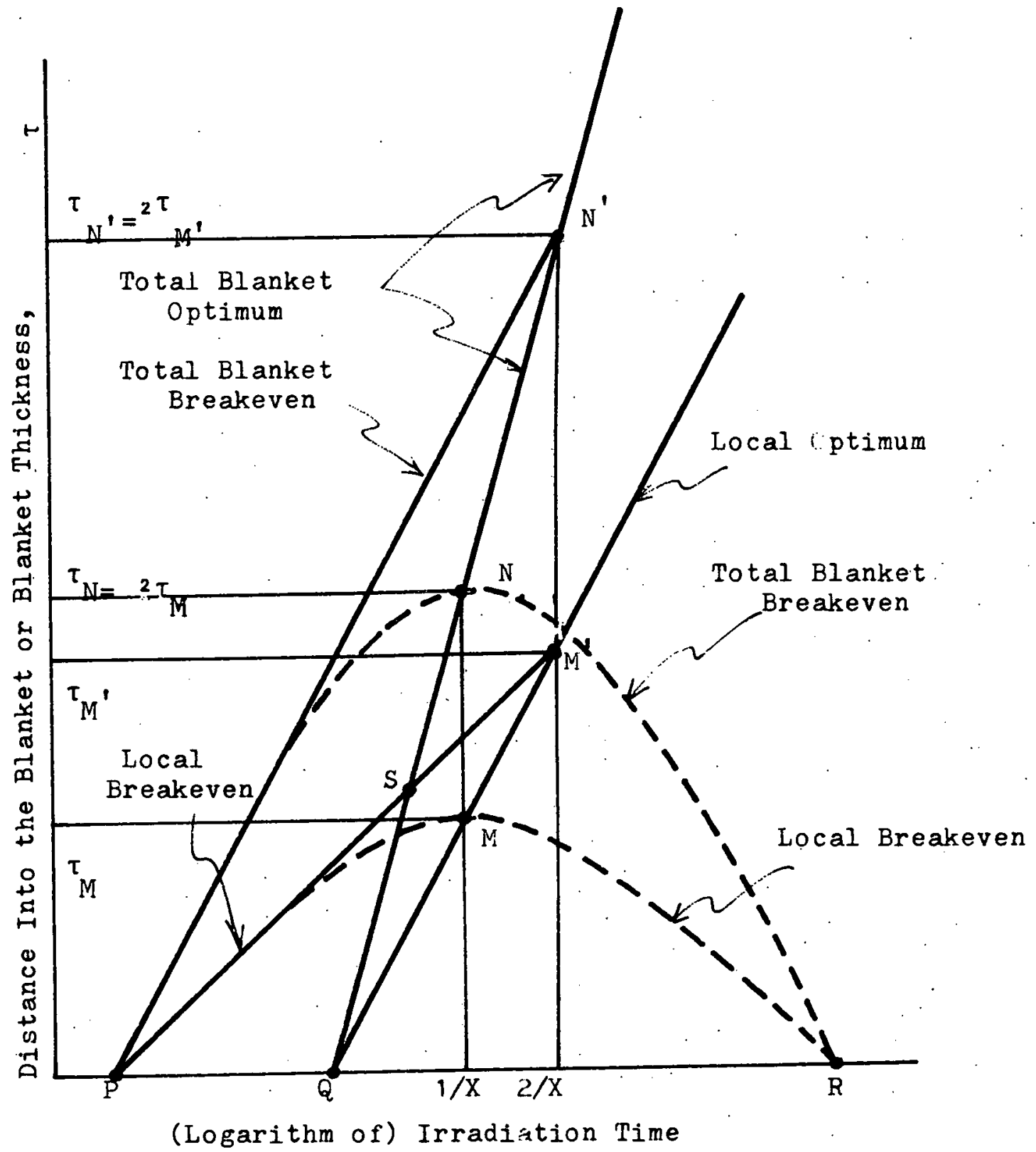

Fig. E.8 Breakeven and Optimum Thickness and Positions as a Function of Irradiation Time 


\section{Table E.l Summary of Relations between Local Blanket Region Position or Total Blanket Thickness and Irradiation Time}

\begin{tabular}{|l|c|c|}
\hline & Local & Total \\
\hline Breakeven & $\tau=\frac{1}{\gamma}\left(\ln \mathrm{T}-\ln \mathrm{T}_{\mathrm{B}}\right)$ & $\tau=\frac{2}{\gamma}\left(\ln \mathrm{T}-\ln \mathrm{T}_{\mathrm{B}}\right)$ \\
\hline Optimum & $\tau=\frac{2}{\gamma}\left(\ln \mathrm{T}-\ln \mathrm{T}_{0}\right)$ & $\tau=\frac{4}{\gamma}\left(\ln \mathrm{T}-\ln \mathrm{T}_{0}\right)$ \\
\hline
\end{tabular}

$\mathrm{T}_{\mathrm{B}}=$ The Interfacial Breakeven Time, Eq. E. 89

$\mathrm{T}_{0}=$ The Interfacial Optimum Time, Eq. E. 86

$\gamma=$ Reclprocal Diffusion Length of the Blanket 
Table E.2 Summary of the Six Key Intercepts Predicted by Simplified CFM Analysis

\begin{tabular}{|c|c|c|c|c|c|c|}
\hline Point & Curves & $\begin{array}{l}\text { Thickness } \\
\text { or } \\
\text { Distance } \\
\text { (CM) }\end{array}$ & & $\begin{array}{l}\text { Irradiat } \\
\text { Time } \\
\text { (Full Power }\end{array}$ & ays ) & $\begin{array}{c}\text { Cost } \\
(m \perp 11 s / k w h r)\end{array}$ \\
\hline$P$ & $\begin{array}{c}\mathrm{L}-\mathrm{B} \\
\mathrm{T}-\mathrm{B} \\
\text { (Left) }\end{array}$ & 0 & 0 & $\frac{W}{S_{0}(0)}$ & 196 & 0 \\
\hline$Q$ & $\begin{array}{l}\mathrm{L}-0 \\
\mathrm{~T}-0\end{array}$ & 0 & 0 & $\sqrt{\frac{2 W}{S_{0}(0) X}}$ & 1211 & 0 \\
\hline $\mathrm{R}$ & $\begin{array}{c}\mathrm{L}-\mathrm{B} \\
\mathrm{T}-\mathrm{B} \\
\text { (R1ght) }\end{array}$ & 0 & 0 & $\frac{2}{X}-\frac{W}{S_{0}(0)}$ & 7464 & 0 \\
\hline M & $\begin{array}{l}\mathrm{L}-\mathrm{B} \\
\mathrm{L}-\mathrm{O}\end{array}$ & $\frac{1}{\gamma} \ln \left[\frac{S_{0}(0)}{2 W X}\right]$ & 45 & $\frac{1}{x}$ & 3750 & N.A. \\
\hline N & $\begin{array}{l}\mathrm{T}-\mathrm{B} \\
\mathrm{T}-\mathrm{O}\end{array}$ & $\frac{2}{\gamma} \ln \left[\frac{S_{0}(0)}{2 W X}\right]$ & 90 & $\frac{1}{\mathrm{X}}$ & 3750 & N.A. \\
\hline S & $\begin{array}{l}L-B \\
T-0\end{array}$ & $\frac{2}{3 \gamma} \ln \left[\frac{2 S_{0}(0)}{W X}\right]$ & 48 & $3 \sqrt{\frac{4 w}{s_{0}(0) x^{2}}}$ & 2224 & N.A. \\
\hline
\end{tabular}


buildup rate, $S_{0}(0)$, and the inverse diffusion length of the blanket, $\gamma$, are known. Using the reference economic conditions of Table 2.14, $\mathrm{T}_{\mathrm{S}}=2224$ full power days ( 7.4 full power years) and $\tau_{\mathrm{S}}=48.5 \mathrm{~cm}$, which is in fair agreement with $2 \mathrm{DB}-\mathrm{BRECON}$ results $-\mathrm{T}_{\mathrm{S}}=1750$ full power days and $\tau_{\mathrm{S}}=31.4 \mathrm{~cm}$ - considering the approximate nature of the preceding analysis. The preceding results were used in the various chapters of this report, in most cases, as a qualitative guide to identify the choice of parameters used for correlations of the more precise 2DB-BRECON results. 


\section{Appendix $\mathrm{F}$ \\ TABULATION OF DATA PLOTTED. IN FIGURES}

In this appendix, the data developed from the output from $2 \mathrm{DB}$ or BRECON and plotted in the various key figures in this report, are listed. The next page contains a list of corresponding figures and tables. 


\begin{tabular}{|c|c|c|c|c|c|}
\hline Fig.No. & $\begin{array}{l}\text { Corresponding } \\
\text { Table Number }\end{array}$ & Fig.No. & $\begin{array}{l}\text { Corresnonding } \\
\text { Table Number } \\
\end{array}$ & Fig. No. & $\begin{array}{l}\text { Corresponding } \\
\text { mable Number } \\
\end{array}$ \\
\hline 3.1 & F.I & 4.7 & F. 17 & 5.1 & $* 3$ \\
\hline 3.2 & F. 1 & 4.8 & $\star 1$ & 5.2 & $\star 3$ \\
\hline 3.3 & F. 2 & 4.9 & F. 18 & 5.3 & $\star 3$ \\
\hline 3.4 & $* 1$ & 4.10 & ${ }^{\star} 1$ & 5.4 & *3. \\
\hline 3.5 & F. 3 & 4.11 & F. 19 & 5.5 & F. 2 \\
\hline 3.6 & F. 4 & 4.12 & F. 20 & 5.6 & F. 3 \\
\hline 3.7 & F. 5 & 4.13 & F. 21 & 5.7 & E. 4 \\
\hline 3.8 & F. 2 & 4.14 & F. 19 & 5.8 & F. 6 \\
\hline 3.9 & F. 6 & 4.15 & F. 19 & 5.9 & F. 8 \\
\hline 3.10 & F. 7 & 4.16 & * & 5.10 & F. 9 \\
\hline 3.11 & F. 8 & 4.17 & F. 22 & 5.11 & F. 10 \\
\hline 3.12 & F. 9 & 4.18 & F. 22 & 5.12 & F. 8 \\
\hline 3.13 & F. 10 & 4.19 & $* 1$ & 5.13 & F.11 \\
\hline 3.14 & F. 8 & 4.20 & $\star 1$ & 5.14 & F. 12 \\
\hline 3.15 & F.11 & 4.21 & F. 23 & 5.15 & F.11 \\
\hline 3.16 & F. 12 & 4.22 & F. 24 & 5.16 & F. 19 \\
\hline \multirow[t]{2}{*}{3.17} & F. 11 & 4.23 & F. 22 & 5.17 & F. 28 \\
\hline & & 4.24 & $\star 1$ & 5.18 & F. 19 \\
\hline 4.1 & $\star 1$ & 4.25 & F. 25 & 5.19 & 5.20 \\
\hline 4.2 & $* 1$ & 4.26 & F. 25 & 5.20 & $* 1$ \\
\hline 4.3 & F. 15 & 4.27 & F. 22 & 5.21 & F. 26 \\
\hline 4.4 & *I & 4.28 & F. 22 & 5.22 & F. 27 \\
\hline 4.5 & $\star 1$ & 4.29 & F. 26 & B. 1 & F. 28 \\
\hline \multirow[t]{2}{*}{4.6} & F. 16 & 4.30 & F. 27 & C. 1 & $\star$ \\
\hline & & & & C. 2 & F.29 \\
\hline
\end{tabular}

* 1 Output of 2DB or BRECON

*2 Fl3.a, b and $\dot{c}$ F.14 Have no Figure in Text *3 Schematic Illustration (No Data) 


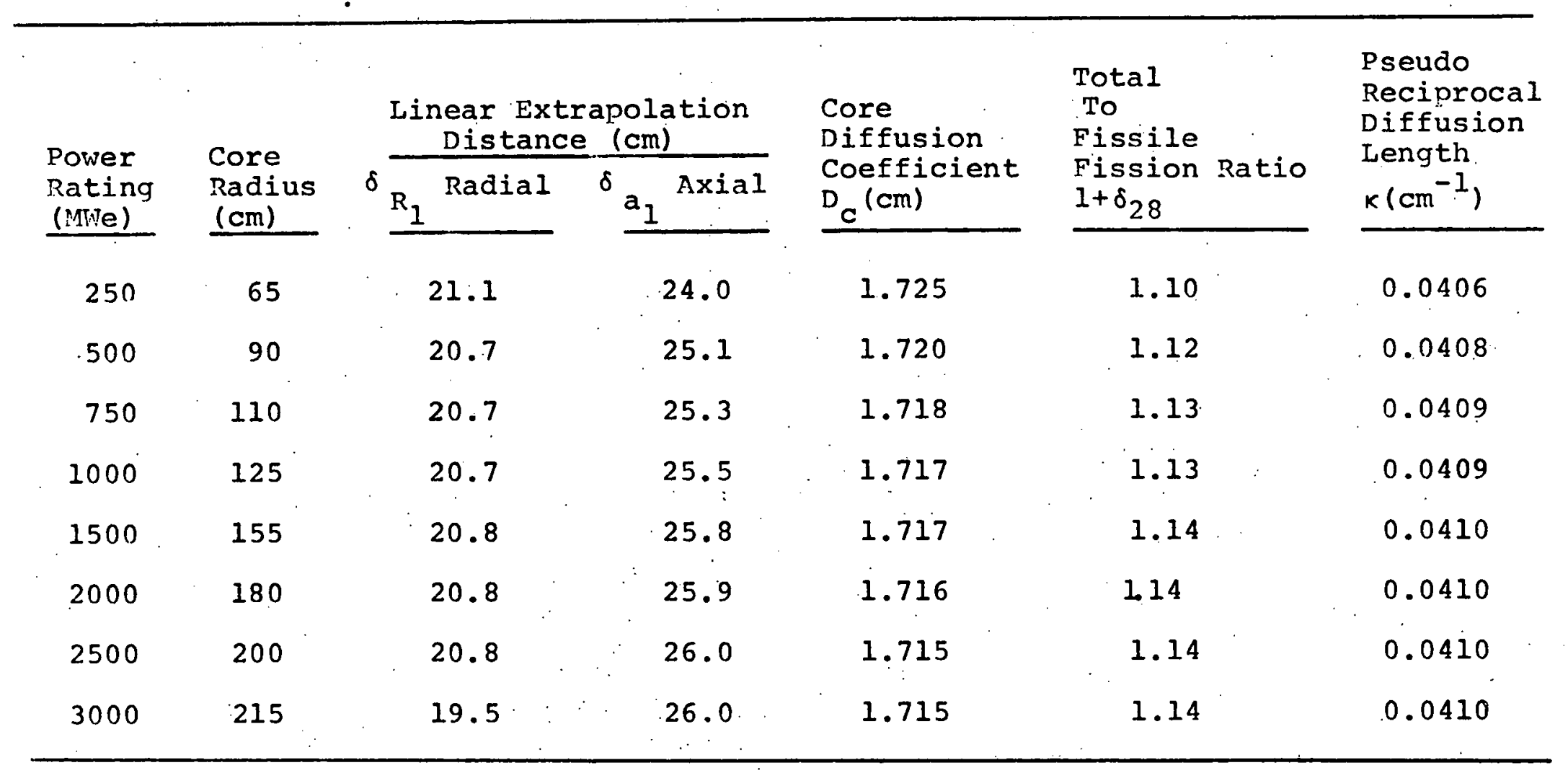

Table F.1 The Effect of Core Radius (Power Rating) on BOL Physics Parameters 
One-Zone Cores

$\begin{array}{ll}\text { Power } & \text { Geometrical } \\ \text { Rating } & \text { Buckling } \\ \text { (MWe) } & \left(10^{-5} \mathrm{xCM}^{-2}\right)\end{array}$

250

500

750

1000

1500

2000

2500

3000

\begin{tabular}{|c|c|c|}
\hline \multirow{2}{*}{$\begin{array}{l}\text { ometrical } \\
\text { ckling } \\
\left.0^{-5} \mathrm{xCM}^{-2}\right)\end{array}$} & \multicolumn{2}{|c|}{ Enrichment $(\%)$} \\
\hline & $\begin{array}{l}\text { One-Group } \\
\text { Model }\end{array}$ & 2DB-BRECO \\
\hline 12.39 & 17.7 & 16.8 \\
\hline 9.17 & 15.3 & 14.7 \\
\hline 7.81 & 14.3 & 13.7 \\
\hline 7.14 & 13.8 & 13.4 \\
\hline 6.28 & 13.1 & 13.0 \\
\hline 5.83 & 12.8 & 12.7 \\
\hline 5.58 & 12.6 & 12.6 \\
\hline 5.43 & 12.5 & 12.5 \\
\hline
\end{tabular}

\section{Radially-Power-Flattened Cores}

$\frac{\text { Enrichment }(z)}{\text { One-Groun }}$
Model
[Perfect Flat]

$\begin{array}{ll}18.2 & 18.8[2] \\ 16.4 & 16.2[2] \\ 15.4 & 15.6[2] \\ 15.0 & 14.7[2] \\ 14.3 & 13.7[3] \\ 14.0 & 13.5[4] \\ 13.7 & 13.4[5] \\ 13.6 & 13.3[6]\end{array}$

18.2

Table F.2 Core-Averaged Critical Enrichment as a Function of Buckling for One-Zone Cores 


\begin{tabular}{|c|c|c|c|c|c|c|}
\hline \multirow{2}{*}{$\begin{array}{l}\text { Power } \\
\text { pating } \\
\text { (ntro) }\end{array}$} & \multirow[b]{2}{*}{$\begin{array}{l}\text { Core } \\
\text { Radius }\end{array}$} & \multirow[b]{2}{*}{$\begin{array}{l}\text { Zone } \\
\text { No. }\end{array}$} & \multicolumn{2}{|c|}{ Central } & \multicolumn{2}{|c|}{ Peripheral } \\
\hline & & & $\begin{array}{l}\text { One-Group } \\
\text { Model }\end{array}$ & 2DB-BRECON & $\begin{array}{l}\text { One-Groun } \\
\text { Model }\end{array}$ & 2DB-BRECON \\
\hline 250 & 65 & 2 & 12.9 & 15.2 & 18.7 & 23.0 \\
\hline 500 & 30 & 2 & 11.6 & 13.3 & 17.3 & 19.1 \\
\hline 750 & 110 & 2 & 11.2 & 12.7 & 16.5 & 17.8 \\
\hline 1000 & 125 & 2 & 11.0 & 12.5 & 16.1 & 17.2 \\
\hline 1500 & 155 & 3 & 10.9 & 11.8 & 16.0 & 16.4 \\
\hline 2000 & 130 & 4 & 10.8 & 11.7 & 16.4 & 17.0 \\
\hline 2500 & 200 & 5 & 10.8 & 11.7 & 16.9 & 17.9 \\
\hline 3000 & 215 & 6 & 10.8 & $12 . ?$ & 17.5 & 19.0 \\
\hline
\end{tabular}

Table T..3 Centràl and Peripheral Zone-Averaqed Enrichment of the Radially-Power Flattened Cores 
Table F.4 Comparison of Peripheral Neutron Energy Spectra

\begin{tabular}{|c|c|c|c|c|c|c|c|}
\hline $\begin{array}{l}\text { N. Energy } \\
\text { Group }\end{array}$ & & 250 MI & $V E-2$ Zone & & 3000 MW - 6 & Zone & \\
\hline Upper Limit & $\phi_{g}$ & $\phi_{g} / \phi_{g} \max$ & $\log \phi_{g} / \phi_{g} \max$ & $\phi_{\mathrm{g}}$ & $\phi_{\mathrm{g}} / \phi_{\mathrm{g}} \max$ & $\log \phi_{g} / \phi_{g}$ & $\max$ \\
\hline $\begin{array}{l}1(10.5 \mathrm{MeV}) \\
2 \\
3 \\
4(0.8 \mathrm{MeV}) \\
5 \\
6 \\
7 \\
8(\phi \mathrm{g} \mathrm{max}) \\
9 \\
10(46.5 \mathrm{KeV}) \\
11 \\
12 \\
13 \\
14 \\
15(10 \mathrm{KeV}) \\
16 \\
17 \\
18 \\
19 \\
20 \\
21 \\
22 \\
23 \\
24 \\
25 \\
26\end{array}$ & $\begin{array}{l}2.02835(-1) \\
1.15599 \\
2.48499 \\
5.89435 \\
8.84728 \\
1.99522(1) \\
2.56371(1) \\
2.61112(1) \\
2.38779(1) \\
1.65973(1) \\
1.43824(1) \\
8.18961 \\
2.41991 \\
5.60919 \\
3.51667 \\
1.90298 \\
8.90473(-1) \\
3.11988(-1) \\
1.08067(-1) \\
2.52270(-2) \\
5.04581(-3) \\
2.94935(-3) \\
1.43782(-3) \\
7.05497(-4) \\
6.87042(-4) \\
6.84745(-5)\end{array}$ & $\begin{array}{c}7.7681(-3) \\
4.4272(-2) \\
9.5170(-2) \\
2.2574(-1) \\
3.3883(-1) \\
7.6412(-1) \\
9.8184(-1) \\
1 \\
9.1447(-1) \\
6.3564(-1) \\
5.5081(-1) \\
3.1364(-1) \\
9.2677(-2) \\
2.1482(-2) \\
1.3468(-2) \\
7.2880(-3) \\
3.4103(-3) \\
1.1948(-3) \\
4.1387(-3) \\
9.6614(-5) \\
1.9324(-5) \\
1.1295(-5) \\
5.6065(-6) \\
2.7019(-6) \\
2.6312(-6) \\
2.6224(-7)\end{array}$ & $\begin{array}{l}0.890 \\
0.646 \\
0.978 \\
0.354 \\
0.530 \\
0.883 \\
0.992 \\
1 \\
0.961 \\
0.803 \\
0.741 \\
0.496 \\
0.967 \\
0.332 \\
0.129 \\
0.663 \\
0.533 \\
0.077 \\
0.616 \\
0.868 \\
0.286 \\
0.053 \\
0.65 \\
0.43 \\
0.37 \\
0.37\end{array}$ & $\begin{array}{l}1.16146(-1) \\
6.60552(-1) \\
1.41267 \\
3.36600 \\
5.16875 \\
1.21375(1) \\
1.60849(1) \\
1.68138(1) \\
1.57563(1) \\
1.11395(1) \\
9.88812 \\
5.69213 \\
1.50440 \\
4.01431 \\
2.59831 \\
1.44703 \\
6.89404(-1) \\
2.35551(-1) \\
7.89732(-1) \\
1.84171(-2) \\
3.63305(-3) \\
2.07236(-3) \\
1.03972(-3) \\
5.08273(-4) \\
2.06155(-4) \\
4.90369(-5)\end{array}$ & $\begin{array}{r}6.9078(-3) \\
3.9286(-2) \\
8.4018(-2) \\
2.002(-1) \\
3.074(-1) \\
7.219(-1) \\
9.567(-1) \\
1 \\
9.371(-1) \\
6.6252(-1) \\
5.8613(-1) \\
3.3854(-1) \\
8.9474(-2) \\
2.3875(-2) \\
1.5453(-2) \\
8.6062(-3) \\
4.1002(-3) \\
1.4009(-3) \\
4.6969(-4) \\
1.0954(-4) \\
2.1608(-4) \\
1.2325(-5) \\
6.1837(-6) \\
3.0230(-6) \\
1.2261(-6) \\
2.9165(-7)\end{array}$ & $\begin{array}{c}0.839 \\
0.594 \\
0.924 \\
0.301 \\
0.488 \\
0.858 \\
0.981 \\
1 \\
0.972 \\
0.821 \\
0.768 \\
0.529 \\
0.951 \\
0.518 \\
0.189 \\
0.934 \\
0.613 \\
0.146 \\
0.671 \\
0.040 \\
0.335 \\
0.091 \\
0.791 \\
0.480 \\
0.089 \\
0.464\end{array}$ & \\
\hline
\end{tabular}




\begin{tabular}{lll}
$\begin{array}{c}\text { Power } \\
\text { Rating } \\
\text { (MIN) }\end{array}$ & $\begin{array}{c}\text { One-Group } \\
\text { Model }\end{array}$ & 2DB \\
\hline 250 & 1.03 & 1.12 \\
500 & 1.07 & 1.10 \\
750 & 1.08 & 1.11 \\
1000 & 1.09 & 1.10 \\
1500 & 1.09 & 1.05 \\
2000 & 1.09 & 1.06 \\
2500 & 1.09 & 1.06 \\
3000 & 1.09 & 1.06 \\
\hline
\end{tabular}

Table F.5 Ratio of Critical Mass for Radially Power-Flattened Cores to UniformlyLoaded Cores as a Function of Core Radius (Power Ratinas) 


\begin{tabular}{|c|c|c|c|c|c|c|}
\hline $\begin{array}{l}\text { Power } \\
\text { Rating } \\
\text { (MINE) }\end{array}$ & $\begin{array}{l}\text { Core } \\
\text { Radius } \\
\text { (CM) }\end{array}$ & $\begin{array}{l}\text { Zone } \\
\text { No. }\end{array}$ & & Row 1 & Row 2 & Row 3 \\
\hline 250 & 65 & 2 & : & 12.46 & 5.01 & 1.86 \\
\hline 500 & 90 & 2 & & 13.81 & 5.57 & 2.09 \\
\hline 750 & 110 & 2 & ; & 13.95 & 5.64 & 2.12 \\
\hline 1000 & 125 & 2 & & 14.22 & 5.76 & 2.17 \\
\hline 1500 & 155 & 3 & . & 13.62 & 5.56 & 2.11 \\
\hline 2000 & 180 & 4 & & 13.94 & 5.75 & 2.19 \\
\hline 2500 & 200 & 5 & & 14.63 & 6.09 & 2.34 \\
\hline 3000 & 215 & 6 & $\cdot$ & 15.39 & 6.46 & 2.48 \\
\hline
\end{tabular}

Table F.6 The Effect of Core-Radius on BOL Fissile Specific Inventory Buildun Pate in the Radial Blanket;

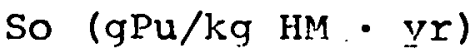




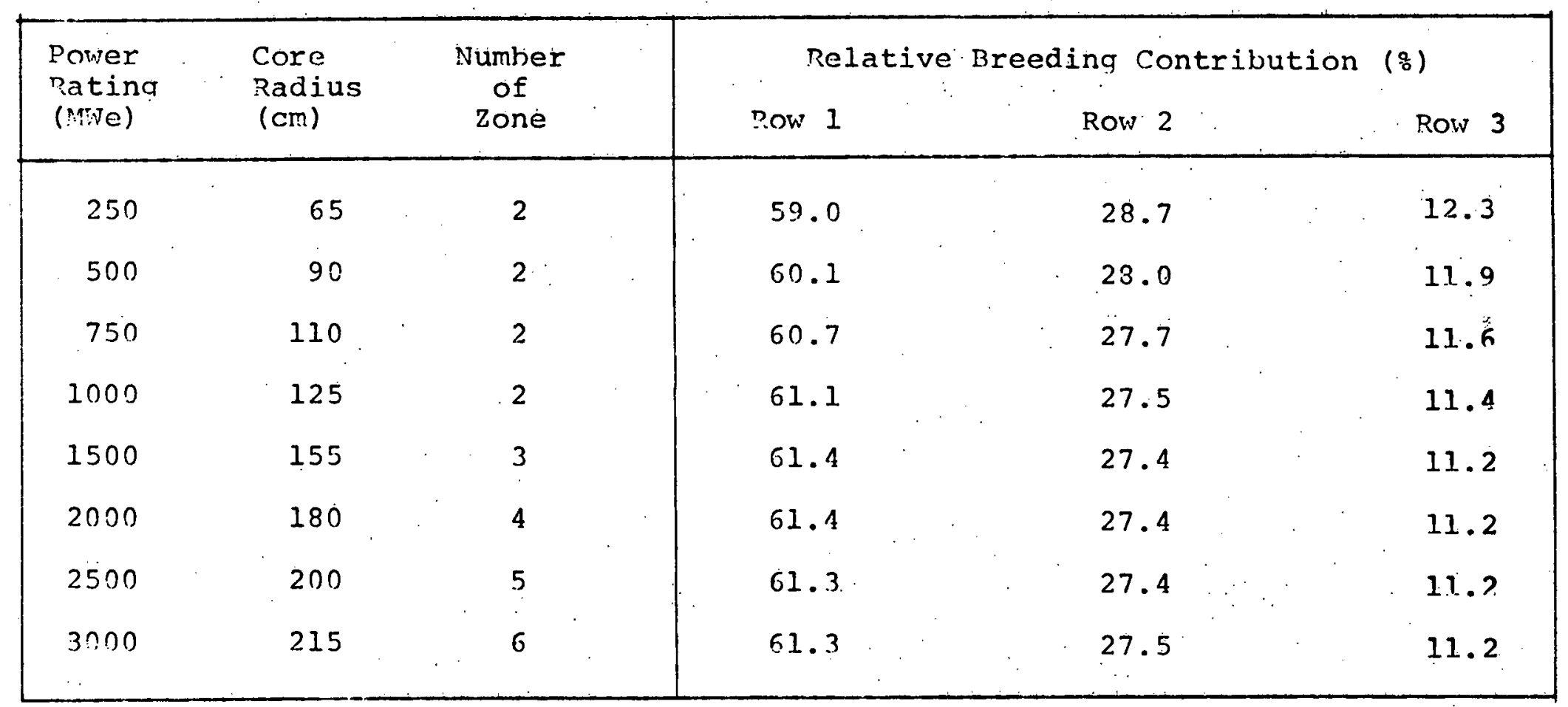

Table F.7 Relative Breeding Contribution of Radial Blanket Rows 


\begin{tabular}{|c|c|c|c|c|c|c|c|c|c|c|}
\hline \multirow[b]{2}{*}{$\begin{array}{l}\text { Power } \\
\text { Rating } \\
\text { (MWE) }\end{array}$} & \multirow[b]{2}{*}{$\begin{array}{l}\text { Core } \\
\text { Radius } \\
(\mathrm{CM})\end{array}$} & \multicolumn{4}{|c|}{ One-Zone Cores } & \multicolumn{5}{|c|}{ Multi-Zone Cores } \\
\hline & & 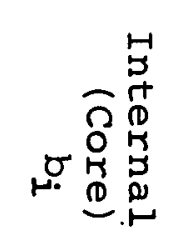 & 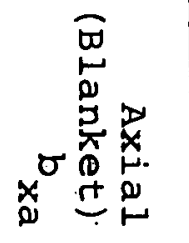 & 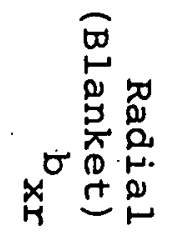 & 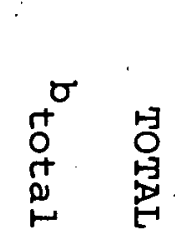 & 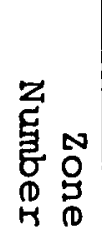 & 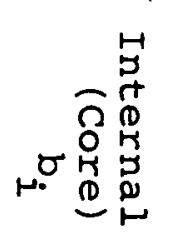 & 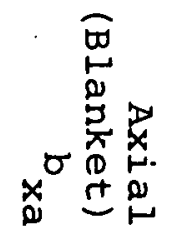 & 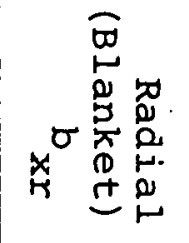 & 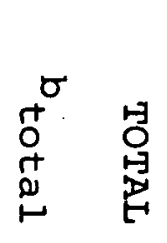 \\
\hline 250 & 65 & 0.6654 & 0.2340 & 0.5840 & 1.4834 & 2 & 0.6371 & 0.2222 & 0.6342 & 1.4935 \\
\hline 500 & 90 & 0.7911 & 0.2816 & 0.3873 & 1.4600 & 2 & 0.7411 & 0.2678 & 0.4625 & 1.4714 \\
\hline 750 & 110 & 0.8525 & 0.3060 & 0.2915 & 1.4500 & 2 & 0.7988 . & 0.2894 & 0.3714 & 1.4596 \\
\hline 1000 & 125 & 0.8864 & 0.3167 & 0.2388 & 1.4419 & 2 & 0.8336 & 0.2979 & 0.3175 & 1.4490 \\
\hline 1500 & 155 & 0.9292 & 0.3370 & 0.1709 & 1.4371 & 3 & 0.8988 & 0.3087 & 0.2485 & 1.4660 \\
\hline 2000 & 180 & 0.9565 & 0.3415 & 0.1314 & 1.4294 & 4 & 0.9177 & 0.3161 & 0.2200 & 1.4538 \\
\hline 2500 & 200 & 0.9695 & 0.3486 & 0.1102 & 1.4283 & 5 & 0.9251 & 0.3229 & 0.2049 & 1.4529 \\
\hline 3000 & 215 & 0.9753 & 0.3500 & 0.0987 & 1.4240 & 6 & 0.9284 & 0.3202 & 0.1926 & 1.4412 \\
\hline
\end{tabular}

Table F.8 The Effect of Changing Core Radius at Constant Core Height on the Breeding Performance of the Blanket 


\begin{tabular}{|c|c|c|c|c|c|c|c|c|}
\hline \multirow{2}{*}{$\begin{array}{l}\begin{array}{l}\text { Power } \\
\text { Rating } \\
(\mathrm{MWE})\end{array} \\
250\end{array}$} & \multirow{2}{*}{$\begin{array}{c}\begin{array}{c}\text { Core } \\
\text { Radius } \\
(\mathrm{CM})\end{array} \\
65\end{array}$} & $\begin{array}{c}\text { So } \\
(\mathrm{gPu} / \mathrm{kgH}\end{array}$ & one Core & $s_{0} \varepsilon_{c}$ & $\begin{array}{c}\text { Zone } \\
\text { No. }\end{array}$ & $\begin{array}{l}\text { Multi } \\
\text { o } \\
\mathrm{u} / \mathrm{kgHM}\end{array}$ & $\begin{array}{c}\text { Core } \\
\varepsilon_{c}\end{array}$ & $s_{0}^{\varepsilon} c$ \\
\hline & & 14.94 & 0.1684 & 2.969 & 2 & 14.17 & 0.1879 & 2.668 \\
\hline 500 & 90 & 18.73 & 0.1471 & 2.756 & 2 & 17.79 & $0 . \overline{1619}$ & 2.878 \\
\hline 750 & 110 & 20.40 & 0.1371 & 2.831 & 2 & 19.28 & 0.1521 & 2.933 \\
\hline 1000 & 125 & 22.55 & 0.1344 & 3.031 & 2 & 21.20 & 0.1465 & 3.106 \\
\hline 1500 & 155 & 22.55 & 0.1295 & 2.922 & 3 & 20.60 & 0.1368 & 2.818 \\
\hline 2000 & 180 & 22.65 & 0.1265 & 2.867 & 4 & 20.84 & 0.1347 & 2.807 \\
\hline 2500 & 200 & 23.34 & 0.1252 & 2.922 & 5 & 21.52 & 0.1337 & 2.877 \\
\hline 3000 & 215 & 25.10 & 0.1246 & 3.127 & 6 & 22.61 & 0.1325 & 2.996 \\
\hline
\end{tabular}

Table F.9 The Effect of Changing Core-Radius at Constant Core Height on Fissile Specific Inventory Buildup Rate in the Axial Blanket (2DB Results) 


\begin{tabular}{|c|c|c|c|c|c|c|c|c|}
\hline \multirow{2}{*}{$\begin{array}{l}\text { Power } \\
\text { Rating } \\
\text { (MWE) }\end{array}$} & \multirow{2}{*}{$\begin{array}{c}\text { Core } \\
\text { Radius } \\
\text { (CM) }\end{array}$} & \multicolumn{3}{|c|}{ One-Core Zone } & \multicolumn{4}{|c|}{ Multi-Zone Core } \\
\hline & & $b_{x a}$ & $\varepsilon_{c}$ & $b_{x a} \varepsilon_{c}$ & $\begin{array}{c}\text { of } \\
\text { zone }\end{array}$ & $b_{x a}$ & $\varepsilon_{c}$ & $b_{x a} \varepsilon_{C}$ \\
\hline 250 & .65 & 0.2340 & 0.1684 & 0.03941 & 2 & 0.2222 & 0.1879 & 0.04175 \\
\hline 500 & 90 & 0.2816 & 0.1471 & 0.04142 & 2 & 0.2678 & 0.1619 & 0.04336 \\
\hline 750 & 110 & 0.3060 & 0.1371 & 0.04195 & 2 & 0.2894 & 0.1521 & 0.04402 \\
\hline 1000 & 125 & 0.3167 & 0.1344 & 0.04256 & 2 & 0.2979 & 0.1465 & 0.04364 \\
\hline 1500 & 155 & 0.3370 & 0.1295 & 0.04364 & 3 & 0.3087 & 0.1368 & 0.04223 \\
\hline 2000 & 180 & 0.3415 & 0.1265 & 0.04320 & 4 & 0.3161 & 0.1347 & 0.04258 \\
\hline 2500 & 200 & 0.3486 & 0.1252 & 0.04364 & 5 & 0.3229 & 0.1337 & 0.04317 \\
\hline 3000 & 215 & 0.3500 & 0.1246 & 0.04361 & 6 & 0.3202 & 0.1325 & 0.04243 \\
\hline
\end{tabular}

Table F.10 The Effect of Changing Core Radius at Constant Core Height on Breeding Ratio in the Axial Blanket (2DB Results) 


\begin{tabular}{|c|c|c|c|c|c|c|}
\hline$X^{\text {Core Type }}$ & \multicolumn{3}{|c|}{1 Zone Cores } & \multicolumn{3}{|c|}{2 Zone Cores } \\
\hline Items & 100 & 150 & 200 & 100 & 150 & 200 \\
\hline Radial Blanket, b x r & 0.243 & 0.248 & 0.254 & 0.320 & 0.324 & 0.334 \\
\hline Axial Blanket, b $x$ a & 0.314 & 0.187 & 0.123 & 0.295 & 0.175 & 0.115 \\
\hline Core, $b_{i}$ & 0.882 & 0.999 & 1.070 & 0.826 & 0.939 & 0.995 \\
\hline Total, b total & 1.439 & 1.434 & 1.447 & 1.441 & 1.438 & 1.444 \\
\hline
\end{tabular}

Table F.11 The Effect of Changing Core Heights at Constant Core Radius on the Breeding Performance 


\begin{tabular}{|c|c|c|c|c|c|c|c|}
\hline \multirow{2}{*}{$\begin{array}{l}\text { Power } \\
\text { Rating } \\
\text { (MWe) }\end{array}$} & \multirow{2}{*}{$\begin{array}{l}\text { Core } \\
\text { Height } \\
\text { (CM) }\end{array}$} & \multicolumn{3}{|c|}{1 Zone Cores } & \multicolumn{3}{|c|}{$\begin{array}{l}2 \text { Zone Radially- } \\
\text { Power-Flattened Cores }\end{array}$} \\
\hline & & $b_{x a}$ & $\varepsilon_{C}$ & $b_{x a} \varepsilon_{c}$ & $b_{x a}$ & $\varepsilon_{c}$ & $\mathrm{~b}_{\mathrm{xa}} \varepsilon_{\mathrm{c}}$ \\
\hline 1000 & 100 & 0.314 & 0.133 & 0.0418 & 0.295 & 0.147 & 0.0434 \\
\hline 1000 & 150 & 0.187 & 0.122 & 0.0228 & 0.175 & 0.133 & 0.0233 \\
\hline 1000 & 200 & 0.123 & 0.166 & 0.0143 & 0.115 & 0.127 & 0.0146 \\
\hline
\end{tabular}

Table F.12 The Effect of Changing Core Heigit at Constant Core Radius on the Preeding Performance of the Axial Blanket 
Table F.13a Fissile and Poison Concentrations of 250 MWE-2 Zone "Equilibrium" System. (103 Atoms/Barns-CM)

The "Equilibrium" system is the poisoned system with $k_{\text {eff }}=1$ at 300 days with any radial. blanket.

\begin{tabular}{|c|c|c|c|c|c|c|c|}
\hline \multirow{3}{*}{ Nuclide } & \multicolumn{4}{|c|}{ Poisoned system (B.O.L.) } & \multicolumn{3}{|c|}{ "Equilibrium" System } \\
\hline & \multicolumn{2}{|c|}{ Core } & \multirow{2}{*}{$\begin{array}{c}\text { Axial } \\
\text { Blanket }\end{array}$} & \multirow{2}{*}{$\begin{array}{r}\text { Radial } \\
\text { Blanket }\end{array}$} & \multicolumn{2}{|c|}{ Core } & \multirow{2}{*}{$\begin{array}{c}\text { Axial } \\
\text { Blanket }\end{array}$} \\
\hline & Zone 1 & Zone 2 & & & Zone 1 & Zone 2 & \\
\hline $\mathrm{Pu}-239$ & 1.0408 & 1.5093 & 0.0 & 0.0 & 0.9070 & 1.3061 & 0.06390 \\
\hline $\mathrm{Pu}-240$ & 0.4511 & 0.6542 & 0.0 & 0.0 & 0.4552 & 0.6570 & 0.00067 \\
\hline $\mathrm{Pu}-241$ & 0.09748 & 0.14135 & 0.0 & 0.0 & 0.08504 & 0.12658 & 0.000007 \\
\hline $\mathrm{Pu}-242$ & 0.07630 & 0.09100 & 0.0 & 0.0 & 0.07360 & 0.08947 & 0.0 \\
\hline$U-235$ & 0.00869 & 0.00722 & 0.01395 & 0.02326 & 0.00607 & 0.00567 & 0.01274 \\
\hline $\mathrm{U}-238$ & 4.3339 & 3.6052 & 6.9630 & 11.61 & 4.1301 & 3.4890 & 6.8933 \\
\hline$P u-F \cdot P$. & 0.0 & 0.0 & 0.0 & 0.0 & 0.33062 & 0.31719 & 0.00589 \\
\hline$B-10$ & 0.1797 & 0.1797 & 4.4133 & 0.0 & 0.1797 & 0.1797 & 0.4133 \\
\hline$k_{\text {eff }}$ & & 1.0 & & & & $1.009 *$ & \\
\hline $\mathrm{b}_{\text {total }}$ & & 1.1 & & & & $1.2436 *$ & \\
\hline P.Power Den. & 682.0 & 674.0 & & $-1.2 * \star$ & 639.7 & 645.4 & $+5 \cdot 7 * *$ \\
\hline
\end{tabular}

* With the same radial blanket as poisoned system burned up 300 days.

** Flattness $\left(\mathrm{P}_{2}-\mathrm{P}_{1}\right) / \mathrm{P}_{1} \quad(\%)$ 
Table F.13b Fissile and Poison Concentrations of 1000 MWE-2 Zone "Equilibrium" System. ( $10^{3}$ Atoms/Barn-CM)

\begin{tabular}{|c|c|c|c|c|c|c|c|}
\hline \multirow[t]{2}{*}{ Nuclide } & \multicolumn{4}{|c|}{ B.O.L. Poisoned System } & \multicolumn{3}{|c|}{ Equilibrium System } \\
\hline & Zone 1 & Zone 2 & Blanket & Blanket & Zone 1 & Zone 2 & Blanket. \\
\hline $\mathrm{Pu}-239$ & 0.8336 & 1.1206 & 0.0 & 0.0 & 0.7543 & 0.9692 & 0.1012 \\
\hline $\mathrm{Pu}-240$ & 0.3453 & 0.4857 & 0.0 & 0.0 & 0.3595 & 0.4922 & 0.00187 \\
\hline $\mathrm{Pu}-241$ & 0.07461 & 0.10494 & 0.0 & 0.0 & 0.06438 & 0.09253 & 0.00003 \\
\hline $\mathrm{Pu}-242$ & 0.04805 & 0.06756 & 0.0 & 0.0 & 0.04677 & 0.06619 & 0.0 \\
\hline$U-235$ & 0.00948 & 0.00831 & 0.01395 & 0.02326 & 0.00560 & 0.00590 & 0.01200 \\
\hline$U-238$ & 4.7288 & 4.1472 & 6.963 & 11.61 & 4.4101 & 3.9607 & 6.8509 \\
\hline $\mathrm{Pu}-\mathrm{F} . \mathrm{P}$ & 0.0 & 0.0 & 0.0 & 0.0 & 0.37101 & 0.32751 & 0.01022 \\
\hline$B-10$ & 0.1106 & 0.1106 & 0.2544 & 0.0 & 0.1106 & 0.1106 & 0.2544 \\
\hline $\begin{array}{c}k_{\text {eff }} \\
b_{\text {total }} \\
\text { Peak P.D. }\end{array}$ & 731.7 & $\begin{array}{l}1.079 \\
1.1311\end{array}$ & & $+2.4 * \star$ & 709.3 & $\begin{array}{l}1.003 \\
1.2059\end{array}$ & $-2.2^{*}$ \\
\hline
\end{tabular}

** Flattness $\left(\mathrm{P}_{2}-\mathrm{P}_{1}\right) / \mathrm{P}_{1}(8)$

P.D. ( KW $_{\text {th }} /$ Liter $)$ 
Table F.13C Fissile and Poison Concentrations of 3000 MWE-2 Zone "Equilibrium" System ( $10^{3}$ Atoms/Barn-CM)

\begin{tabular}{|c|c|c|c|c|c|c|c|}
\hline \multirow[t]{2}{*}{ Nuclide } & \multicolumn{4}{|c|}{ B.O.L. Poisoned System } & \multicolumn{3}{|c|}{ Equilibrium System } \\
\hline & Zone 1 & Zone 2 & Blanket & Blanket & Zone 1 & Zone 2 & Blanket \\
\hline $\mathrm{Pu}-239$ & 0.7688 & 0.9140 & 0.0 & 0.0 & 0.7106 & 0.8223 & 0.1213 \\
\hline$P u-240$ & 0.3333 & 0.3960 & 0.0 & 0.0 & 0.3486 & 0.4054 & 0.00281 \\
\hline $\mathrm{Pu}-241$ & 0.07201 & 0.08501 & 0.0 & 0.0 & 0.06183 & 0.07524 & 0.00007 \\
\hline $\mathrm{Pu}-242$ & 0.04639 & 0.05512 & 0.0 & 0.0 & 0.04506 & 0.05400 & 0.0 \\
\hline $\mathrm{U}-235$ & 0.00958 & 0.00912 & 0.01395 & 0.02326 & 0.00518 & 0.00614 & 0.01159 \\
\hline$U-238$ & 4.7784 & 4.5486 & 6.9630 & 11.61 & 4.4060 & 4.3159 & 6.8270 \\
\hline$P u-F \cdot P$. & 0.0 & 0.0 & 0.0 & $0: 0$ & $0: 39693$ & 0.30904 & 0.01313 \\
\hline$B-10$ & 0.0872 & 0.0872 & 0.2006 & 0.0 & 0.0872 & 0.0872 & 0.2006 \\
\hline $\begin{array}{c}\mathrm{K}_{\text {eff }} \\
\mathrm{b}_{\text {total }}\end{array}$ & & $\begin{array}{l}1.064 \\
1.1549\end{array}$ & & . & & $\begin{array}{l}1.001 \\
1.1891\end{array}$ & \\
\hline Peak P.D. & 776.7 & 747.9 & & -3.78 & $733: 3$ & 702.7 & -4.28 \\
\hline
\end{tabular}




\begin{tabular}{|l|c|c|c|c|c|c|}
\hline Material & Core & $\begin{array}{c}\text { Axial } \\
\text { Blanket }\end{array}$ & $\begin{array}{c}\text { Radial } \\
\text { Blanket }\end{array}$ & $\begin{array}{c}\text { Axial } \\
\text { Reflector }\end{array}$ & $\begin{array}{c}\text { Radial } \\
\text { Reflector }\end{array}$ & $\begin{array}{c}\text { Axial Reflector } \\
\text { on the } \\
\text { Radial Blanket }\end{array}$ \\
\hline Iron & 0.01213 & 0.01213 & 0.01213 & 0.03033 & 0.05459 & 0.03033 \\
Chromium & 0.00312 & 0.00312 & 0.0312 & 0.0078 & 0.01404 & 0.0078 \\
Nickel & 0.00195 & 0.00195 & 0.00195 & 0.004875 & 0.008775 & 0.004875 \\
Sodium & 0.01096 & 0.01096 & 0.006576 & 0.01096 & 0.002192 & 0.01096 \\
\hline
\end{tabular}

* Atoms/barn-cm

Table F.14 Non-Fuel Material Number Densities used in the Present Work 
Table F.15 The Effect of Core-Radius (Power-Rating) on Peak Power Density Change and Peak Power Flatness Change Due to Irradiation

\begin{tabular}{|c|c|c|c|c|c|c|c|c|c|}
\hline $\begin{array}{c}\text { Irr.Time } \\
\text { (Days) }\end{array}$ & \multicolumn{3}{|c|}{$\begin{array}{l}250 \text { MWE (65 CM) } \\
\text { Peak Zone Power } \\
\text { Density (KWT/Liter) }\end{array}$} & $\begin{array}{l}\mathrm{P} \cdot \mathrm{Z} \\
\mathrm{P}_{1}\end{array}$ & $\mathrm{P}_{2}$ & $\begin{array}{l}\mathrm{PPF} \equiv \\
\frac{\mathrm{P}_{2}-\mathrm{P}_{1}}{\mathrm{P}_{1}} \\
(8)\end{array}$ & $\begin{array}{l}\mathrm{P} \cdot \mathrm{Z} . \\
\mathrm{P}_{1}\end{array}$ & $\mathrm{P}_{2}$ & $\begin{array}{l}\mathrm{PPF} \equiv \\
\frac{\mathrm{P}_{2}-\mathrm{P}_{1}}{\mathrm{P}_{1}} \\
(\mathrm{z})\end{array}$ \\
\hline 0 & 682.0 & 674.0 & -1.17 & 731.7 & 749.5 & +2.43 & 776.7 & 747.9 & -3.71 \\
\hline 100 & 668.3 & 666.8 & -0.22 & 722.4 & 733.6 & +1.55 & 757.3 & 735.2 & -2.92 \\
\hline 200 & 654.2 & 657.1 & +0.44 & 715.7 & 715.6 & -0.01 & 744.1 & 719.7 & -3.28 \\
\hline 300 & 639.7 & 645.5 & +0.91 & 709.3 & 696.4 & -1.82 & 733.3 & 702.7 & -4.17 \\
\hline 400 & 624.7 & 632.3 & +1.18 & 702.6 & 676.2 & -3.76 & 723.4 & 684.7 & -5.35 \\
\hline 500 & 609.7 & 617.9 & +1.34 & 693.9 & 655.6 & -5.52 & 712.3 & 666.3 & -6.46 \\
\hline 600 & 593.9 & 602.1 & +1.38 & 683.6 & 634.5 & -7.18 & 699.2 & 647.8 & -7.35 \\
\hline
\end{tabular}


Table F.16 The Effect of Core Radius on Fissile Material Specific Inventory, $\frac{M^{49}+M^{41}}{M_{H M}},(g P u / k g H M)$

\begin{tabular}{|c|c|c|c|c|c|c|c|c|c|}
\hline \multirow{2}{*}{$\begin{array}{c}\text { Irradiation } \\
\text { Time } \\
\text { (Full Power } \\
\text { Days). }\end{array}$} & \multicolumn{3}{|c|}{250 MWE } & \multicolumn{3}{|c|}{$1000 \mathrm{MWE}$} & \multicolumn{3}{|c|}{3000 . MWE } \\
\hline & Row 1 & Row 2 & Row 3 & Row 1 & Row 2 & Row 3 & Row 1 & Row 2 & Row 3 \\
\hline $\begin{array}{l}100 \\
200 \\
300 \\
400 \\
500 \\
600 \\
700 \\
800 \\
900 \\
1000 \\
1100 \\
1200 \\
1300 \\
1400 \\
1500 \\
1600 \\
1700 \\
1800\end{array}$ & $\begin{array}{r}3.36 \\
6.70 \\
9.98 \\
13.18 \\
16.35 \\
19.34 \\
22.39 \\
25.15 \\
27.93 \\
30.61 \\
33.21 \\
35.75 \\
38.17 \\
40.52 \\
42.81 \\
44.99 \\
47.13 \\
49.17\end{array}$ & $\begin{array}{r}1.39 \\
2.82 \\
4.25 \\
5.71 \\
7.15 \\
8.62 \\
10.08 \\
11.53 \\
N . A . \\
14.42 \\
15.86 \\
17.29 \\
18.70 \\
20.11 \\
21.51 \\
22.990 \\
24.27 \\
25.64\end{array}$ & $\begin{array}{r}0.52 \\
1.07 \\
1.63 \\
2.21 \\
2.81 \\
3.41 \\
4.03 \\
4.66 \\
5.29 \\
5.94 \\
6.59 \\
7.25 \\
7.92 \\
8.59 \\
9.27 \\
10.00 \\
10.64 \\
11.33\end{array}$ & $\begin{array}{r}3.77 \\
7.56 \\
11.31 \\
15.02 \\
18.65 \\
22.20 \\
25.66 \\
29.02 \\
32.29 \\
35.47 \\
38.55 \\
41.54 \\
44.41 \\
47.21 \\
49.93 \\
52.56 \\
55.07 \\
57.52\end{array}$ & $\begin{array}{r}1.56 \\
3.18 \\
4.85 \\
6.55 \\
8.27 \\
10.02 \\
11.79 \\
13.56 \\
15.35 \\
17.15 \\
18.95 \\
20.76 \\
22.56 \\
24.37 \\
26.21 \\
28.06 \\
29.88 \\
31.71\end{array}$ & $\begin{array}{r}0.59 \\
1.2 .2 \\
1.88 \\
2.58 \\
3.30 \\
4.05 \\
4.82 \\
5.61 \\
6.43 \\
7.27 \\
8.13 \\
9.01 \\
9.92 \\
10.84 \\
11.80 \\
12.78 \\
13.77 \\
14.78\end{array}$ & $\begin{array}{r}3.33 \\
6.71 \\
10.09 \\
13.45 \\
16.76 \\
20.04 \\
23.27 \\
26.44 \\
29.54 \\
32.59 \\
35.57 \\
38.48 \\
41.32 \\
44.09 \\
46.80 \\
49.43 \\
51.99 \\
54.47\end{array}$ & $\begin{array}{r}1.37 \\
2.80 \\
4.27 \\
5.79 \\
7.34 \\
8.91 \\
10.52 \\
12.14 \\
13.79 \\
15.47 \\
17.16 \\
18.86 \\
20.58 \\
22.32 \\
24.06 \\
25.83 \\
27.60 \\
29.37\end{array}$ & $\begin{array}{r}0.52 \\
1.07 \\
1.66 \\
2.28 \\
2.92 \\
3.59 \\
4.29 \\
5.01 \\
5.75 \\
6.52 \\
7.32 \\
8.14 \\
8.99 \\
9.86 \\
10.76 \\
11.47 \\
12.62 \\
13.59\end{array}$ \\
\hline
\end{tabular}


Table F.17 Burnup Dependence of the BOL-Normalized Fissile Buildup Rate Ratio for Various Power Ratings

\begin{tabular}{|c|c|c|c|c|c|c|c|c|c|}
\hline & \multicolumn{3}{|c|}{$250 \mathrm{MWE}$} & \multicolumn{3}{|c|}{$1000 \mathrm{MWE}$} & \multicolumn{3}{|c|}{$3000 \mathrm{MWE}$} \\
\hline & Row 1 & Row 2 & Row 3 & Row 1 & Row 2 & Row 3 & Row 1 & Row 2 & Row 3 \\
\hline $\begin{array}{l}100 \\
200 \\
300 \\
400 \\
500 \\
600 \\
700 \\
8000 \\
9000 \\
1000 \\
11000 \\
12000 \\
13000 \\
1400 \\
15000 \\
16000 \\
1700 \\
1800\end{array}$ & $\begin{array}{l}1.000 \\
0.942 \\
0.974 \\
0.953 \\
0.927 \\
0.902 \\
0.876 \\
0.849 \\
0.822 \\
0.797 \\
0.770 \\
0.750 \\
0.717 \\
0.695 \\
0.674 \\
0.643 \\
0.632 \\
0.601\end{array}$ & $\begin{array}{l}1.000 \\
1.021 \\
1.034 \\
1.042 \\
1.046 \\
1.046 \\
1.046 \\
1.044 \\
1.039 \\
1.035 \\
1.029 \\
1.025 \\
1.016 \\
1.010 \\
1.001 \\
0.995 \\
0.985 \\
0.976\end{array}$ & $\begin{array}{l}1.000 \\
1.042 \\
1.077 \\
1.107 \\
1.131 \\
1.157 \\
1.176 \\
1.196 \\
1.210 \\
1.229 \\
1.243 \\
1.263 \\
1.267 \\
1.286 \\
1.291 \\
1.306 \\
1.315 \\
1.320\end{array}$ & $\begin{array}{l}1.000 \\
1.005 \\
0.997 \\
0.983 \\
0.962 \\
0.940 \\
0.916 \\
0.890 \\
0.865 \\
0.839 \\
0.813 \\
0.787 \\
0.757 \\
0.736 \\
0.715 \\
0.690 \\
0.549 \\
0.638\end{array}$ & $\begin{array}{l}1.000 \\
1.041 \\
1.069 \\
1.091 \\
1.108 \\
1.122 \\
1.133 \\
1.141 \\
1.147 \\
1.152 \\
1.152 \\
1.163 \\
1.152 \\
1.163 \\
1.174 \\
1.185 \\
1.163 \\
1.174\end{array}$ & $\begin{array}{l}1.000 \\
1.066 \\
1.123 \\
1.172 \\
1.220 \\
1.263 \\
1.306 \\
1.345 \\
1.383 \\
1.423 \\
1.455 \\
1.493 \\
1.525 \\
1.560 \\
1.624 \\
1.653 \\
1.183 \\
1.709\end{array}$ & $\begin{array}{l}1.000 \\
1.012 \\
1.013 \\
1.008 \\
0.994 \\
0.981 \\
0.956 \\
0.949 \\
0.929 \\
0.911 \\
0.891 \\
0.866 \\
0.849 \\
0.825 \\
0.805 \\
0.783 \\
0.759 \\
0.735\end{array}$ & $\begin{array}{l}1.000 \\
1.045 \\
1.078 \\
1.108 \\
1.131 \\
1.154 \\
1.172 \\
1.188 . \\
1.203 \\
1.226 \\
1.234 \\
1.242 \\
1.258 \\
1.266 \\
1.274 \\
1.290 \\
1.290 \\
1.290\end{array}$ & $\begin{array}{l}1.000 \\
1.068 \\
1.127 \\
1.184 \\
1.237 \\
1.285 \\
1.338 \\
1.383 \\
1.434 \\
1.485 \\
1.532 \\
1.579 \\
1.628 \\
1.675 \\
1.726 \\
1.761 \\
1.820 \\
1.859\end{array}$ \\
\hline
\end{tabular}




\begin{tabular}{cccc}
$\begin{array}{c}\text { Irradiation } \\
\text { inime (Days) }\end{array}$ & Ror 1 & Row 2 & Por 3 \\
\hline 100 & $1.59(-5)$ & $3.71(-6)$ & $7.25(-7)$ \\
300 & $1.44(-4)$ & $3.46(-5)$ & $7.10(-6)$ \\
600 & $5.70(-4)$ & $1.43(-4)$ & $3.14(-5)$ \\
900 & $1.52(-3)$ & $3.26(-4)$ & $7.65(-5)$ \\
1200 & $2.15(-3)$ & $5.84(-4)$ & $1.45(-4)$ \\
1500 & $3.27(-3)$ & $9.10(-4)$ & $2.74(-4)$ \\
1800 & $4.57(-3)$ & $1.33(-3)$ & $3.96(-4)$ \\
\hline
\end{tabular}

Table F.18 Burnup Dependence of the Batio of Pu-241 Inventory to $\mathrm{Pu}-239$ Inventory 


\begin{tabular}{|c|c|c|c|c|c|}
\hline & $\begin{array}{l}\text { No. } \\
\text { of } \\
\text { Row }\end{array}$ & $\begin{array}{l}\text { Power Rating (MWE) } \\
\text { Thermal Power }\left(\mathrm{MW}_{\mathrm{th}}\right) \\
\text { Core Radius } \\
\text { Items }\end{array}$ & $\begin{array}{r}250 \\
625 \\
65\end{array}$ & $\begin{array}{r}1000 \\
2500 \\
125\end{array}$ & $\begin{array}{r}3000 \\
7500 \\
215\end{array}$ \\
\hline 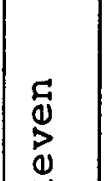 & 1 & $\begin{array}{l}\text { Irr. Time } \\
\quad \text { (Full Power Days) } \\
\text { Enrichment }(z)\end{array}$ & $\begin{array}{l}433 \\
1.42\end{array}$ & $\begin{array}{l}375 \\
1.40\end{array}$ & $\begin{array}{l}421 \\
1.42\end{array}$ \\
\hline 苟 & 2 & $\begin{array}{l}\text { Irr. Time (F.P.D.) } \\
\text { Enrichment }\left(\frac{\circ}{8}\right)\end{array}$ & $\begin{array}{l}1.167 \\
1.67\end{array}$ & $\begin{array}{l}929 \\
1.58\end{array}$ & $\begin{array}{r}1053 \\
1.04\end{array}$ \\
\hline 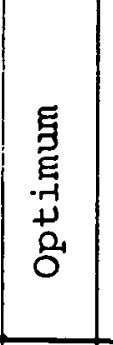 & 1 & $\begin{array}{l}\text { Irr. Time (F.P.D.) } \\
\text { Enrichment }(q) \\
\text { Fuel Cycle Cost } \\
\quad(\text { Mills/KWhr) } \\
\text { Revenue per Assembly } \\
\quad(\$ / \mathrm{kgHM} \text { yr) }\end{array}$ & $\begin{array}{c}1373 \\
4.01 \\
-0.1228 \\
-39.00\end{array}$ & $\begin{array}{l}1290 \\
4.44 \\
-0.0728 \\
-50.05\end{array}$ & $\begin{array}{c}1460 \\
4.61 \\
-0.0364 \\
-45.90\end{array}$ \\
\hline 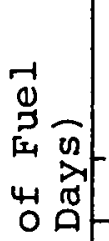 & 1 & $\begin{array}{l}\text { Enrichment }(\%) \\
\text { Cost (Mills/KWhr). } \\
\text { Revenue ( } \$ / \text { kgHM yr). }\end{array}$ & 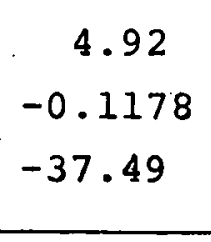 & $\begin{aligned} & 5.75 \\
-0.0690 & \\
- & 48.09\end{aligned}$ & $\begin{array}{r}5.45 \\
-0.0355 \\
-44.22\end{array}$ \\
\hline 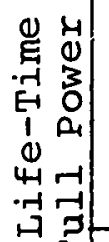 & 2 & $\begin{array}{l}\text { Enrichment }\left(\frac{o}{0}\right) \\
\text { Cost (Mills/KWHR) } \\
\text { Revenue }(\$ / \mathrm{kgHM} \text { yr) }\end{array}$ & $\begin{aligned} & 2.56 \\
-0.0289 & -7.61\end{aligned}$ & $\begin{array}{l}3.17 \\
-0.0245 \\
-15.33\end{array}$ & $\begin{array}{r}2.94 \\
-0.0106 \\
-12.35\end{array}$ \\
\hline 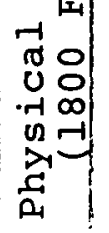 & 3 & $\begin{array}{l}\text { Enrichment }\left(\frac{o}{0}\right) \\
\text { Cost (Mills } / \mathrm{KWHR}) \\
\text { Revenue }(\$ / \mathrm{kgHM} \mathrm{yr})\end{array}$ & $\begin{array}{l}1.13 \\
+0.0468 \\
+\quad 10.54\end{array}$ & $\begin{array}{r}1.48 \\
+0.0109 \\
+\quad 6.16\end{array}$ & $\begin{array}{r}1.36 \\
+0.0070 \\
+\quad 7.68\end{array}$ \\
\hline
\end{tabular}

Table F.19 The Effect of Changing Core Radius at Constant Core Height on Breakeven, Optimum and Physical Lifetime Points of the Radial Blanket 
Table F.20 Comparison of Optimum and Breakeven Irradiation Times for the Radial. Blanket-Row 1 (the one-Row Radial Blanket) Predicted by Correlation and $2 \mathrm{DB}-\mathrm{BRECON}$

\begin{tabular}{|c|c|c|c|c|c|}
\hline & $\begin{array}{l}\text { Dis- } \\
\text { count } \\
\text { Rate } \\
\left(\mathrm{yr}^{-1}\right)\end{array}$ & $\begin{array}{l}\text { Pu price } \\
\begin{array}{c}\text { Fulf } \\
\text { Power } \\
\text { Days }\end{array}\end{array}$ & 0.02123 & 0.01274 & 0.009095 \\
\hline \multirow{2}{*}{$\begin{array}{l}\text { Fab.Cost } \\
69 \$ / \mathrm{kgHM} \\
\text { Repro- } \\
\text { cessing } \\
\text { Cost }\end{array}$} & 0.04 & $\begin{array}{l}\text { Correlation } \\
\text { 2DB-Brecon" } \\
\text { Difference }\end{array}$ & $\begin{array}{r}1867 \\
1841 \\
+26\end{array}$ & $\begin{array}{r}1417 \\
1406 \\
+11\end{array}$ & $\begin{array}{r}1181 \\
1186 \\
-5\end{array}$ \\
\hline & 0.08 & $\begin{array}{l}\text { Correlation } \\
\text { 2DB-Brecon } \\
\text { Difference }\end{array}$ & $\begin{array}{r}1682 \\
1704 \\
-22\end{array}$ & $\begin{array}{r}1277 \\
1283 \\
-6\end{array}$ & $\begin{array}{r}1065 \\
1076 \\
-11\end{array}$ \\
\hline \multirow[t]{2}{*}{$50 \$ / \mathrm{kgHM}$} & 0.12 & $\begin{array}{l}\text { Correlation } \\
\text { 2DB-Brecon } \\
\text { Difference }\end{array}$ & $\begin{array}{r}1583 \\
1591 \\
-8\end{array}$ & $\begin{array}{r}1202 \\
1201 \\
+1\end{array}$ & $\begin{array}{r}1001 \\
1005 \\
-4\end{array}$ \\
\hline & 0.16 & $\begin{array}{l}\text { Correlation } \\
\text { 2DB-Brecon } \\
\text { Difference }\end{array}$ & $\mathrm{N}, \mathrm{A}$. & $\begin{array}{r}1150 \\
1136 \\
+14\end{array}$ & $\begin{array}{l}960 \\
948 \\
+12\end{array}$ \\
\hline
\end{tabular}

\begin{tabular}{|ccc|}
\hline 6 & 10 & 14 \\
\hline 0.02123 & 0.01274 & 0.009095 \\
\hline 627 & 350 & 237 \\
597 & 348 & 250 \\
+30 & +2 & -13 \\
\hline 688 & 384 & 260 \\
683 & 376 & 266 \\
+5 & +8 & -6 \\
\hline 740 & 413 & 280 \\
809 & 405 & 281 \\
-69 & +8 & -1 \\
\hline N.A. & 435 & 295 \\
& 453 & 296 \\
& -18 & -1 \\
\hline
\end{tabular}

\begin{tabular}{|l|l|l|rrr|}
\hline Fab. Cost & & W & 0.04282 & 0.02569 & 0.018 .35 \\
$140(\$ / \mathrm{kgHM})$ & \multirow{3}{*}{0.08} & Correlation & 2457 & 1864 & 1555 \\
Rep.Cost & 2DB-Brecon & 2571 & 1894 & 1567 \\
$100(\$ / \mathrm{kgHM})$ & & Difference & -114 & -30 & -12 \\
\hline
\end{tabular}

(A) Optimum Irradiation Time (Full Power Days) Correlation: $\quad\left(9.22 \times 10^{3}\right) \mathrm{w}^{0.54} \mathrm{x}^{-0.15}$

\begin{tabular}{|ccc|}
\hline 0.04282 & 0.02869 & 0.01835 \\
\hline N.A. & 877 & 1603 \\
& 888 & 1567 \\
& -11 & +36 \\
\hline
\end{tabular}

(B) Breakeven Irradiation $\left(8.75 \times 10^{4}, \mathrm{w}^{1.14} \mathrm{x}^{0.17}\right.$ 
Comparison of optimum and Breakeven Irradiation Times for the Radial Blanket - Row 2 Predicted by Correlations and 2DB-BRECON.

\begin{tabular}{|c|c|c|c|c|c|}
\hline & $\begin{array}{r}\text { Pu pri } \\
+\$ / g P\end{array}$ & & 6. & 10 & 14 \\
\hline $\begin{array}{l}\text { Discount } \\
\text { Rate } \\
\left(y^{-1}\right)\end{array}$ & $\begin{array}{l}\text { Full } \\
\text { Power } \\
\text { Days }\end{array}$ & W & 0.02123 & 0.01274 & 0.009095 \\
\hline 0.04 & $\begin{array}{l}\text { Correla } \\
\text { 2DB-Bre } \\
\text { Differe }\end{array}$ & $\begin{array}{l}\text { ion } \\
\text { on } \\
\text { ce }\end{array}$ & N.A. & N.A. & $\begin{array}{r}2560 \\
2592 \\
-32\end{array}$ \\
\hline 0.08 & $\begin{array}{l}\text { Correla } \\
\text { 2DB-Bre } \\
\text { Differe }\end{array}$ & $\begin{array}{l}\text { ion } \\
\text { on } \\
\text { ce }\end{array}$ & $\mathrm{N}, \mathrm{A}$. & $\begin{array}{r}2480 \\
2499 \\
-19\end{array}$ & $\begin{array}{r}2168 \\
2171 \\
-3\end{array}$ \\
\hline 0.12 & $\begin{array}{l}\text { Correla } \\
\text { 2DB-Bre } \\
\text { Differe }\end{array}$ & $\begin{array}{l}\text { ion } \\
\text { on } \\
\text { ce }\end{array}$ & $\begin{array}{r}2760 \\
2718 \\
-42\end{array}$ & $\begin{array}{r}2250 \\
2206 \\
+44\end{array}$ & $\begin{array}{r}1967 \\
1910 \\
+57\end{array}$ \\
\hline 0.16 & $\begin{array}{l}\text { Correla } \\
\text { 2DB-Bre } \\
\text { Differe }\end{array}$ & $\begin{array}{l}\text { ion } \\
\text { on } \\
\text { ce }\end{array}$ & N.A. & $\begin{array}{l}2100 \\
1986 \\
+114\end{array}$ & $\begin{array}{r}1835 \\
1718 \\
+117\end{array}$ \\
\hline
\end{tabular}

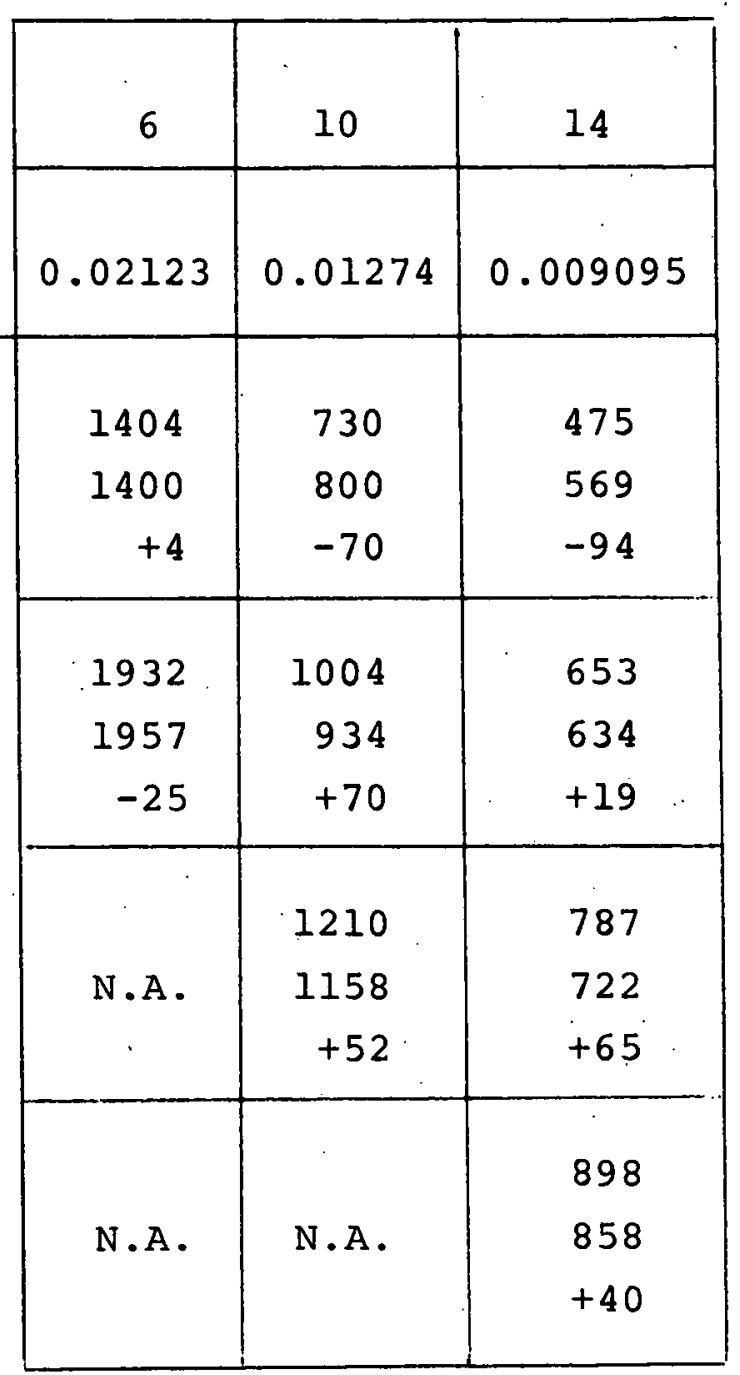

(A) Optimum Time
$\mathrm{T}_{\text {opt }}=\left(7.75 \times 10^{3}\right) \mathrm{w}^{0.40} \mathrm{x}^{-0.24}$

(B) Breakeven Time $1.28 \times 0.46$
$\mathrm{~T}_{\mathrm{BE}}=\left(8.55 \times 10^{5}\right) \mathrm{W}^{1.28} \mathrm{x}^{0.4}$ 


\begin{tabular}{|c|c|c|c|c|c|c|c|c|c|c|}
\hline \multirow{3}{*}{$\begin{array}{l}\text { No. } \\
\text { of } \\
\text { Row }\end{array}$} & \multirow{3}{*}{$\begin{array}{l}\text { No. } \\
\text { of } \\
\text { Zone }\end{array}$} & \multirow{3}{*}{$\begin{array}{l}\text { Zone } \\
\text { Position } \\
\text { (cm) }\end{array}$} & \multirow{3}{*}{$\begin{array}{l}\text { Entire } \\
\text { Blanket } \\
\text { Thickness } \\
\text { (cm) }\end{array}$} & \multicolumn{3}{|c|}{ Breakeven $* 1$} & \multicolumn{4}{|c|}{ Optimum } \\
\hline & & & & \multirow{2}{*}{$\begin{array}{l}\frac{\text { Loca }]}{\text { Time }} \\
\text { (Ful] }\end{array}$} & & \multirow{2}{*}{$\frac{\text { Tota } 1}{\text { Time }}$} & \multicolumn{2}{|r|}{ Loca 1} & \multicolumn{2}{|r|}{ Total } \\
\hline & & & & & Powe & & $\begin{array}{l}\text { Time } \\
\text { (FPD) }\end{array}$ & $\begin{array}{c}\text { Cost } \\
\text { (Mills/kwhr) }\end{array}$ & $\begin{array}{l}\text { Time } \\
\text { (FPD) }\end{array}$ & $\begin{array}{c}\text { Cost } \\
\text { (Mills/KwHr) }\end{array}$ \\
\hline \multirow{3}{*}{1} & 1 & 2.5 & & 293 & & 293 & 1053 & -0.0306 & 1053 & -0.0306 \\
\hline & 2 & 7.5 & 15 & 375 & & 332 & 1293 & -0.0243 & 1163 & -0.0546 \\
\hline & 3 & 12.5 & & 493 & & 376 & 1621 & -0.0183 & 1283 & -0.0720 \\
\hline \multirow{3}{*}{2} & 4 & 17.5 & & 678 & & 425 & 2043 & -0.0130 & 1417 & $-0.0833^{\circ}$ \\
\hline & 5 & 22.5 & 30 & 952 & & 485 & 2550 & -0.0088 & 1558 & -0.0 .896 \\
\hline & 6 & 27.5 & & 1361 & & 556 & NA & NA & 1707 & -0.0917 \\
\hline \multirow{3}{*}{3} & 7 & 32.5 & & 1980 & & 633 & NA & NA & 1848 & -0.0911 \\
\hline & 8 & 37.5 & 45 & $\mathrm{NA}$ & & 718 & NA & NA & 2054 & -0.0874 \\
\hline & 9 & 42.5 & & NA & & 811 & NA & NA & 2155 & -0.0827 \\
\hline
\end{tabular}

*1 By Linear Interpolation

*2 By Quadratic Fitting 1000 MWe - 2 zone Core for the Reference Economic Conditions

Table F.22 2DB-Results for Four Key Loci (Irradiation Time - Blanket Position or Entire-Blanket Thickness Loci) and Two Key Curves (Cost - Blanket Row Position or Entire-Blanket Thickness Curves) 
Table F.23 Comparison of Optimum and Breakeven Irradiation Times. For the Two-Row Radial Blanket Predicted by Correlation and 2DB-BRECON

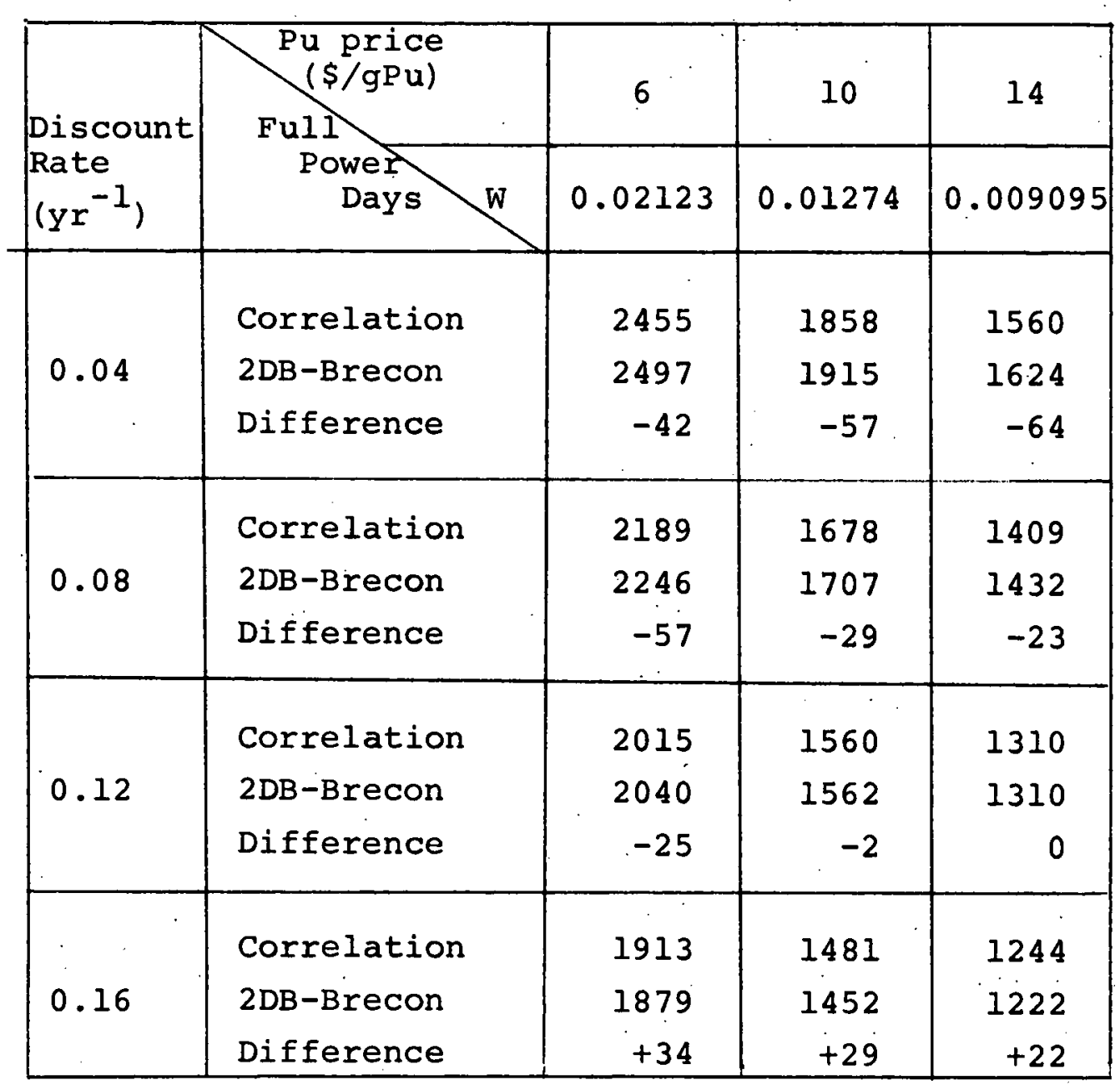

(A) Optimum Irradiation Time (Full Power Correlation: $\mathrm{T}_{\text {opt }-2}=\left(1.03 \times 10^{4}\right) \mathrm{w}^{0.52} \mathrm{x}-0.18$

\begin{tabular}{|c|c|c|}
\hline 6 & 10 & 14 \\
\hline 0.02123 & 0.01274 & 0.009095 \\
\hline 938 & 483 & 312 \\
882 & 497 & 355 \\
+56 & -14 & -43 \\
\hline 1139 & 586 & 379 \\
1061 & 556 & 382 \\
+78 & +30 & -3 \\
\hline 1276 & 657 & 424 \\
1574 & 628 & 414 \\
-298 & +29 & +10 \\
\hline$N . A$. & 737 & 460 \\
& -25 & 0 \\
\hline
\end{tabular}

(B) Breakeven Irradiation Time (Full Power Days) Correlation: $\mathrm{T}_{\mathrm{BE}-2}=\left(3.46 \times 10^{4}\right) \mathrm{W} 1.30 \times 0.28$ 


\begin{tabular}{|c|c|c|c|c|}
\hline & $P u P_{1}$ & 6 & 10 & 14 \\
\hline & Days) & 0.02123 & 0.01274 & 0.009095 \\
\hline 0.04 & $\begin{array}{l}\text { Correlation } \\
\text { 2DB-BRECON } \\
\text { Difference }\end{array}$ & $\mathrm{NA}$ & $\begin{array}{r}2492 \\
2477 \\
+15\end{array}$ & $\begin{array}{r}2106 \\
2100 \\
+6\end{array}$ \\
\hline 0.08 & $\begin{array}{l}\text { Correlation } \\
\text { 2DB-BRECON } \\
\text { Difference }\end{array}$ & $\begin{array}{r}2724 \\
2820 \\
-96\end{array}$ & $\begin{array}{r}2109 \\
2155 \\
-46\end{array}$ & $\begin{array}{r}1783 \\
1808 \\
-25\end{array}$ \\
\hline 0.12 & $\begin{array}{l}\text { Correlation } \\
\text { 2DB-BRECON } \\
\text { Difference }\end{array}$ & $\begin{array}{r}2471 \\
2489 \\
-18\end{array}$ & $\begin{array}{r}1914 \\
1933 \\
-19\end{array}$ & $\begin{array}{r}1618 \\
1629 \\
-11\end{array}$ \\
\hline 0.16 & $\begin{array}{l}\text { Correlation } \\
\text { 2DB-BRECON } \\
\text { Difference }\end{array}$ & $\begin{array}{r}2307 \\
2234 \\
+73\end{array}$ & $\begin{array}{r}1787 \\
1771 \\
+16\end{array}$ & $\begin{array}{r}1510 \\
1500 \\
+10\end{array}$ \\
\hline
\end{tabular}

(A) Optimum Irradiation Time (Full Power Days) Correlation: $T_{\text {opt }}-3=\left(1.02 \times 10^{4}\right) \mathrm{w}^{0.50} \mathrm{x}-0.24$

\begin{tabular}{|c|r|c|}
\hline 6 & 10 & 14 \\
\hline & & \\
0.02123 & 0.01274 & 0.009095 \\
\hline 1490 & 751 & 479 \\
1276 & 702 & 499 \\
+214 & 49 & -20 \\
\hline 1805 & 910 & 602 \\
1789 & 311 & 546 \\
+16 & +99 & +56 \\
& & \\
\hline NA & 1079 & 688 \\
& +987 & 611 \\
& +99 & +99 \\
\hline INA & 1187 & 756 \\
& -358 & +46 \\
\hline
\end{tabular}

(B) Breakeven Irradiation Time (Full Power Days) Correlation: $\mathrm{T}_{\mathrm{BE}}-3=\left(7.53 \times 10^{5}\right) \mathrm{W} 1.34 \times 0.40$

Table F.24 Comparison of optimum and Breakeven Irradiation Times for

Three-Row Radial Blanket Predicted by Correlation and 2DB-BRECON. 


\begin{tabular}{|c|c|c|c|c|c|}
\hline & $\begin{array}{l}\text { No. } \\
\text { of } \\
\text { Row }\end{array}$ & $\underbrace{\begin{array}{l}\text { Power Rating (MWE) } \\
\text { Thermal Power }\left(\mathrm{MW}_{\mathrm{th}}\right)\end{array}}_{\text {Items }}$ & $\begin{array}{r}250 \\
625 \\
65\end{array}$ & $\begin{array}{l}1000 \\
2500\end{array}$ & $\begin{array}{l}3000 \\
7500\end{array}$ \\
\hline \multirow{3}{*}{ 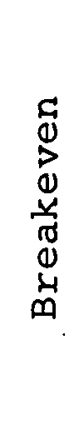 } & 1 & $\begin{array}{l}\text { Irr.Time (FPD) } \\
\text { Enrichment }(\%)\end{array}$ & $\begin{array}{l}433 \\
1.42\end{array}$ & $\begin{array}{l}375 \\
1.40\end{array}$ & $\begin{array}{l}421 \\
1.42\end{array}$ \\
\hline & 2 & $\begin{array}{l}\text { Irr.Time (FPD) } \\
\text { Enrichment }(\%)\end{array}$ & $\begin{array}{l}669 \\
1.50\end{array}$ & $\begin{array}{l}554 \\
1.46\end{array}$ & $\begin{array}{l}620 \\
1.48\end{array}$ \\
\hline & 3 & $\begin{array}{l}\text { Irr.Time (FPD) } \\
\text { Enrichment }(q)\end{array}$ & $\begin{array}{l}1054 \\
1.64\end{array}$ & $\begin{array}{l}807 \\
1.54\end{array}$ & $\begin{array}{l}892 \\
1.57\end{array}$ \\
\hline 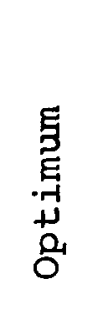 & 1 & $\begin{array}{l}\text { Irr.Time (FPD) } \\
\text { Enrichment }\left(\frac{8}{}\right) \\
\text { Fuel Cycle Cost } \\
\quad(\text { Mills } / \mathrm{KWhr}) \\
\text { Revenue per Assembly } \\
(\$ / \mathrm{kgHM})\end{array}$ & $\begin{array}{r}1373 \\
4.01 \\
-0.1228 \\
-39.00\end{array}$ & $\begin{array}{l}1290 \\
4.44 \\
-0.0728 \\
-50.05\end{array}$ & $\begin{array}{l}1460 \\
4.61 \\
-0.0364 \\
-45.90\end{array}$ \\
\hline \multirow{3}{*}{ 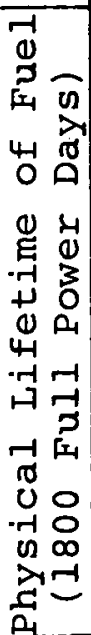 } & 1 & $\begin{array}{l}\text { Enrichment ( } \%) \\
\text { Cost (Mills/KWhr) } \\
\text { Revenue ( } \$ / \mathrm{kgHM})\end{array}$ & $\begin{aligned} & 4.92 \\
-0.1178 & -37.49\end{aligned}$ & $\begin{array}{l}5.75 \\
-0.0690 \\
-48.09\end{array}$ & $\begin{aligned} & 5.45 \\
-0.0355 & -44.22\end{aligned}$ \\
\hline & 2 & $\begin{array}{l}\text { Enrichment }(\%) \\
\text { Cost (Mills/KWhr) } \\
\text { Revenue ( } \$ / \mathrm{kgHM})\end{array}$ & $\begin{array}{r}3.60 \\
-0.1467 \\
-21.15 \\
\end{array}$ & $\begin{aligned} & 4.39 \\
&-0.0935 \\
&-30.83 \\
&\end{aligned}$ & $\begin{array}{r}4.15 \\
-0.0461 \\
-27 . .77 \\
\end{array}$ \\
\hline & 3 & $\begin{array}{l}\text { Enrichment }(\%) \\
\text { Cost (Mills/KWhr) } \\
\text { Revenue ( } \$ / \mathrm{kgHM})\end{array}$ & $\begin{array}{l}2.66 \\
-0.0998 \\
-8.77\end{array}$ & $\begin{array}{l}3.32 \\
-0.0827 \\
-17.25\end{array}$ & $\begin{aligned} & 3.16 \\
&-0.0392 \\
&-15.21\end{aligned}$ \\
\hline
\end{tabular}

Table F.25 The Effect of Changing Core Radius at Constant Core Height on Breakeven, Optimum and Physical Lifetime Points of an EntireBlanket Batch-Irradiated Radial Blanket 
Table F.26 Comparison of Global Optimum Irradiation Time and Thickness for the Radial Blanket Predicted by Correlations and 2DB-BRECON

\begin{tabular}{|c|l|c|c|c|}
\hline \multirow{2}{*}{$\begin{array}{l}\text { Discount } \\
\text { Rate } \\
\left(\mathrm{yr}^{-1}\right)\end{array}$} & $\begin{array}{c}\text { Pu price } \\
\text { Full } \\
\text { Power } \\
\text { Days }\end{array}$ & 6 & 10 & 14 \\
\hline \multirow{4}{*}{0.04} & Correlation & 0.02123 & 0.01274 & 0.009095 \\
& 2DB-Brecon & 2661 & 2367 & 2190 \\
& Difference & +20 & -27 & -10 \\
\hline \multirow{3}{*}{0.08} & Correlation & 1948 & 1732 & 1603 \\
& 2DB-Brecon & 1950 & 1744 & 1580 \\
& Difference & -2 & -12 & +23 \\
\hline \multirow{2}{*}{0.12} & Correlation & 1623 & 1443 & 1336 \\
& 2DB-Brecon & 1626 & 1425 & 1.301 \\
& Difference & -3 & +18 & +35 \\
\hline \multirow{3}{*}{0.16} & Correlation & 1426 & 1268 & 1174 \\
& 2DB-Brecon & 1363 & 1232 & 1132 \\
& Difference & +63 & +36 & +42 \\
\hline
\end{tabular}

(A) Global Optimum Irradiation Time (Full Power Days)

Correlation: $\mathrm{T}_{\mathrm{s}}=\left(1.53 \times 10^{3}\right) \mathrm{w}^{0.23} \mathrm{x}^{-0.45}$

\begin{tabular}{|c|c|c|}
\hline 6 & 10 & 14 \\
\hline 0.02123 & 0.01274 & 0.009095 \\
\hline 33.4 & 42.2 & 48.0 \\
32.8 & 42.7 & 47.9 \\
+0.6 & -0.5 & +0.1 \\
\hline 22.1 & 30.8 & 36.6 \\
22.4 & 31.4 & 35.9 \\
-0.3 & -0.6 & +0.7 \\
\hline 15.4 & 24.2 & 30.0 \\
16.2 & 24.6 & 29.6 \\
-0.8 & -0.4 & +0.4 \\
\hline 10.7 & 19.5 & 25.2 \\
9.2 & 19.8 & 25.1 \\
+1.5 & -0.3 & +0.1 \\
\hline
\end{tabular}

(B) Global Optimum Thickness (CM)

$\tau_{S}=\left(1.38 \times 10^{-2}\right) w^{-0.86} x^{-0.82}$ 


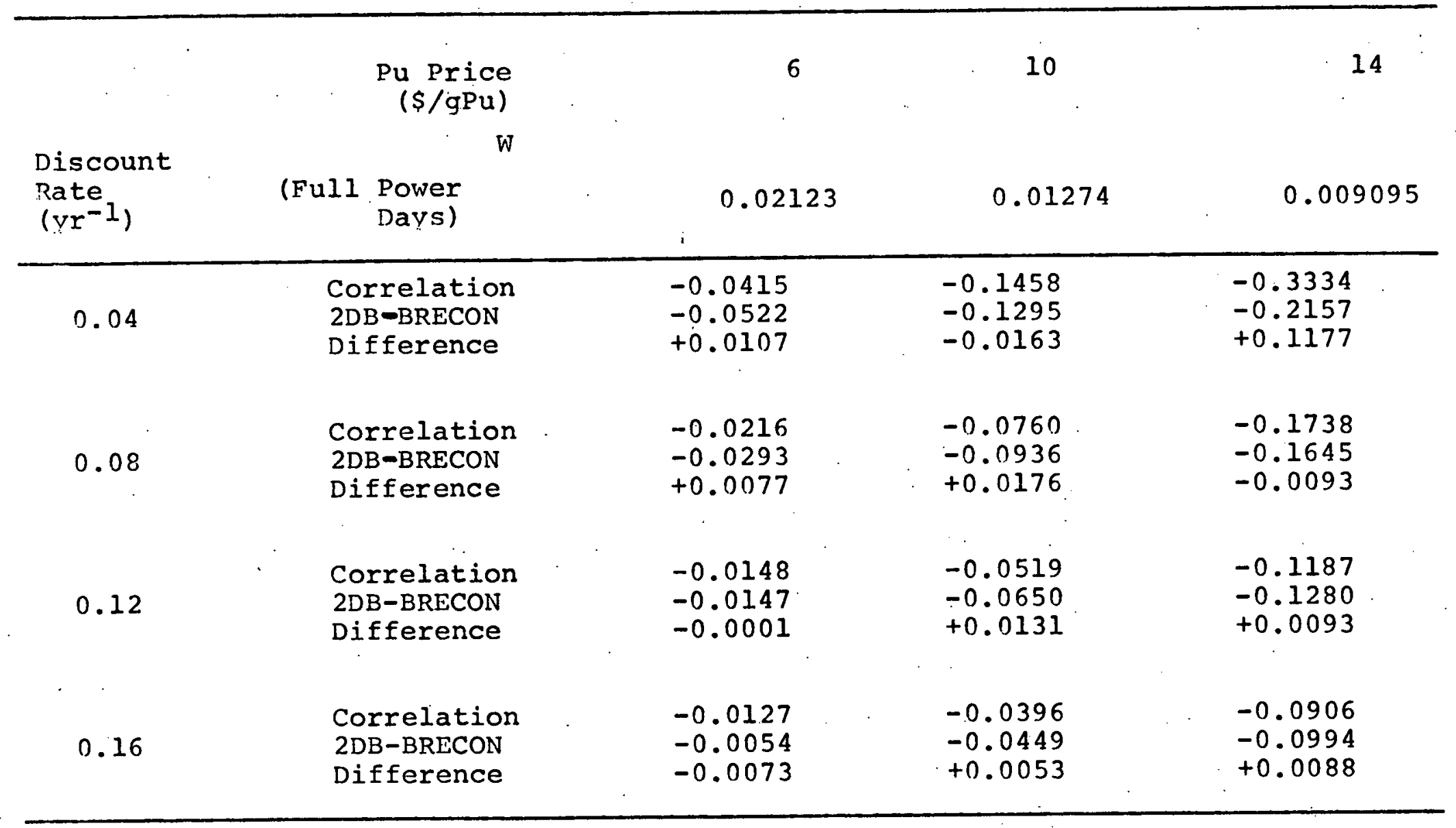

(c) Global Minimum Fuel Cycle Cost Contribution (Mills/KWhr) Correlation $e_{s}=\left(-1.50 \times 10^{-7}\right) w^{-2.46} \mathrm{x}^{-0.94}$

Table F.27 Comparison of the Global Minimum Fuel Cycle Core Contribution of the Radial Blanket Predicted by Correlations and 2DB-BRECON 


\begin{tabular}{|c|c|c|c|c|c|c|c|c|c|c|}
\hline $\begin{array}{l}\text { Power } \\
\text { Rating } \\
\text { (MWE) }\end{array}$ & $\begin{array}{l}\text { Core } \\
\text { Radius } \\
\text { (CM) }\end{array}$ & $\begin{array}{l}\text { One } \\
\text { Group } \\
\text { Model }\end{array}$ & $\begin{array}{l}\text { ternal (Co } \\
\text { Normalize } \\
\text { One } \\
\text { Group } \\
\text { Model } \\
\text { (To 1000 } \\
\text { MWE) }\end{array}$ & $2 \mathrm{DB}$ & Axia & $\begin{array}{l}\text { Al Blan } \\
\text { Norm. } \\
\text { IGM }\end{array}$ & ret & $\begin{array}{l}\text { Radia } \\
1 \mathrm{GM}\end{array}$ & $\begin{array}{l}1 \mathrm{Blan}] \\
\text { Norm. } \\
\text { IGM }\end{array}$ & ket \\
\hline 250 & 65 & 0.688 & 0.670 & 0.665 & 0.243 & 0.253 & 0.234 & 0.443 & 0.554 & 0.584 \\
\hline 500 & 90 & 0.808 & 0.798 & 0.791 & 0.278 & 0.289 & 0.282 & 0.303 & 0.378 & 0.387 \\
\hline 750 & 110 & 0.877 & 0.866 & 0.853 & 0.298 & 0.310 & 0.306 & 0.232 & 0.291 & 0.292 \\
\hline 1000 * & 125 & 0.897 & 0.886 & 0.886 & 0.305 & 0.317 & 0.317 & 0.191 & 0.239 & 0.239 \\
\hline 1500 & 155 & 0.936 & 0.926 & 0.929 & 0.314 & 0.326 & 0.337 & 0.135 & 0.169 & 0.171 \\
\hline 2000 & 180 & 0.962 & 0.950 & 0.957 & 0.431 & 0.334 & 0.342 & 0.106 & 0.132 & 0.131 \\
\hline 2500 & 200 & 0.973 & 0.962 & 0.970 & 0.324 & 0.337 & 0.349 & 0.088 & 0.110 & 0.110 \\
\hline 3000 & 215 & 0979 & 0.967 & 0.975 & 0.326 & 0.340 & 0.350 & 0.078 & 0.097 & 0.099 \\
\hline
\end{tabular}

* Normalized to 1000 MWE

Table F.28 Comparison of the Breeding Ratio Predicted by the One-Group Model and $2 \mathrm{DB}$ as a Function of Core Radius (One-zone cores) 


\begin{tabular}{|c|c|c|c|c|c|c|c|c|}
\hline \multirow{3}{*}{$\begin{array}{l}\text { Power } \\
\text { Rating } \\
\text { (Mwe) }\end{array}$} & \multirow{3}{*}{$\begin{array}{l}\text { Core } \\
\text { Radius } \\
(\mathrm{cm})\end{array}$} & \multirow[b]{3}{*}{ Zone } & \multicolumn{3}{|c|}{ Central Enrichment } & Peripheral & \multicolumn{2}{|c|}{ Enrichment } \\
\hline & & & \multicolumn{2}{|c|}{ One-Group Model } & \multirow{2}{*}{ 2DB } & One-Group & Model & \multirow{2}{*}{$\frac{2 D B}{\text { Multi }}$} \\
\hline & & & $\infty$ & Multi & & $\infty$ & Multi & \\
\hline 250 & 65 & 2 & 12.9 & 15.3 & 15.2 & 27.6 & 18.7 & 23.0 \\
\hline 500 & 30 & 2 & 11.6 & 13.5 & 13.3 & 26.3 & 17.3 & 19.0 \\
\hline 750 & 110 & 2 & 11.2 & 12.8 & 12.7 & 25.7 & 16.6 & 17.7 \\
\hline 1000 & 125 & 2 & 11.0 & 11.8 & 12.5 & 24.7 & 16.1 & 17.2 \\
\hline 1500 & 155 & 3 & 10.9 & 11.8 & 11.8 & 2.4 .4 & 16.0 & 16.4 \\
\hline 2000 & 180 & 4 & 10.8 & 11.8 & 11.7 & 24.2 & 16.4 & 17.0 \\
\hline 2500 & 200 & 5 & 10.8 & 11.8 & 11.7 & 24.2 & 16.9 & 17.9 \\
\hline 3000 & 215 & . 6 & 10.8 & 11.8 & 12.0 & 24.1 & 17.5 & 19.0 \\
\hline
\end{tabular}

Table F.29 The Effect of Core Radius on Central and Peripheral or Central-zone and outermost Zone Enrichment 
Appendix G

REFERENCES

A 1 Aubert, M., et al., "The Phenix-4 Fast Breeder Power Plant," Nuc. Eng. Int., Vol. 19, No. 218 (July 1974), pp. 563-568.

A 2 Argonne National Laboratory, 1000 MWe LMFBR Follow-on Study: Evaluation Report, draft (January 16, 1970).

A 3 Abagyan, L. P., et al., Group Constants for Nuclear Reactor Calculations, I.I. Bondarenko (Ed.), Consultants Bureau, New York (1964).

A4 Alvim, A.C.M. , "Special Problem Report," MIT Subject 22.90, Summer Session (1973).

B1 Bishop, J.F.W. , "Fuel Element Evolution of Power Reactors," Journal of British Nucl. Eng. Soc., Vol. 12, No. 3 (July 1973).

B2 Bowers, M.I. and Myers, M. L., "Estimated Capital Cost of Nuclear and Fossil Power Plants," ORNL-TM-3243, ORNL (March 1971).

B3 Brewer, S.T., E.A. Mason, and M.J. Driscoll, "The Economics of Fuel Depletion in Fast Breeder Reactor Blankets," COO-3060-4, MITNE-123 (November 1972).

B4 Brown, G.J. and M.J. Driscoll, "Evaluation of High Performance LMFBR Blanket Configurations, "COO-2050-4, MITNE-150 (May 1974).

B5 Barthold, W. P., "Fuel Shuffling in LMFBR Blankets," Applied Physics Division, Argonne National Laboratory, FRA-TM-40 (August 1972).

D1. Denielou, G., et al. ; "French Large LMFBR Design," Trans. Am. Nuc. Soc., Vol. 15, Supplement No. 2 (August 1972), pp. 14-15.

D2 DRDT, USAEC, "Updated (1970) Cost Benefit Analysis of Breeder," WASH-1184 (January 1972).

D3 Ducat, G.A., M.J. Driscoll, and N.E. Todreas, "Evaluation of the Parfait Blanket Concept for Fast Breeder Reactors, " COO-2250-5, MITNE-157 (January 1974).

D4 Driscoll, M.J., "Notes on Fast Reactor Physics," MIT Subject $22.94(1968)$, p. 1.9 . 
D5 DRDT, USAEC, "Reactor. Fuel Cycle Costs for Nuclear Power Evaluation," WASH-1099 (1971).

D6 Driscoll, M.J., et al., "LMFBR Blanket Physics Project Progress Report No. 3," COO-3060-6, MITNE-143 (June 30,1972 ).

E1 Edis on Electric Institute, "Fast Breeder Reactor Report," EEI Pub. No. 68-28 (April 1968).

E2 Engle, W. W., Jr., "A Users Manual for ANISN, a OneDimensional Discrete Ordinates Transport Code with Anisotropic Scattering," K-1693 (March 30, 1967).

F1 Forbes, I. A., et al., "Design Construction and Evaluation of a Facility for the Simulation of Fast Reactor Blankets," MITNE-110, MIT-4105-2 (February 1970).

F2 Fuller, E. L., "Reactivity Effects of Core Slumping in Fast Reactors: A Case Study," FRA-TM-35, ANL (1972).

H1 Hoover, J., and D.A. Menley, "Alternative Neutron Energy Group Collapsing Schemes Applied to Fuel Cycle Calculations," ANL-7710 (January 1971).

H2 Hasnain, S.D., and D. Okrent, "On the Design and Management of Fast Reactor Blankets," Nucl. Sci. Eng. , 9 , 314-322 (1961).

H3 Hirons, T.J. and R.D. O'Dell, "Calculational Modelling Effects on Fast Breeder Fuel Cycle Analysis," LA-4187 (September 1969).

K1 Kobayashi, Y., et al. "Design and Optimization Study of 10, 000 MWe, Very Large Fast Reactor Core," Journal of Nucl. Sci. and Tech., Vol. 10, No. 10 (October 1973), pp. 607-618.

L1 Little, W. W., Jr., and R.W. Hardie, "2DB User's Manual, Revision 1," BNWL-831, Rev. 1 (August 1969).

M1 Murray, P. and M. W. Dyos, "Progress Toward the Commercial LMFBR," BNWL-831, Rev. 1 (August 1969).

N1 Nelson, J.V., "Cross Sections for Preliminary Design of FTR, FTR Set No. 200," HEDL-TME-71-65 (1971).

N2 Noyes, R.C., et al., "Planning for the Second LMFBR Demonstration Plant," Combustion (September 1974), pp. 5-11. 
O1 Okrent, D., K.P. Cohen, and W.B. Loewenstein, "Some Nuclear and Safety Considerations in the Design of Large Fast Power Reactors," Proceedings of the Third International Conference on the Peaceful Uses of Atomic Energy, Vol: 6 (1965).

P1 Pellaud, B. "The Physics Design of the Gas-Cooled Fast Breeder Reactor Demonstration Plant," GA-10509, Gulf General Atomic, San Diego, California (August 29, 1971).

R1 Rohan, P.E., "Comparisons of Transport and Diffusion Theory Calculations of Performance Characteristics for Large Fast Reactors," Ph.D. Thesis, Nuclear Engineering Program, University of Illinois (1970).

S1 Scarborough, J.C., "Economics of Nuclear Power," Course Notes for MIT Subject 22. 35 (Spring, 1974).

T1 Tzanos, C.P., E.P. Gyftopoulos, and M.J. Driscoll, "Optimization of Material Distributions in Fast Breeder Reactors," MIT-4105-6, MITNE-128 (August 1971).

W1 Westinghouse Advanced Reactor Development, "Design Analysis of the LMFBR Radial Blanket," WARD-3045-T 2B-9 (March 1973).

W2 Wood, P.J. and M.J. Driscoll, "Assessment of Thorium Blankets for Fast Breeder Reactors," MITNE-148, COO2250-2 (July 1973). 